UNIVERSIDADE DE SÃO PAULO

FFCLRP - DEPARTAMENTO DE PSICOLOGIA E EDUCAÇÃO

PROGRAMA DE PÓS-GRADUAÇÃO EM PSICOLOGIA

A preferência pela prática de atividades físicas e esportivas: uma abordagem psicofísica

MARCELO ANTONIO FERRAZ

RIBEIRÃO PRETO 
UNIVERSIDADE DE SÃO PAULO

FFCLRP - DEPARTAMENTO DE PSICOLOGIA E EDUCAÇÃO

PROGRAMA DE PÓS-GRADUAÇÃO EM PSICOLOGIA

\title{
A preferência pela prática de atividades físicas e esportivas: uma abordagem psicofísica
}

\author{
MARCELO ANTONIO FERRAZ \\ Orientador: Prof. Dr. JOSÉ APARECIDO DA SILVA \\ Tese apresentada à Faculdade de Filosofia Ciência e \\ Letras de Ribeirão Preto da USP, como parte das \\ exigências para obtenção do título de Doutor em \\ Ciências, Área: Psicologia.
}


AUTORIZO A REPRODUÇÃO E DIVULGAÇÃO TOTAL OU PARCIAL DESTE TRABALHO POR QUALQUER MEIO CONVENCIONAL OU ELETRÔNICO, PARA FINS DE ESTUDO E PESQUISA, DESDE QUE CITADA A FONTE.

\section{FICHA CATALOGRÁFICA}

\section{Ferraz, Marcelo Antonio}

A preferência pela prática de atividades físicas e esportivas: uma abordagem psicofísica.

Ribeirão Preto, 2005.

176 p. : il.; $30 \mathrm{~cm}$

Tese apresentada à Faculdade de Filosofia Ciência e Letras de Ribeirão Preto / USP - Departamento de Psicologia e Educação.

Orientador: Da Silva, José Aparecido

1. Preferência. 2. Prática de Atividades Físicas e Esportivas. 3. Psicofísica sensorial. 4. Estimação de Magnitudes. 


\section{FOLHA DE APROVAÇÃO}

Marcelo Antonio Ferraz

A preferência pela prática de atividades físicas e esportivas: uma abordagem psicofísica

Tese apresentada à Faculdade de Filosofia Ciência e Letras de Ribeirão Preto da USP, como parte das exigências para obtenção do título de Doutor em Ciências, Área: Psicologia.

Aprovado em:

Banca Examinadora

Prof. Dr.

Instituição:

Assinatura:

Prof. Dr.

Instituição:

Assinatura:

Prof. Dr.

Instituição:

Assinatura:

Prof. Dr.

Instituição:

Assinatura:

Prof. Dr.

Instituição:

Assinatura: 
Ao Pedro Henrique èa Andrea, meu filho e minha esposa, com muito amor e gratidão. Ao lado de vocês, senti a alegria, a paz e o desejo de nunca desistir, por saber que meu esforço seria a glória daqueles que sempre me apoiaram ao longo de todo o período de elaboração deste trabalho. 


\section{AGRADECIMENTOS}

A Deus, que me deu o dom de poder viver.

Aos meus familiares (Pai, Mãe e Irmão), por todo o apoio emocional e afetivo que foram necessários para suportar os entraves do caminho. Que o sentimento da minha vitória seja estendido a vocês com o dobro de intensidade, pois vocês são os verdadeiros vitoriosos.

Ao Prof. Dr. José Aparecido da Silva, que nos anos de convivência, muito me ensinou, compartilhou, apoiou e contribuiu para o meu crescimento científico, profissional e intelectual.

Ao Prof. Dr. Sergio Sheiji Fukusima, pelo fornecimento do software para o cálculo dos expoentes.

Um agradecimento especial à Maria Lucia Ganimi e ao Luciano Aparecido Caetano, que verdadeiramente, foram mais do que amigos e colaboradores na construção deste meu objetivo de vida.

Pelo apoio indireto, porém fundamental nos momentos de dificuldades: Aos meus sobrinhos (Izabela e Felipe), Elisa, Tia Lu, Tio Hélio, Tia Otilia, Tio Martini, Sr. Julião, D. Áurea e Marcelinho a todos o meu muito obrigado.

Aos professores, funcionários, alunos, amigos e parceiros do Instituto Diocesano de Assis/SP (IEDA) e das Faculdades Integradas de Bauru (FIB) por todo o apoio e ajuda na coleta dos dados e por colocar a disposição a área experimental.

A todos os amigos do Laboratório de Psicofísica: Professor Romualdo, Luiz Carlos, José Ricardo, Elenice, Beatriz, Junior, Elton, Denis e Josiane. Em especial à Regina por toda a contribuição junto ao orientador.

Aos funcionários da FFCLRP e da Secretaria da Pós-graduação do curso de Psicologia. Em especial ao Igor, à Denise e à Renata. Um verdadeiro muito obrigado !!!

"Digo; o real não está na saída, nem na chegada. Ele se dispõe para gente é no meio da travessia." 
"Coloque seus ideais nas estrelas, mesmo que você não consiga alcançar a metade do caminho"

Tolstoi

"O único homem que nunca comete erros é aquele que nunca faz coisa alguma. Não tenha medo de errar pois você aprenderá a não cometer duas vezes o mesmo erro". 


\section{RESUMO}

FERRAZ, M. A. A preferência pela prática de atividades físicas e esportivas: uma análise psicofísica. 2005. 176 f. Tese de Doutorado em Psicologia - Faculdade de Filosofia Ciência e Letras de Ribeirão Preto (FFCLRP) - Universidade de São Paulo, Ribeirão Preto/SP.

A preferência pela prática de atividades físicas e esportivas é um atributo subjetivo de difícil mensuração e que tem sido um dos critérios fundamentais, na escolha e na decisão para a sua prática, nos dias atuais. Deste modo, a preferência pela prática de atividades físicas e esportivas foi investigada por meio de métodos psicofísicos escalares diretos e indiretos e, conseqüentemente, escalas de razão, escalas intervalares e escalas ordinais foram comparadas. Os objetivos secundários foram verificar se este contínuo subjetivo possui características protéticas ou metatéticas, verificar se os princípios da Lei de Ekman é valida também para este contínuo subjetivo e identificar diferenças no julgamento da preferência de homens e mulheres. Três experimentos foram realizados. No primeiro experimento participaram vinte sujeitos, dez homens e dez mulheres entre 20 e 25 anos de idade, graduandos que não pertencem ao curso superior de Educação Física. Todos os sujeitos foram submetidos a uma avaliação prévia, que constou do julgamento em testes psicofísicos: a) Teste de estimação de magnitudes (com módulo) e b) Teste de estimação em categorias 1-7. No segundo experimento participaram outros vinte sujeitos, sendo respeitada a mesma divisão do primeiro experimento com relação ao gênero, a idade e a não vinculação com o curso de Educação Física. Os testes deste experimento foram: a) Teste de emparelhamento intermodal com as modalidades de comprimento de linhas e b) Teste de estimação de magnitudes (com módulo). No terceiro experimento participaram quarenta sujeitos, sendo vinte homens e vinte mulheres entre 20 e 25 anos de idade Os testes deste experimento foram: a) Teste de comparação aos pares e b) Teste de estimação de magnitudes (com módulo). Os resultados indicaram que a atividade física de Caminhada foi a atividade de maior preferência, seguida pelos esportes coletivos de Voleibol e Futebol, por outro lado, a atividade física de Remo estacionário obteve a menor preferência, seguida pelas atividades físicas de Dardos (na parede) e do esporte Judô. As demais atividades foram escalonadas de modo intermediário pelos sujeitos. Nos julgamentos dos participantes masculinos as atividades de menor preferência foram: Remo Estacionário, Tênis (simples) e Dardos (na parede), já para as participantes femininas foram os esportes Judô, Remo Estacionário e Dardos. Com as atividades de maior preferência, os sujeitos masculinos apontaram o Futebol, a Caminhada e a Inatividade e os sujeitos do sexo feminino indicaram a Caminhada, o Voleibol e a Hidroginástica. As ordenações resultantes dos métodos produzem posições de preferência altamente concordantes. Os participantes mensuraram razões e não apenas diferenças, portanto, o contínuo subjetivo avaliado possui características protéticas. $\mathrm{O}$ teste de emparelhamento intermodal apontou uma alta correlação entre as estimativas de comprimentos de linhas com as estimativas numéricas de magnitudes, indicando a validade da escala de razão. A variabilidade das estimativas foi uma função linear das estimativas de magnitudes, confirmando os princípios da Lei de Ekman, também para este contínuo subjetivo. Independente do método psicofísico utilizado, tanto homens quanto mulheres apresentaram consistência nos seus julgamentos. Os resultados fornecem uma escala de preferência, em nível de mensuração de razão, que é válida, estável e consistente.

Palavras chaves: Preferência, prática de atividades físicas e esportivas, psicofísica e estimação de magnitudes. 


\begin{abstract}
FERRAZ, M. A. The preference for the practice of physical and sporting activities: an psychophysical analysis.. 2005. 176 f. Thesis (Doctorate) Psychology - Faculdade de Filosofia Ciência e Letras de Ribeirão Preto (FFCLRP) - University of São Paulo, Ribeirão Preto/SP.
\end{abstract}

The preference for practicing physical and sporting activities is a subject attribute that is difficult to be measured and it has been one of the fundamental approaches, in the choice and in the decision for its practice, in the current days. This way, the preference for practicing physical and sporting activities was investigated through psychophysical methods in direct and indirect scales, and consequently, ratio scales, interval scales and ordinal scales were compared. The secondary objectives were to check if this social continuous has prothetic or metathetic characteristics, cheking if the fundaments of Ekman Law has been worth for this social continuous and identify differences in the judgments from men and women's preferences. Three experiments were accomplished. In the first experiment there were twenty participants, there were ten men and ten women among 20 to 25 years old, graduating students but not from Physical Education. All the participants were submitted to a previous evaluation, that consisted from the judgments in psychophysical tests: a) Test of magnitudes estimation (with module) and b) Test of categories estimation 1-7. In the second experiment there were other twenty participants, respecting the same division from the first experiment in relation to gender, age, and non-link to the Physical Education course. The tests of these experiments were: a) Test of cross-modality matches with the modalities of line's length and b) Test of magnitude estimation (with module). In the third experiment there were forty participants, twenty men and twenty women among the age of 20 to 25 years. The tests of these experiments were: a) Comparison test in pairs and b) Test of magnitude estimation (with module). The results indicated that the physical activity of Walking was the most preferred, followed by collective sports as Volleyball and Soccer; on other hand, the physical activity of Stationary Row obtained the least preference, followed by the physical activities of Darts (on the wall) and Judo. The other activities were in scaled by the participants in an intermediate way. In men's judgments the least preferred activities were: Stationary Row, Tennis (simple) and Darts (on the wall). To women's judgments they were Judo, Stationary Row and Darts. The most preferred that men aimed were Soccer, Walking and the Inactivity. To women were Walking, Volleyball and Water Aerobic. The orderings results from the methods produce preference positions highly related. The participants measured ration and not only differences, so the social continuous appraised has prothetic characteristics. The test of cross-modality matches aimed a high correlation between the lengths estimate of line with the numeric magnitudes estimation, indicating the validity of the ratio scale. The variability of the estimates was a lineal function of the magnitudes estimation, confirming the fundaments of Ekman Law, also for this social continuous. Independent of the psychophysical method used, as men as women presented consistency in their judgments. The results supply a preference scale, in level of ratio measurements, which is valid, stable and consistent.

Keywords: Preference, practice of physical and sporting activities, psychophysical and magnitudes estimation. 


\section{LISTA DE ILUSTRAÇÕES}

\section{Página}

Quadro 1 - Atividades físicas e esportivas que foram apresentadas aos participantes, em ordem aleatória, para julgamentos nos métodos de estimação de magnitudes e estimação em categorias 


\section{LISTA DE SIGLAS}

$\begin{array}{ll}\text { USP } & \text { Universidade de São Paulo } \\ \text { RPE } & \text { Ratio Perception Exertion } \\ \text { UTI } & \text { Unidade de Terapia Intensiva } \\ \text { IEDA } & \text { Instituto Educacional de Assis } \\ \text { FIB } & \text { Faculdades Integradas de Bauru } \\ \text { FFCLRP } & \text { Faculdade de Filosofia Ciência e Letras de Ribeirão Preto } \\ \text { CEP } & \text { Comitê de Ética em Pesquisa }\end{array}$




\section{LISTA DE SÍMBOLOS}

\begin{tabular}{ll}
$\mathrm{R}$ & magnitude do julgamento \\
$\mathrm{E}$ & magnitude física do estímulo \\
$\mathrm{K}$ & expoente da função de potência \\
log-log & constante arbitrária da função de potência \\
$\mathrm{r}^{2}$ & coordenadas logarítmicas \\
$\mathrm{Hz}$ & hertz de freqüência \\
$\mathrm{mm}$ & milímetro \\
$\%$ & porcentagem \\
$\mathrm{m}$ & metros \\
$\mathrm{P}-\mathrm{level}$ & nível de significância \\
$\mathrm{Cm}$ & centímetros \\
$\mathrm{N}$ & número de sujeitos \\
$\mathrm{W}$ & coeficiente de concordância Kendall \\
& score z médios \\
\hline &
\end{tabular}




\section{SUMÁRIO}

Página

1 INTRODUÇÃO

2 A LEI DE POTÊNCIA OU LEI DE STEVENS …...................................................... 7

2.1 O significado psicobiológico do expoente da função de potência . ............................. 11

2.2 O método de estimação em categorias ..................................................................... 16

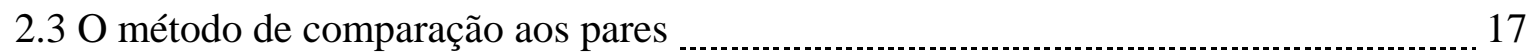

2.4 O método de estimação de magnitudes .................................................................. 18

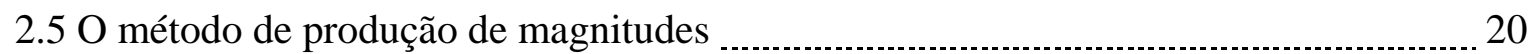

2.6 O método de emparelhamento intermodal ............................................................ 20

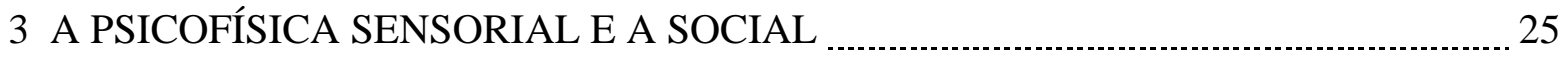

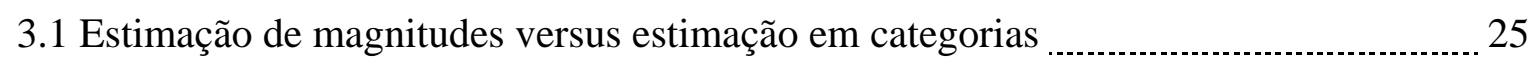

3.2 Contínuo protético versus contínuo metatético _.................................................... 26

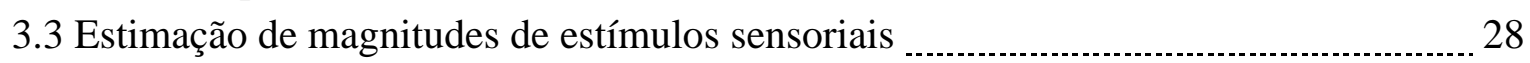

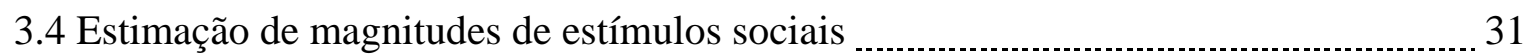

3.5 O paradigma do emparelhamento intermodal aplicado a estímulos e/ou a atributos

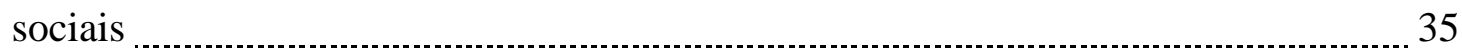

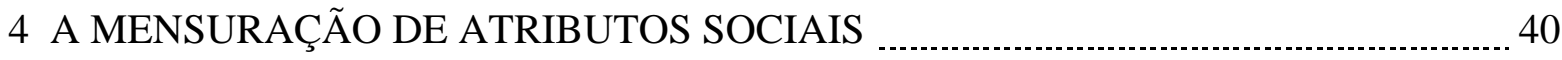

5 A PREFERÊNCIA PELA PRÁTICA DE ATIVIDADES FÍSICAS E ESPORTIVAS..... 46

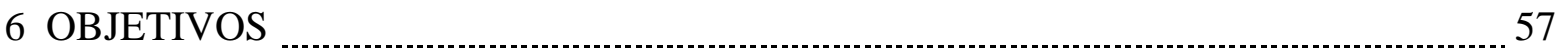

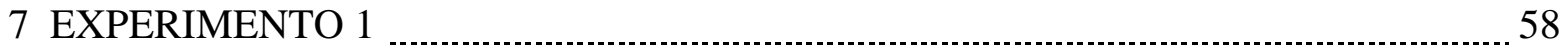

7.1 A comparação entre os métodos psicofísicos escalares de estimação de

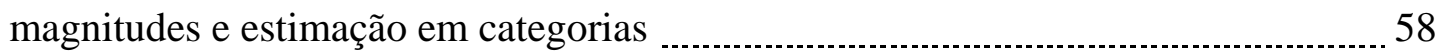

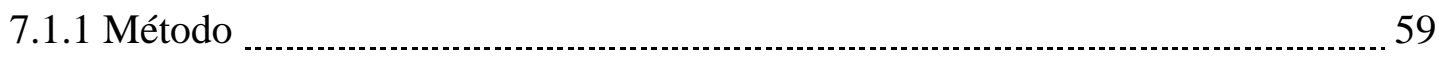

7.1.1.1 Participantes _................................................................... 59

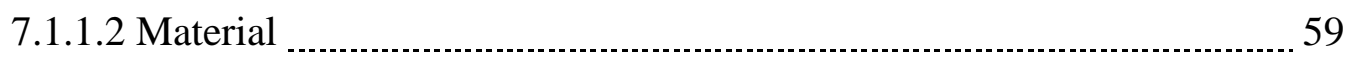

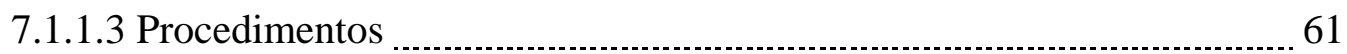

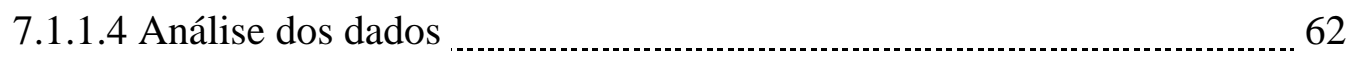

7.1.2 Resultados

7.1.3 As diferenças entre Homens e Mulheres no julgamento da preferência pela prática de atividades físicas e esportivas (estimação em categorias versus

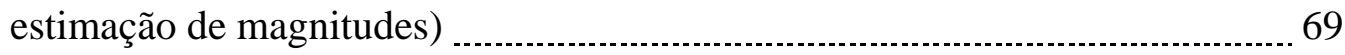

8 EXPERIMENTO $2 \ldots \ldots$ 
8.1 A validação da escala de razão da preferência pela prática de atividades físicas e esportivas pelo método de emparelhamento intermodal (comprimento de linhas) .... 77

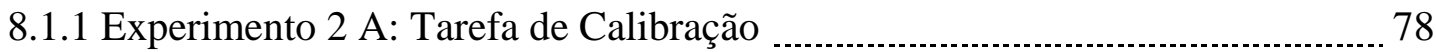

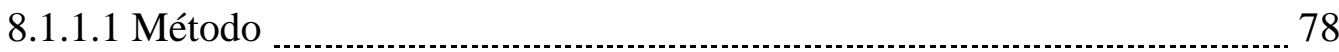

8.1.1.1.1 Participantes ............................................................ 78

8.1.1.1.2 Material ........................................................ 79

8.1.1.1.3 Procedimentos

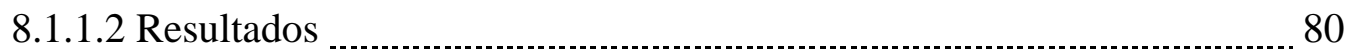

8.1.2 Experimento 2 B: Validação psicofísica da escala de razão pela prática de

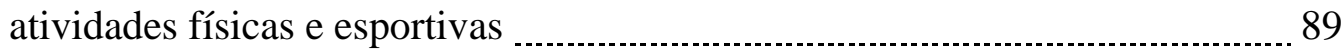

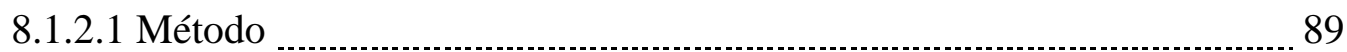

8.1.2.1.1 Participantes ......................................................... 89

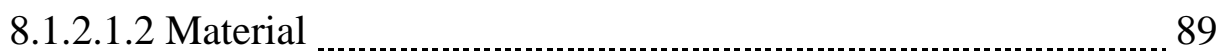

8.1.2.1.3 Procedimentos _............................................... 90

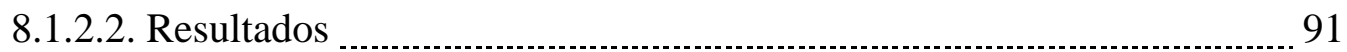

9 EXPERIMENTO 3

9.1 Comparação entre os métodos psicofísicos escalares de estimação de magnitudes e estimação de comparação aos pares _........................................ 108

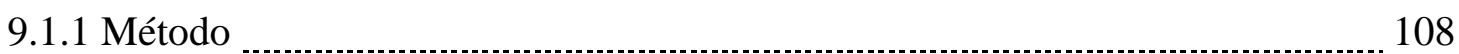

9.1.1.1 Participantes _................................................................. 108

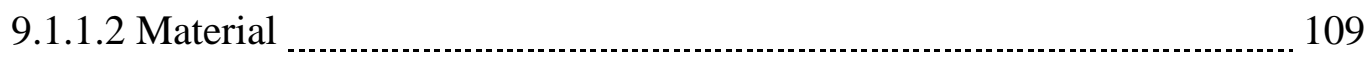

9.1.1.3 Procedimentos ............................................................... 109

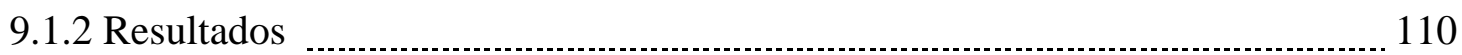

10 COMPARAÇÃO ENTRE OS MÉTODOS DE ESTIMAÇÃO DE MAGNITUDES DOS TRÊS EXPERIMENTOS. 130

10.1 Comparação entre os métodos psicofísicos escalares de estimação de magnitudes dos três experimentos, de todos os sujeitos .................................. 130

10.2 Comparação entre os métodos psicofísicos escalares de estimação de magnitudes dos três experimentos, tanto dos sujeitos do sexo masculino como do sexo feminino

11 DISCUSSÃO 


\section{LISTA DE FIGURAS}

\section{Página}

Figura 1 - Magnitudes subjetivas em função das magnitudes físicas dos estímulos, em coordenadas lineares

Figura 2 - Magnitudes subjetivas em função das magnitudes físicas dos estímulos, em coordenadas logarítmicas

Figura 3 - Funções de potência ajustadas para diferentes modalidades sensoriais obtidas dos emparelhamentos de força dinamométricas e várias intensidades de estímulos tomados como critérios. A posição relativa de uma função em relação à abscissa é arbitrária. As coordenadas são logarítmicas

Figura 4 - Relação entre as médias aritméticas das estimativas em categorias e as médias geométricas das estimativas de magnitudes, da preferência pela prática de atividades físicas e esportivas em coordenadas lineares

Figura 5 - Relação entre as médias aritméticas das estimativas em categorias e os logaritmos das médias geométricas, das estimativas de magnitudes, da preferência pela prática de atividades físicas e esportivas

Figura 6 - Desvio-padrão aritmético, em função da média aritmética, das estimativas de magnitudes, da preferência pela prática de atividades físicas e esportivas

Figura 7 - Desvio-padrão da média aritmética, em função da média aritmética, das estimativas em categorias da preferência pela prática de atividades físicas e esportivas

Figura 8 - Relação entre as médias aritméticas das estimativas em categorias e as médias geométricas das estimativas de magnitudes, da preferência pela prática de atividades físicas e esportivas em coordenadas lineares. Participantes do sexo masculino

Figura 9 - Relação entre as médias aritméticas das estimativas em categorias e os logaritmos das médias geométricas, das estimativas de magnitudes, da preferência pela prática de atividade física e esportiva. Participantes do sexo masculino

Figura 10 - Relação entre as médias aritméticas das estimativas em categorias e as médias geométricas das estimativas de magnitudes, da preferência pela prática de atividades físicas e esportivas em coordenadas lineares. Participantes do sexo feminino 
Figura 11 - Relação entre as médias aritméticas das estimativas em categorias e os logaritmos das médias geométricas, das estimativas de magnitudes, da preferência pela prática de atividades físicas e esportivas. Participantes do sexo feminino

Figura 12 - Desvio-padrão aritmético, em função da média aritmética, das estimativas de magnitudes, da preferência pela prática de atividades físicas e esportivas. Participantes do sexo masculino

Figura 13 - Desvio-padrão da média aritmética, em função da média aritmética, das estimativas em categorias da preferência pela prática de atividades físicas e esportivas. Participantes do sexo masculino

Figura 14 - Desvio-padrão aritmético, em função da média aritmética, das estimativas de magnitudes, da preferência pela prática de atividades físicas e esportivas. Participantes do sexo feminino

Figura 15 - Desvio-padrão da média aritmética, em função da média aritmética, das estimativas em categorias da preferência pela prática de atividades físicas e esportivas. Participantes do sexo feminino

Figura 16 - Relação entre os logaritmos das médias geométricas das estimativas de magnitudes e os logaritmos das medias geométricas dos comprimentos de linhas na Tarefa de Calibração 1. Dados do Experimento 2 A

Figura 17 - Relação entre os logaritmos das médias geométricas das produções de magnitudes e os logaritmos dos estímulos apresentados aos sujeitos, na tarefa de Calibração 2. Dados do Experimento 2 A

Figura 18 - Relação entre os logaritmos das médias geométricas das estimativas de magnitudes e os logaritmos das médias geométricas dos comprimentos de linhas na Tarefa de Calibração 1, sujeitos do sexo masculino. Dados do Experimento $2 \mathrm{~A}$

Figura 19 - Relação entre os logaritmos das médias geométricas das produções de magnitudes e os logaritmos dos estímulos apresentados aos sujeitos, na tarefa de Calibração 2, dos sujeitos do sexo masculino. Dados do Experimento $2 \mathrm{~A}$

Figura 20 - Relação entre os logaritmos das médias geométricas das estimativas de magnitudes e os logaritmos das medias geométricas dos comprimentos de linhas na Tarefa de Calibração 1, sujeitos do sexo feminino. Dados do Experimento $2 \mathrm{~A}$

Figura 21 - Relação entre os logaritmos das médias geométricas das produções de magnitudes e os logaritmos dos estímulos apresentados aos sujeitos, na tarefa de Calibração 2, dos sujeitos do sexo feminino. Dados do Experimento $2 \mathrm{~A}$ 
Figura 22 - Relação entre os logaritmos das médias geométricas das estimativas de magnitudes e os logaritmos das médias geométricas dos emparelhamentos de comprimentos de linhas, da preferência pela prática de atividades físicas e esportivas. Dados do Experimento 2 B

Figura 23 - Relação entre os logaritmos das médias geométricas dos emparelhamentos de comprimentos de linhas e os logaritmos das médias geométricas das estimativas de magnitudes da preferência pela prática de atividades físicas e esportivas. Dados do Experimento $2 \mathrm{~B}$

Figura 24 - Desvio-padrão da média aritmética em função da média aritmética das estimativas de magnitudes da preferência pela prática de atividades físicas e esportivas. Dados do Experimento $2 \mathrm{~B}$

Figura 25 - Desvio-padrão da média aritmética em função da média aritmética dos emparelhamentos de comprimentos de linhas da preferência pela prática de atividades físicas e esportivas. Dados do Experimento 2 B

Figura 26 - Relação entre os logaritmos das médias geométricas das estimativas de magnitudes e os logaritmos das médias geométricas dos emparelhamentos de comprimentos de linhas, da preferência pela prática de atividades físicas e esportivas, dos sujeitos do sexo masculino. Dados do Experimento $2 \mathrm{~B}$

Figura 27 - Relação entre os logaritmos das médias geométricas das estimativas de magnitudes e os logaritmos das médias geométricas dos emparelhamentos de comprimentos de linhas, da preferência pela prática de atividades físicas e esportivas, dos sujeitos do sexo feminino. Dados do Experimento $2 \mathrm{~B}$

Figura 28 - Relação entre os logaritmos das médias geométricas dos emparelhamentos de comprimentos de linhas e os logaritmos das médias geométricas das estimativas de magnitudes da preferência pela prática de atividades físicas e esportivas, dos sujeitos do sexo masculino. Dados do Experimento $2 \mathrm{~B}$

Figura 29 - Relação entre os logaritmos das médias geométricas dos emparelhamentos de comprimentos de linhas e os logaritmos das médias geométricas das estimativas de magnitudes da preferência pela prática de atividades físicas e esportivas, dos sujeitos do sexo feminino. Dados do Experimento 2 B

Figura 30 - Desvio-padrão da média aritmética em função da média aritmética das estimativas de magnitudes da preferência pela prática de atividades físicas e esportivas, dos sujeitos do sexo masculino. Dados do Experimento $2 \mathrm{~B}$ 
Figura 31 - Desvio-padrão aritmético da média aritmética em função da média aritmética dos emparelhamentos de comprimentos de linhas da preferência pela prática de atividades físicas e esportivas, dos sujeitos do sexo masculino. Dados do Experimento 2 B

Figura 32 - Desvio-padrão da média aritmética em função da média aritmética das estimativas de magnitudes da preferência pela prática de atividades físicas e esportivas, dos sujeitos do sexo feminino. Dados do Experimento $2 \mathrm{~B}$

Figura 33 - Desvio-padrão da média aritmética em função da média aritmética dos emparelhamentos de comprimentos de linhas da preferência pela prática de atividades físicas e esportivas, dos sujeitos do sexo feminino. Dados do Experimento $2 \mathrm{~B}$

Figura 34 - Relação entre as proporções médias e as médias geométricas das estimativas de magnitudes da preferência pela prática de atividades físicas e esportivas em coordenadas lineares. Dados do Experimento 3

Figura 35 - Relação entre as proporções médias e os logaritmos das médias geométricas das estimativas de magnitudes da preferência pela prática de atividades físicas e esportivas. Dados do Experimento 3

Figura 36 - Relação entre os valores escalares ajustados e as médias geométricas das estimativas de magnitudes da preferência pela prática de atividades físicas e esportivas em coordenadas lineares. Dados do Experimento 3

Figura 37 - Relação entre os valores escalares ajustados e os logaritmos das médias das estimativas de magnitudes da preferência pela prática de atividades físicas e esportivas. Dados do Experimento 3

Figura 38 - Desvio-padrão da média aritmética em função das médias aritméticas das estimativas de magnitudes da preferência pela prática de atividades físicas e esportivas. Dados do Experimento 3

Figura 39 - Desvio-padrão da média aritmética em função das médias aritméticas das proporções médias da preferência pela prática de atividades físicas e esportivas. Dados do Experimento 3

Figura 40 - Relação entre as proporções médias e as médias geométricas das estimativas de magnitudes da preferência pela prática de atividades físicas e esportivas em coordenadas lineares. Dados do Experimento 3, participantes do sexo masculino 
Figura 41 - Relação entre as proporções médias e as médias geométricas das estimativas de magnitudes da preferência pela prática de atividades físicas e esportivas em coordenadas lineares. Dados do Experimento 3, participantes do sexo feminino

Figura 42 - Relação entre as proporções médias e os logaritmos das médias geométricas das estimativas de magnitudes da preferência pela prática de atividades físicas e esportivas. Dados do Experimento 3, participantes do sexo masculino

Figura 43 - Relação entre as proporções médias e os logaritmos das médias geométricas das estimativas de magnitudes da preferência pela prática de atividades físicas e esportivas. Dados do Experimento 3, participantes do sexo feminino

Figura 44 - Relação entre os valores escalares ajustados e as médias geométricas das estimativas de magnitudes da preferência pela prática de atividades físicas e esportivas em coordenadas lineares. Dados do Experimento 3, participantes do sexo masculino

Figura 45 - Relação entre os valores escalares ajustados e as médias geométricas das estimativas de magnitudes da preferência pela prática de atividades físicas e esportivas em coordenadas lineares. Dados do Experimento 3, participantes do sexo feminino

Figura 46 - Relação entre os valores escalares ajustados e os logaritmos das médias das estimativas de magnitudes da preferência pela prática de atividades físicas e esportivas. Dados do Experimento 3, participantes do sexo masculino

Figura 47 - Relação entre os valores escalares ajustados e os logaritmos das médias das estimativas de magnitudes da preferência pela prática de atividades físicas e esportivas. Dados do Experimento 3, participantes do sexo feminino

Figura 48 - Desvio-padrão da média aritmética em função das médias aritméticas das estimativas de magnitudes da preferência pela prática de atividades físicas e esportivas. Dados do Experimento 3, dos participantes do sexo masculino

Figura 49 - Desvio-padrão da média aritmética em função das médias aritméticas das estimativas de magnitudes da preferência pela prática de atividades físicas e esportivas. Dados do Experimento 3, dos participantes do sexo feminino 128

Figura 50 - Desvio-padrão da média aritmética em função das médias aritméticas das proporções médias da preferência pela prática de atividades físicas e esportivas. Dados do Experimento 3, dos participantes do sexo masculino .. 128 
Figura 51 - Desvio-padrão da média aritmética em função das médias aritméticas das proporções médias da preferência pela prática de atividades físicas e esportivas. Dados do Experimento 3, das participantes do sexo feminino 


\section{LISTA DE TABELAS}

\section{Página}

Tabela 1 - Média e desvio-padrão dos expoentes da função de potência para uma variedade de modalidades sensoriais e/ou perceptivas baseados em julgamentos de razão

Tabela 2 - Resultados dos métodos de estimação de magnitude (EM) demonstração das médias geométricas (MG), a ordenação de posições, de preferência, deste método (OP/EM). Método de estimação em categorias (EC), demonstração das respectivas médias aritméticas (MA), a ordem de posições, de preferência, deste método (OP/EC)

Tabela 3 - Resultados dos métodos de estimação de magnitude (EM) demonstração das médias geométricas (MG), a ordenação de posições, de preferência, deste método (OP/EM). Método de estimação em categorias (EC), demonstração das respectivas médias aritméticas (MA), a ordem de posições, de preferência, deste método (OP/EC), tanto dos participantes do sexo masculino como do sexo feminino

Tabela 4 - Expoente (n), constante escalar $(\mathrm{k})$ e coeficiente de determinação $\left(\mathrm{r}^{2}\right)$ das funções de potência individuais ajustadas separadamente para estimativas de magnitudes e produção de magnitudes

Tabela 5 - Resultados da análise estatística do Teste t de Student, entre os expoentes obtidos dos métodos de estimação de magnitudes e produção de magnitudes

Tabela 6 - Expoente (n), constante escalar (k) e coeficiente de determinação $\left(r^{2}\right)$ das funções de potência individuais ajustadas separadamente para estimação de magnitudes e produção de magnitudes dos sujeitos do sexo masculino ... 84

Tabela 7 - Resultados da análise estatística do Teste t de Student, entre os expoentes obtidos dos métodos de estimação de magnitudes e produção de magnitudes, dos sujeitos do sexo masculino

Tabela 8 - Expoente (n), constante escalar $(k)$ e coeficiente de determinação $\left(r^{2}\right)$ das funções de potência individuais ajustadas separadamente para estimação de magnitudes e produção de magnitudes dos sujeitos do sexo feminino

Tabela 9 - Resultados da análise estatística do Teste t de Student, entre os expoentes obtidos dos métodos de estimação de magnitudes e produção de magnitudes, dos sujeitos do sexo feminino 
Tabela 10 - Média geométrica das estimativas de magnitudes (EM), média geométrica dos emparelhamentos de comprimentos de linhas (EMCL) e a ordenação das posições da preferência pela prática de atividades físicas ou esportivas de todos os sujeitos

Tabela 11 - Expoente (n), constante escalar (k) e coeficiente de determinação $\left(r^{2}\right)$ das funções de potência individuais ajustadas para as duas diferentes combinações entre as duas modalidades de respostas: numérica (EM) e comprimento de linhas (CL)

Tabela 12 - Resultados da análise estatística do Teste t de Student, entre os expoentes obtidos dos métodos de estimação de magnitudes e comprimento de linhas, a partir dos julgamentos de preferência pela prática de atividades físicas e esportivas. Comparados com os valores dos expoentes médios de 0,91 e 0,89 obtidos a partir do teste de calibração no Experimento 2 A

Tabela 13 - Média geométrica das estimativas de magnitudes (EM), média geométrica dos emparelhamentos de comprimentos de linhas (EMCL) e a ordenação das posições da preferência pela prática de atividades físicas ou esportivas dos sujeitos do sexo masculino

Tabela 14 - Média geométrica das estimativas de magnitudes (EM), média geométrica dos emparelhamentos de comprimentos de linhas (EMCL) e a ordenação das posições da preferência pela prática de atividades físicas ou esportivas dos sujeitos do sexo feminino

Tabela 15 - Resultado do teste de correlação de Spearman (rho), indicando a baixa correlação entre os julgamentos de homens e mulheres na preferência pela prática de atividade física ou esportiva. Dados do Experimento $2 \mathrm{~B}$

Tabela 16 - Expoente (n), constante escalar (k) e coeficiente de determinação $\left(r^{2}\right)$ das funções de potência individuais ajustadas para as duas diferentes combinações entre as duas modalidades de respostas: numérica (EM) e comprimento de linhas (CL), sujeitos masculinos e femininos resultados separados

Tabela 17 - Média geométrica das estimativas de magnitudes de todos os sujeitos (EM-MG-TODOS), proporções médias (PM), escores z médios (Z) e valores escalares ajustados (VA) derivados da matriz de julgamentos pelo método de comparação aos pares, com suas respectivas ordenações de posições OP, OP/PM e OP de preferência julgadas a cada atividade física e esportiva.

Tabela 18 - Média geométrica das estimativas de magnitudes dos sujeitos do sexo masculino (EM-MG-MASC), proporções médias (PM), escores z médios (Z) e valores escalares ajustados (VA) derivados da matriz de julgamentos pelo método de comparação aos pares, com suas respectivas ordenações de posições OP, OP/PM e OP de preferência julgadas a cada atividade física e esportiva 
Tabela 19 - Média geométrica das estimativas de magnitudes dos sujeitos do sexo feminino (EM-MG-FEMIN), proporções médias (PM), escores z médios (Z) e valores escalares ajustados (VA) derivados da matriz de julgamentos pelo método de comparação aos pares, com suas respectivas ordenações de posições OP, OP/PM e OP de preferência julgadas a cada atividade física e esportiva

Tabela 20 - Resultado da análise estatística do coeficiente de concordância de Kendall (W), das ordens de posição, das estimativas de magnitudes (EM), proporções médias (PM) e dos valores ajustados (VA), dos sujeitos do sexo masculino $(\mathrm{M})$

Tabela 21 - Resultado da análise estatística do coeficiente de concordância de Kendall (W), das ordens de posição, das estimativas de magnitudes (EM), proporções médias (PM) e dos valores ajustados (VA), dos sujeitos do sexo feminino (F)

Tabela 22 - Resultado da análise estatística do coeficiente de concordância de Kendall (W), das ordens de posição, das estimativas de magnitudes (EM), proporções médias (PM) e dos valores ajustados (VA), tanto dos sujeitos do sexo masculino (M) como do sexo feminino (F)

Tabela 23 - Média geométrica das estimativas de magnitudes, de todos os sujeitos, ordenados nas posições de maior preferência para a de menor preferência, dos três experimentos

Tabela 24 - Média geométrica das estimativas de magnitudes, de sujeitos do sexo masculino, ordenados nas posições de maior preferência para a de menor preferência, dos três experimentos

Tabela 25 - Média geométrica das estimativas de magnitudes, dos sujeitos do sexo feminino, ordenados nas posições de maior preferência para a de menor preferência, dos três experimentos 


\section{INTRODUÇÃO}

Muitas pessoas procuram a prática de determinados exercícios físicos por diversos fatores que, freqüentemente, são determinados quer pela personalidade quer pela influência exercida pelo meio cultural no qual a pessoa está inserida. Fatores como: demanda fisiológica, facilidade para coordenar os movimentos, disponibilidade de tempo e condições monetárias, são exigidos para o acesso e principalmente pelo prazer que os exercícios proporcionam, influenciando na escolha por este ou aquele ou ainda aqueles exercícios físicos, para praticálos em seus momentos livres ou, até mesmo como "meio de vida” (GALLAHUE; OZMUN, 2001; SOUZA JR; DARIDO, 2002; WEINBERG; GOULD, 2001).

A escolha para a prática de atividades físicas é ato individual e subjetivo, ou seja, uma intersubjetividade pessoal. Quine (1990) coloca que o requerimento de intersubjetividade é que torna a ciência objetiva. Isto indica que o principal requisito para a intersubjetividade é que o ser humano perceba o mundo dos objetos e eventos mais ou menos da mesma forma. Porém, não se pode afirmar que exista uma perfeita subjetividade, ou melhor, não é possível perceber da mesma forma que outra pessoa percebe, porém pode-se perceber algo bem semelhante ao que outra pessoa percebe. A partir dessa afirmação, parece que podemos perceber as atuais atividades físicas, de modo diferente, uns dos outros e de modo bem particular. Dentre estas atividades podem estar todas as formas de expressões de movimentos e entre esses os esportes de modo geral.

Freqüentemente, a intensidade e a duração dos exercícios físicos, exigidos nos esportes, são facilmente determinados (TURIBIO, 1997; FOX; MATHEWS, 1983) bem como, o nível de coordenação (GALLAHUE; OZMUN, 2001), a demanda calórica exigida 
nas atividades físicas (POWERS; HOWLEY, 2000) e as medidas de performance como, por exemplo, diminuição de tempo, distâncias, pesos etc. (SCHIMIDT; WRISBERG, 2001).

A avaliação da intensidade, por exemplo, pode ser medida pelas demandas fisiológicas (aeróbica e anaeróbica) que o praticante apresenta. Entretanto, o real motivo de se escolher este ou aquele esporte ou atividade física, ou seja, as preferências ou o gosto pela prática nem sempre condizem precisamente com as demandas (gasto calórico, esforço fisiológico ou até mesmo o nível de coordenação) do praticante.

Uma forma prazerosa da prática de exercício físico comum nos dias atuais é a prática de atividades esportivas, não apenas pelo seu fator competitivo, mas por outros fatores que ultrapassam as demandas fisiológicas que este ou aquele esporte pode proporcionar. Esta constatação permite inferir que muitos esportes e diversas atividades físicas podem estar sendo praticados de modo não adequado por muitas pessoas, podendo causar-lhes lesões e traumas agudos ou crônicos se não orientadas adequadamente.

Atualmente, as questões relacionadas diretamente às atividades físicas e, especialmente, às esportivas, vêm sendo amplamente discutidas nos cursos de formação de futuros professores de Educação Física. Por outro lado, a sociedade de modo geral, parece posicionar-se diferentemente destas pessoas que estudam e que se mantêm em contato permanente com as notícias relacionadas a este mundo esportivo e ativo corporalmente. Isto remete-nos ao fato que a sociedade pode ter uma percepção subjetiva diferente daquela vivenciada pelos futuros professores de Educação Física, constatando-se, portanto, uma forma perigosa de ambigüidade. A ambigüidade deve-se ao fato de que estes mesmos profissionais estão sendo formados com o intuito de fornecer à sociedade as melhores formas e sugestões críticas a respeito da percepção dessas atividades físicas e esportivas. Se não houver um ajustamento entre as informações captadas e as percebidas durante a formação na graduação, com os anseios esperados pela sociedade, este profissional pode ter seu campo de atuação 
reduzido e, deste modo, não corresponder de forma condizente ao momento atual de expectativa por parte das pessoas que compõem a sociedade, podendo, ainda, causar prejuízos emocionais, sociais e físicos aos clientes que usufruem de seus serviços.

É neste sentido que surgiu a intenção de buscar as informações e as possíveis explicações na psicofísica sensorial. A psicofísica sensorial é um ramo experimental da Psicologia que trata da mensuração e análise dos mecanismos e processos subjacentes às diferentes modalidades sensoriais e/ou perceptivas. Em outras palavras, a capacidade do ser humano em fazer escolhas (por exemplo, de preferência) se deve a relação que o mesmo estabelece entre o que ele percebe do meio a sua volta e as respostas que ele emite a partir do que foi percebido (DA SILVA; MACEDO, 1983).

Na tentativa de esclarecer melhor esta relação entre as informações disponíveis no ambiente e as respostas dos seres humanos é que tem sido estudado, em termos quantitativos, o que está verdadeiramente ocorrendo. Para Stevens (1960), perceber o ambiente e ter a capacidade de medir as alterações no mundo físico pode ser conseguido por meio da atribuição de números aos objetos ou eventos de acordo com determinadas regras. Desta forma, o pesquisador elaborou uma teoria de medida, utilizada por vários ramos da ciência, que trata do estabelecimento das condições nas quais, os números são designados aos objetos ou atributos, de modo que, as relações entre os atributos sejam representadas pelas relações entre os números. Tal condição é denominada de tipo de escala ou nível de mensuração. Assim, é possível fazer uma mensuração quantitativa em diferentes ramos das ciências sociais, humanas e biológicas, tais como a Antropologia, a Sociologia, a Psicologia, a Enfermagem, a Biologia, a Economia, a Medicina e também a Educação Física.

As escalas de razão têm sido muito utilizadas com o propósito de mensurar atributos sensoriais, conhecidos também como atributos com propriedades métricas e sociais, que a princípio são atributos difíceis de mensurar, pois parecem não possuir propriedades 
métricas quantificáveis (SOUSA; KAMIZAKI; DA SILVA, 2001). O uso deste modelo conceitual de medida se justifica pelo fato de observarmos, na literatura de Educação Física, que atributos com propriedades métricas bem identificáveis, como por exemplo: intensidade de atividades físicas, nível de performance, nível de coordenação, cálculos de distâncias saltadas, distâncias percorridas etc., têm sido obtidos freqüentemente, enquanto que, atributos não métricos, ou seja, atributos sociais, como a preferência ou o gosto, propriamente dito, não têm sido investigados.

Geralmente, os instrumentos de medidas geram apenas dados descritivos ou no nível de mensuração ordinal, no qual apenas a ordenação entre os valores escalares é admissível. Em outras palavras, apenas algumas medidas de tendência central, como mediana, moda, percentis e correlação de ordem podem ser calculadas a partir dos dados escalares obtidos. Em contra partida, no escalonamento em nível de razão, que é um dos objetivos deste estudo, torna-se possível obter diferentes medidas de tendência central e outras operações estatísticas admissíveis. O mais importante é que é possível estabelecer, a partir de agora, o quanto (quantitativamente) um atributo é maior do que um outro e não somente que eles são apenas diferentes (SOUSA; DA SILVA, 2001).

A contribuição do presente estudo, encaminha-se no sentido de fornecer uma forma precisa de mensuração de um atributo social, a princípio, com propriedades métricas difíceis de serem obtidas (preferência pela prática de atividade física), para possibilitar aos profissionais que trabalham com o movimento corporal, melhor adaptação e organização aos programas voltados para o fornecimento da prática de atividades físicas e esportivas, nos seus objetivos específicos. Um trabalho direcionado individualmente e com parâmetros mensuráveis para obtenção de avaliação dos aspectos físicos e não físicos que envolvem o comportamento humano, é o que está sendo almejado. 
A preferência pela prática de atividade física e esportiva vem sendo definida, como a quantidade de preferência que a maioria da população atribui em nosso meio social, (INDOW, 1961; SOUZA; DA SILVA, 2001). Serão evidenciadas a importância da prática de atividades físicas e esportivas e ainda qual atividade física é encarada como a mais prazerosa e preferível na opinião das pessoas de um modo geral. Também serão comparadas tanto as opiniões dos homens quanto das mulheres, com o objetivo de se obter maior precisão no diagnóstico da preferência.

A partir destas considerações, este trabalho visa apresentar as definições a respeito da preferência pela prática de atividade física e esportiva, de modo a adequar a escolha do tipo de atividade física ou esportiva para melhor sugerir qual atividade física escolhida pode trazer melhores benefícios ao praticante, aliando a preferência, ou seja, o gosto, com o executar. Investigar-se-á a preferência de diferentes tipos de atividades físicas e esportivas (coletivas e individuais).

A justificativa do presente estudo é reforçada pelo fato de sugerir, de modo mais preciso, qual a melhor e a mais prazerosa atividade física ou esportiva que cada pessoa poderá praticar, minimizando possíveis riscos para a sua saúde, tanto com relação ao descontentamento quanto à desmotivação e ao desalento em praticar algo de que não se tem uma total preferência. Pretende-se, ainda, tentar maximizar o prazer e os benefícios fisiológicos, adequando o sentimento de prazer ao querer praticar determinados esportes em detrimento a outros tipos de prática. Além disso, fornecer informações aos profissionais que trabalham com atividades físicas e esportivas, bem como aos pscicofísicos a importância da relação e da relevância da utilização de escalas de mensuração como meio eficaz para diagnosticar e mapear as reais intenções subjetivas na escolha da prática dos esportes e das atividades físicas, de modo geral. 
Em seguida, abordaremos alguns conceitos e métodos derivados da Psicofísica Sensorial, sua transição para a Psicofísica Social e a aplicação dessa metodologia a diversas áreas científicas. Será conceituada a Lei de Potência ou Lei de Stevens, a transição entre a Psicofísica Sensorial e a Social, a mensuração de atributos sociais e a mensuração de outros atributos sociais nas mais diversas áreas do saber científico. 


\section{A LEI DE POTÊNCIA OU LEI DE STEVENS}

O ser humano, constantemente, necessita perceber o ambiente a sua volta e interagir com ele a partir de suas sensações e percepções do mundo. Fazer comparações a respeito do que se sente ou se percebe com modelos quantitativos é algo constante nas ações humanas, por exemplo, está pouco ou muito frio (referindo-se à temperatura ambiental), caminhamos perto ou longe (referindo-se à distância percorrida). A partir dessas mensurações, que a todo o momento nos servem de parâmetros para uma melhor integração com o meio, é que vários pesquisadores têm discutido métodos que possibilitam quantificar e dar melhores informações a respeito do que sentimos a partir de estímulos que captamos do ambiente ou até mesmo do nosso próprio corpo. A partir desta concepção serão detalhados, a seguir, a lei que sustenta esta pesquisa e alguns métodos e testes de medição psicofísica citados por Sousa (1993).

O objetivo da psicofísica é determinar a relação funcional entre a magnitude física e a magnitude psicológica dos estímulos captados tanto do ambiente como do próprio ser humano. De acordo com Stevens (1975), a relação entre a magnitude sensorial e a magnitude física do estímulo pode ser descrita pela função de potência:

$$
\mathbf{R}=\mathbf{K} \mathbf{E}^{\mathbf{n}}
$$

$\mathbf{R}=$ magnitude do julgamento

$\mathbf{E}=$ magnitude física do estímulo

$\mathbf{n}=$ expoente cujo valor determina a relação entre a magnitude física e a psicológica

$\mathbf{K}=$ constante arbitrária 
Se o expoente é exatamente igual a 1,0, a função segue uma linha reta. Neste caso, a magnitude da sensação registrada (resposta) varia diretamente com a intensidade do estímulo. Quando o expoente é maior do que 1,0, a linha que representa esta função apresenta uma concavidade ascendente. Se o expoente é menor do que 1,0, a concavidade é apresentada para baixo. Porém, quando a curva é projetada em coordenadas log-log a função de potência que representa a relação entre a magnitude do estímulo e a magnitude da resposta é uma linha reta, independente do fato do expoente apresentar um valor maior ou menor do que 1,0 (ver Figuras 1 e 2).

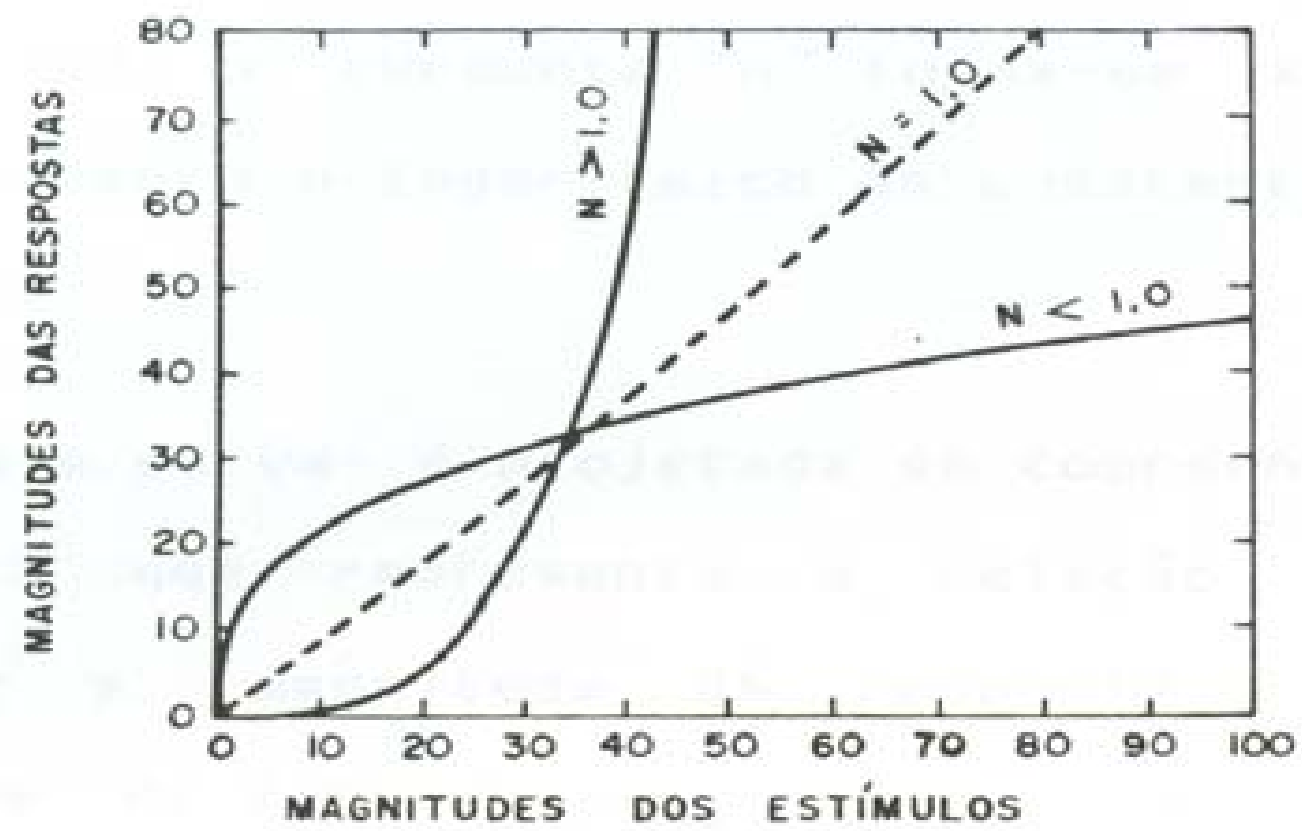

Figura 1 - Magnitudes subjetivas em função das magnitudes físicas dos estímulos, em coordenadas lineares. 


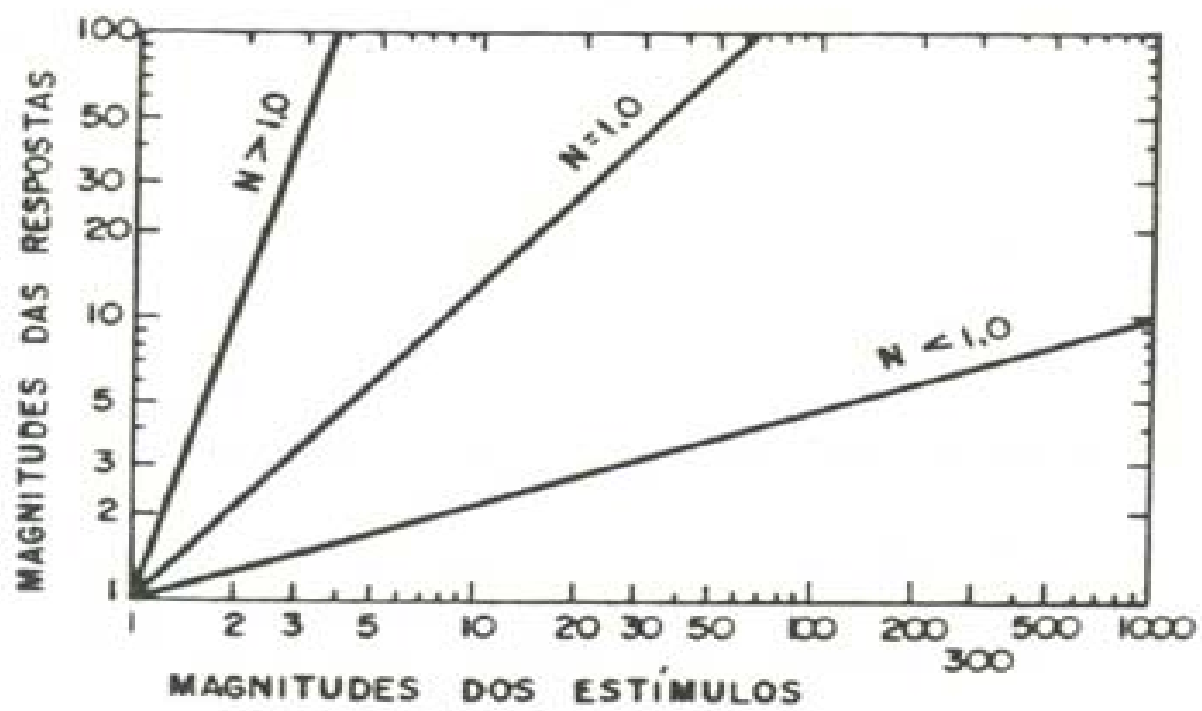

Figura 2 - Magnitudes subjetivas em função das magnitudes físicas dos estímulos, em coordenadas logarítmicas.

Tomando os logarítmicos de ambos os lados da Equação (1), uma função linear pode ser facilmente obtida. Esta expressão é mais conveniente tanto para fins estatísticos quanto para determinar os parâmetros da função de potência ajustada aos dados. Então,

$$
\log R=\log K+n \log E
$$

Na Equação (2), o expoente “n” torna-se a inclinação da função linear, enquanto o logarítmico da constante escalar K torna-se a intersecção.

A Equação (1) é conhecida como Lei de Potência ou, como foi popularizada, Lei de Stevens. A Lei de Stevens tem sido utilizada para uma variedade de dimensões sensoriais 
aditivas tais como: brilho, peso, comprimento, área, volume, distância visual, odor, sabor etc. Porém, esta Lei não se restringe às medidas puramente quantitativas, ou seja, nos últimos anos tem sido estendida para mensurar quantitativamente atributos sociais, físicos, políticos, econômicos, emocionais, como: a importância política de líderes e dirigentes; a preferência por tipos diferentes de música; a gravidade de crimes e/ou ofensas; o poder nacional; o grau de masculinidade; o conformismo e o julgamento moral; entre outros.

Os diferentes métodos escalares popularizados por Stevens (1957, 1971, 1975) produzem uma função de potência que relaciona os julgamentos sensoriais, perceptuais e/ou sociais com a magnitude física dos estímulos para uma ampla variedade de modalidades e/ou atributos. De fato, a relação entre a magnitude subjetiva e a magnitude física via de regra obedece a Lei de Potência, tal como expressada na Equação (1). Esta função descreve uma situação, na qual um aumento geométrico na escala de magnitude física corresponde a um aumento geométrico na escala subjetiva ou psicológica, com o expoente refletindo a taxa de aumento ao longo das duas escalas. A Equação (1), portanto, reflete o princípio de que razões iguais entre os estímulos produzem razões iguais entre as respostas. Este princípio pode ser resumido nas equações abaixo:

$$
\begin{gathered}
\underset{i}{\mathrm{R}_{\mathrm{i}}}=\mathrm{K} \mathrm{E}_{\mathrm{i}}^{\mathrm{n}} \\
\mathrm{e}_{\mathrm{j}} \mathrm{K} \mathrm{E}_{\mathrm{j}}^{\mathrm{n}}
\end{gathered}
$$

então,

$$
\left(\mathrm{R}_{\mathrm{i}} / \mathrm{R}_{\mathrm{j}}\right)=\left(\mathrm{E}_{\mathrm{i}} / \mathrm{E}_{\mathrm{j}}^{\mathrm{n}}\right.
$$


independente dos valores absolutos de $\left(E_{i}\right)$ e $\left(E_{j}\right)$ para os quais a razão das intensidades físicas é uma constante (C), o princípio diz que a razão das magnitudes psicológicas será também uma constante (D). De forma que se

$$
\underset{i}{(E} / \underset{j}{E})=C \text {, então } \underset{i}{R} / \underset{j}{R})=D
$$

no qual C e D são constantes.

A simplicidade da função potência reside no fato de que é possível reescrevê-la obtendo os logaritmos de ambos os lados da Equação (1). Assim, se reescreve tal como é expressado na Equação (2). Obtendo os logaritmos da Equação (6) o resultado é que, se log E

${ }_{i}-\log E_{j}=\log C$, então $\log R_{i}-\log R_{j}=\log D$, no qual, $\log C$ e $\log D$ são constantes. Isto implica que, em coordenadas logarítmicas, quaisquer dois estímulos que sejam eqüidistantes na escala física serão eqüidistantes na escala psicológica. Deste modo, esta função será uma linha reta em coordenadas logarítmicas. O Expoente “n” da função de potência para um conjunto de dados experimentais pode, portanto, ser estimado projetando-se o logaritmo dos valores de $\mathrm{R}$ em função dos correspondentes valores de $\mathrm{E}$, em seguida determinando-se a inclinação da linha reta (coeficiente angular) ajustada aos pontos.

\subsection{O significado psicobiológico do expoente da função de potência}

O significado psicobiológico do expoente da função de potência tem sido interpretado de diversas formas. De acordo com Stevens (1970, 1975), o valor do expoente fornece informações sobre as propriedades básicas do "input-output” da dimensão sensorial e/ou perceptual em questão. Isto caracteriza a taxa pela qual um sistema de "output”, indexado pela sensação, cresce como uma função do “input” do estímulo. 
Guyton (1988) coloca que uma pessoa pode detectar o peso de uma pulga na ponta de seu dedo, como também pode detectar o peso de um homem que pisa o mesmo dedo. A diferença entre os pesos desses dois seres é da ordem de 20 milhões de vezes, contudo, a partir das sensações que percebe, a pessoa pode fazer uma estimativa do peso dos dois objetos. A justificativa para o fato de se poder discriminar diferenças tão acentuadas de intensidade é a de que o número de impulsos transmitidos pela maioria dos receptores sensoriais é, dentro de certos limites, proporcional ao logaritmo da intensidade da sensação e não à própria intensidade. No caso da pulga e do homem, a diferença entre os logaritmos de seus pesos é de apenas sete vezes, mesmo com a diferença entre os pesos verdadeiros sendo da ordem de 20 milhões de vezes. Outro exemplo, também citado por este mesmo autor, é quando se pede para que uma pessoa segure em suas mãos um objeto que pesa 28 gramas e se esse objeto é trocado por outro que pesa 30,8 gramas, haverá certa dificuldade em discriminar o peso dos dois objetos, já que a diferença real é 2,8 gramas. Em seguida, é seguro um objeto com 280 gramas. Para discriminar uma diferença de peso com outro objeto, esse segundo objeto deve pesar, no mínimo 308 gramas para que possa ser avaliada a diferença de peso. O aumento de peso, nessa nova situação, é de 28 gramas e não de 2,8 gramas. Entretanto nos dois casos, o aumento é de $10 \%$ do peso original.

Se admitirmos que esta lei é válida para todas modalidades sensoriais, seremos levados a concluir que a reação da célula diante de um estímulo é proporcional ao logaritmo da amplitude do estímulo. Esta regra é conhecida como lei de Weber-Fechner, ou ainda, lei básica da psicofísica. Todavia, esta “lei” somente é válida para determinadas faixas de intensidades e não pode ser aplicada a todas as modalidades. Um bom exemplo refere-se à visão: dentro dos limites de luminosidade de pelo menos 1:10.000, a reação das células do córtex visual pode ser descrita pela lei de Potência de Stevens, ao passo que a lei de Weber- 
Fechner só pode ser aplicada com um grau razoável de aproximação para os graus médios de luminosidade, com relações de intensidades da ordem de 1:100 (SCHMIDT et al., 1980).

A função potência diz respeito a uma invariância entre as razões do estímulo e da sensação, que parece aplicar-se a todos os sistemas sensoriais, e que é de importância biológica fundamental para a sobrevivência do organismo. Nas modalidades sensoriais em que a variação de energia estimuladora do ambiente é muito pequena, usualmente encontra-se um expoente maior do que 1,0. Neste caso, o transdutor sensorial funcionaria como um “expansor” da energia estimuladora, como por exemplo, o expoente de 2,8 encontrado para choque elétrico (ver Tabela 1). Do contrário, quando a energia estimuladora ambiental é muito grande, o transdutor sensorial comporta-se como um "compressor", de forma a evitar uma possível sobrecarga do sistema sensorial (para detalhes dos problemas de sobrecarga sensorial ver Jacob, Francone e Lossow, 1990). Neste caso, o expoente encontrado é usualmente menor do que 1,0. Por exemplo, o expoente de 0,26 (ver Tabela 1), comumente encontrado para brilho, provavelmente reflete uma atividade de compressão do transdutor sensorial específico para tal modalidade sensorial, que o possibilita manipular a variação de energia luminosa de estimulação a que está sujeito (STEVENS, 1961, 1975; DA SILVA, 1985). A seguir, na Tabela 1, encontram-se demonstrados diferentes valores de expoentes para diferentes modalidades perceptuais e/ou sensoriais escalonadas por método baseado em julgamentos de razão. 
Tabela 1 - Média e desvio-padrão dos expoentes da função de potência para uma variedade de modalidades sensoriais e/ou perceptivas baseados em julgamentos de razão.

\begin{tabular}{|c|c|c|c|c|}
\hline Modalidade ou atributo & $\mathrm{I}$ & Expoente médio & $\mathrm{I}$ & Desvio-padrão \\
\hline Som & & $0,56^{*}$ & & 0,13 \\
\hline Sabor (sacarina) & & 0,53 & & 0,29 \\
\hline Sabor (salgado) & & 1,07 & & 0,41 \\
\hline Sabor (amargo) & & 0,57 & & 0,23 \\
\hline Sabor (azedo) & & 0,94 & & 0,28 \\
\hline Odor (amil-acetato) & & 0,19 & & 0,14 \\
\hline Odor (benzeno) & & 0,56 & & 0,01 \\
\hline Tempo & & 0,91 & & 0,18 \\
\hline Brilho & & 0,26 & & 0,13 \\
\hline Temperatura (frio) & & 1,04 & & 0,05 \\
\hline Temperatura (quente) & & 1,14 & & 0,37 \\
\hline Numerosidade & & 0,84 & & 0,22 \\
\hline Número & & 0,72 & & 0,21 \\
\hline Peso & & 1,18 & & 0,17 \\
\hline Aceleração Angular & & 1,39 & & 0,52 \\
\hline Choque elétrico & & 2,80 & & 0,99 \\
\hline Comprimento visual & & $\mathbf{1 , 0 1}$ & & 0,27 \\
\hline Área visual & & 0,77 & & 0,16 \\
\hline Volume visual & & 0,72 & & 0,10 \\
\hline Distância visual & & 0,97 & & 0,22 \\
\hline
\end{tabular}

* Valor correspondente a 0,28 em termos de intensidade sonora.

A função de potência refletiria a operação de mecanismos sensoriais, quando eles traduzem energia estimuladora em atividade neural. Como as respostas neurais do sistema sensorial são uma função de potência da intensidade do estímulo, os julgamentos do observador também devem seguir uma função de potência da magnitude física do estímulo. Assim, o expoente da função de potência revela algo sobre as propriedades transdutoras dos receptores sensoriais. Deste modo, por causa da invariância de razão que está subjacente à lei de potência somos capazes de ajustar-nos adaptativamente ao rico padrão de estimulação do ambiente, apesar da enorme variação de energia dos estímulos aos quais estamos sujeitos. Sem a característica operante da lei de potência, nossa tarefa de ajustamento seria, sem dúvida, mais difícil. Na verdade, a lei de potência está subjacente aos mecanismos de quase todas as constâncias perceptivas. 
Para as modalidades em que existe uma ampla variação de energia espera-se que haja expoentes baixos. Em outras palavras, quando a variação de energia estende-se a valores muito altos que podem ser nocivos a determinados órgãos, como a visão e a audição, há necessidade de expoentes baixos. Portanto, os expoentes são o que são por causa da natureza do transdutor sensorial que para algumas modalidades sensoriais comporta-se de maneira nãolinear. Nas modalidades em que a variação de energia é muito grande, fato que pode sobrecarregar o sistema nervoso central, o transdutor deve atuar como um compressor, o que faz com que o expoente seja menor que 1. Em outras modalidades nas quais a compressão não é necessária, o expoente pode ser igual a 1, o que significa que a função é linear ou pode ser maior que 1. Assim, é provável que os expoentes para luz e som sejam menores que 1, porque seus transdutores sensoriais comportam-se essencialmente como compressores, uma característica que os capacita a manipularem a enorme variação dinâmica de estimulação a que estão sujeitos. Em outro extremo, no processo de transdução envolvido com a corrente elétrica aplicada aos dedos, há uma operação de expansão no sentido de que a magnitude psicológica cresce numa função positivamente acelerada da variável física, isto é, o expoente é maior que a unidade. Neste sentido é que se acredita que seja improvável que a forma da função seja aprendida pelo observador (DA SILVA; MACEDO, 1982; 1983; DA SILVA, 1985; SCHMIDT et al., 1980; MAGILL, 2000).

A partir desta identificação do significado psicobiológico do expoente da função de potência é que serão discutidos os procedimentos metodológicos que têm sido feitos para uma melhor obtenção dos dados que sustentam estas informações. Os métodos psicofísicos que serão detalhados têm sido freqüentemente utilizados para escalonar diferentes modalidades perceptivas, devido à rapidez de aplicação e à fácil compreensão destes por observadores adultos. 


\subsection{0 método de estimação em categorias}

O método de estimação em categorias é feito por meio de uma escala do tipo ordinal, ou seja, é um tipo de escala que permite não somente categorizar os objetos, mas também ordena-los segundo a propriedade medida. Este tipo de escala não somente diferencia os individuos nomeando-os, mas também informa se um indivíduo tem mais ou menos, de uma determinada qualidade. Por exemplo, ao terminar uma corrida pedestre, se diz que a pessoa que chega um primeiro lugar tem mais qualidade que se julga, neste caso a velocidade para correr, do que os outros competidores. Porém, deve-se ficar bem ressaltado, que esta escala não indica o tamanho das diferenças que existem entre o ganhador e os outros participantes. (SOUSA, 1993; WILLS; MOORE, 1994; SOUSA; KAMIZAKI; DA SILVA, 2001).

Tem sido relatado na literatura que o número de categorias nas escalas varia de acordo com o problema a ser pesquisado e com os tipos exigidos de julgamentos. As escalas de 5 ou de 7 categorias são as mais comuns e mais utilizadas, sendo que alguns pesquisadores têm usado 9, 10 ou até 40 categorias. No estudo de Sousa e Da Silva (2001) foram utilizadas categorias expandidas de 1 a 40. Essas escalas devem ser elaboradas, sendo esses atributos relevantes aos objetos sociais estudados. No presente estudo, será utilizado o método de estimação em categorias de 1 a 7 atributos, no qual será solicitado aos participantes do experimento que julguem os atributos, posicionando-se no contínuo de 1 a 7 pontos ou categorias.

Para o método de estimação em categorias, a tarefa dos participantes (julgadores) consiste em assinalar um escore, que varia freqüentemente de 5, 7 a 40 categorias. Essas escalas de categorias devem ter itens elaborados, sendo esses atributos pertinentes ao objeto 
social estudado. Aos sujeitos solicita-se que respondam às declarações posicionando-se no contínuo de 7 pontos ou categorias, podendo ser bipolar, como exemplo, a escalas contendo 5 ou 6 alternativas (método de Likert) e de 6 a 20, escala de esforço percebido (RPE) de Borg (2000), com adjetivos que vão desde “absolutamente nada” de esforço a “o mais intenso possível” ou a escala para mensuração de dor (CR10), citado por este mesmo autor, que inicia de 0 “sem dor” a 10 “dor máxima”. Então, o participante é instruído para assinalar números máximos e mínimos. Os outros números intermediários, devem ser utilizados para indicar graus intermediários das magnitudes que os estímulos possuem. Porém, os sujeitos são lembrados de não utilizarem números decimais e sim assinalar apenas utilizando os números inteiros do contínuo de 1 a 7, por se tratar de julgamentos intervalares.

\subsection{O método de comparação aos pares}

A característica básica do método de comparação aos pares (STEVENS, 1957; KREIMAN; GERRATT, 1998; SOUTHWOOD; FLEGE, 1999) consiste em expor o sujeito a pares de estímulos, desta foma será requerido para que o mesmo selecione qual estímulo do

par apresentado contém mais ou menos da qualidade que está sendo escalonada. O sujeito pode julgar um dado estímulo em várias ocasiões, ou muitos sujeitos podem julgar o mesmo estímulo, fornecendo, assim, uma medida de dispersão. Essa técnica proporciona mais que uma simples afirmação de cada par e permite, também, o surgimento de variação no final da avaliação. A quantidade de variação para um dado estímulo fornecerá informação adicional a respeito dos atributos deste estímulo.

Cada sujeito é testado individualmente. Os estímulos são arranjados em pares de tal modo que um estímulo em particular não surja em sucessão e que cada estímulo apareça igualmente e freqüentemente à direita e à esquerda. 
Pode-se notar, neste ponto, que o método de comparação aos pares é similar ao método psicofísico dos estímulos constantes, em que o sujeito é requisitado a determinar se um estímulo é maior ou menor que um segundo estímulo. Deste modo, a resposta do sujeito é extensivamente um julgamento comparativo. O mesmo sujeito pode julgar todos os estímulos em pares um grande número de vezes em diferentes ocasiões, resultando em uma matriz ocasional, ou muitos sujeitos podem julgar todos os pares apenas uma vez, ocasionando uma matriz individual. Em um ou outro caso, o resultado obtido é o número e a proporção de vezes em que cada estímulo é julgado maior na escala, em relação a outro estímulo.

\subsection{O método de estimação de magnitudes}

A tarefa de fazer julgamentos requer que se relacione suas respostas aos estímulos sensoriais apresentados. Geralmente, as respostas podem ser divididas em três tipos: a) aquelas que requerem que o sujeito faça uma simples discriminação ordinal do estímulo apresentado; b) aquelas que requerem que o sujeito ajuste o estímulo a um contínuo sensorial subjetivamente em intervalos iguais; c) aquelas que requerem do sujeito a atribuição de números a estímulos que presumidamente representem a magnitude das sensações (exemplos: estimação de magnitudes ou escalas em categorias), ainda nesta mesma classe aqueles que requerem que o sujeito ajuste estímulos a um conjunto de números apresentados pelo experimentador (produção de magnitudes).

O método de estimação de magnitudes é freqüentemente empregado para que se consigam análises psicofísicas (GESCHEIDER, 1988), como também para escalonar diferentes modalidades perceptivas devido à rapidez de aplicação e à fácil compreensão deste por observadores adultos. Neste método, o observador recebe instruções previamente e atribui 
números a uma seqüência de estímulos apresentados individualmente, para que faça um julgamento da magnitude percebida daquele estímulo, de forma que esses números reflitam sua impressão subjetiva dos estímulos apresentados (Magnitude Física).

Segundo Stevens (1975), o método de estimação de magnitudes, denominado por ele de emparelhamento numérico, também é uma forma de emparelhamento intermodal, sendo que os números são equiparados aos estímulos. Dois são os tipos de estimação de magnitudes: com a presença do módulo e com o módulo livre. No primeiro tipo, um estímulo é apresentado pelo experimentador como estímulo padrão e a ele é designado um valor numérico, denominado módulo. Em seguida, o observador deve assinalar aos estímulos subseqüentes, números que sejam proporcionais ao atribuído a esse módulo, os quais representarão a razão julgada entre os diferentes estímulos apresentados pelo experimentador. Dessa forma, se um estímulo da série apresentada é considerado como tendo o dobro da intensidade do módulo apresentado, ele deve receber um valor numérico que seja duas vezes maior do que aquele atribuído ao estímulo padrão (módulo).

No segundo tipo, o método de estimação de magnitudes não tem um estímulo padrão estabelecido previamente, ou seja, o módulo é livre e o observador poderá assinalar qualquer número ao primeiro estímulo apresentado, devendo os números assinalados para a série de estímulos apresentados refletirem razões entre os estímulos julgados.

Em síntese, independente dessas duas variações no método de estimação de magnitudes, representadas pela presença ou ausência do módulo, a razão entre os números assinalados deve refletir a razão entre as intensidades percebidas dos estímulos julgados. 


\subsection{0 método de produção de magnitudes}

O método de produção de magnitudes consiste em executar o processo inverso àquele aplicado pelo método de estimação de magnitudes (SOUSA, 2000). Neste sentido, a tarefa dos participantes (julgadores) deverá consistir em produzir um determinado estímulo (exemplos: comprimentos de linhas, força dinamométrica, ajuste de som ou brilho etc.) a partir de números que lhes serão apresentados.

O participante (julgador) deve, deste modo, receber instruções para fazer estimação de diferentes números produzindo estímulos que sejam proporcionais à dimensão aparente do número designado. Por exemplo, se o participante julgar que um dado número é duas vezes maior do que aquele primeiro apresentado, ele deve assinalar-lhe um estímulo que seja duas vezes maior. Se o participante julgar que um outro número parece ter a metade da dimensão do número apresentado primeiro, ele deverá assinalar junto a ele um estímulo que seja metade daquele anotado com o primeiro apresentado. Assim como no método de estimação de magnitudes, estímulo padrão e módulo podem ser estabelecidos para auxiliar os participantes. Utilizando-se um método de produção de magnitudes, por meio do julgamento de comprimento de linhas, o estímulo padrão poderá ser 30 cm e o módulo 100.

\subsection{O método de emparelhamento intermodal}

O método do emparelhamento intermodal é considerado o mais criativo e elegante proposto por Stevens (1960), para confirmar os preceitos da Lei de Potência e validar as escalas de magnitudes. Cotidianamente, estamos relacionando tipos de mensurações, e toda forma de mensuração é um exercício de emparelhamento (SOUSA, 1993). Estes 
emparelhamentos são obtidos de maneiras simples e freqüentes. Os períodos do dia são contados normalmente pelos movimentos dos ponteiros e dos números indicativos de um relógio; a temperatura corporal pode ser obtida pelo emparelhamento de alterações no mercúrio de um termômetro que possui numerações. Uma distância é normalmente medida por meio do emparelhamento com os múltiplos de uma unidade de comprimento, seja ela arbitrária seja padronizada, e assim por diante.

No processo de mensuração das sensações corporais não é tão diferente dos exemplos citados acima. A intensidade da sensação pode ser emparelhada com qualquer unidade. Por exemplo, assim que uma pessoa é submetida a uma estimulação, ela sente a sua intensidade e emparelha-a com aquilo que lhe é mais familiar, nos casos experimentais o que tem sido utilizado é o número. Esse procedimento permite a construção da escala de sensação cuja relação com a escala de estímulo é representada por uma lei Psicofísica (ver também, PASHLER, 2002).

A partir da idéia de que é possível emparelhar o número, que é algo que as pessoas, principalmente os adultos, utilizam constantemente no seu dia-a-dia para fazer quase tudo, é que atualmente, vários pesquisadores, por iniciativa de Stevens (1958), vêm usando emparelhamento, ao invés de um contínuo sensorial aos números, dois diferentes contínuos sensoriais, tais como: comprimento de linhas aos números, força dinamométrica aos números, etc.

Na verdade, o equipamento construído por Stevens (1958) permite, ao mesmo tempo, estimular diferentes modalidades. A explicação de como isto ocorre é a seguinte: ao observador cabe manipular o controlador de um dos estímulos, de modo que a sensação provocada por este pareça igual à causada por outro. Em outras palavras, este equipamento proporciona um teste de transitividade da escala sensorial em que,

$$
\text { se } A=B \text { e } A=C \text {, então } B=C
$$


Em notação fundamental, se $E_{f}$ e $E_{s}$ são dois contínuos emparelhados a $R$, o teste tradicional de transitividade pode ser ilustrado para a Lei de Stevens. Deste modo, imagine que

$$
\begin{gathered}
R_{\mathrm{f}}=\mathrm{f}\left(E_{\mathrm{f}}\right) \quad \text { e } R_{\mathrm{s}}=\mathrm{g}\left(E_{\mathrm{s}}\right) \\
\text { Então } \\
\mathrm{f}\left(E_{\mathrm{f}}\right)=\mathrm{g}\left(E_{\mathrm{s}}\right)
\end{gathered}
$$

Usando este argumento, concretizemos: imagine que um observador faça estimativas de magnitudes de duas modalidades sensoriais e/ou perceptivas diferentes, por exemplo, comprimento de linhas e som, e em seguida funções de potência são ajustadas do modo usual. Desta forma:

$$
\mathrm{R}_{\mathrm{f}}=\mathrm{E}_{\mathrm{f}}^{\mathrm{a}} \quad \text { e } \quad \mathrm{R}_{\mathrm{s}}=\mathrm{E}_{\mathrm{s}}^{\mathrm{b}} \quad \text { no qual, }
$$

(f) e (s) indicam, respectivamente, os apontamentos para comprimento de linhas e som e (a) e (b) representam os expoentes característicos destas duas modalidades (o fato de $\mathrm{K}$ ter sido omitido a partir da Equação (1) não afeta o argumento acima). Então, quando $R_{f}$ e $R_{s}$ são emparelhados em vários níveis de intensidade a equação resultante será

$$
\mathrm{E}_{\mathrm{f}}^{\mathrm{a}}=\mathrm{E}_{\mathrm{s}}^{\mathrm{b}}
$$

Obtendo os logarítmicos de cada lado desta equação podemos escrever

$$
a \log E_{f}=b \log E_{s} \quad \text { ou } \quad \log E_{f}=(b / a) \log E_{s}
$$

Os expoentes (a) e (b) são empiricamente determinados por procedimentos separados, usando o método de estimação de magnitudes numéricas. Quando os valores são projetados em coordenadas logarítmicas a expressão acima representa uma linha reta, ou seja, 
uma função de potência com inclinação igual à razão (b/a) dos expoentes originais obtidos pelo método de estimação de magnitudes. Como os expoentes podem ser calculados a partir dos dados observáveis, esta relação é plenamente testável e pode ser feita em ambas as direções, como no exemplo de som emparelhado com o comprimento de linhas e vice-versa, para corrigir o efeito de regressão, ou seja, a tendência que os observadores têm de comprimir a variável que está sob controle (produção de magnitude). Para melhor ilustrar, a Figura 3 representa um emparelhamento entre força dinamométrica com diferentes estímulos obtidos como critérios. Como se pode observar, cada modalidade sensorial e/ou perceptiva é caracterizada por um diferente expoente observado, o qual, na maioria das vezes, não é diferente daquele predito pela propriedade de transitividade. Esta diferença dada em decilog é menor que 5\% (STEVENS, 1975, p. 113).

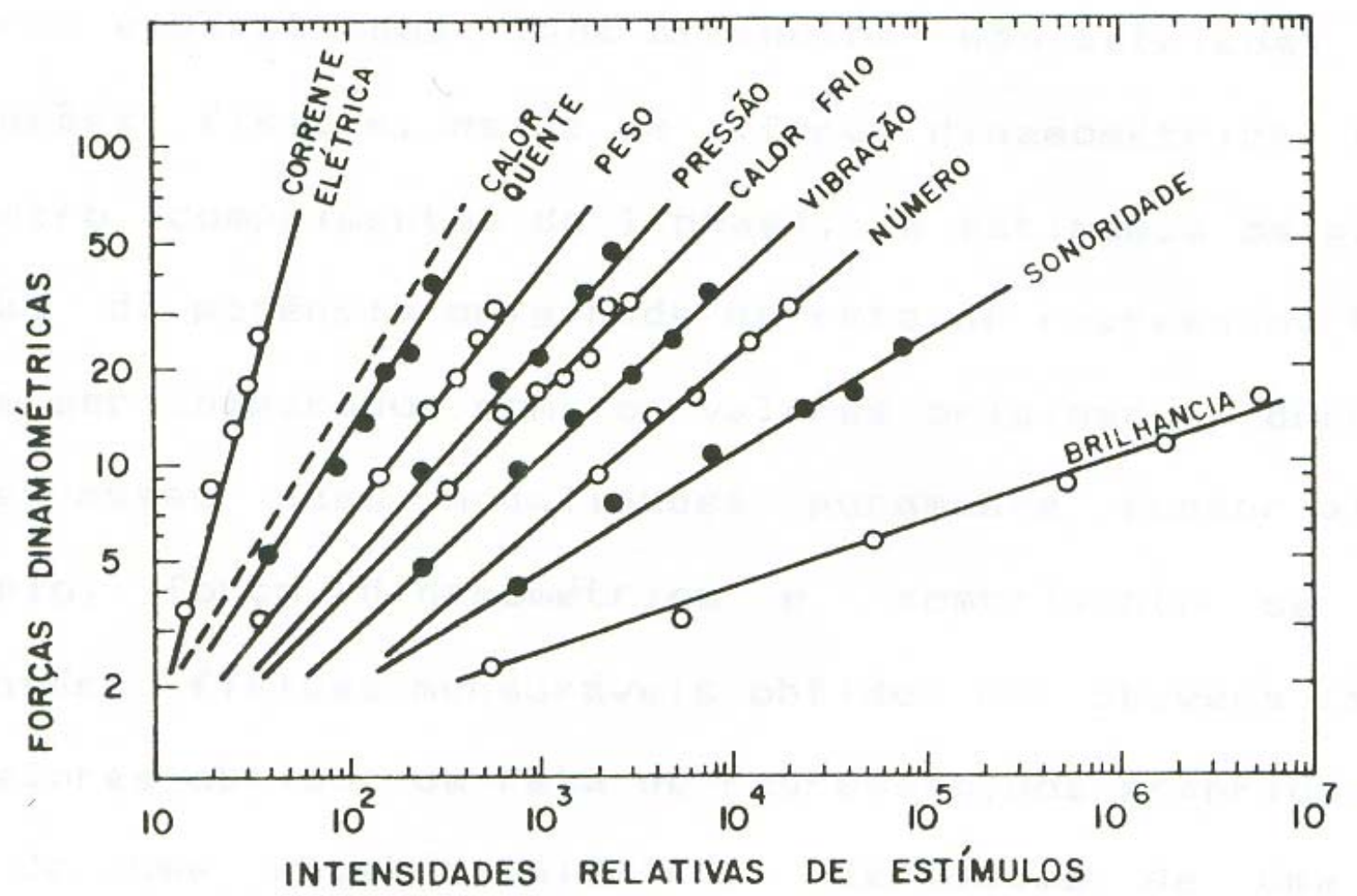

Figura 3 - Funções de potência ajustadas para diferentes modalidades sensoriais obtidas dos emparelhamentos de força dinamométricas e várias intensidades de estímulos tomados como critérios. A posição relativa de uma função em relação à abscissa é arbitrária. As coordenadas são logarítmicas. 
A partir destas considerações, uma outra questão surge: como esta idéia pode ser aplicada quando da tentativa de se mensurar estímulos sociais ? Seguindo as colocações de Sousa (1993) e Pashler (2002) será solicitado aos observadores para emparelharem duas modalidades sensoriais quaisquer (por exemplo, forças dinamométricas e comprimentos de linhas) a diferentes atributos sociais. Em seguida, será projetado o diferente valor emparelhado (aos atributos sociais) destas duas dimensões físicas, os de um (força dinamométrica) em função dos do outro (comprimento de linhas), e será estimado o parâmetro da função de potência originado da reta de regressão. Estes valores podem ser comparados com os valores originados do emparelhamento entre essas duas modalidades puramente sensoriais (como, por exemplo, força dinamométrica e comprimento de linhas) com dimensões físicas mensuráveis obtidas por Stevens (1975), ou com os valores obtidos da reta de regressão, dos observadores ou de uma amostra similar, derivados de uma tarefa que se denomina calibração, cujo procedimento é o mesmo daquele adotados por Stevens. Os detalhes deste processo de emparelhamento serão descritos mais adiante. 


\section{A PSICOFÍSICA SENSORIAL E A SOCIAL}

Até então, tem sido considerada a natureza e a derivação da função de potência (Lei de Stevens) a partir das estimativas numéricas e do emparelhamento intermodal, a seguir será feita uma relação entre a aplicação da metodologia e da teoria psicofísica na mensuração de atributos sensoriais e na mensuração de atributos sociais. Deste modo, será evidenciado como estes procedimentos de mensurações podem ser aplicados no escalonamento de atributos sociais referentes à preferência pela prática de atividades físicas e esportivas.

\subsection{Estimação de magnitudes versus estimação em categorias}

As escalas, quaisquer que sejam a sua natureza, devem sempre ter por hipótese a existência de um contínuo seja ele sensorial seja social. As escalas de atitudes são elaboradas a partir do momento em que o conhecimento objetivo dos fenômenos exige mais do que a afirmação ou negação de que uma diferença existe entre as qualidades e que, além disso, é preciso que se estabeleça o grau dessa diferença.

Nas estimativas numéricas, os participantes podem utilizar uma amplitude infinita de números que representam suas impressões sensoriais ou sociais de um objeto, um evento ou um atributo qualquer. Já as escalas em categorias têm a sua amplitude de números restrita. Como conseqüência, a medida de razão constitui a mensuração ideal para um pesquisador, uma vez que é, provavelmente, um ideal inatingível para uma grande variedade de atributos de natureza psicológica. Deste modo, o pesquisador tentará ao máximo construir os instrumentos de medida num alto nível de mensuração, uma vez que fundamentalmente os 
níveis mais altos fornecem mais informações e são mais receptivos a procedimentos analíticos, mais sensíveis e poderosos do que os níveis mais baixos, como a mensuração ordinal conseguida pelos testes de estimação em categorias.

Dependendo do tipo de julgamento ou processo requerido, uma relação logarítmica ou de potência é obtida. No caso do método de estimação em categorias, usualmente uma função logarítmica é obtida. Pelo método de estimação de magnitudes a função de potência é geralmente obtida. Segundo Stevens (1975), a relação entre estes dois métodos se aproxima de uma função logarítmica, o que atesta que ambos os procedimentos revelam processos perceptivos diferentes.

A seguir, iremos descrever como podemos identificar quando o que está sendo julgado está sendo feito de modo quantitativo (protético) ou de modo qualitativo (metatético).

\subsection{Contínuo protético versus contínuo metatético}

Os contínuos metatéticos e protéticos são definidos por Stevens (1974; 1975). Este destaca que, os julgamentos podem ser feitos de forma qualitativa ou quantitativa quanto à propriedade de um estímulo apresentado. Podemos julgar a intensidade de brilho de uma lâmpada como sendo alta ou baixa, ou podemos julgar a qualidade deste estímulo de luz como sendo uma luz de cor amarelada ou extremamente branca. Deste modo, quando julgamos quantidades, devemos pensar em um contínuo protético e quando julgamos qualidades em um contínuo metatético.

A explicação fisiológica para esta distinção entre os dois contínuos é que: quando o contínuo for protético, ou seja, apresenta características quantitativas, isto quer dizer que uma nova excitação é adicionada à excitação já existente. Por outro lado, um processo de 
substituição do estímulo já existente está subjacente aos contínuos denominados metatéticos ou qualitativos.

Diversos estudos realizados indicam quando o contínuo tem características protéticas ou metatéticas. No estudo de Schiavetti, Metz e Sitler (1981) foi investigada a inteligibilidade da fala, por meio de um método de estimação de magnitudes e um de estimação em categorias para identificar se o contínuo de inteligibilidade da fala é um contínuo com propriedades protéticas ou metatéticas. Os resultados indicaram que a estimação da fala tem características protéticas.

Em outro, Schiavetti et al. (1983) avaliaram o entendimento por parte de sujeitos que escutam normalmente, a partir da pronúncia de sujeitos com gagueira severa, por meio do método de estimação de magnitudes e de estimação em categorias, para determinar se o contínuo possui características protéticas ou metatéticas. Como geralmente tem sido definido por Stevens (1975), um contínuo revela características protéticas quando o gráfico obtido da estimação em categorias e da estimação de magnitudes apresenta uma forma curvilínea, do mesmo conjunto de estímulos, enquanto que no contínuo metatético é obtida uma linha reta. Portanto, os resultados do estudo de Schiavetti et al. (1983), citado acima, indicaram que os dois conjuntos de dados, quando projetados graficamente (estimação de magnitudes e estimação em categorias), apresentaram uma linha curvilínea, indicando um típico contínuo protético. Segundo estes autores, estes resultados apontam que o método de estimação de magnitudes é preferível em relação ao método de estimação em categorias, para julgamento da pronúncia de pessoas com gagueira severa.

Sousa e Da Silva (2001) investigaram o prestígio social de profissões de nível superior, exercidas por: assistente social, biólogo, dentista, enfermeiro, engenheiro, farmacêutico, físico, fisioterapeuta, fonoaudiólogo, médico, psicólogo, químico e sociólogo; escalonados pelos métodos psicofísicos de estimação de magnitudes e em categorias 
expandidas. Os resultados mostraram que: a) quando foi aumentada a amplitude limitada das categorias, esse método passa a ter as mesmas características das estimações de magnitudes; b) as relações entre as estimativas de magnitudes e as estimativas em categorias apontam para um contínuo protético.

\subsection{Estimação de magnitudes de estímulos sensoriais}

A estimação de magnitudes de estímulos sensoriais consiste no processo de julgamentos pelo qual observadores emparelham números a diferentes níveis de sua própria impressão sensorial e/ou perceptiva e constitui-se num dos métodos freqüentemente utilizados para construir escalas de razão de sensação. Nos experimentos psicofísicos típicos, os observadores são levados a responderem a uma série de estímulos, por exemplo, vários comprimentos de linhas ou forças dinamométricas, sendo apresentados um de cada vez e aleatoriamente. As instruções para a execução deste método são para que o sujeito faça emparelhamentos de números aos comprimentos de linhas ou índices de força dinamométricas (no caso destes modelos, citados acima), sendo esses estabelecidos proporcionalmente em relação ao estímulo inicial denominado de estímulo padrão.

Portanto, a tarefa do observador é julgar quão maior são os diferentes comprimentos de linhas apresentados, de tal forma que emparelhem com esses estímulos físicos números proporcionais em relação ao estímulo determinado como estímulo padrão. Deste modo, cada número dado a um estímulo refletirá o quão maior ou menor ele é em relação ao estímulo padrão, ou seja, o primeiro estímulo apresentado. Quanto menor o comprimento de linha em relação ao estímulo padrão tanto menor proporcionalmente deve ser 
a estimativa numérica da resposta dada. Entretanto, quanto maior o estímulo físico em relação ao padrão tanto maior deve ser a estimativa numérica.

Não existe neste escalonamento de magnitudes um limite para a amplitude de números que o observador poderá usar para estabelecer sua estimativa para cada estímulo físico, de modo que essas estimativas avaliem os comprimentos de linhas, conforme os observadores as vêem. A exemplo disso, se o observador considera que uma determinada linha é três vezes maior do que a estabelecida como padrão, ele deve dar-lhe uma estimativa numérica três vezes maior do que aquela atribuída ao comprimento de linha padrão.

Uma característica peculiar do escalonamento de magnitudes consiste no fato de que os julgamentos são estabelecidos em relação a um estímulo tomado como padrão, devendo o mesmo ser de intensidade baixa ou moderada, de preferência no meio da série de estímulos físicos. Isto justifica-se porque a posição do estímulo padrão na série de estímulos é uma das variáveis de procedimento que pode afetar, para algumas modalidades sensoriais e/ou perceptuais, o valor do expoente da função potência (BAIRD, 1970; DA SILVA; MACEDO, 1983; ALLIPRANDINI; DA SILVA, 2000).

Essa tarefa de emparelhamento, embora pareça fácil de se aprender, não é familiar ao observador, todavia, antes de executa-la, deve ser feito um treino que consiste em julgar estímulos físicos em um contínuo sensorial. O ideal é que os estímulos sejam apresentados várias vezes e em ordens diferentes para eliminar ou minimizar o efeito seqüencial.

Uma maneira simples de determinar se a magnitude dos julgamentos é proporcional à magnitude dos estímulos físicos utilizados no experimento, é calcular esse relacionamento num gráfico com coordenadas logarítmicas após terem sido calculadas as médias geométricas das estimativas numéricas estabelecidas pelos observadores e a média geométrica das magnitudes dos estímulos físicos. O princípio subjacente é que distâncias 
iguais numa escala logarítmica marcam razões iguais, sendo assim, se o gráfico resultante é uma linha reta em coordenadas logarítmicas, este representa uma função de potência.

Então, a magnitude do estímulo físico julgada pelo observador (estimativa numérica) cresce proporcionalmente com o aumento da magnitude do estímulo verdadeiro (comprimento de linha-físico). O expoente obtido para estimativas numéricas dos estímulos métricos num contínuo quantitativo tal como o comprimento de linhas é uma unidade, ou seja, uma função de potência com um expoente igual a 1,0 (ver DA SILVA; MACEDO, 1982). Quanto mais próximo de 1,0 for o expoente obtido para comprimento de linhas, mais se confirma que os observadores estão usando essa medida de resposta de magnitude para fazer julgamentos de razão. Testes e critérios estabelecidos deverão ser utilizados posteriormente para validar essa escala psicofisicamente, comprovando que as estimativas numéricas representam julgamentos de nível de razão. Centenas de experimentos em que são utilizadas estimativas numéricas comprovam que os observadores são capazes de fazer julgamentos proporcionais quando recebem estímulos referentes a todos os atributos dos diferentes sentidos.

Quando essas estimativas numéricas são tratadas de forma logarítmica, calculando-se a média geométrica de cada uma delas e representando-as graficamente em função da média geométrica dos valores físicos em coordenadas log-log, os pontos caem numa linha reta. Deste modo, o princípio, que é a essência da lei de potência, preconiza que razões iguais entre os estímulos produzem razões iguais entre as respostas dadas pelos sujeitos. Esta relação é usualmente descrita por uma função de potência tal como a representada pela Equação (1).

No desenvolvimento do escalonamento de magnitudes foi descoberto, a partir de experimentos bem controlados, que quando os observadores emparelhavam as estimativas numéricas com as suas impressões de vários atributos de visão, audição, tato, olfato e paladar 
(modalidades sensoriais), o expoente da função de potência obtido empiricamente variava fidedignamente entre as modalidades sensorais, ou seja, crescia em taxas diferentes. Cada modalidade ou atributo sensorial e/ou perceptivo é caracterizado por um expoente, ou seja, cada modalidade ou atributo tem sua própria assinatura ou impressão digital (ver Tabela 1).

A seguir serão apresentadas as considerações sobre as escalas de razão para contínuos sociais, com o intuito de esclarecer as analogias destas com aquelas referentes aos contínuos físicos, uma vez que, no presente estudo, empregamos as escalas de razão para contínuos sociais.

\subsection{Estimação de magnitudes de estímulos sociais}

Quando se trata de estímulos sociais, os atributos físicos agora são substituídos por palavras e frases (atributos) que descrevem os objetos ou eventos sociais. A lógica e os métodos para utilização da estimativa numérica no escalonamento de magnitudes dos estímulos sociais em uma dimensão sóciopsicológica são os mesmos utilizados quando os estímulos são físicos em um contínuo sensorial.

A aplicação de métodos psicofísicos usualmente utilizados na mensuração de atributos sociais para a mensuração de julgamentos sociais foi realizado inicialmente por Sellin e Wolfgang (1964) no estudo sobre “A medida da delinquência”. Nesse trabalho, os observadores receberam instruções para estabelecerem estimativas numéricas a várias frases que descreviam ofensas criminais, sendo que, assim expressariam a sua opinião a respeito de quão grave eles achavam os crimes descritos. Dessa forma, os números que estabelecessem ficariam emparelhados com seu julgamento da gravidade de crimes, tais como "estar onde não 
deveria”, “roubar e abandonar um veículo”, “um roubo de várias quantias de dinheiro”, “atear fogo”, “estupro” e “assassinato”.

Cada estímulo social foi apresentado em uma variedade de circunstância, desde ameaças verbais até o apontar de uma arma com graus diferentes de danos para a vítima. Nas instruções não foi estabelecido um limite para a amplitude de números. O atributo social referente ao roubo de uma bicicleta recebeu o escore 10. Esse foi considerado o estímulo padrão. Os demais deveriam ser julgados e comparados com esse, na medida em que os observadores considerassem um crime declarado mais ou menos grave do que aquele estabelecido como estímulo padrão.

Calculando-se o tratamento logarítmico das estimativas numéricas dos estímulos sociais, conforme é feito nas escalas de razão para contínuos sensoriais (contínuos métricos), essas não podem ser calculadas graficamente em função dos valores verdadeiros dos estímulos sociais, uma vez que esses são desconhecidos. Portanto, fica indeterminado o relacionamento psicofísico entre a magnitude da sensação e a magnitude de estimulação. Diante dessa impossibilidade os investigadores são forçados a utilizar formas de validações mais lógicas. Para exemplificar este tipo de validação, Lodge (1982) sugere que talvez no estudo de Sellin e Wolfgang (1964), pudesse ter sido solicitado aos observadores que, além de estimarem a magnitude dos atributos sociais, categorizassem-nos numa amplitude limitada de 7 categorias e depois calcular-se-iam as estimativas numéricas em função das avaliações categóricas num gráfico mono-log. O gráfico resultante seria curvilíneo, mas ele não indicaria qual método de escalonamento representa melhor a gravidade percebida dos crimes. Uma outra alternativa, esta feita por Sellin e Wolfgang (1964), foi quando compararam os julgamentos de magnitudes feitos por juízes de tribunais juvenis com os realizados por estudantes e efetuados por oficiais de livramento condicional, em coordenadas log-log. O resultado final projetado num gráfico mostra uma linha reta e altas correlações produto- 
momento, demonstrando, assim, um grau considerável de concordância entre estes grupos diferentes de observadores.

Sellin e Wolfgang (1964) e Fligio (1976), em outro estudo, fizeram comparações entre 5 ofensas criminais que envolviam o roubo de 10, 50, 1.000 e 10.000 dólares nas mesmas condições de não violência. Foram colocadas em coordenadas log-log a média geométrica das estimativas numéricas da gravidade de cada roubo em função das quantias em dólares. A relação gráfica é descrita por uma linha reta, sendo que para os sujeitos utilizados por Fligio (1976) o expoente obtido foi de 0,27 e para os sujeitos utilizados por Sellin e Wolfgang (1964) o expoente obtido foi de 0,17. A inclinação de 0,27 significa que para um roubo ser considerado 2 vezes mais grave do que um outro, a quantidade de dólares roubados precisa ser aproximadamente 13 vezes maior.

Atualmente, vários estudos continuam empregando estes métodos psicofísicos, para mensuração de atributos sociais, relacionados a ofensas e a comportamentos que resultam em crimes, demonstrando a grande contribuição deste tipo de estudo na mensuração e no detalhamento de explicações científicas precisas. Para melhor ilustrar estas contribuições sugere-se a apreciação de alguns exemplos que abordam esta temática. Estes exemplos encontram-se no estudo de Stylianou (2003) cujo objetivo foi identificar as características dos atos que afetam a percepção da gravidade criminal e, também, examinar os graus de consenso na percepção da gravidade de uma variedade de comportamentos, bem como, de condutas não condizentes com as normas legais. Foram discutidas, ainda, questões metodológicas (métodos de mensuração, estrutura e conteúdos de questionários, níveis de mensuração, etc). O estudo de Piquero (2000), também forneceu uma importante ajuda para descrever as informações sobre a aprendizagem da carreira criminal. Vários fatores foram mensurados como a taxa de ofensas, a relação entre a cronicidade e não-cronicidade dos ofensores, a seriedade de ofensas e o papel dos gêneros neste processo. Ainda, outros como Lynch e Danner (1999) 
desenvolveram uma análise dos cenários de uma cena de crime como fator influenciador na interpretação da gravidade dos crimes e Kwan, Cheung e Kwan (2000) trataram da interpretação da gravidade criminal.

Recentemente, Morgon e Guirardello (2004) também utilizaram a medição de um atributo não métrico em seu estudo, com o objetivo de validar, em nível de razão, a escala de necessidades de familiares em Unidade de Terapia Intensiva (UTI). Participaram deste estudo 52 familiares que visitaram o seu parente durante a hospitalização na UTI. Os autores utilizaram os métodos psicofísicos de estimação de magnitudes e emparelhamento de comprimento de linhas, com cálculo da média geométrica para cada uma das necessidades julgadas, em ambos os métodos. Os resultados mostraram uma concordância significativa, entre os participantes, no julgamento das necessidades, com um coeficiente de correlação de Pearson de $r^{2}=0,97(p<0,0001)$. A relação entre esses métodos pode ser descrita por uma função de potência, confirmando que a escala de necessidades de familiares é valida, estável e consistente.

Resumindo, o ajustamento dos dados às perspectivas obtidas nesses estudos foi o suficiente para despertar interesse na aplicação do escalonamento de magnitudes para atributos sociais. De fato, esses estudos demonstraram que o sujeito experimental médio é capaz de, uma vez recebidas as devidas instruções de uso das estimativas numéricas, fazer julgamentos proporcionais sobre a intensidade percebida de muitos estímulos sociais em várias dimensões sociopsicológicas.

Uma problemática que surge é como devem ser colocados no eixo x estímulos com propriedades não métricas, como no caso dos experimentos citados, o estupro e o assassinato que são, por natureza, não métricos ? Deste modo, como podemos projetá-los graficamente numa função tal como é feito para valores como a quantidade de dólares roubados ? A resposta pode ser encontrada no paradigma do emparelhamento intermodal, no 
qual os princípios representam uma contribuição significativa para o avanço da metodologia de julgamentos tanto de dimensões sensoriais quanto de dimensões sociais. Em seguida, passaremos a descrição dos processos para validação psicofísica pelo método de emparelhamento intermodal.

\subsection{O paradigma do emparelhamento intermodal aplicado a estímulos e/ou atributos sociais}

As escalas de razão que visam a mensuração de atitudes, devem ser submetidas a processos de validação psicofísica por meio de procedimentos específicos. Alguns métodos para esta validação serão descritos a partir desse momento para explicar os procedimentos de validação psicofísica que serão tomados no presente estudo.

O método de emparelhamento intermodal representa uma significativa contribuição para a medida de julgamentos sensoriais, bem como de sociais (LODGE, 1982;

STEVENS, 1966a; 1975). É importante mencionar que esse método veio complementar resultados de estudos (SELLIN; WOLFGANG, 1964; FLIGIO, 1976) que se apoiaram apenas nas estimativas numéricas como modalidade de resposta. Dessa forma, tornava-se impossível verificar a Lei de Potência ou confirmar o expoente característico para cada modalidade sensorial e/ou perceptiva, deixando de ser comprovado que as pessoas são capazes de fazer julgamentos proporcionais independente da modalidade utilizada como resposta ser ou não estimativa numérica (GESCHEIDER, 1988; KRUEGER, 1989).

Este método foi desenvolvido por Stevens (1961), e fornece meios para a confirmação da Lei de Stevens, para a verificação do expoente característico que relaciona a magnitude de estímulos à magnitude de resposta subjetiva, sendo que dessa forma demarca critérios de validação das escalas de magnitude sensorial e social (LODGE, 1982). Nesse 
emparelhamento intermodal, além das estimativas numéricas, qualquer uma das modalidades sensoriais pode ser utilizada como medida de resposta de magnitude. Isso se deve ao fato de que cada sensação tem representado seu expoente característico, sendo esse obtido pelos vários estudos de laboratório em que foram feitos relacionamentos de estimativas numéricas com cada modalidade sensorial, como a altura do som, luminosidade, comprimento visual, etc. (LODGE, 1982).

Nesses estudos o experimentador pede aos observadores que utilizem, por exemplo, a força dinamométrica ou a intesidade do som como modalidade de resposta, ao invés de somente estimativas numéricas. Assim, para medir a intesidade de um estímulo social, cada sujeito deve ser instruído a apertar um dinamômetro manual calibrado, de maneira que sua impressão de força dinamométrica no instrumento seja igual a sua impressão do estímulo social, de modo que quanto mais forte a impressão do estímulo social tanto mais forte deve ser a força dinamométrica. Similarmente, usando-se a intensidade do som como modalidade de resposta, o observador deve variar a intensidade do som por meio de um potenciômetro de um par de fones de ouvido, de modo que a intensidade percebida seja emparelhada com a impressão do estímulo social, de forma que quanto mais forte a impressão do estímulo social tanto mais alta deve ser a intensidade do som.

Lodge (1982) comenta ainda que sendo a Lei de Potência válida e os expoentes derivados das estimativas de magnitudes verdadeiramente característicos, então quaisquer das duas medidas de respostas quantitativas com expoentes determinados poderiam ser utilizadas para julgamento de um contínuo sensorial. A validade de uma escala de razão poderia ser confirmada obtendo-se um emparelhamento próximo entre as razões teóricas e as obtidas empiricamente entre as duas medidas de respostas.

Deste modo, quando duas ou mais modalidades de respostas de magnitude são emparelhadas a um mesmo conjunto de estímulos sociais, o princípio subjacente a esse 
relacionamento é o de que objetos iguais a um mesmo objeto são iguais entre si. Assim, uma escala de magnitude subjetiva é validada pelo método de emparelhamento intermodal quando a inclinação obtida dos emparelhamentos com um conjunto comum de estímulos sociais se aproxima da razão característica entre as duas medidas de respostas psicofísicas (CROSS, 1974).

É interessante ressaltar que a razão predita (teste de critério para validar a escala de magnitude) é uma função das duas modalidades de respostas e não dos estímulos, uma vez que os sujeitos estão usando as duas respostas para expressar suas impressões das intensidades dos estímulos. No escalonamento social, uma primeira alternativa seria a de comparar o expoente empírico (inclinação derivada), quando as modalidades de respostas são emparelhadas com estímulos sociais, com o expoente teórico (inclinação teórica) característico dos relacionamentos dessas modalidades quando emparelhadas com estímulos físicos (ver Tabela 1). Em outras palavras, a razão empírica, obtida quando os sujeitos fazem o emparelhamento das duas modalidades de respostas com os estímulos sociais, deve ser então a mais próxima da razão estabelecida para essas mesmas duas modalidades de respostas emparelhadas a estímulos físicos (LODGE, 1982).

Uma segunda alternativa seria a comparação desse expoente empírico derivado das estimativas dos estímulos sociais com o expoente empírico obtido num primeiro procedimento de calibração, no qual os mesmos sujeitos tenham emparelhado as mesmas duas modalidades de respostas com estímulos sensoriais. Esse procedimento de calibração envolve uma tarefa de escalonamento psicofísico que serve como treino dos observadores no uso das duas modalidades de respostas para que façam julgamentos proporcionais. Essas mesmas duas modalidades deverão ser empregadas num segundo procedimento de escalonamento de magnitude, no qual os observadores julgarão a intensidade de um dado estímulo social. 
O pressuposto é que os mesmos viéses que afetam as respostas aos estímulos sensoriais/perceptuais atuariam com mesma intensidade e/ou teriam efeitos similares nas respostas aos estímulos sociais. Qualquer que seja a alternativa de comparação, o importante é que cada um dos expoentes empíricos e a razão entre eles precisam ser funções de potência (LODGE, 1982). Sendo assim, quando esse critério é satisfeito, a escala derivada é uma escala de razão é considerada psicofisicamente validada (BAIRD; NOMA, 1978; STEVENS, 1975).

Outra forma de se obter a validade da escala de razão é por meio da obtenção de resultados que comprovam os indícios da ocorrência da Lei ou Princípio de Ekman (SOUSA; DA SILVA, 2001). A Lei de Ekman supõe que o tamanho subjetivo das diferenças apenas perceptíveis (d.a.p.), aumenta em proporção com a magnitude percebida da sensação (PETROV, 2003; ALLEN, 2000). A Lei de Ekman em sua forma mais simples pode ser descrita como:

$\Delta \Psi=\mathrm{b} \Psi$, no qual $\Delta \Psi$ é o tamanho subjetivo das d.a.p.(s) e b $\Psi$ a magnitude das sensações.

Esta equação, quando aplicada ao contínuo psicológico, é exatamente análoga a Lei de Weber, $\Delta \phi=c \phi$, no contínuo físico. Esta analogia é também identificada em outros estudos como os de Allen (2000) e Donald e colaboradores (2001). É interessante que a Lei de Potência de Stevens, a qual deriva principalmente dos resultados dos procedimentos obtidos das escalas de magnitudes, implica que o Princípio de Ekman precisa também ser validado. A magnitude da sensação $\Psi$ aumenta com o aumento da intensidade do estímulo, deste modo a Lei de Ekman mede que o correspondente tamanho subjetivo dos d.a.p.(s) aumenta.

Representando matematicamente, isto indica que a magnitude da sensação crescerá como uma função de potência da intensidade dos estímulos, com o expoente da 
função de potência representando este crescimento. O Princípio de Ekman pode ser encontrado tanto no contínuo de sensação como no contínuo do estímulo.

Para acrescentar que isto esteja correto, então a Lei de Ekman pode ser demonstrada mais precisamente como $\Delta \Psi=.03 \Psi$. O sujeito é capaz de discriminar $100 \mathrm{C} \%$ de mudança na magnitude sensorial (na qual $C=\Delta \Psi / \Psi$ ) independentemente da forma do estímulo percebido. Tal suposição é consistente com a hipótese de que as discriminações são baseadas nos resultados (output) da magnitude sensorial (mais detalhes em TEGHTSOONIAN, 1973). 


\section{A MENSURAÇÃO DE ATRIBUTOS SOCIAIS}

Serão apresentados, neste tópico, experimentos que de algum modo foram escalonados atributos sociais por rigorosos métodos psicofísicos desenvolvidos no domínio da Psicofísica Sensorial. A proposta deste tópico é demonstrar a riqueza da diversidade metodológica utilizada para o escalonamento de contínuos de diferentes naturezas, bem como descrever o processo de validação psicofísica, envolvido nesses escalonamentos.

Alguns exemplos claros dessa riqueza e diversidade metodológica no escalonamento de contínuos de diferentes naturezas são os estudos de Sousa (2000) e Pashler (2002). Nesses estudos foram detalhados vários experimentos que envolveram a mensuração de atributos sociais. Nestes textos os experimentos estão organizados por temáticas, da seguinte forma: a) a importância política dos monarcas suecos; b) valores estéticos de desenhos e manuscritos; c) preferências musicais; d) preferência por relógios de pulso; e) julgamento moral; f) comportamento racista; g) agradabilidade de odores; h) o grau de liberalismo-conservadorismo; i) percepção de poder nacional; j) pronunciabilidade de trigramas e de frases; k) utilidade subjetiva de bens e de benefícios públicos; l) opiniões sociopolíticas; m) seriedade de ofensas e crimes; n) preferência e prestígio profissionais e ocupacionais; o) status social; p) stress e reajustamento social e q) gravidade de enfermidades. Além de ser um grande número de temáticas abordadas, para cada uma delas foram descritos sempre mais do que um experimento para demonstrar a riqueza dos estudos, que utilizaram tal abordagem metodológica.

Para reforçar e confirmar este grande uso dos métodos psicofísicos na mensuração de atributos sociais (difíceis de serem medidos), detalhamos, aqui, alguns experimentos, que abrangem esta temática, e que têm sido realizados nos últimos anos, e ainda continuam 
confirmando o grande interesse e a importância por parte dos diversos pesquisadores, nas mais variadas áreas do saber científico.

No estudo de Han et al. (1998) foi utilizado um experimento psicofísico para avaliar o desenho (design) interior de um trem de alta velocidade, conhecido popularmente como "trem-bala”. O desenho (design) interior envolve diferentes variáveis para que o passageiro sinta-se confortável neste ambiente. As formas e a ordenação das poltronas, as facilidades do interior do trem, o corredor de deslocamento entre as poltronas, as portas, entre outros requisitos, formam um conjunto de variávies que podem ser mensuradas pelos passageiros para inferência sobre as condições de conforto do trem. O conforto do passageiro não depende apenas dos espaços entre as poltronas, mas também de atividades que o mesmo faz durante a viagem. Estas atividades vão desde trabalhos profissionais, passando por comer, dormir, conversar, ler jornais e revistas, escutar músicas até somente descansar durante a viagem.

Para medir a quantidade de conforto dos passageiros foi utilizado o método de estimação de magnitudes, com módulo livre. Para testar a validade deste experimento os autores também utilizaram o método de emparelhamento intermodal de comprimento de linhas. Participaram deste estudo 24 sujeitos, divididos em três grupos com oito participantes cada, sendo um grupo formado por jovens, um por adultos e outro por idosos. Os resultados obtidos neste estudo foram: a) o procedimento utilizado de medidas diretas de estimação de magnitudes demonstrou uma obtenção melhor de resultados individuais das mensurações feitas pelos passageiros do que uma simples comparação entre as respostas dadas pelos mesmos; b) os métodos de medidas psicofísicas quantitativas podem fornecer muitos dados úteis para ajudar os engenheiros na melhor utilização dos desenhos (design) dos interiores dos trens; c) as poltronas dos passageiros poderiam ser organizadas em relação ao movimento do trem (poltronas viradas para frente) e uma variedade de facilidades no interior poderia 
fornecer segurança e conforto aos passageiros, como, escutar música mesmo estando em poltronas viradas para trás sendo opostas à direção na qual o trem está se deslocando; d) ainda, neste estudo foi fornecido um guia para analisar os dados, utilizando-se escalas de razão. Quando se empregou o método de estimação de magnitudes de módulo livre, tornou-se necessária a padronização dos dados pelas respostas máximas de cada sujeito. Respostas negativas em uma região de respostas bipolares seriam convertidas em formas inversas para manter as propriedades da escala de razão. Também, há de se fazer a transformação em log dos dados para serem obtidas as análises de variância (ANOVA).

Outro estudo que teve como objetivo investigar as contribuições dos métodos psicofísicos em atributos sociais foi o de Whitehill, Lee e Chun (2002). As medidas psicofísicas de estimação de magnitudes e as escalas de intervalo foram utilizadas para medir a hipernasalidade. A hipernasalidade é definida como uma qualidade perceptiva associada com uma resonância nasal excessiva durante a fala. Esta doença pode ser encontrada em um grande número de pessoas, incluindo aquelas com fissuras lábio-palatais ou outras anomalias congênitas, alguns defeitos nos lábios ou no palato e ainda aquelas que sofreram algum tipo de cirurgia oral, da qual resultou esta disfunção.

O primeiro objetivo deste estudo foi determinar a validade e a confiabilidade das escalas intervalares que medem a razão perceptiva da hipernasalidade. O segundo objetivo foi comparar a escala intervalar com a escala de estimação de magnitudes para saber qual escala traria mais confiabilidade de validade nas medidas das razões percebidas da disfunção em questão (a hipernasalidade). Participaram deste estudo 20 crianças, entre 5 e 15 anos de idade, com físsuras lábio-palatais, reparadas por cirurgia, e diagnosticadas com problema de hipernasalidade, sendo 8 do sexo masculino e 12 do sexo feminino. A tarefa do experimento foi atribuída a outro grupo, chamado de grupo dos ouvintes que iriam ouvir as crianças com hipernasalidade e fazer o julgamento do entendimento das sentenças. Este grupo foi formado 
por 20 sujeitos, 2 homens e 18 mulheres, estudantes graduandos. Os métodos psicofísicos utilizados foram o de estimação de magnitudes com módulo (número 100), estimação de magnitudes sem módulo e uma escala de intervalo com 7 itens.

Os resultados indicaram uma relação curvilínea entre a escala intervalar e a escala de estimação de magnitudes (tanto para a condição com ou sem módulo). Estes resultados sugerem que os ouvintes (sujeitos do grupo experimental) têm dificuldades em distinguir a hipernasalidade em intervalos iguais, indicando que as escalas de intervalo podem não ser um instrumento apropriado para avaliação de hipernasalidade. Por outro lado, as escalas de estimação de magnitudes com e sem módulo demonstraram maior confiabilidade e melhor validade na mensuração para avaliação da hipernasalidade no grupo de ouvintes.

No estudo de Ebe e Griffin (2000) também foram adotados os métodos de estimação de magnitudes e de comparação aos pares para mensurar um atributo social (nãométrico), neste caso, o conforto ao se sentar em poltronas de automóveis. Muitos fatores podem influenciar o conforto ao se sentar ao volante de um carro, tais como, o apoio postural, a pressão exercida pelo corpo na superfície de contato e propriedades como a temperatura e a umidade da poltrona. Em condições dinâmicas, ou seja, quando os veículos estão se locomovendo isto causa um atrito (vibração) da poltrona com o corpo da pessoa, (isto, indicado como sendo um desconforto dinâmico) tem sido considerado alguns dos importantes fatores no planejamento de poltronas mais confortáveis para os condutores. A otimização dos modelos de poltronas requer um conhecimento sobre quais fatores influenciam no conforto do condutor e como estes fatores se combinam para produzir uma impressão de conforto ao dirigir e ao levar consigo outros passageiros.

A capacidade de se criar um modelo para predizer a importância geral e relativa das características do sentar estático e dinâmico no conforto dos condutores foi testada em dois experimentos. No primeiro experimento, foi utilizado o método de comparação aos pares, 
usando quatro poltronas com materiais de poliuretano (50, 70, 100, $120 \mathrm{~mm}$ de espessura), fornecendo diferentes confortos estáticos e dinâmicos quando 12 sujeitos foram expostos a uma vibração vertical com freqüência de 2,5 e 5,5 Hz. Os sujeitos julgaram o desconforto relativo em diferentes condições dependendo da condição estática ou dinâmica em uma maneira consistente com o modelo. No segundo experimento, com participação de 20 sujeitos, os efeitos dos fatores do sentar dinâmico e estático foram investigados pelo método de estimação de magnitudes, usando três espumas diferentes (rigidez variada) e uma poltrona de madeira com seis magnitudes de vibrações. Os resultados dos dois experimentos confirmaram que os julgamentos do desconforto, de sentar, podem ser afetados por ambas as condições do sentar tanto a estática como a dinâmica, com este efeito ainda exercendo uma forte correlação com a freqüência da magnitude da vibração. Quando a magnitude da vibração foi baixa, o desconforto foi dominado pelos fatores do sentar estático, porém com o aumento da magnitude da vibração o desconforto tornou-se dominado por fatores do sentar dinâmico.

Outro estudo que também investigou a preferência, neste caso a preferência por cores de acordo com o sexo e a orientação sexual foi o de Ellis e Ficek (2001). Nele o objetivo foi verificar a preferência por cor de pessoas de sexo diferentes (homens e mulheres) e ainda buscar saber se a preferência pela cor era influenciada pela orientação sexual dos testados (heteroxessuais, homosexuais, bissexuais e indecisos). Participaram deste estudo 1924 homens e 3766 mulheres, com idades que variavam de 17 a 63 anos, perfazendo uma média total de 22,82 anos de idade para os homens e 22,54 para as mulheres. Para saber a orientação sexual dos participantes, os experimentadores aplicavam um questionário que indagava a pessoa sobre, qual era a sua própria opinião (ou autodefinição) para sua orientação sexual: heterossexual, homossexual, bissexual ou indeciso. De todos os testados, 53 (2,86\%) homens e $62(1,71 \%)$ mulheres se declararam homossexuais ou bissexuais. Os resultados da preferência por cor, expressada por homens e mulheres, indicaram uma diferença 
significativa. Verificou-se que os homens preferem mais as cores derivadas do azul, já as mulheres escolheram como cores de sua maior preferência o rosa e as derivadas da vermelha. Não houve diferenças na preferência de cor com relação à orientação sexual. Neste estudo, o método de análise foi centrado na freqüência com a qual as cores eram indicadas como sendo a de maior preferência, gerando uma escala ordinal de apontamentos. Com este tipo de resultado obtido ficou impossibilitada a obtenção da quantificação da preferência que poderia ser obtida pela utilização das escalas de razão. 


\section{A PREFERÊNCIA PELA PRÁTICA DE ATIVIDADES FÍSICAS E ESPORTIVAS}

Atualmente, muitas pessoas procuram a prática de determinados exercícios físicos buscando a melhora considerável na qualidade do funcionamento corporal. A atividade física regular ajuda a manter um peso corporal desejável; fortalece músculos e ossos; melhora o funcionamento de órgãos, extremamente vulneráveis, como o coração e os pulmões; melhora o equilíbrio da pressão arterial e principalmente previne o aparecimento de possíveis enfermidades. Além desses fatores físicos, deve-se considerar os fatores de ordem psicosociais, como a integração na sociedade, o convívio harmonioso com o grupo, a melhora da auto-estima, o equilíbrio emocional e ainda participar de os chamados "modismos culturais do culto ao corpo” (PAPALIA; OLDS, 2000).

No Brasil, bem como em outros países industrializados, o ponto inicial de interesse pela prática de atividades físicas, exercícios regulares e práticas desportivas são moldados ainda na infância. Porém, com a diminuição de áreas seguras e apropriadas para estas práticas, é que cada vez mais crianças vêm brincando menos ou sendo encaminhadas para centros especializados neste trabalho (TUBINO, 1988; MEDINA, 1987; SILVA, 1995).

Neste sentido, tratando do ponto de vista do desenvolvimento motor, do ser humano, vários pesquisadores como Gallahue e Ozmun (2001), Ekcert (1993) e Bee (1997), colocam que o processo é conseguido mediante alterações no comportamento motor, ao longo das primeiras fases da infância, conseguida quase que na maioria das vezes sob a supervisão e acompanhamento de um profissional ou professor formado em Educação Física. Crianças, em idade pré-escolar e de primeiro grau, estão inicialmente envolvidas em aprender a se

movimentar de forma eficaz. É possível notar diferenças de desenvolvimento nos comportamentos motores, causados por fatores biológicos e ambientais, por meio da 
observação de mudanças no processo (forma do movimento) e no produto (desempenho do movimento). Portanto, a melhor maneira de observar o processo de desenvolvimento motor é por intermédio do desenvolvimento progressivo das habilidades motoras.

As habilidades motoras fundamentais representam a época de descoberta do desempenho de uma variedade de movimentos locomotores, de estabilidade e de manipulação, primeiramente isolados, depois em combinação, um com o outro. Crianças que estão desenvolvendo padrões fundamentais de movimento estão aprendendo a responder com adaptabilidade e versatilidade a uma variedade de estímulos. Estão ganhando maior controle no desempenho de movimentos discretos, seriados e contínuos, evidentes na crescente fluidez e controle dos movimentos (SCHIMIDT; WRISBERG, 2001).

Padrões fundamentais de movimentos são padrões básicos observáveis do comportamento. Atividades locomotoras, tais como correr e saltar, atividades de manipulação tais como arremessar e receber e atividades de estabilidade tais como, caminhar em uma trave de equilíbrio e equilibrar-se em uma perna só, são exemplos de habilidades fundamentais de movimento que devem ser desenvolvidas durante a primeira fase da infância da criança. Uma concepção errada sobre o conceito de desenvolvimento de habilidades de movimentos fundamentais é a noção de que estas habilidades são determinadas pela maturação e, são muito pouco influenciadas por fatores ambientais.

Alguns especialistas em desenvolvimento da criança têm documentado repetidamente sobre o desdobramento natural do movimento da criança ou habilidade para jogar, e sobre a idéia de que apenas com o passar dos anos irá desenvolver tais habilidades. A maturação realmente tem um papel no desenvolvimento de habilidades fundamentais do movimento, mas não é o único fator influenciador. Os fatores de oportunidade, motivação e instrução conferem um papel importante sobre o grau desenvolvido pelas habilidades fundamentais do movimento. 
A fase de desenvolvimento motor, relacionada ao esporte é um processo sequencial da fase fundamental do movimento. Durante esta fase, o movimento, ao invés de estar diretamente relacionado com aprender a se mover por se mover, agora se torna instrumento que pode ser aplicado a uma variedade de jogos competitivos e esportes cooperativos, danças e atividades recreacionais. Esse é um período em que habilidades locomotoras, manipulativas e de estabilidade são progressivamente refinadas, combinadas e elaboradas em uma ordem tal que possam ser utilizadas em uma crescente demanda de atividades. Os movimentos fundamentais de saltitar em uma perna e saltar, por exemplo, são agora usados para pular corda, desempenhar uma dança folclórica ou mesmo um salto triplo na pista de atletismo.

O aparecimento e a extensão do desenvolvimento de habilidades relacionadas ao desporto depende de uma variedade de fatores cognitivos, afetivos e psicomotores. Tempo de reação e velocidade de movimento, coordenação, constituição corporal, altura e peso, costumes, pressão de companheiros e constituição emocional são alguns dos fatores.

Gallahue e Ozmun (2001), destacam três estágios desta fase relacionados ao esporte: a) Estágio Geral ou de Transição, o estágio geral é uma época excitante para os pais e professores, bem como para a criança. Durante este estágio, as crianças são ativamente envolvidas em descobrir e combinar numerosos padrões de movimento e habilidades, e são freqüentemente acrescidas pelas suas habilidades que estão rapidamente se expandindo. O objetivo do pai e do professor durante este estágio deveria ser de ajudar a criança a desenvolver e expandir suas habilidades em uma grande variedade de atividades relacionadas ao esporte. Deve-se tomar cuidado evitando situações tais que a criança se especialize ou restrinja seu envolvimento na atividade. Um foco reduzido nas habilidades durante este estágio é capaz de produzir efeitos indesejáveis, nos últimos dois estágios da fase relacionada 
ao esporte. Na verdade, Schmidt e Wrisberg (2001) propõem que "uma variedade de experiência de movimento produz uma crescente capacidade de movimento”.

b) Estágio do Movimento de Habilidades Específicas, a partir de 11 a 13 anos (por volta da $6^{\mathrm{a}}$ a $8^{\mathrm{a}}$ série escolar) mudanças interessantes acontecem no desenvolvimento de habilidades do indivíduo. Uma outra criança, com características similares, que não gosta de esforços de equipe pode escolher especializar-se em melhorar suas habilidades em uma variedade de atividades de atletismo. Em outras palavras, o indivíduo começa a tomar decisões conscientes baseadas em uma variedade de gostos e desgostos, forças e fraquezas, oportunidades e restrições, para estreitar sua base de atividades específicas. Uma crescente ênfase deveria ser agora colocada na forma das habilidades na sua previsão de desempenho. Esta é a época para habilidades mais complexas serem refinadas e usadas no desempenho de atividades avançadas de preparação e na escolha do esporte a ser praticado.

c) Estágio do Movimento de Habilidades Especializadas, carateriza-se pelo estágio especializado da fase de desenvolvimento motor relacionada ao esporte que começa em torno do décimo quarto ano de vida e continua durante a fase adulta. O estágio especializado representa o ponto mais alto do processo de desenvolvimento e é caracterizado pelo desejo do indivíduo em participar de um número limitado de atividades de movimento, durante um período de anos. Os interesses, habilidades e escolhas feitas durante os estágios prévios são carregados para este estágio e refinados a fundo. Fatores como viabilidade de tempo e dinheiro, equipamento e facilidade para participação afetam este estágio. O nível de participação vai depender dos talentos do indivíduo, oportunidades, condições físicas e motivação. O desempenho da pessoa pode variar do nível profissional ao olímpico, interuniversitário e intercolegial, até a participação em esportes organizados ou não, competitivos, cooperativos e recreacionais. 
Em essência, o estágio especializado representa a culminância de todos os estágios e fases precedentes. Todavia, isto deveria ser visto como uma continuação de um processo para toda a vida. Um dos primeiros objetivos da educação é desenvolver indivíduos a um ponto tal que eles se tornem felizes, saudáveis e sejam membros que contribuam para a sociedade.

Atualmente, as questões relacionadas ao desenvolvimento motor como sendo um meio desencadeador da escolha e da consciência da importância da prática de atividades físicas e esportivas regulares vêm sendo amplamente discutidas nos cursos de formação de graduação, de futuros professores de Educação Física.

Por outro lado, a sociedade de uma maneira geral, parece posicionar-se de modo diferenciado destas pessoas que estudam e que se mantêm em contato permanente com as noticias relacionadas a este mundo esportivo e ativo corporalmente, uma vez que a busca pela estética perfeita e por benefícios imediatos cria uma procura desenfreada e descontrala pela prática de atividades físicas e esportivas, sem levar em conta, toda uma formação desenvolvimental dos movimentos já descrita.

Isto nos leva a pensar que a sociedade pode ter uma percepção subjetiva diferente, daquela vivenciada pelos futuros professores de Educação Física, constatando-se, portanto, uma forma perigosa de ambigüidade. A ambigüidade deve-se ao fato de que estes mesmos profissionais estão sendo formados com o intuito de fornecer a esta sociedade as melhores formas e sugestões críticas a respeito da percepção dessas atividades físicas e das atividades esportivas. Se não houver um ajustamento entre as informações captadas e percebidas durante a formação na graduação desses profissionais com os anseios esperados pela sociedade, este profissional pode ter seu campo de atuação reduzido e deste modo, não corresponder de forma condizente ao momento atual de expectativa por parte das pessoas que 
compõem a sociedade, podendo, ainda, causar prejuízos emocionais, sociais e físicos aos clientes que usufruem de seus serviços.

Deste modo, é interessante ressaltar que a preferência pela prática de atividades físicas e esportivas não é algo determinista ou fácil de se prever ou de ser moldado no ser humano ao longo de seu desenvolvimento, apesar de termos consciência de que muito pode ser feito neste sentido pelo trabalho do profissional ou professor de Educação Física. O papel da educação consciente da importância da prática regular de atividades físicas, o respeito aos elementos e as fases da vida formadoras dos comportamentos motor e ainda os fatores sociais, psicológicos e individuais compõem este processo complexo. A escolha da atividade física ainda passa por outros diversos fatores, que muitas vezes, são determinados quer pela personalidade quer pela influência que o meio cultural, no qual a pessoa está inserida, exerce sobre ela. Fatores como: demanda fisiológica (TURIBIO, 1997; FOX; MATHEWS, 1983), facilidade para coordenar os movimentos (SCHIMIDT; WRISBERG, 2001), disponibilidade de tempo e condições monetárias (POWERS; HOWLEY, 2000), os quais são exigidos para o acesso e principalmente pelo prazer que os exercícios proporcionam, faz com que a sua escolha recaia neste ou naquele ou ainda naqueles exercícios físicos, para praticá-los em seus momentos livres ou, até mesmo, como "meio de vida” (GALLAHUE; OZMUN, 2001; WEINBERG; GOULD, 2001).

O fator social e cultural constitui-se, também, outro determinante na escolha de práticas de atividades físicas, porém muito mais na escolha de práticas esportivas (SOARES et eli, 1992; VIANA, 1994). O esporte como prática social que institucionaliza temas lúdicos da cultura corporal, se projeta numa dimensão complexa de fenômeno que envolve códigos, sentidos e significados da sociedade que o cria e o pratica; deste modo, os esportes podem ser classificados visando um melhor detalhamento de estudo. Segundo Kroger e Roth (2002), que classificam diferentes esportes como coletivos e individuais, estas classificações facilitam o 
detalhamento da modalidade a ser estudada, bem como, formalizam uma linguagem unificada e padronizada da profissão (profissionais da Educação Física) no entendimento do movimento humano organizado. Os esportes individuais são aqueles nos quais o indivíduo executa a habilidade motora e cognitiva exigida de modo individual, e que pode ter como padrão de mensuração de performance competitiva de rendimento. Exemplos de esportes individuais, que serão utilizados no presente estudo: judô, ciclismo, corrida, natação (estilos livre, costas, e peito), arremesso de dardos (na parede) e tênis (modalidade de jogo simples). Já os esportes coletivos são aqueles que necessitam de dois ou mais participantes (grupos de participantes) na execução de habilidades cognitivas e motoras que visam o mesmo objetivo de performance e rendimento. Os esportes coletivos, que serão utilizados no presente estudo são: basquetebol, voleibol, handebol e futebol. As modalidades conhecidas apenas como atividades físicas, podem depender da participação apenas individual como coletiva, diferenciando na ausência do caráter competitivo de rendimento almejado nos esportes são exemplos de atividades físicas que serão utilizadas no presente estudo: bicicleta ergométrica, remo estacionário (aparelho utilizado em aulas de musculação), hidroginástica, dança (Valsa), caminhada, pular corda e tocar um instrumento.

Algumas atividades físicas e esportivas têm sua própria identidade, relacionadas ao movimento empregado, e isto pode ser um fator limitador ou facilitador na escolha de sua prática e por conseqüência aumentar ou diminuir o teor de preferência dos praticantes. Um bom exemplo disso é o dos diferentes estilos de natação. Netto (1995) e Massaud e Correa (2001) apontam que o nado estilo livre é o mais eficiente com relação à velocidade e ao menor gasto energético em comparação aos nados de peito, costas e borboleta. Para estes autores, estes outros nados apresentam movimentos que fogem dos padrões naturais do nadar reflexo que aparece nos primeiros meses de vida do ser humano. Acrescentam ainda que, o nado estilo peito, apesar de não imprimir uma velocidade considerável (comparado ao estilo 
livre), apresenta uma adaptação mais rápida para nadadores iniciantes do que o nado de costas e borboleta, em função da forma pela qual se faz a respiração durante o nado. No nado estilo costas por exemplo, ocorre o desconforto, para atletas iniciantes pela quantidade de água que pode penetrar pelo nariz causando leve asfixia.

Segundo Lovisolo (1997) quando os brasileiros afirmam que gostam de samba, carnaval e futebol estão construindo a identidade nacional. Esses símbolos de suas identidades se vinculam profundamento no piso emocional que as sustena. O gosto tem a ver com a interioridade, com a sensibilidade e os sentimentos. Desenvolver o próprio gosto pela prática de atividades físicas e esportivas é visto como caminho de autoconstrução, de autonomia e de liberdade, de formação do eu. Entretanto, desde que refletimos sobre o gosto, constatamos seu paradoxo: sendo o gosto profundamente individual, ao mesmo tempo o gosto é amplamente compartilhado, como indicam os êxitos no número e na preferência de práticas tidas como culturais, no caso do Brasil, o futebol, voleibol, o judô (esportes com notada ênfase cultural no nosso país). Ocorre deste modo que o gosto ou a preferência, não tem apenas a função de construção da identidade pessoal, mas também constroem-se as identidades coletivas.

Por mais coletivo e individual que possam ser nossas preferências pelas práticas de atividades físicas e esportivas, historicamente coloca-se, a todo o momento, em discussão a preferência e o gosto como formas distintas por parte de homens e mulheres, gerando ainda influências culturais e históricas interessantes, que de algum modo compõem o universo das escolhas das práticas de atividades físicas e esportivas (TUBINO, 1988).

Para melhor compreender este processo de diferenciação da preferência e gostos por parte de homens e mulheres, torna-se necessária a conceituação com relação à categoria “gênero”. Segundo Scott (1995), o gênero é um elemento constitutivo de relações sociais baseadas nas diferenças percebidas entre os sexos e o gênero, e é uma forma primária de dar significado às relações de poder. Deste modo, ser do gênero feminino ou masculino leva a 
perceber o mundo de forma diferente, a estar no mundo de modos diferentes e, em tudo isso há diferenças quanto à distribuição do poder, o que vai significar que o gênero está implicado na concepção e na construção do poder.

A história da Educação Física mostra que sempre houve uma discriminação, mantendo papéis distintos e determinados, caracterizando os comportamentos tipicamente masculinos e femininos, a serviço de uma ideologia sexista. Para melhor exemplificar, na época da República quando a Educação Física foi introduzida na escola, a idéia de estender atividade prática, também para o sexo feminino, foi veementemente rechaçada pela opinião pública, inclusive por alguns pais que chegaram a proibir a prática de atividades físicas por suas filhas, mesmo com risco de vê-las perder o ano escolar (ROMERO, 1994).

Romero (1994) acrescenta que, durante o Estado Novo a Educação Física serviu de instrumento ideológico à ditadura instalada, o governo militar investiu nessa disciplina em função das diretrizes pautadas no nacionalismo, na integração (entre os Estados) e na segurança nacional. Este quadro acabou colaborando para que a participação feminina ficasse restrita à comemorações e desfiles cívicos, já que no campo esportivo, a maior concentração centrava-se no sexo masculino. Este tratamento diferenciado, acabou resultando em um desempenho motor igualmente diferenciado. Complementando, Romero (1994) argumenta que em uma observação da prática dos professores e profissionais de Educação Física, constata-se, muitas vezes, a insistência de discriminação entre os sexos para as atividades físicas. Isto leva a uma compreensão do porquê da falta de habilidades motoras que envolvem os grandes grupos musculares evidenciados pelo grupo feminino. Meninas que ao quinto ano da escolarização, quando normalmente são trabalhadas por professores da área, apresentam um estágio de habilidades motoras significativamente inferior aos dos meninos.

Altmann (1998) questiona sobre a exclusão nos esportes, e aponta características muito interessantes que revelam não ser o gênero o principal motivo de exclusão nas aulas de 
Educação Física, nos esportes e, por conseqüência, a preferência pela prática de atividades físicas e esportivas. Em seu estudo, a autora observou que apesar dos meninos em média participarem dos jogos mais do que as meninas, tanto quantitativa como qualitativamente, podia-se notar meninas que tinham um nível de participação próximo ao dos meninos e viceversa. A autora sustenta que, mais do que uma exclusão de gênero, ou ao menos além dela, existe uma exclusão por habilidade.

Um dos fatores apontados por Altmann (1998) que leva a esta exclusão por habilidade, é o caráter competitivo presente na prática esportiva. Este caráter competitivo acaba por promover uma “seleção natural”, na qual apenas os mais aptos são aceitos. Deste modo, acoplado à habilidade têm-se a idade, a força e o gênero agindo como critérios determinantes desta "seleção natural”.

Portanto, o que podemos constatar é que por força do processo de transmissão cultural reforçam-se os preconceitos, colaborando para que as meninas não tenham as mesmas experiências dos meninos, criando-se então uma cadeia de situações que leva à exclusão e à falta de motivação por parte das mesmas quanto à prática de atividades físicas e esportivas.

No estudo de Souza Junior e Darido (2002), sobre a prática do futebol feminino no ensino fundamental, fica claro que um dos principais empecilhos para a expansão desta prática no Brasil refere-se ao discurso preconceituoso e estereotipado que predominou durante o último século. Segundo estes autores, para manter as mulheres afastadas da prática do futebol e de outros esportes (que envolviam um grande número de grupos musculares) foram utilizados argumentos de caráter biológico, cultural e psicológico. Complementam ainda que na Educação Física Escolar, momento fundamental para escolhas de preferência pela prática de atividades físicas e esportivas, enquanto que o futebol, por exemplo, constitui-se no principal, quando não o único, conteúdo das aulas dos meninos, em contra partida às meninas são oferecidos jogos e brincadeiras infantis e entre as modalidades esportivas podia-se 
encontrar o voleibol, o basquetebol e o handebol. Os dados deste estudo foram coletados mediante a aplicação de um questionário a 70 alunas de sétima série do Ensino Fundamental, sendo cinco de cada uma das 14 escolas da rede estadual do município de Rio Claro/SP. Os resultados deste estudo indicaram que o futebol tem sido praticado pelas meninas na escola, sendo que $87,14 \%$ das alunas participantes deste estudo afirmaram já ter experienciado o futebol nas aulas de Educação Física. Porém, os meninos ainda dominam amplamente os espaços destinados à prática esportiva, especificamente o futebol na escola, de acordo com 88,57\% das alunas. Quanto à preferência esportiva das meninas participantes do estudo, observa-se que o voleibol (53,52\%) aparece como o esporte predileto, seguido pelo futebol $(39,43)$, havendo uma grande diferença entre estes dois e o handebol $(4,22 \%)$ e o basquetebol (2,81\%). Os autores ainda concluíram que o futebol feminino passou a fazer parte do contexto escolar, embora a ocupação dos espaços destinados à prática esportiva ainda seja predominantemente masculina.

Com base nestas informações se torna cada vez mais interessante investigar a preferência, em dados quantitativos, pela prática de atividades físicas e esportivas entre homens e mulheres no sentido de fornecer maiores informações aos profissionais que trabalham na construção de um melhor desenvolvimento motor tanto para homens como para mulheres. 


\section{OBJETIVOS}

O presente estudo tem como objetivo geral e principal promover o escalonamento da preferência pela prática de atividades físicas e esportivas e ainda, demonstrar como é feito o escalonamento dessa preferência, analisando, em separado, o julgamento de homens e mulheres. Deste modo, a preferência pela prática de atividades físicas e esportivas foi investigada pelos métodos psicofísicos escalares diretos e indiretos e, conseqüentemente, escalas de razão, escalas intervalares e escalas ordinais foram comparadas. Os objetivos específicos foram verificar se o contínuo social de preferência pela prática de atividades físicas e esportivas possui características protéticas ou metatéticas e se houve indícios da ocorrência dos princípios da Lei de Ekman para este contínuo. Os detalhes de cada objetivo estão descritos em cada um dos experimentos apresentados a seguir. 


\section{EXPERIMENTO 1}

\subsection{Comparação entre os métodos psicofísicos escalares de estimação de magnitudes e estimação em categorias}

As considerações a seguir baseiam-se na metodologia desenvolvida no domínio da psicofísica sensorial. Os objetivos deste experimento foram os seguintes: a) escalonar a preferência pela prática de 20 atividades físicas e esportivas, apontadas por Powers e Honley (2000) como uma grande variedade de atividades físicas que são praticadas pelos seres humanos, independente de sua nacionalidade; b) comparar as escalas derivadas de julgamentos intervalares (estimativas em categorias) com as escalas derivadas de julgamentos de razão (estimativas de magnitudes); c) verificar se o contínuo de preferência pela prática de atividades físicas e esportivas possui características protéticas ou metatéticas; d) verificar se as ordenações dos graus de preferência pela prática de atividades físicas e esportivas derivadas dos dois métodos psicofísicos são similares entre si; e e) verificar se a variabilidade das estimativas de magnitudes e em categorias é uma função linear das médias geométricas dessas estimativas, ou seja, se seguem alguns princípios da Lei de Ekman tal como verificada para contínuos sensoriais. Todos esses objetivos também foram almejados comparando-se, em separado, os resultados obtidos dos julgamentos dos homens e das mulheres que participaram deste estudo. 


\subsubsection{Método}

\subsubsection{Participantes}

Participaram 20 sujeitos, 10 homens (média de idade 22 anos e 9 meses) e 10 mulheres (média de idade: 22 anos e 1 mês), entre 20 e 25 anos, alunos universitários, graduandos do Instituto Educacional de Assis - IEDA e das Faculdades Integradas de Bauru FIB, que não estavam matriculados em curso superior de formação em Educação Física. Todos desconheciam os propósitos do experimento a priori, bem como assinaram um termo de consentimento, aprovado pelo Comitê de Ética em Pesquisa da FFCLRP-USP, de acordo com Processo CEP-FFCLRP número 123/2003 - 2003.1.1848.59.8 (ver Anexo A, p. 176).

\subsubsection{Material}

Foram elaborados dois blocos de papel contendo, na primeira página, instruções específicas para cada tipo de método psicofísico e, na página seguinte, uma lista com 20 atividades físicas e esportivas relacionadas a partir da verificação bibliográfica da incidência da prática (ver Quadro 1). 
Quadro 1 -Atividades físicas e esportivas que foram apresentadas aos participantes, em ordem aleatória, para julgamentos nos métodos de estimação de magnitudes e estimação em categorias

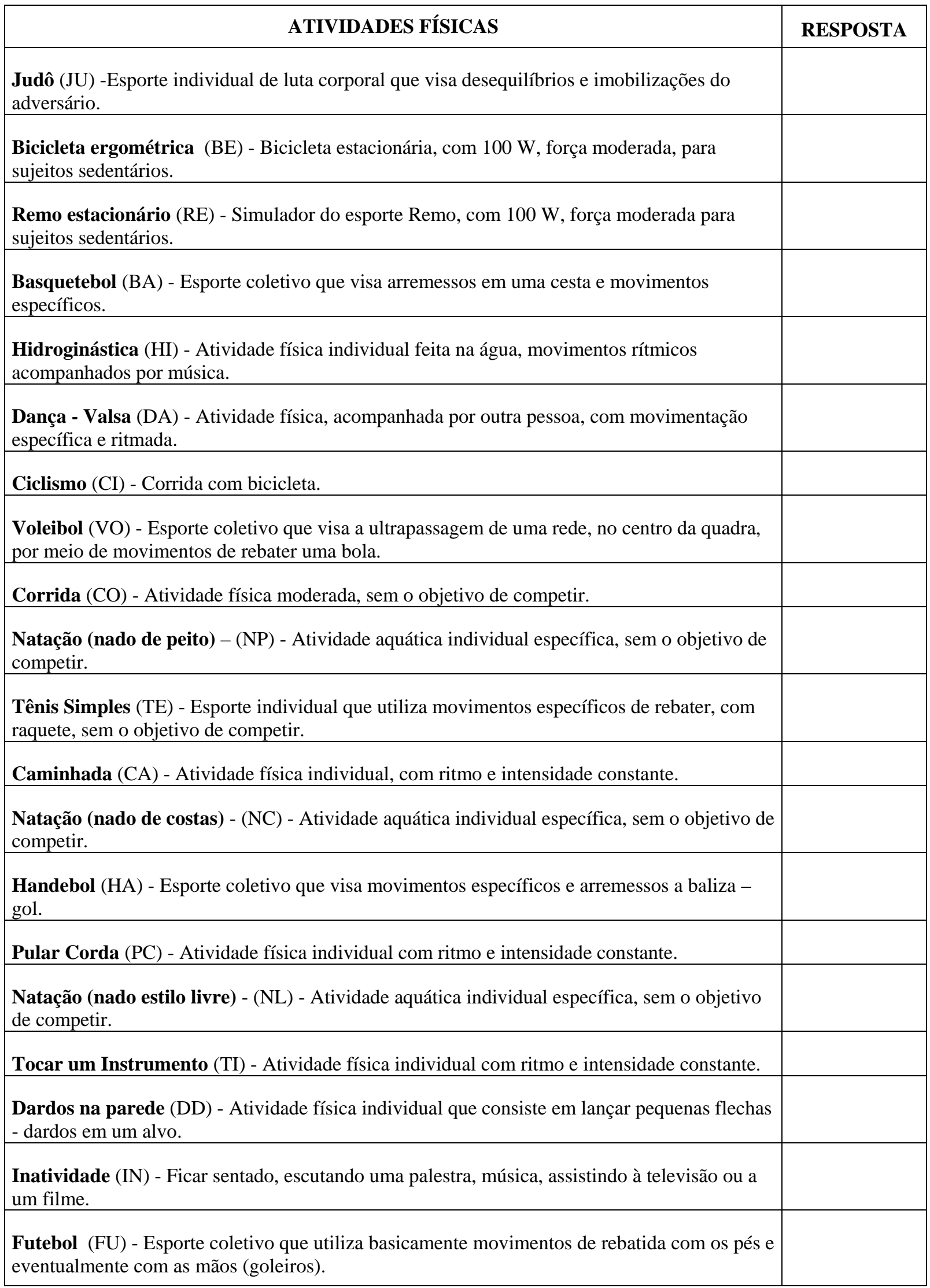




\subsubsection{Procedimentos}

Os métodos psicofísicos utilizados foram a estimação de magnitudes com módulo e a estimação em categorias contendo escalações de 1 a 7. No método escalar de estimação de magnitudes, a tarefa dos participantes foi assinalar um número para cada atividade física e esportiva que fosse proporcional à quantidade de preferência (afeição) pela sua prática. Dessa forma, se o participante julgasse que uma dada atividade física ou esportiva possuísse duas vezes mais a sua preferência, em relação a uma outra atividade física ou esportiva, ele assinalaria um número duas vezes maior. Se ele julgasse que uma dada atividade física ou esportiva possuísse a metade da sua preferência em relação a outra, ele assinalaria um número que representasse a metade do atributo da atividade dada. A ordem da apresentação dos estímulos, para os participantes, foi aleatória, e para facilitar a comparação entre as atividades físicas e esportivas quanto à estimação de magnitudes, estabeleceu-se um módulo padrão. Este módulo foi à atividade física CORRIDA, à qual foi assinalada, previamente, a indicação com o número 100. Tal escolha se deveu ao fato de que a corrida é uma atividade que todas as pessoas costumeiramente executam um movimento natural (POWERS; HONLEY, 2000; GUEDES; GUEDES, 1997) que não é encarado como uma atividade intensa e nem leve, ou seja, é moderada quanto à sua intensidade. Então, a cada julgamento assinalado pelo participante, ele deveria comparar com o módulo padrão $(100=$ corrida $)$, para produzir o julgamento de cada atributo, que lhe era apresentando, em ordem aleatória.

Para o método de estimação em categorias, a tarefa dos participantes foi assinalar um escore, que variou de 1 a 7, à cada atividade física e esportiva em função da sua preferência (gosto pela prática). Então, o participante foi instruído a assinalar, para a preferência que foi considerada a maior, o escore máximo de 7, e ao de menor preferência, o escore 1 . Os outros escores intermediários, de 2 a 6, deveriam ser utilizados para indicar graus 
médios de preferência pelas atividades físicas e esportivas. Os sujeitos foram lembrados de não utilizarem números decimais e sim assinalarem, apenas utilizando os números inteiros do contínuo de 1 a 7, por se tratar de julgamentos intervalares. As atividades físicas e esportivas foram apresentadas tal como no método de estimação de magnitudes, ou seja, de modo aleatório.

As instruções dadas aos participantes, independentemente do método psicofísico utilizado, foram requeridas para que os julgamentos fossem realizados em função do grau de preferência (afeição) pela prática de atividade física e esportiva, independentemente, do fato de ter vivenciado ou não a atividade ou a modalidade esportiva. Os mesmos 20 participantes, foram submetidos aos dois métodos (estimação de magnitudes e estimação em categorias), de maneira que a metade do número total de participantes, julgou primeiro pelo método de estimação de magnitudes e após uma semana julgou pelo método de estimação em categorias, e a outra metade avaliou na ordem inversa. Realizou-se a coleta dos dados em instituições de Ensino Superior, em uma sala, na qual permaneceram, durante toda a aplicação do experimento, apenas o experimentador e o participante.

\subsubsection{Análise dos dados}

Para analisar os dados deste experimento, primeiramente, foram calculadas as médias geométricas (MG) e as médias aritméticas (MA) dos julgamentos de todos os sujeitos, para cada uma das atividades físicas e esportivas apresentadas. Também, foram obtidas as ordenações das posições julgadas, tanto para o método de estimação de magnitudes (EM), como para o método de estimação em categorias (EC). Em seguida, obteve-se o coeficiente de correlação de ordem de Spearman (rho) resultante das ordenações tanto do método de 
estimação em categorias como do método de estimação de magnitudes. Esses valores indicaram o grau de concordância dos julgamentos utilizando dois métodos psicofísicos diferentes (EM e EC).

Com o objetivo de saber se o contínuo de preferência pela prática de atividade física e esportiva possuía características protéticas ou metatéticas foi obtido o coeficiente de determinação $\left(r^{2}\right)$, bem como foram confeccionados gráficos que demonstraram tal relação. Para a construção dos gráficos foram colocadas no eixo $\mathrm{X}$, as médias geométricas das estimativas de magnitudes e no eixo $\mathrm{Y}$, as médias aritméticas das estimativas em categorias. A curva apresentou uma concavidade voltada para baixo, concluiu-se, portanto, que o contínuo tem características protéticas (quantitativo), pois esta curva permite verificar nas estimativas em categorias, que os participantes julgaram diferenças, enquanto que nas estimativas de magnitudes, julgaram razões. Caso a curva obtida fosse uma linha reta, então o contínuo possuiria características metatéticas (qualitativo). Reforçando o fato de que o contínuo possuía características protéticas, construiu-se o mesmo tipo de gráfico, porém substituindo as médias geométricas das estimativas de magnitudes (eixo X) pelos logaritmos dessas médias. A tendência esperada era a inversão da curva.

Outro objetivo almejado era visualizar a ocorrência dos princípios da Lei de Ekman. Para obter este resultado foram, primeiramente, calculadas as médias aritméticas (MA) e os respectivos desvios-padrão aritméticos (DPA), tanto do teste de estimação de magnitudes como do teste de estimação em categorias.

Em seguida, os dados foram organizados em gráficos e confeccionados da seguinte forma: foram colocadas as médias aritméticas das estimativas de magnitudes no eixo $\mathrm{X}$ e os respectivos desvios-padrão aritméticos no eixo Y. O padrão de resultados esperado para confirmar indícios da Lei de Ekman consiste em uma linha reta ascendente, indicando que quanto maior for a estimativa de magnitude tanto maior será o desvio padrão da média. 
Porém, a mesma relação não deverá ocorrer quando for efetuado o mesmo procedimento, utilizando-se o teste de estimação em categorias, ou seja, foram colocadas as estimativas em categorias no eixo $\mathrm{X}$ e os desvios-padrão das médias aritméticas, resultantes deste mesmo método. Deste modo, foi obtida a informação de que quanto maior a estimativa em categoria, menor o erro padrão da média aritmética.

Pretendia-se, ainda, conferir se havia diferença no julgamento da preferência pela prática de atividades físicas e esportivas de homens e mulheres. Para a obtenção das possíveis diferenças entre os gêneros, foram adotados os mesmos procedimentos para análise dos dados de todos os participantes, descritos acima.

\subsubsection{Resultados}

Os dados, apresentados na Tabela 2, mostram as atividades físicas e esportivas, com suas respectivas médias geométricas (MG) derivadas do método de estimação de magnitudes (EM) e as ordenações das posições (OP/EM), obtidas a partir das médias geométricas do método de estimação de magnitudes. Apresenta, também, as médias aritméticas (MA), obtidas a partir do método de estimação em categorias (EC); e as ordenações das posições (OP/EC), obtidas a partir dessas médias aritméticas, do método de estimação em categorias. No total, os 20 participantes fizeram 40 julgamentos, para cada um dos métodos (EC e EM).

Observa-se nitidamente nesta tabela que, independente do método escalar utilizado, a atividade física de REMO ESTACIONÁRIO foi julgada como a de menor preferência, enquanto que a CAMINHADA a de maior preferência. No entanto, existem algumas diferenças fundamentais nos escalonamentos obtidos. Segundo Stevens (1975), pelo 
método de estimação em categorias podemos obter tanto a ordenação quanto a diferença entre os graus de preferência, porém não podemos afirmar o quanto o grau de preferência pela prática de atividade física e esportiva é maior ou menor em comparação ao grau de uma outra. Entretanto, com o método de estimação de magnitudes, podemos obter a ordenação, a diferença, e também as razões, entre os graus de preferência das diferentes atividades físicas e esportivas. Dos dados mostrados na Tabela 2, podemos afirmar que o grau de preferência da atividade física CAMINHADA $(\mathrm{EM}=233,67)$ é aproximadamente uma vez e meia maior do que o grau de preferência da CORRIDA (EM = 100), ou aproximadamente, nove vezes maior do que a atividade de REMO ESTACIONÁRIO $(\mathrm{EM}=24,22)$.

Tabela 2 - Resultados dos métodos de estimação de magnitudes (EM) demonstração das médias geométricas (MG), ordenação de posições, de preferência, deste método (OP/EM). Método de estimação em categoria (EC), demonstração das respectivas médias aritméticas (MA), ordem de posições, de preferência, deste método $(\mathrm{OP} / \mathrm{EC})$

\begin{tabular}{lrccc}
\hline \multicolumn{1}{c}{ ATIVIDADES } & \multicolumn{1}{c}{ EM } & OP/EM & EC & OP/EC \\
\hline Corrida (CO) & 100,00 & 8 & 3,45 & 14 \\
Bicicleta Ergométrica (BE) & 95,75 & 9 & 3,85 & 9 \\
Remo (RE) & $\mathbf{2 4 , 2 2}$ & $\mathbf{2 0}$ & $\mathbf{1 , 9 5}$ & $\mathbf{2 0}$ \\
Hidroginástica (HI) & 114,16 & 7 & 4,50 & 3 \\
Dança (DA) & 49,87 & 16 & 3,50 & 13 \\
Ciclismo (CI) & 138,81 & 4 & 4,40 & 4 \\
Basquetebol (BA) & 66,92 & 14 & 3,85 & 7 \\
Handebol (HA) & 61,93 & 15 & 3,30 & 15 \\
Judô (JU) & 36,31 & 18 & 2,50 & 19 \\
Pular Corda (PC) & 70,07 & 13 & 3,80 & 10 \\
Voleibol (VO) & 184,11 & 2 & 5,20 & 2 \\
Tênis (TE) & 40,47 & 17 & 2,95 & 17 \\
Caminhada (CA) & $\mathbf{2 3 3 , 6 7}$ & $\mathbf{1}$ & $\mathbf{5 , 8 0}$ & $\mathbf{1}$ \\
Natação - costas (NC) & 79,82 & 11 & 3,10 & 16 \\
Natação - peito (NP) & 86,95 & 10 & 3,60 & 11 \\
Natação - livre (NL) & 123,52 & 6 & 4,50 & 3 \\
Tocar um Instrumento (TI) & 76,20 & 12 & 3,60 & 12 \\
Dardos (DD) & 27,78 & 19 & 2,90 & 18 \\
Futebol (FU) & 157,58 & 3 & 4,15 & 6 \\
Inatividade (IN) & 130,56 & 5 & 4,15 & 5 \\
\hline
\end{tabular}


O coeficiente de correlação de ordem de Spearman (rho) calculado entre as ordenações das estimativas resultantes dos métodos de estimação de magnitudes e de estimação em categorias foi igual a 0,88 ( $<<0,001$ ), portanto, esses valores demonstram que os dois métodos (estimativas de magnitudes e estimativas em categorias) produzem preferências altamente concordantes.

Para verificar se o contínuo de preferência pela prática de atividade física e esportiva apresenta características protéticas ou metatéticas, as médias aritméticas das estimativas em categorias, foram projetadas em função das médias geométricas e das estimativas de magnitudes das atividades. Em coordenadas lineares a relação entre estas duas estimativas indicou uma leve concavidade ascendente. Também, quando as médias aritméticas das estimativas de categorias foram projetadas em função dos logaritmos das médias geométricas das estimativas de magnitudes, a relação mostrou uma concavidade descendente. O coeficiente de determinação $\left(r^{2}\right)$ foi aproximadamente igual a $0,879(p<$ 0,001). Figuras 4 e 5 indicam estas relações em coordenadas lineares e mono-logarítmicas, respectivamente. Confrontadas, fica demonstrado que o contínuo de preferência de atividades físicas e esportivas é um contínuo protético aditivo. 


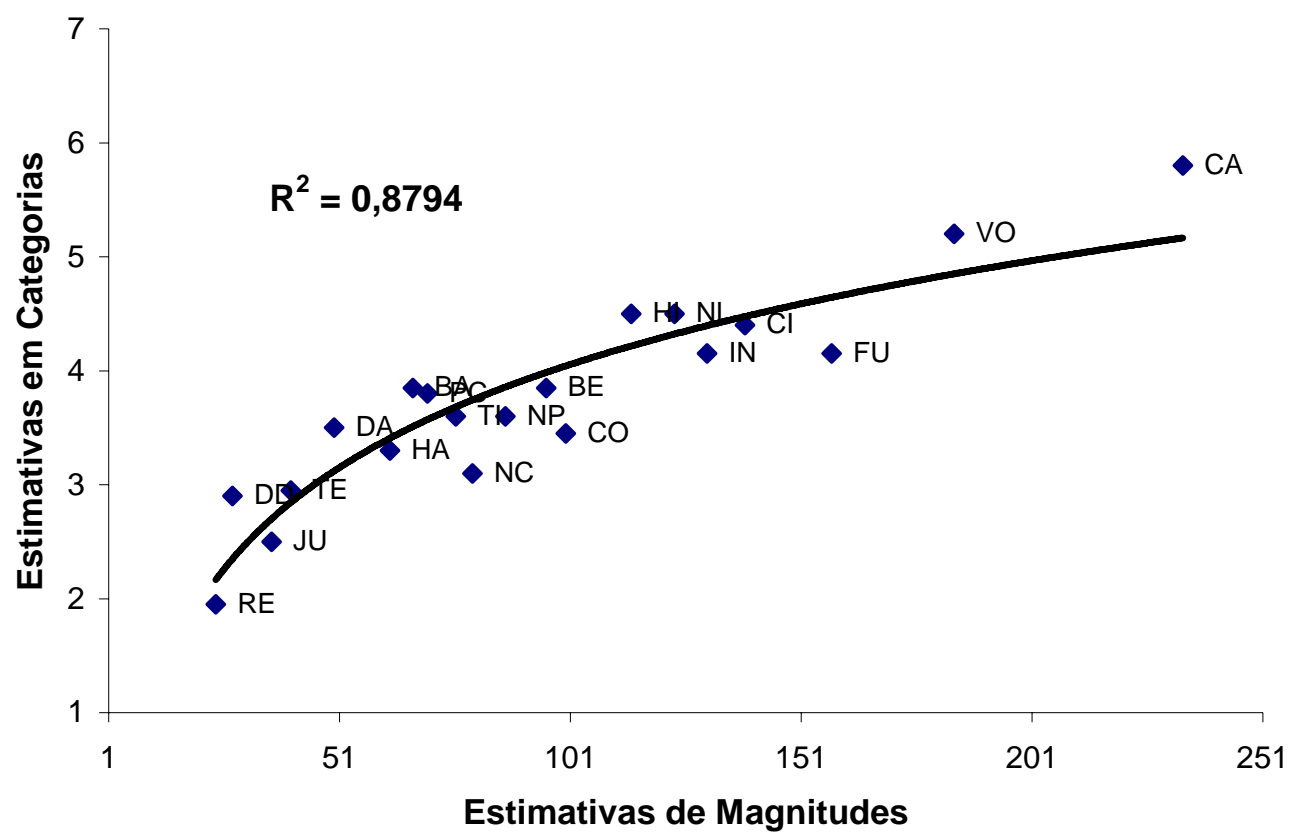

Figura 4 - Relação entre as médias aritméticas das estimativas em categorias e as médias geométricas das estimativas de magnitudes, da preferência pela prática de atividades físicas e esportivas em coordenadas lineares

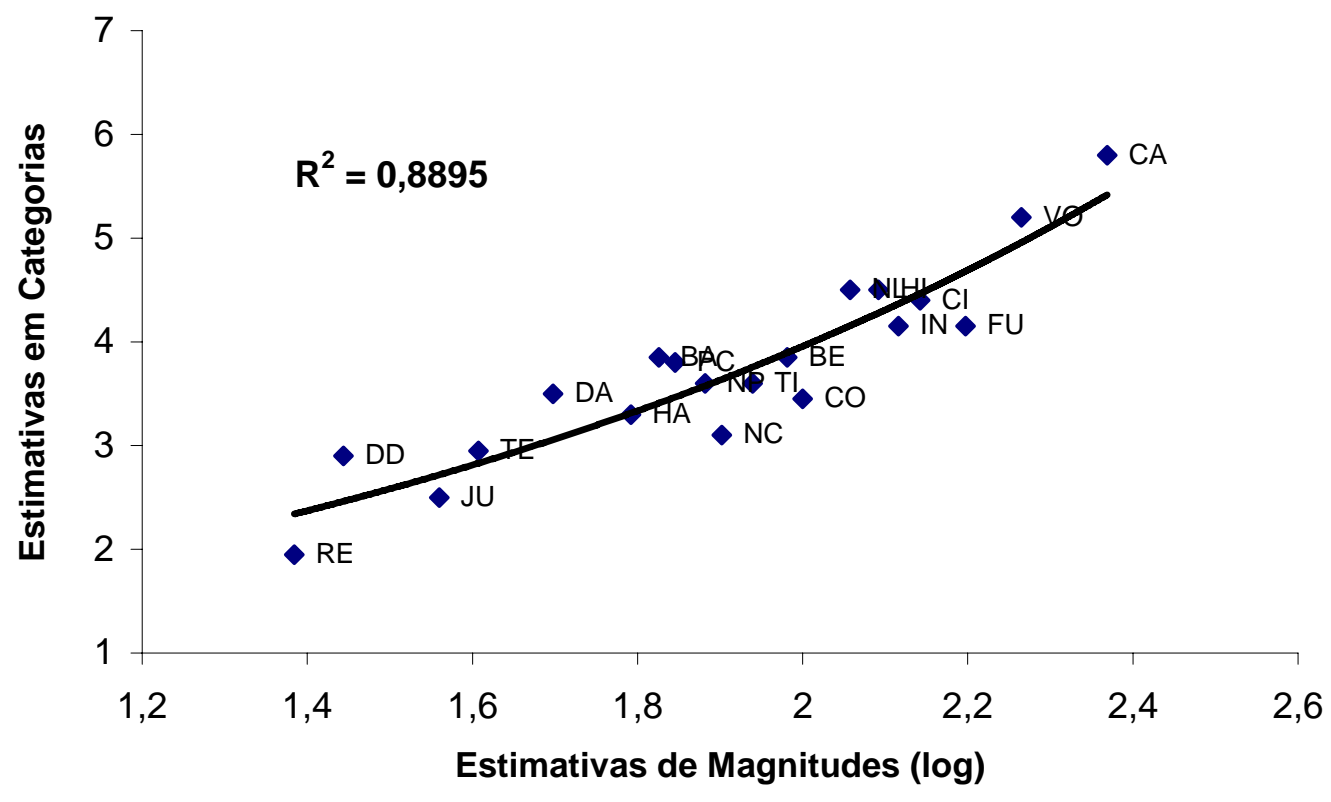

Figura 5 - Relação entre as médias aritméticas das estimativas em categorias e os logaritmos das médias geométricas, das estimativas de magnitudes, da preferência pela prática de atividades físicas e esportivas 
Observou-se, também, um resultado bastante interessante na relação entre os desvios-padrão da média aritmética e as médias aritméticas das estimativas de magnitudes (ver Figura 6). Evidentemente, nota-se uma relação linear, indicando que quanto maior a estimativa de magnitude maior será a variabilidade produzida. Em contrapartida, a mesma relação não ocorreu com as estimativas em categorias, revelando que quanto maior a estimativa em categoria menor o desvio padrão da média aritmética (ver Figura 7).

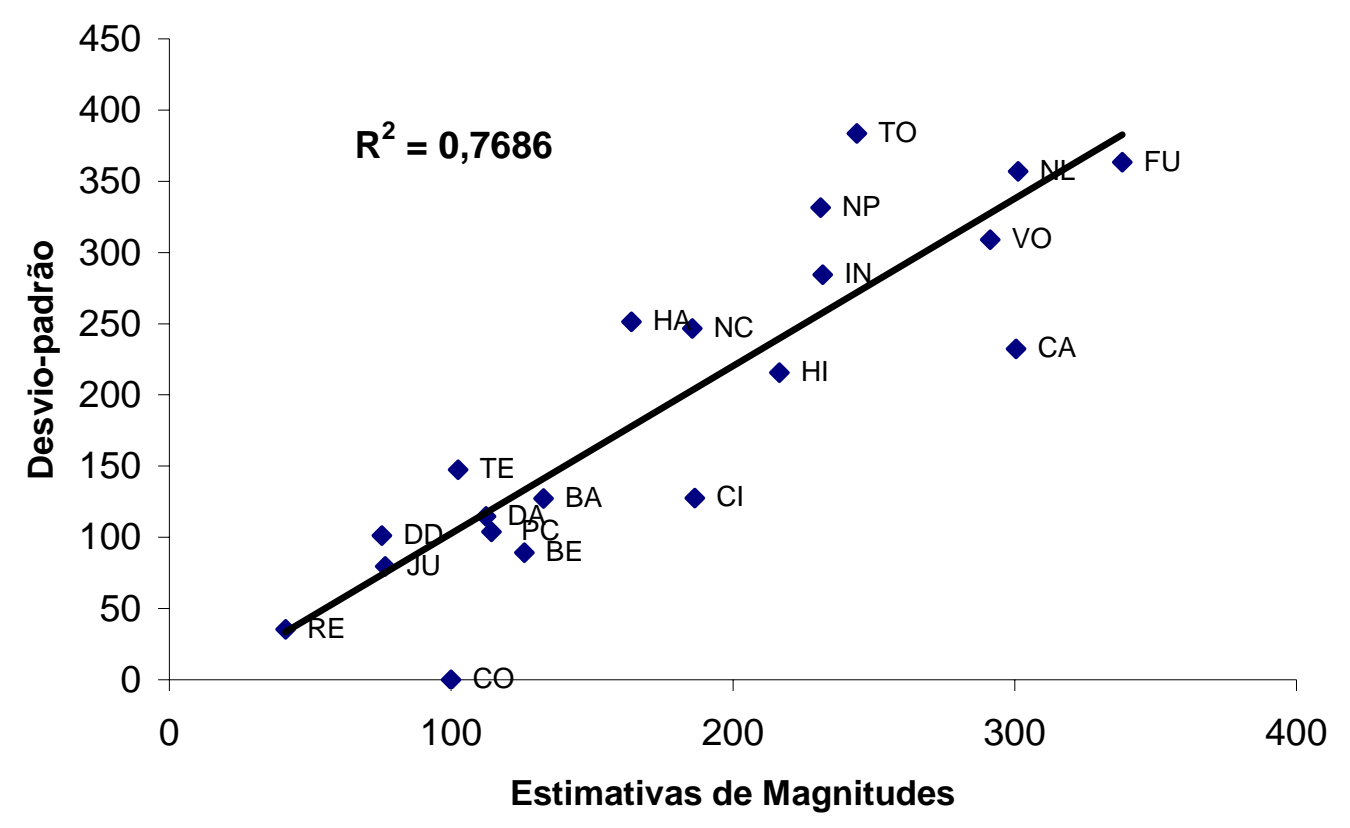

Figura 6 - Desvio-padrão aritmético, em função da média aritmética, das estimativas de magnitudes, da preferência pela prática de atividades físicas e esportivas 


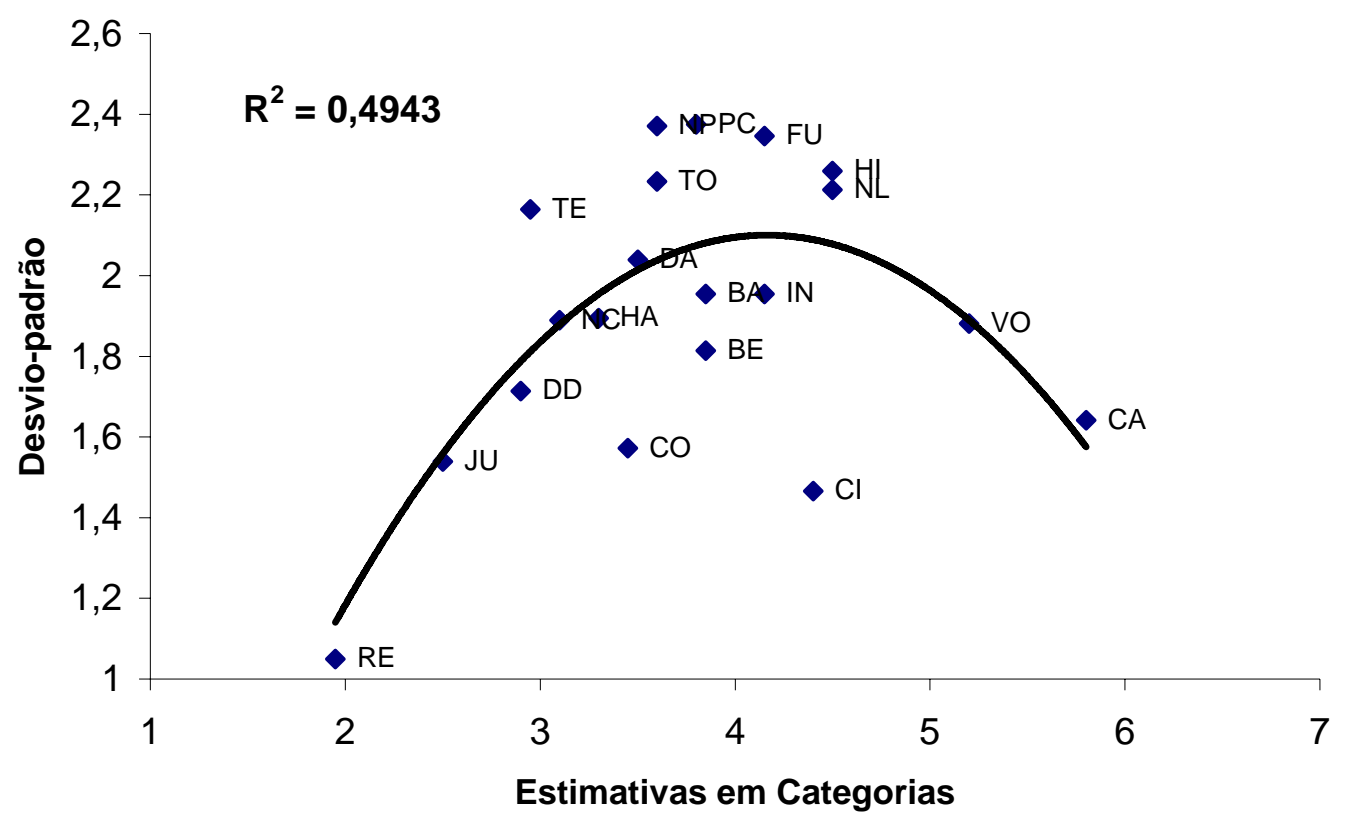

Figura 7 - Desvio-padrão aritmético, em função da média aritmética, das estimativas em categorias da preferência pela prática de atividades físicas e esportivas

\subsubsection{As diferenças entre Homens e Mulheres no julgamento da preferência pela prática de atividades físicas e esportivas (estimação em categorias versus estimação de magnitudes)}

Neste item serão demonstrados os resultados obtidos separadamente, a partir da comparação dos julgamentos tanto dos homens como das mulheres participantes deste experimento.

A Tabela 3, apresenta as médias geométricas das estimativas de magnitudes (EM), as respectivas ordenações de posições (OP/EM), as médias aritméticas das estimativas em categorias (EC) e as respectivas ordenações de posições (OP/EC) da preferência pela prática de atividades físicas e esportivas, julgadas pelos 10 participantes do sexo masculino, como também, pelas 10 participantes do sexo feminino. 
Tabela 3 - Resultados do método de estimação de magnitudes (EM), demonstração das médias geométricas (MG), ordenação de posições, de preferência, deste método (OP/EM). Método de estimação em categoria (EC), demonstração das respectivas médias aritméticas (MA), ordem de posições, de preferência, deste método (OP/EC), tanto dos participantes do sexo masculino como do sexo feminino

\begin{tabular}{lrrrrrrrr}
\hline & \multicolumn{3}{c}{ MASCULINO } & \multicolumn{3}{c}{ FEMININO } \\
ATIVIDADES & EM & OP/EM & EC & OP/EC & EM & OP/EM & EC & OP/EC \\
\hline Corrida (CO) & 100,00 & 7 & 4,0 & 7 & 100,00 & 7 & 2,9 & 17 \\
Bicicleta ergométrica (BE) & 65,89 & 12 & 3,1 & 14 & 139,15 & 4 & 4,6 & 5 \\
Remo (RE) & $\mathbf{2 2 , 6 2}$ & $\mathbf{2 0}$ & $\mathbf{2 , 0}$ & $\mathbf{2 0}$ & 25,94 & 19 & 1,9 & 19 \\
Hidroginástica (HI) & 90,03 & 8 & 4,1 & 6 & 144,75 & 3 & 4,9 & 4 \\
Dança (DA) & 37,11 & 17 & 2,5 & 17 & 67,02 & 15 & 4,5 & 6 \\
Ciclismo (CI) & 158,16 & 6 & 4,6 & 5 & 121,84 & 5 & 4,2 & 9 \\
Basquetebol (BA) & 69,68 & 11 & 3,6 & 10 & 64,27 & 16 & 4,1 & 10 \\
Handebol (HA) & 50,52 & 15 & 2,9 & 15 & 75,91 & 14 & 3,7 & 13 \\
Judô (JU) & 65,66 & 13 & 3,4 & 11 & $\mathbf{2 0 , 0 8}$ & $\mathbf{2 0}$ & $\mathbf{1 , 6}$ & $\mathbf{2 0}$ \\
Pular Corda (PC) & 44,44 & 16 & 2,5 & 18 & 110,47 & 6 & 5,1 & 3 \\
Voleibol (VO) & 160,01 & 5 & 4,7 & 3 & 211,83 & 2 & 5,7 & 2 \\
Tênis (TE) & 29,88 & 19 & 2,1 & 19 & 54,81 & 17 & 3,8 & 12 \\
Caminhada (CA) & 215,16 & 2 & 5,2 & 2 & $\mathbf{2 5 3 , 7 8}$ & $\mathbf{1}$ & $\mathbf{6 , 4}$ & $\mathbf{1}$ \\
Natação - costas (NC) & 82,03 & 10 & 2,7 & 16 & 77,68 & 13 & 3,5 & 14 \\
Natação - peito (NP) & 88,73 & 9 & 3,2 & 12 & 85,22 & 11 & 4,0 & 11 \\
Natação - livre (NL) & 162,96 & 4 & 4,6 & 4 & 93,63 & 9 & 4,4 & 7 \\
Tocar um Instrumento (TI) & 64,47 & 14 & 3,8 & 9 & 90,08 & 10 & 3,4 & 15 \\
Dardos (DD) & 30,52 & 18 & 3,2 & 13 & 25,29 & 18 & 2,6 & 18 \\
Futebol (FU) & $\mathbf{2 9 8 , 9 5}$ & $\mathbf{1}$ & $\mathbf{5 , 4}$ & $\mathbf{1}$ & 83,06 & 12 & 2,9 & 16 \\
Inatividade (IN) & 173,58 & 3 & 4,0 & 8 & 98,20 & 8 & 4,3 & 8 \\
\hline & & & & & & &
\end{tabular}

Conforme a Tabela 3, independentemente do método escalar empregado, as atividades de menor e maior preferência foram indicadas como sendo as mesmas. Porém, quando se observa o julgamento dos participantes do sexo masculino a atividade física de menor preferência foi apontada como sendo a de REMO ESTACIONÁRIO, TÊNIS e 
DARDOS, já para as participantes do sexo feminino a de JUDÔ foi a de menor preferência, seguida, por REMO ESTACIONÁRIO e DARDOS, indicando uma semelhança entre homens e mulheres. Para as atividades apontadas como as de maior preferência, tem-se para os participantes masculinos o FUTEBOL, a CAMINHADA e a INATIVIDADE e para as participantes femininas a CAMINHADA, o VOLEIBOL e a HIDROGINÁSTICA, revelando preferências distintas.

Os coeficientes de correlações de ordem de Spearman (rho) calculados entre as ordenações das estimativas resultantes dos métodos de estimação de magnitudes e de estimação em categorias encontram-se descritos, a seguir: os participantes do sexo masculino apresentaram uma correlação entre os dois métodos investigados de 0,90 ( $\mathrm{p}<0,001$ ); as participantes do sexo feminino indicaram uma correlação dos dois métodos de 0,77 (p < 0,001). Na comparação entre homens e mulheres, no método de EM, a correlação foi menor 0,64 ( $<$ 0,01), já no método de EC a correlação foi ainda menor 0,26 ( $<<0,05)$.

Estes resultados revelam que a utilização dos diferentes métodos (EM e EC) foi fidedigna tanto para participantes do sexo masculino como do sexo feminino, porém houve uma pequena diferença entre os julgamentos feitos entre homens e mulheres, indicando que a prática de atividades físicas e esportivas, por estas pessoas, é percebida, de modo diferente na escolha da preferência.

Outra variável a ser investigada é se o contínuo de preferência pela prática de atividades físicas e esportivas apresenta características protéticas ou metatéticas. Os mesmos demonstrativos dos gráficos serão exibidos a seguir, do mesmo modo que foi feito com todos os participantes, porém o que difere agora é a separação para melhor visualização dos gráficos produzidos pelos julgamentos tanto dos participantes do sexo masculino como do sexo feminino (veja Figuras 8, 9, 10 e 11). 


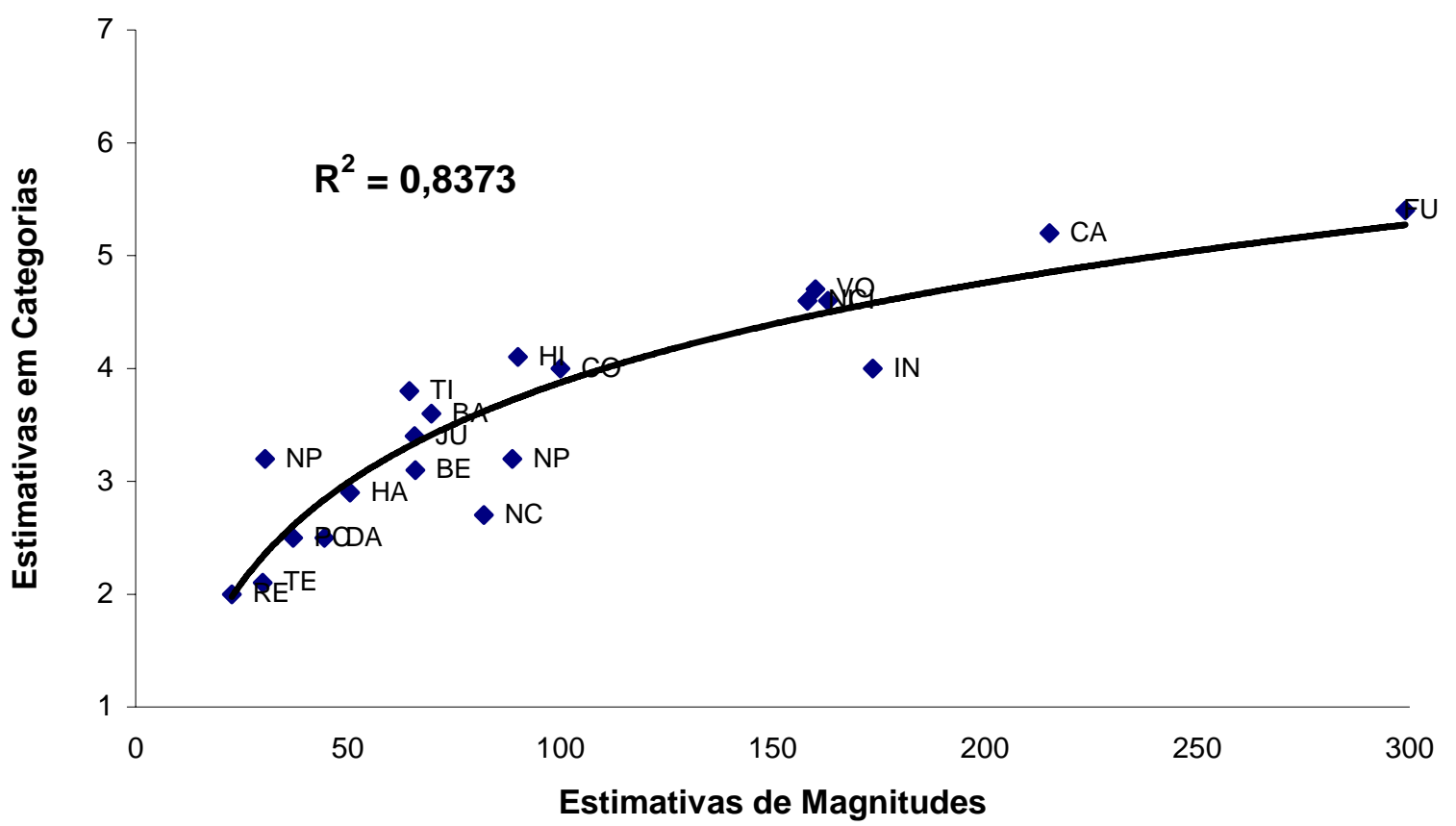

Figura 8 - Relação entre as médias aritméticas das estimativas em categorias e as médias geométricas das estimativas de magnitudes, da preferência pela prática de atividades físicas e esportivas em coordenadas lineares. Participantes do sexo masculino

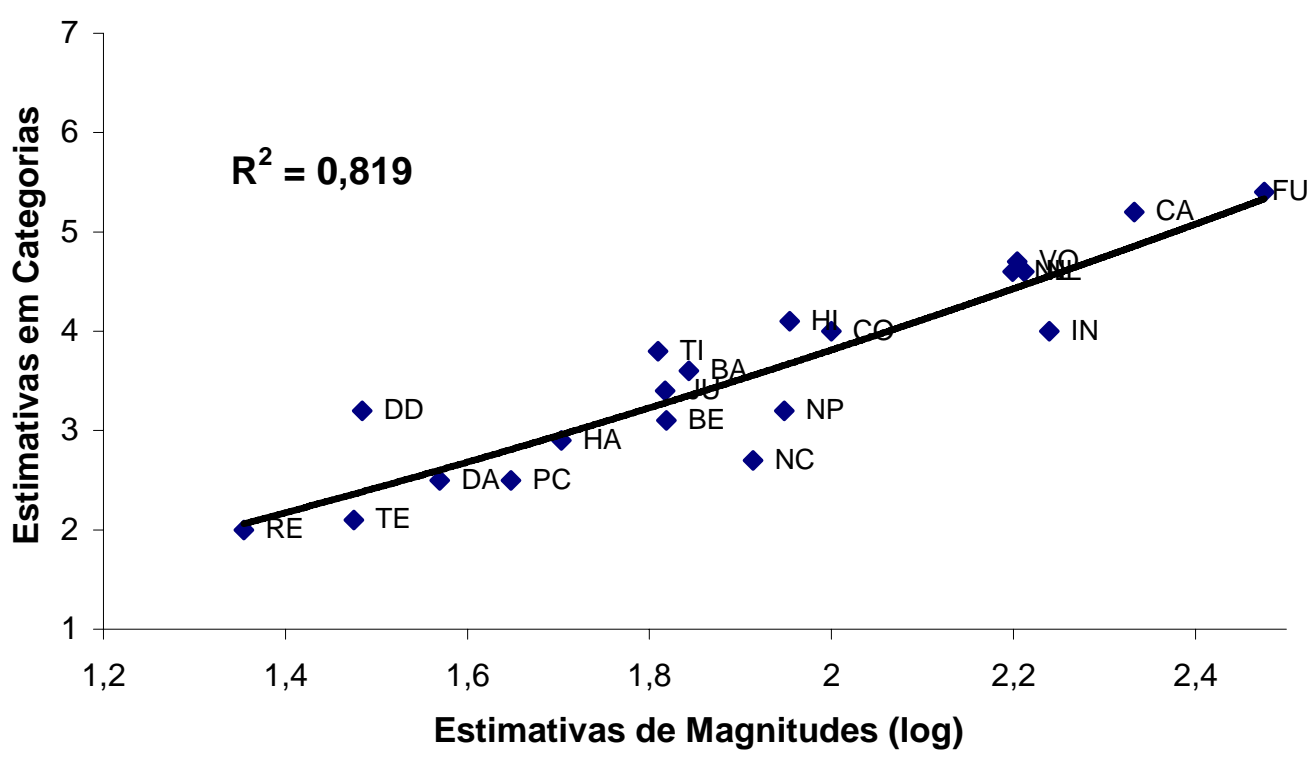

Figura 9 - Relação entre as médias aritméticas das estimativas em categorias e os logaritmos das médias geométricas, das estimativas de magnitudes, da preferência pela prática de atividades físicas e esportivas. Participantes do sexo masculino 


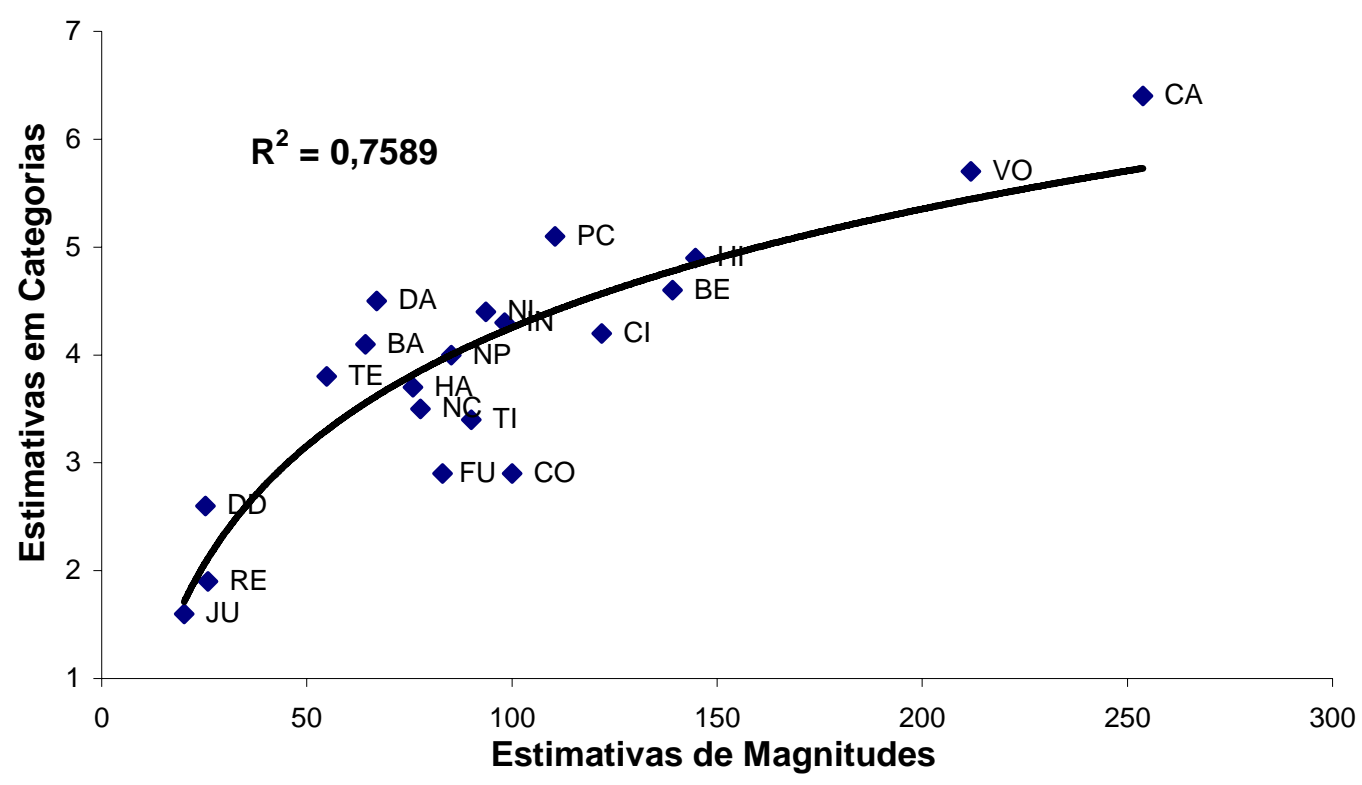

Figura 10 - Relação entre as médias aritméticas das estimativas em categorias e as médias geométricas das estimativas de magnitudes, da preferência pela prática de atividades físicas e esportivas em coordenadas lineares. Participantes do sexo feminino

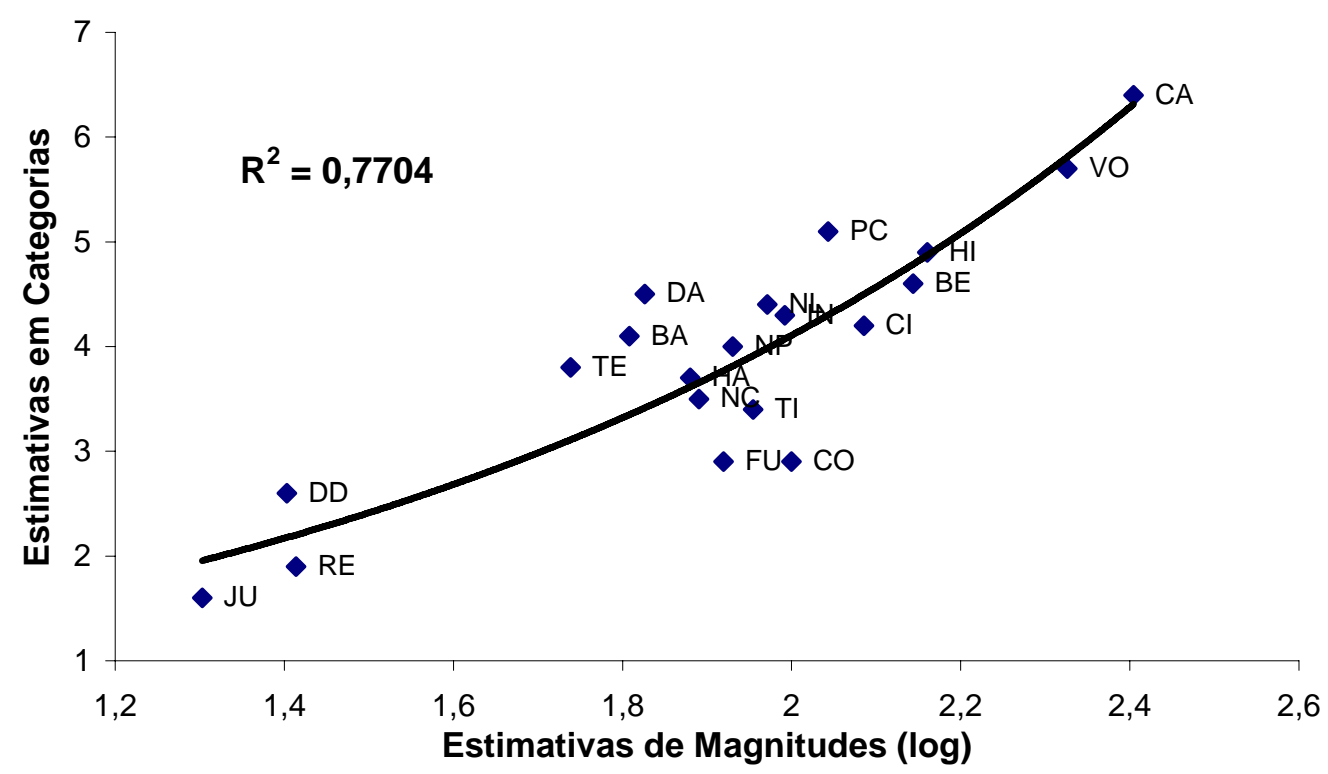

Figura 11 - Relação entre as médias aritméticas das estimativas em categorias e os logaritmos das médias geométricas, das estimativas de magnitudes, da preferência pela prática de atividades físicas e esportivas. Participantes do sexo feminino 
Os resultados em coordenadas lineares também indicaram uma relação entre as duas estimativas (EM e EC), uma leve concavidade ascendente. Além disso, quando as médias aritméticas das estimativas em categorias foram projetadas em função dos logaritmos das médias geométricas das estimativas de magnitudes, a relação mostrou uma concavidade descendente. Os coeficientes de determinação $\left(r^{2}\right)$ encontrados foram: para os participantes masculinos 0,83 e para as femininas 0,75. Deste modo, fica demonstrado que o contínuo de preferência pela prática de atividades físicas e esportivas é um contínuo protético ou aditivo.

Possíveis indícios dos princípios da Lei de Ekman também foram buscados na comparação entre os participantes de sexo oposto, como evidenciam as Figuras 12, 13, 14 e 15.

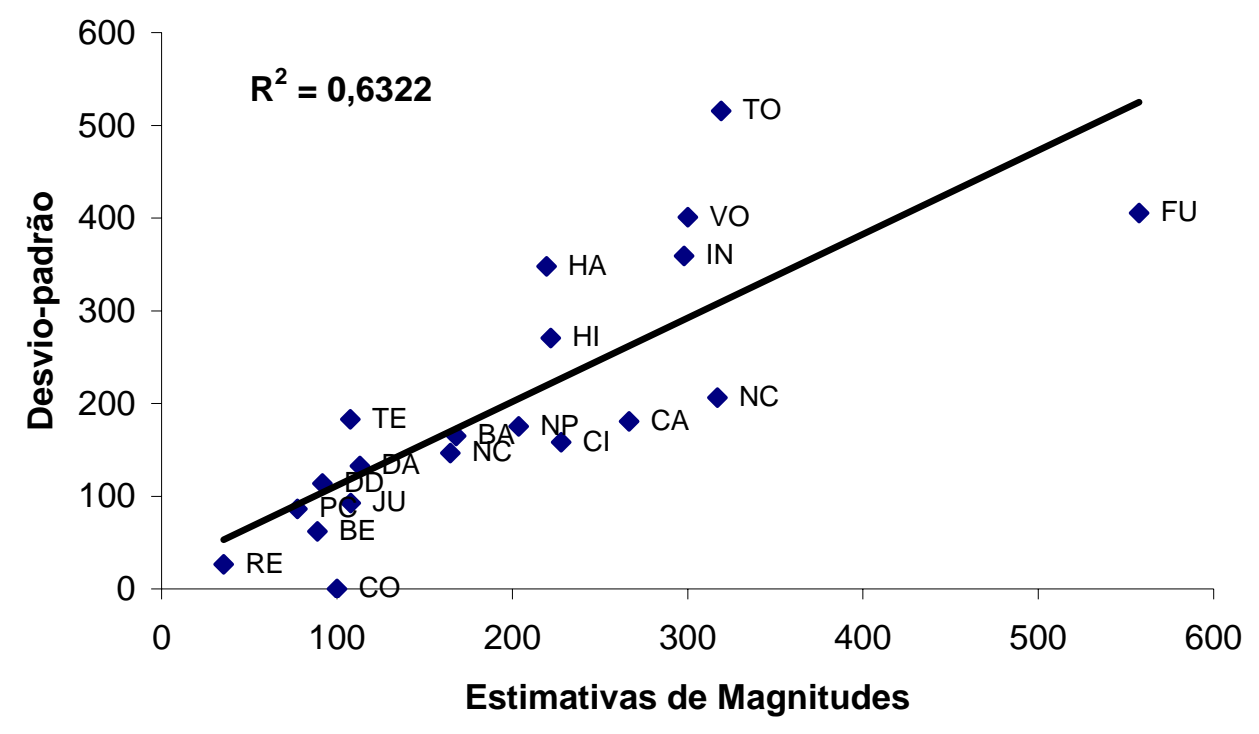

Figura 12 - Desvio-padrão aritmético, em função da média aritmética, das estimativas de magnitudes, da preferência pela prática de atividades físicas e esportivas. Participantes do sexo masculino 


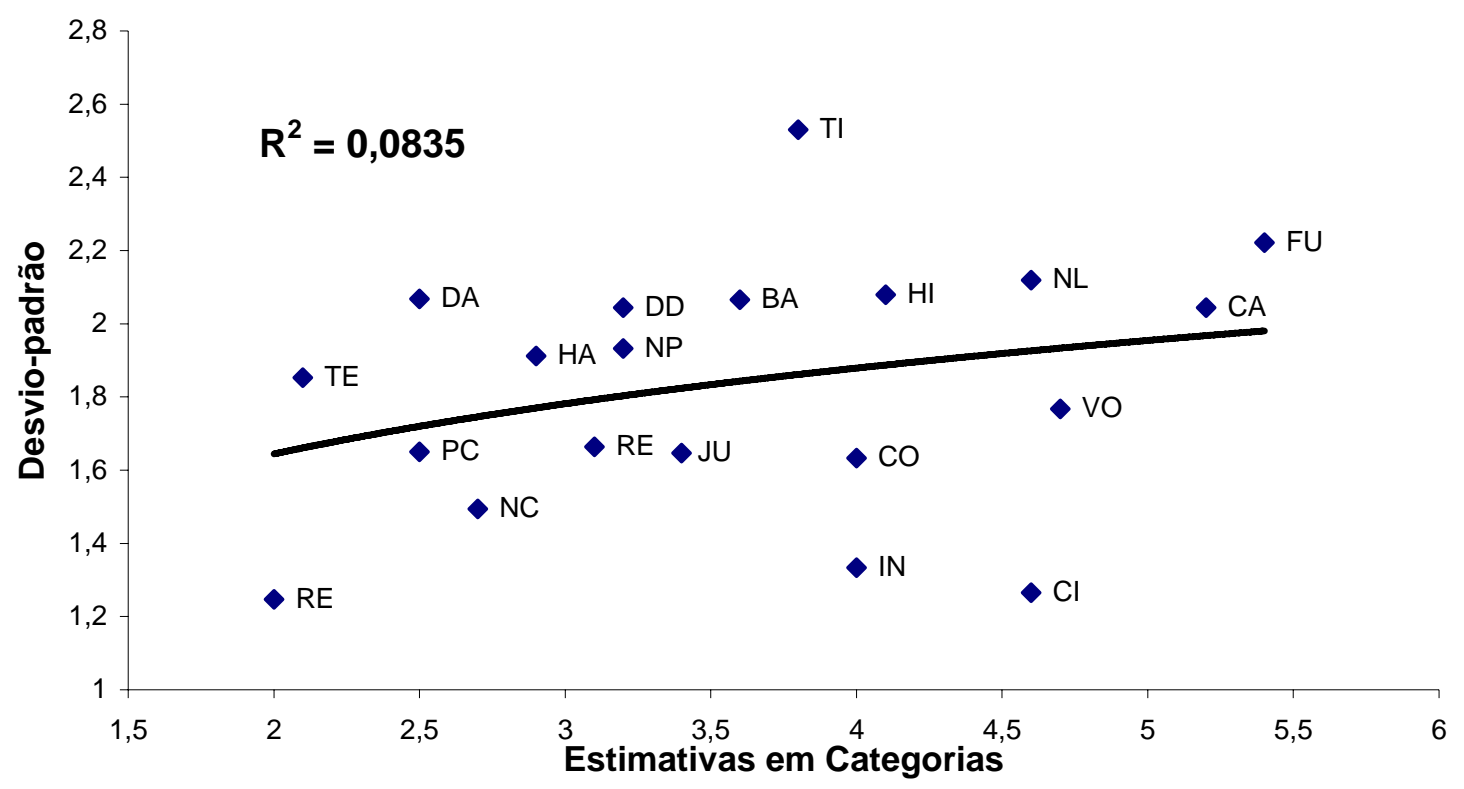

Figura 13 - Desvio-padrão da média aritmética, em função da média aritmética, das estimativas em categorias da preferência pela prática de atividades físicas e esportivas. Participantes do sexo masculino

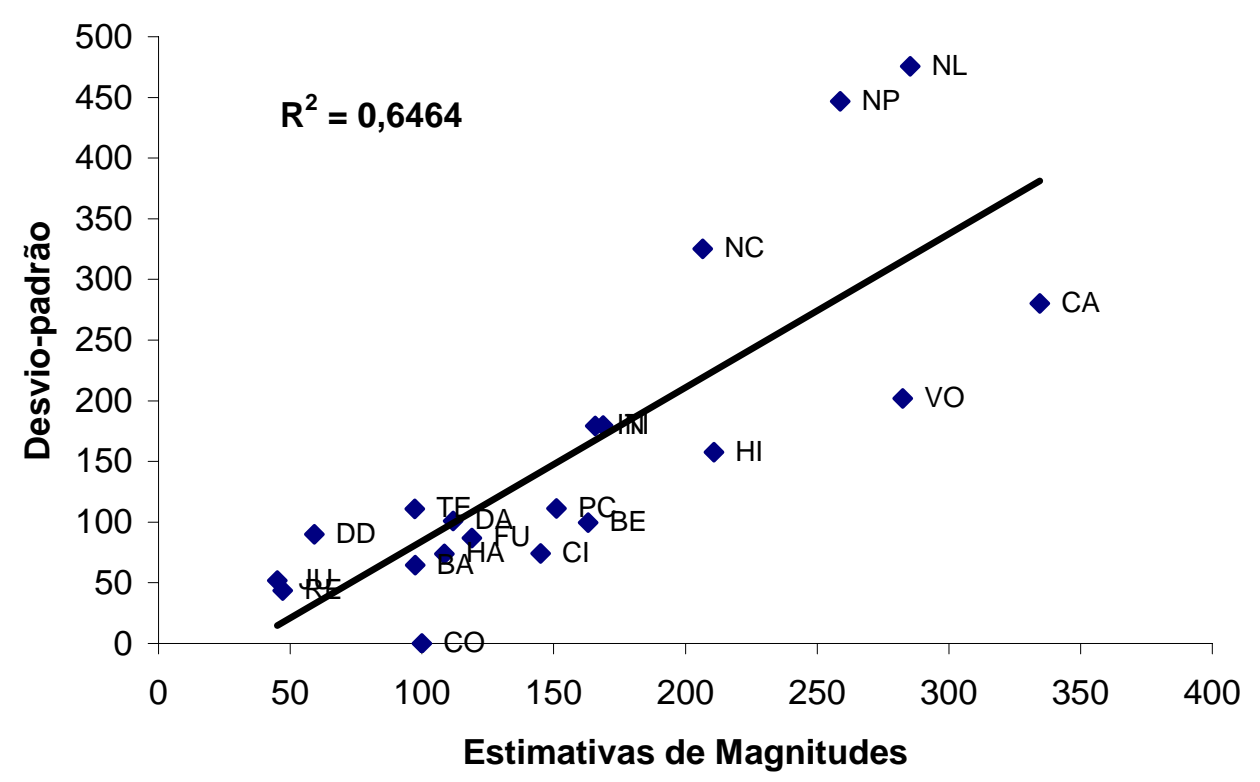

Figura 14 - Desvio-padrão aritmético, em função da média aritmética, das estimativas de magnitudes, da preferência pela prática de atividades físicas e esportivas. Participantes do sexo feminino 


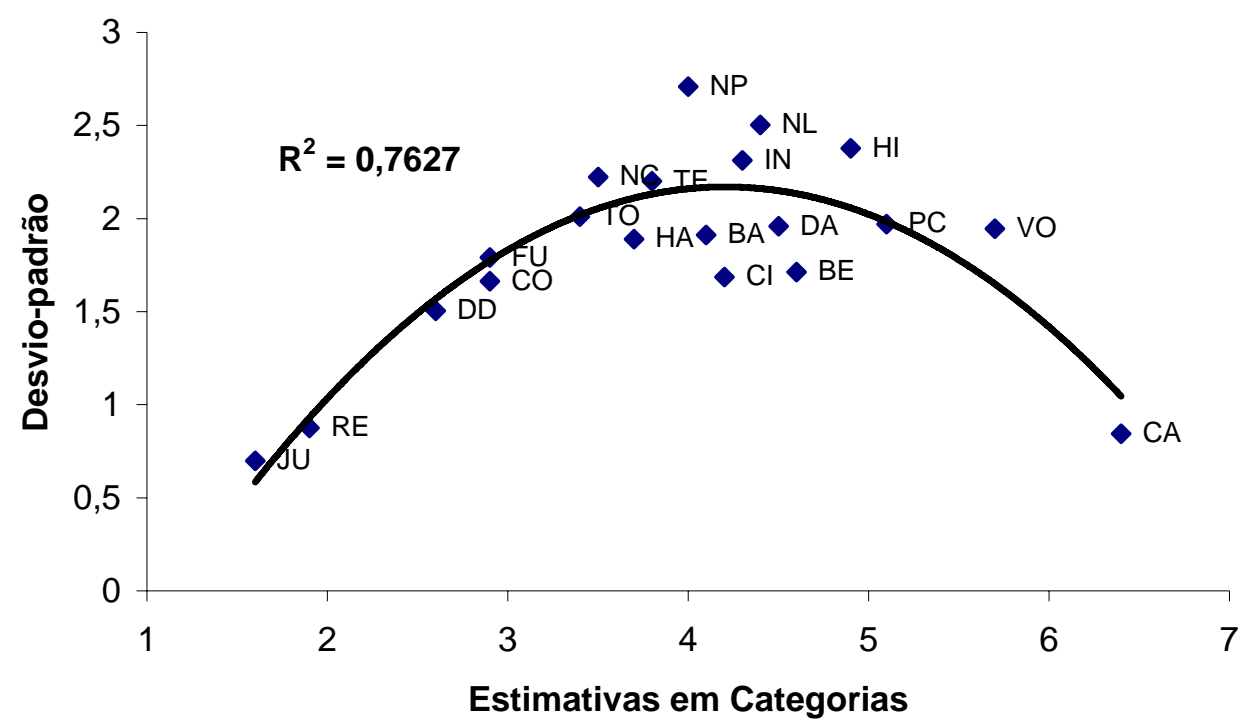

Figura 15 - Desvio-padrão da média aritmética, em função da média aritmética, das estimativas em categorias da preferência pela prática de atividades físicas e esportivas. Participantes do sexo feminino

Os resultados demonstrados acima, também confirmam a visualização dos indícios dos princípios da Lei de Ekman, tanto nos julgamentos dos participantes do sexo masculino, como no dos participantes do sexo feminino. Constatou-se, portanto, que existe uma relação linear, de modo que quanto maior a estimativa de magnitudes maior é o desvio padrão da média (ver Figuras 12 e 14). Por outro lado, a mesma relação não ocorre com as estimativas em categorias, nas quais, quanto maior a estimativa em categoria menor o desvio padrão da média aritmética (ver Figuras 13 e 15). 


\section{EXPERIMENTO 2}

\subsection{Validação da escala de razão de preferência pela prática de atividades físicas e esportivas pelo método de emparelhamento intermodal (comprimento de linhas)}

A preferência pela prática de atividades físicas e esportivas foi avaliada anteriormente no Experimento 1, a partir dos métodos independentes de estimação de magnitudes e em categorias.

Os resultados mostraram, nitidamente, que o contínuo social, de preferência pela prática de atividade física e esportiva, têm comprovado as relações entre as estimativas de magnitudes e em categorias, de forma tal a caracterizá-lo fundamentalmente como um contínuo com propriedades protéticas (quantitativo). A consistência dos sujeitos permeou os resultados obtidos nesse experimento anterior, independente dos métodos utilizados, também confirmada pelos indícios da Lei de Ekman.

No presente experimento, os objetivos foram: a) validar a escala de razão derivada para o contínuo social de preferência pela prática de atividades físicas e esportivas por intermédio do método de emparelhamento intermodal (comprimento de linhas), uma vez que já foi mencionada na Introdução, a possibilidade deste método fornecer critérios para tal, e como conseqüência; b) verificar a estabilidade e/ou equivalência da escala de razão, por meio de duas modalidades de respostas diferentes, a numérica (estimativas de magnitudes) e a visual (comprimento de linhas). Para tanto, foi feita a comparação entre o expoente empírico derivado das estimativas de preferência pela prática de atividades físicas e esportivas, com o expoente predito obtido, num experimento de calibração e também como predito por Stevens (1975), pelos inúmeros métodos psicofísicos, conforme apresentados na Tabela 1. 
Como também mencionamos na Introdução desse trabalho, ao descrevermos este paradigma e os diferentes contínuos sociais escalonados, o método de emparelhamento intermodal tem sido aplicado com sucesso em diferentes áreas do saber e tem permitido a quantificação de diversas variáveis sociais, outrora mensuradas apenas qualitativamente.

Para uma melhor compreensão, dividimos esse Experimento 2 em dois, 2 A (tarefas de calibração) e 2 B (validação psicofísica da escala de razão da preferência pela prática da atividades físicas e esportivas), ambos os experimentos estão fundamentados no método de emparelhamento intermodal.

\subsubsection{Experimento 2 A: Tarefa de Calibração}

\subsubsection{Método}

\subsection{Participantes}

Nas tarefas de calibração foram utilizados 20 estudantes universitários, 10 homens (média 24 anos e 6 meses) e 10 mulheres (média 26 anos e 7 meses), dos diferentes cursos de graduação do Instituto Educacional de Assis - IEDA (Assis-SP) e das Faculdades Integradas de Bauru - FIB (Bauru-SP), com idades variando entre 20 e 29 anos de idade; os 20 sujeitos participaram, tanto da tarefa de Calibração 1, como da Calibração 2. Todos os sujeitos compreenderam as instruções transmitidas para realização dos testes, fato comprovado pelos valores muito altos dos coeficientes de determinação $\left(r^{2}\right)$ calculados sujeito por sujeito, os quais foram maiores que 0,70 para todos os contínuos de repostas destes sujeitos. Todos 
desconheciam a priori os propósitos do experimento e nenhum tinha sido submetido ao experimento anteriormente.

\subsection{Material}

Na tarefa de Calibração 1, foram utilizadas duas folhas de papel, contendo cada uma instruções específicas do método de comprimento de linhas, a ser julgado, pelo método de estimação de magnitudes; e uma folha de registros, contendo cinco comprimentos de linhas. Na tarefa de Calibração 2, foi usada uma folha de papel com uma instrução específica para a modalidade sensorial (comprimento de linhas), a ser julgada pelo método de produção de magnitudes. Em ambas as tarefas, utilizou-se uma trena de $3 \mathrm{~m} / 10$ de comprimento/largura (3M/do Brasil).

\subsection{Procedimentos}

Na tarefa de Calibração 1 foi adotado o método psicofísico de estimação de magnitudes. A tarefa dos participantes consistia em estimar os seguintes comprimentos de linhas 5, 16, 30, 42, 53 e $82 \mathrm{~cm}$. Os sujeitos receberam as instruções para estimar os cinco diferentes comprimentos de linhas, assinalando a cada comprimento um número que fosse proporcional a sua dimensão aparente. Por exemplo, se o sujeito julgasse que um dado comprimento era duas vezes maior do que aquele primeiramente apresentado, ele deveria assinalar-lhe um número duas vezes maior. Se o sujeito julgasse que um outro comprimento 
parecesse ter a metade do comprimento apresentado primeiro, ele deveria assinalar a este um número que fosse metade daquele assinalado ao primeiro comprimento apresentado.

Os cinco diferentes comprimentos de linhas foram apresentados em duas séries de cinco, os quais foram indicados pelo experimentador numa trena, um a um, em ordem totalmente aleatória para cada sujeito. Cada sujeito estabeleceu 10 estimativas, duas para cada comprimento de linha. O estímulo padrão ou módulo foi estabelecido como sendo o comprimento de $30 \mathrm{~cm}$ produzido pelo experimentador na trena e informado ao sujeito o seu valor (conforme Apêndice C, p. 163).

Na tarefa de Calibração 2, os sujeitos foram convidados a produzir os comprimentos de linhas indicados, utilizando uma trena, a partir de comprimentos de linhas obtidos da média geométrica dos comprimentos assinalados pelo sujeito no teste de Calibração 1. Cada sujeito estabeleceu 10 produções, duas para cada comprimento de linha apresentado. O estímulo padrão ou módulo foi estabelecido como sendo o comprimento de 30 cm, por ser o padrão fixado pelo experimentador no teste de Calibração 1. (Apêndice D, p. 164).

\subsubsection{Resultados}

Para a tarefa de Calibração 1, inicialmente foram calculadas separadamente as médias geométricas das estimativas de comprimento de linhas. Em seguida, foram ajustadas funções de potência, utilizando-se separadamente os logaritmos dos comprimentos físicos e os logaritmos de suas respectivas estimativas de magnitudes. Os parâmetros dessa função (expoente e constante escalar) e o coeficiente de determinação $\left(\mathrm{r}^{2}\right)$ o qual indica o seu grau de ajustamento, foram calculados para cada sujeito. Estes valores estão indicados na Tabela 4. 
Na tarefa de Calibração 2, também foram calculadas as médias geométricas da produção de magnitudes a cada comprimento de linha apresentado pelo experimentador. Os mesmos ajustes do teste de Calibração 1 foram feitos com relação à obtenção do (n), (k) e ( $\left.\mathrm{r}^{2}\right)$ para cada um dos 20 participantes deste experimento. Estes valores também constam da Tabela 4.

Tabela 4 - Expoente (n), constante escalar (k) e coeficiente de determinação $\left(r^{2}\right)$ das funções de potência individuais ajustadas separadamente para estimativas de magnitudes e produção de magnitudes

\begin{tabular}{rcccccc}
\hline & \multicolumn{3}{c}{ Estimação de Magnitudes } & \multicolumn{3}{c}{ Produção de Magnitudes } \\
SUJEITOS & $\mathbf{n}$ & $\mathbf{k}$ & $\mathbf{r}^{2}$ & $\mathbf{n}$ & $\mathbf{k}$ & $\mathbf{r}^{2}$ \\
\hline 1-Masculino & 0,74 & 0,86 & 0,99 & 0,64 & 0,16 & 0,99 \\
2-Masculino & 1,03 & 0,46 & 0,99 & 0,91 & 0,31 & 0,99 \\
3-Masculino & 0,99 & 0,52 & 0,99 & 0,93 & 0,33 & 0,98 \\
4-Masculino & 0,63 & 1,08 & 0,99 & 0,83 & 0,16 & 0,99 \\
5-Masculino & 1,16 & 0,20 & 0,99 & 0,94 & 0,38 & 0,96 \\
6-Masculino & 0,73 & 0,89 & 0,99 & 0,80 & 0,08 & 0,97 \\
7-Masculino & 0,84 & 0,73 & 0,99 & 0,81 & 0,10 & 0,98 \\
8-Masculino & 1,04 & 0,49 & 0,97 & 0,96 & 0,37 & 0,92 \\
9-Masculino & 0,61 & 1,05 & 0,99 & 0,80 & 0,08 & 0,98 \\
10-Masculino & 0,69 & 0,98 & 0,99 & 0,66 & 0,11 & 0,98 \\
11-Feminino & 0,98 & 0,57 & 0,99 & 0,95 & 0,36 & 0,93 \\
12-Feminino & 0,74 & 0,90 & 0,97 & 0,77 & 0,03 & 0,97 \\
13-Feminino & 1,19 & 0,07 & 0,96 & 1,20 & 0,93 & 0,97 \\
14-Feminino & 1,16 & 0,21 & 0,98 & 0,99 & 0,40 & 0,95 \\
15-Feminino & 1,18 & 0,15 & 0,97 & 0,97 & 0,37 & 0,96 \\
16-Feminino & 1,30 & 0,02 & 0,92 & 0,95 & 0,46 & 0,99 \\
17-Feminino & 1,29 & 0,01 & 0,91 & 0,96 & 0,47 & 0,99 \\
18-Feminino & 1,01 & 0,47 & 0,99 & 0,83 & 0,18 & 0,98 \\
19-Feminino & 0,82 & 0,78 & 0,99 & 0,96 & 0,41 & 0,97 \\
20-Feminino & 0,07 & 0,70 & 0,99 & 0,96 & 0,41 & 0,98 \\
\hline Média & 0,91 & 0,55 & 0,97 & 0,89 & 0,30 & 0,97 \\
\hline Mediana & 0,98 & 0,54 & 0,99 & 0,94 & 0,34 & 0,98 \\
\hline DP & 0,29 & 0,35 & 0,02 & 0,12 & 0,20 & 0,01 \\
\hline
\end{tabular}

Uma comparação entre os expoentes obtidos nas Tarefas de Calibração 1 e 2 é bastante ilustrativa da robustez do paradigma do emparelhamento intermodal. Os expoentes médios obtidos para estimativas de magnitudes e produção de magnitudes foram 0,91 (mediana 
$=0,98)$ e 0,89 (mediana =0,94), respectivamente (ver Tabela 4). As Figuras 16 e 17 representam estas funções em coordenadas logarítmicas. Supondo que a produção e a estimação de magnitudes sejam emparelhadas, esperar-se-ia um expoente igual ou próximo a 1,0 considerando-se a razão entre os expoentes médios $(0,91 / 0,89)$, ou igual a 1,02 tomando-se a razão entre os expoentes medianos $(0,98 / 0,94)$, obtém-se 1,05 . O expoente desta função $(1,02)$ não foi diferente do expoente esperado $(1,0)$ resultante da transitividade das escalas (ver Tabela 5).

Tabela 5 - Resultados da análise estatística do Teste t de Student, entre os expoentes obtidos dos métodos de estimação de magnitudes e produção de magnitudes

\begin{tabular}{lcccccccc}
\hline & & \multicolumn{1}{c}{ Std.Dv. } \\
& Mean & Std.Dv. & $\mathrm{N}$ & Diff. & Diff. & $\mathrm{t}$ & $\mathrm{df}$ & $\mathrm{p}$ \\
\hline EM vs. PM & $\mathbf{1 , 0 2}$ & $\mathbf{0 , 2 7 9}$ & & & & & \\
VALOR HIPOTÉTICO & $\mathbf{1}$ & $\mathbf{0}$ & 20 & 0,0207 & 0,2795 & 0,3320 & 19 & $\mathbf{0 , 7 4 3 5 0 4}$ \\
\hline
\end{tabular}

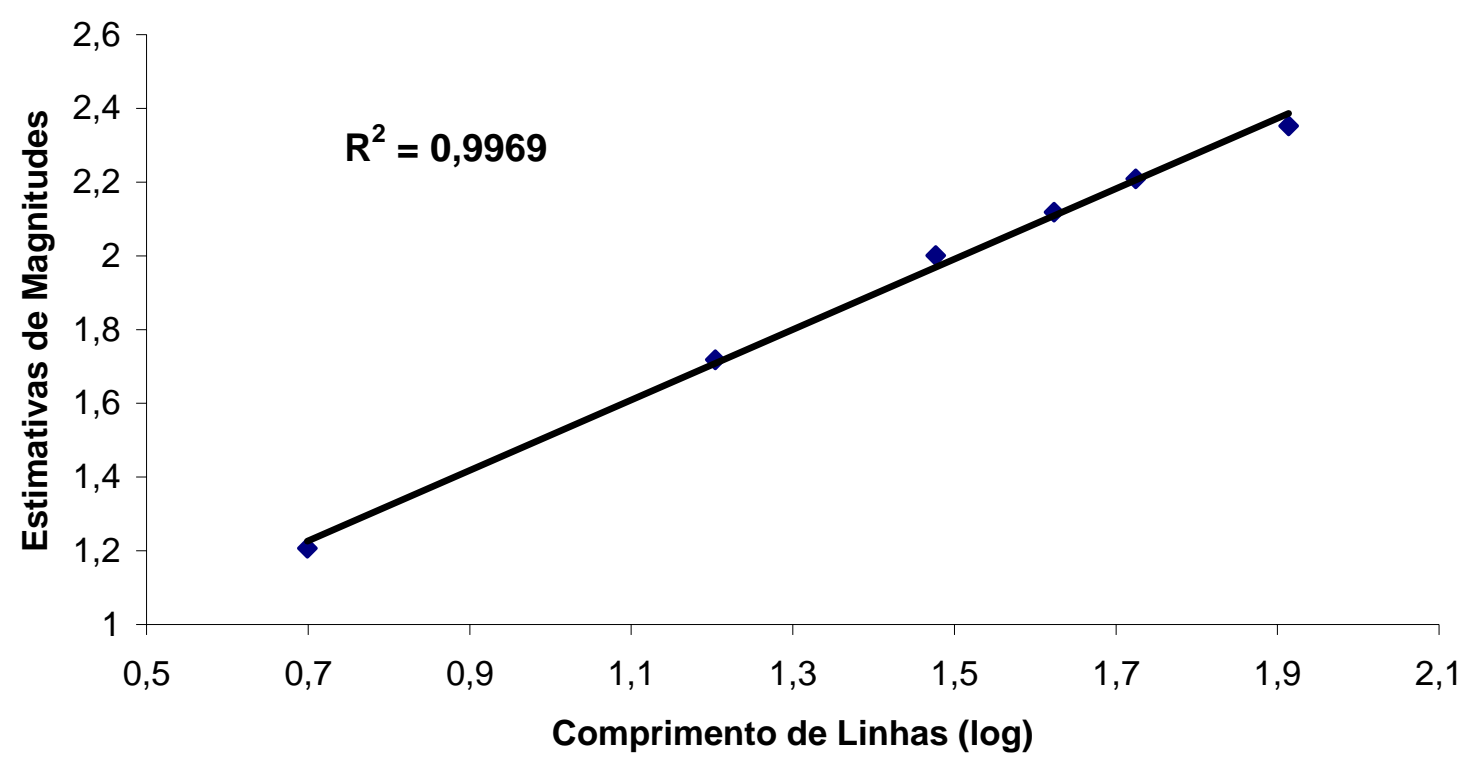

Figura 16 - Relação entre os logaritmos das médias geométricas das estimativas de magnitudes e os logaritmos das médias geométricas dos comprimentos de linhas na Tarefa de Calibração 1. Dados do Experimento $2 \mathrm{~A}$ 


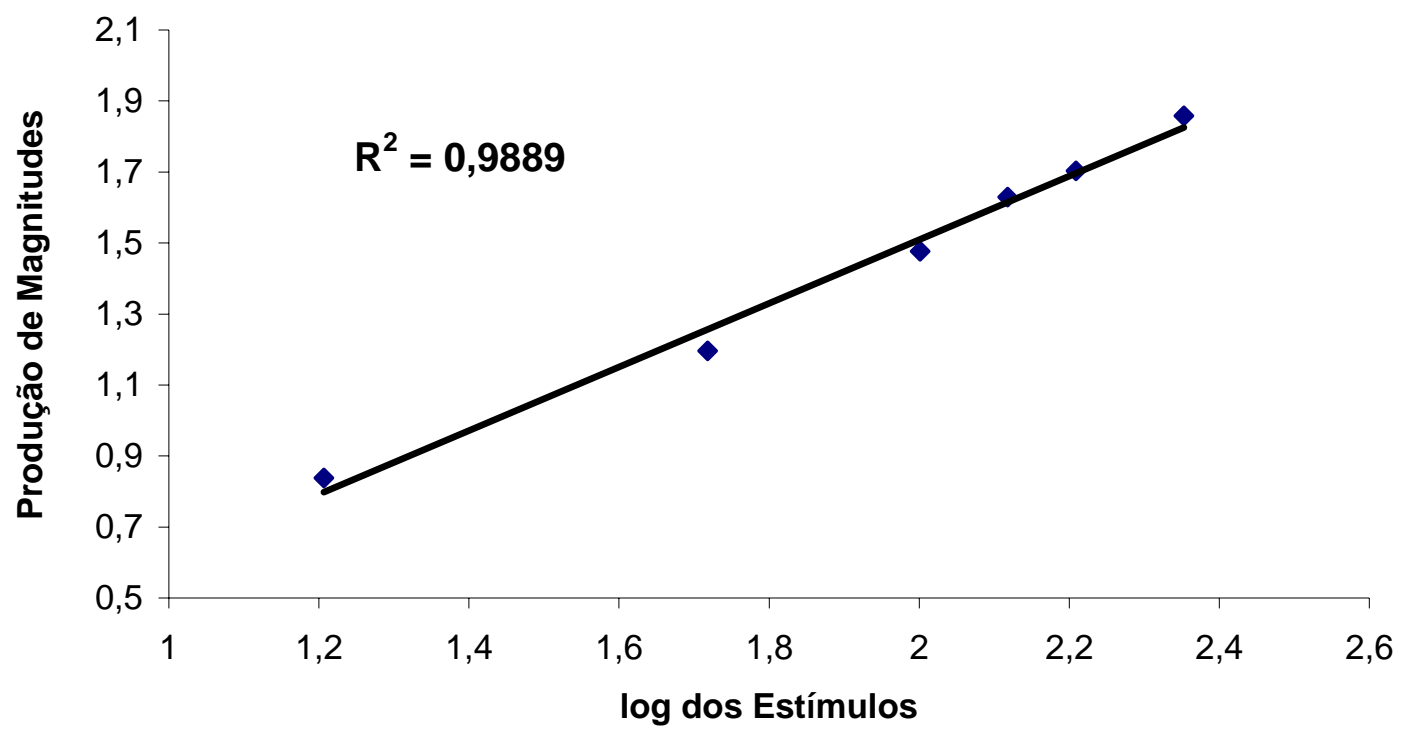

Figura 17 - Relação entre os logaritmos das médias geométricas das produções de magnitudes e os logaritmos dos estímulos apresentados aos sujeitos, na tarefa de Calibração 2. Dados do Experimento $2 \mathrm{~A}$

Para as tarefas de Calibração 1 e 2 apresenta-se, a seguir, os resultados separados dos sujeitos homens e mulheres. Para os homens, os resultados dos métodos de estimação de magnitudes e do método de produção de magnitudes de comprimento de linhas, são mostrados na Tabela 6 e Figuras 18 e 19. 
Tabela 6 - Expoente (n), constante escalar $(k)$ e coeficiente de determinação $\left(\mathrm{r}^{2}\right)$ das funções de potência individuais, ajustadas separadamente para estimação de magnitudes e produção de magnitudes dos sujeitos do sexo masculino

\begin{tabular}{lcccccc}
\hline & \multicolumn{3}{c}{ Estimação de Magnitudes } & \multicolumn{3}{c}{ Produção de Magnitudes } \\
SUJEITOS & $\mathbf{n}$ & $\mathbf{k}$ & $\mathbf{r}^{2}$ & $\mathbf{n}$ & $\mathbf{k}$ & $\mathbf{r}^{\mathbf{2}}$ \\
\hline 1-Masculino & 0,74 & 0,86 & 0,99 & 0,64 & 0,16 & 0,99 \\
2-Masculino & 1,03 & 0,46 & 0,99 & 0,91 & 0,31 & 0,99 \\
3-Masculino & 0,99 & 0,52 & 0,99 & 0,93 & 0,33 & 0,98 \\
4-Masculino & 0,63 & 1,08 & 0,99 & 0,83 & 0,16 & 0,99 \\
5-Masculino & 1,16 & 0,20 & 0,99 & 0,94 & 0,38 & 0,96 \\
6-Masculino & 0,73 & 0,89 & 0,99 & 0,80 & 0,08 & 0,97 \\
7-Masculino & 0,84 & 0,73 & 0,99 & 0,81 & 0,10 & 0,98 \\
8-Masculino & 1,04 & 0,49 & 0,97 & 0,96 & 0,37 & 0,92 \\
9-Masculino & 0,61 & 1,05 & 0,99 & 0,80 & 0,08 & 0,98 \\
10-Masculino & 0,69 & 0,98 & 0,99 & 0,66 & 0,11 & 0,98 \\
\hline Média & 0,85 & 0,73 & 0,99 & 0,83 & 0,21 & 0,97 \\
\hline Mediana & 0,79 & 0,79 & 0,99 & 0,82 & 0,16 & 0,98 \\
\hline DP & 0,20 & 0,30 & 0,01 & 0,11 & 0,12 & 0,02 \\
\hline
\end{tabular}

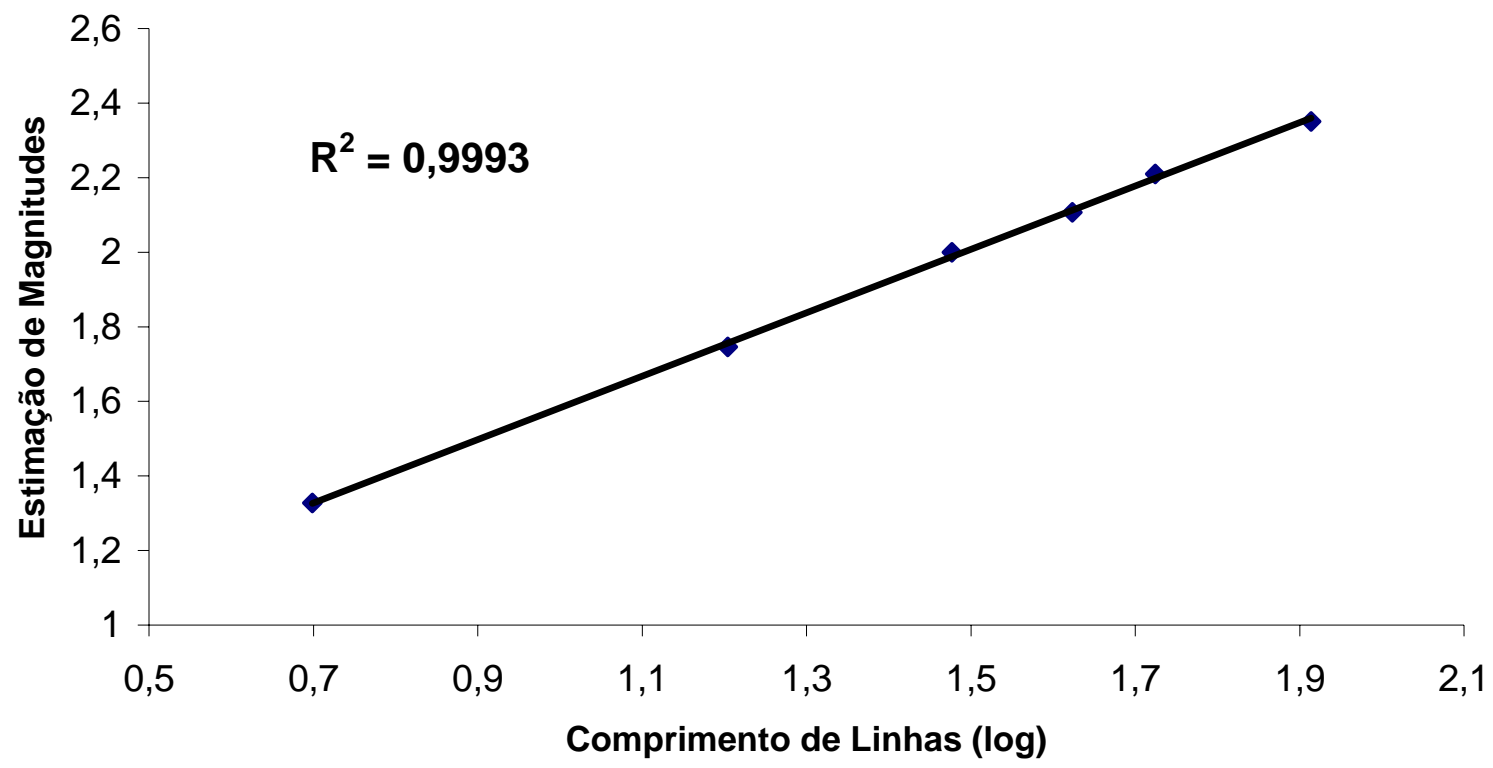

Figura 18 - Relação entre os logaritmos das médias geométricas das estimativas de magnitudes e os logaritmos das medias geométricas dos comprimentos de linhas na Tarefa de Calibração 1, sujeitos do sexo masculino. Dados do Experimento 2 A 


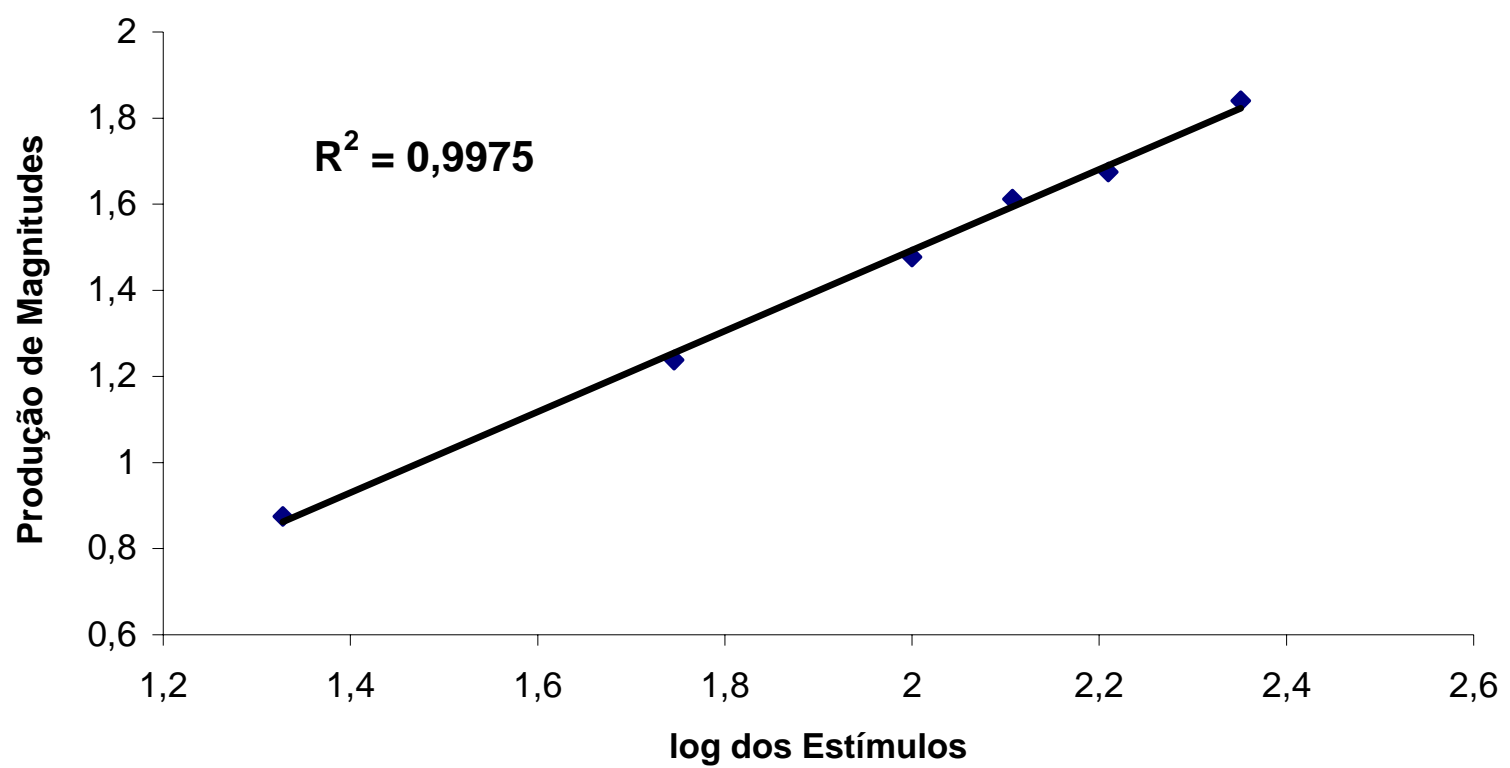

Figura 19 - Relação entre os logaritmos das médias geométricas das produções de magnitudes e os logaritmos dos estímulos apresentados aos sujeitos, na tarefa de Calibração 2, dos sujeitos do sexo masculino. Dados do Experimento 2 A

Os expoentes médios obtidos para estimativas de magnitudes e de produção de magnitudes, dos sujeitos masculinos apontaram os seguintes resultados: 0,85 (mediana $=$ 0,79) e 0,83 (mediana = 0,82), respectivamente (ver Tabela 6). As Figuras 18 e 19 representam estas funções em coordenadas logarítmicas. Supondo que a produção e a estimação de magnitudes sejam emparelhadas, esperar-se-ia um expoente igual ou próximo a 1,0 considerando-se a razão entre os expoentes médios $(0,85 / 0,83)$, ou igual a 1,02 tomandose a razão entre os expoentes medianos $(0,79 / 0,82)$, obtém-se 0,96 . O expoente desta função $(1,02)$ não foi diferente do expoente esperado $(1,0)$ resultante da transitividade das escalas (ver Tabela 7). 
Tabela 7 - Resultados da análise estatística do Teste t de Student, entre os expoentes obtidos dos métodos de estimação de magnitudes e produção de magnitudes, dos sujeitos do sexo masculino

\begin{tabular}{lcccccccc}
\hline & Mean & Std.Dv. & $\mathrm{n}$ & Diff. & $\begin{array}{c}\text { Std.Dv. } \\
\text { Diff. }\end{array}$ & $\mathrm{t}$ & $\mathrm{df}$ & $\mathrm{P}$ \\
\hline EM vs. PM & $\mathbf{1 , 0 2}$ & $\mathbf{0 , 1 5 9}$ & & & & & & \\
VALOR HIPOTÉTICO & 1 & 0 & 10 & 0,0186 & 0,1597 & 0,3691 & 9 & $\mathbf{0 , 7 2 0 5}$ \\
\hline
\end{tabular}

No caso das mulheres, os resultados dos métodos de estimação de magnitudes e do método de produção de magnitudes de comprimento de linhas, são indicadas na Tabela 8 e nas Figuras 20 e 21. 
Tabela 8 - Expoente (n), constante escalar (k) e coeficiente de determinação $\left(\mathrm{r}^{2}\right)$ das funções de potência individuais, ajustadas separadamente para estimação de magnitudes e produção de magnitudes dos sujeitos do sexo feminino

\begin{tabular}{|c|c|c|c|c|c|c|}
\hline \multirow[b]{2}{*}{ SUJEITOS } & \multicolumn{3}{|c|}{ Estimação de Magnitudes } & \multicolumn{3}{|c|}{ Produção de Magnitudes } \\
\hline & $\mathbf{n}$ & $\mathbf{k}$ & $\mathbf{r}^{2}$ & $\mathbf{n}$ & $\mathbf{k}$ & $\mathbf{r}^{2}$ \\
\hline 11-Feminino & 0,98 & 0,57 & 0,99 & 0,95 & 0,36 & 0,93 \\
\hline 12-Feminino & 0,74 & 0,90 & 0,97 & 0,77 & 0,03 & 0,97 \\
\hline 13-Feminino & 1,19 & 0,07 & 0,96 & 1,20 & 0,93 & 0,97 \\
\hline 14-Feminino & 1,16 & 0,21 & 0,98 & 0,99 & 0,40 & 0,95 \\
\hline 15-Feminino & 1,18 & 0,15 & 0,97 & 0,97 & 0,37 & 0,96 \\
\hline 16-Feminino & 1,30 & 0,02 & 0,92 & 0,95 & 0,46 & 0,99 \\
\hline 17-Feminino & 1,29 & 0,01 & 0,91 & 0,96 & 0,47 & 0,99 \\
\hline 18-Feminino & 1,01 & 0,47 & 0,99 & 0,83 & 0,18 & 0,98 \\
\hline 19-Feminino & 0,82 & 0,78 & 0,99 & 0,96 & 0,41 & 0,97 \\
\hline 20-Feminino & 0,07 & 0,70 & 0,99 & 0,96 & 0,41 & 0,98 \\
\hline Média & 0,97 & 0,39 & 0,97 & 0,95 & 0,40 & 0,97 \\
\hline Mediana & 1,09 & 0,34 & 0,98 & 0,96 & 0,41 & 0,97 \\
\hline DP & 0,37 & 0,34 & 0,03 & 0,11 & 0,23 & 0,02 \\
\hline
\end{tabular}

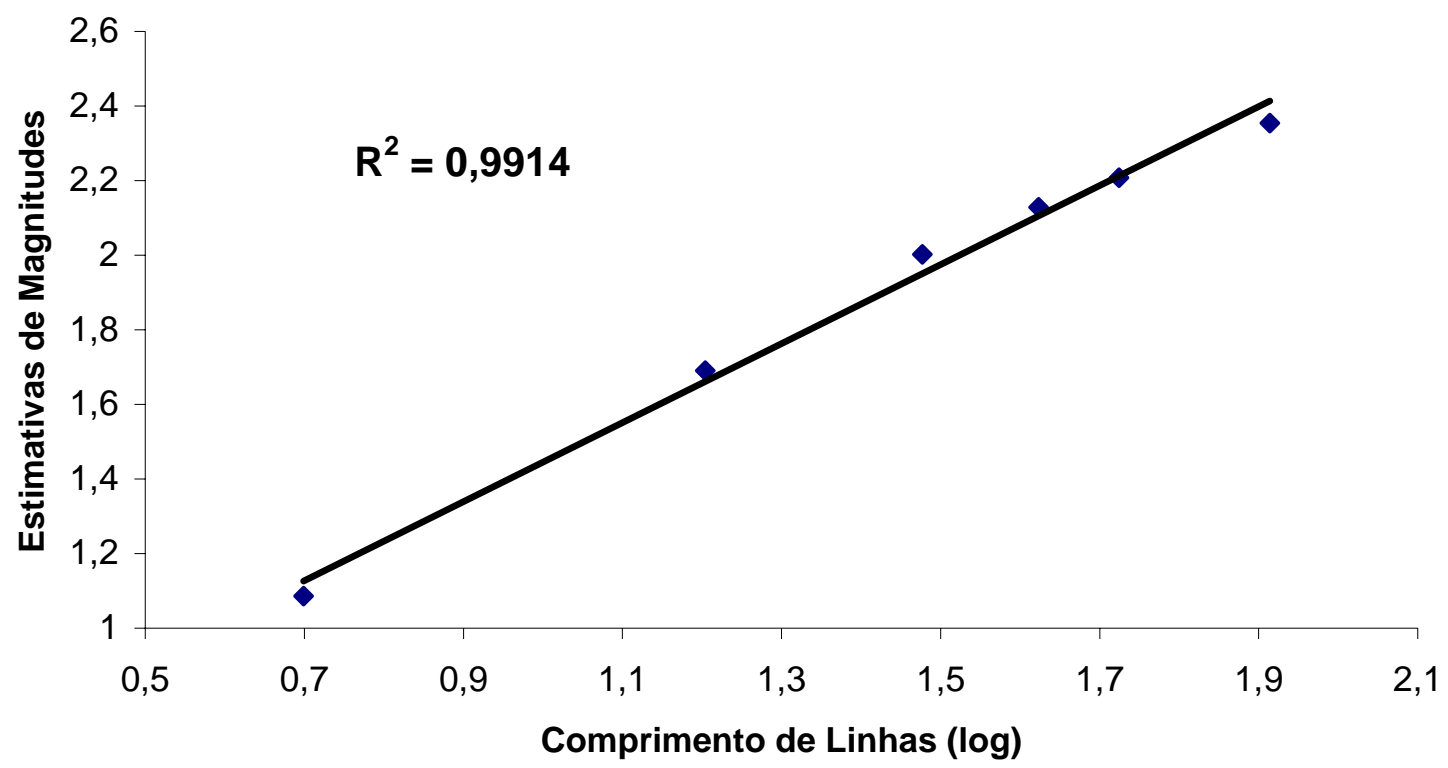

Figura 20 - Relação entre os logaritmos das médias geométricas das estimativas de magnitudes e os logaritmos das médias geométricas dos comprimentos de linhas na Tarefa de Calibração 1, sujeitos do sexo feminino. Dados do Experimento $2 \mathrm{~A}$ 


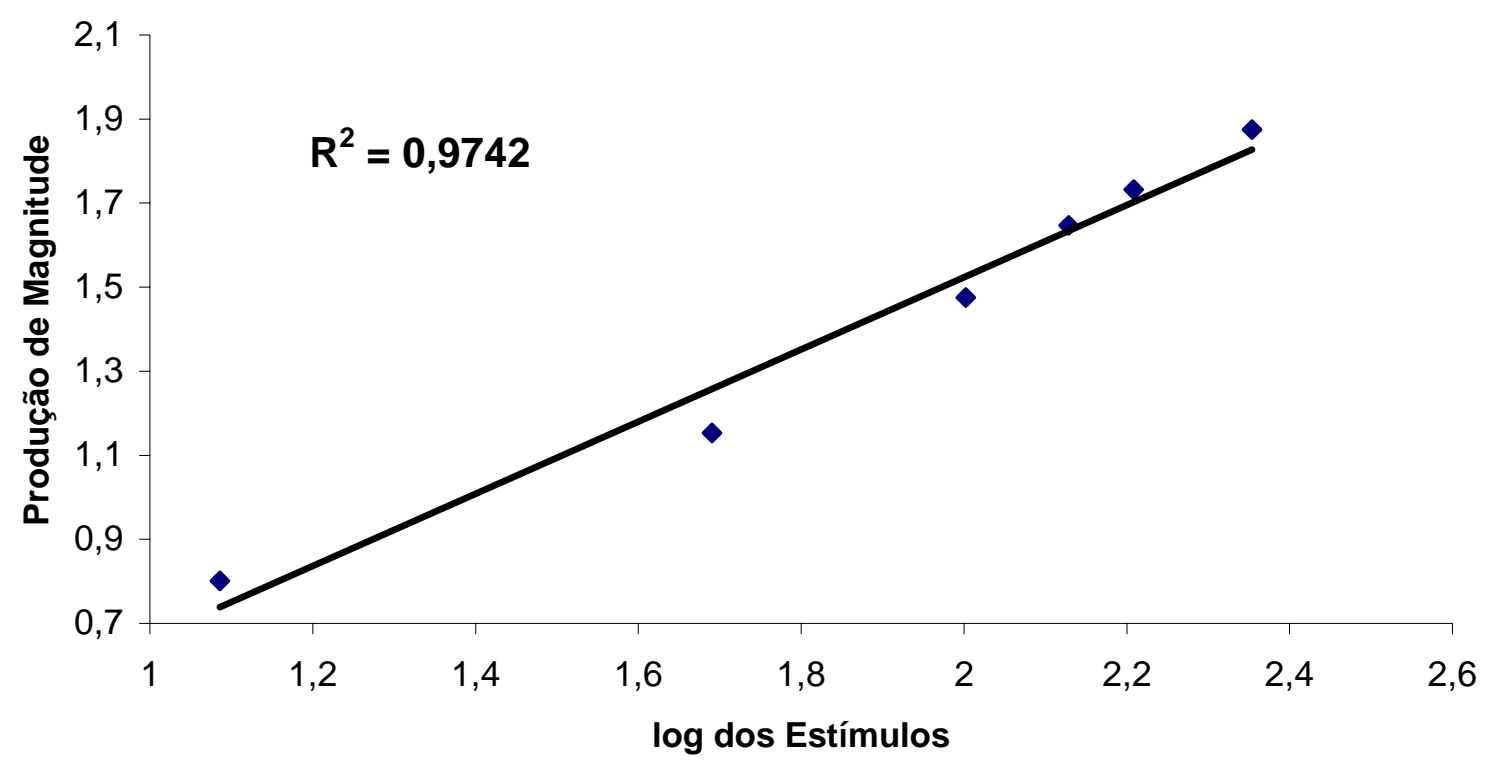

Figura 21 - Relação entre os logaritmos das médias geométricas das produções de magnitudes e os logaritmos dos estímulos apresentados aos sujeitos, na tarefa de Calibração 2, dos sujeitos do sexo feminino. Dados do Experimento 2 A

Os expoentes médios obtidos para estimativas de magnitudes e produção de magnitudes, dos sujeitos do sexo feminino apontaram os seguintes resultados: 0,97 (mediana $=1,09$ ) e 0,95 (mediana $=0,96$ ), respectivamente (ver Tabela 8). As figuras 20 e 21 representam estas funções em coordenadas logarítmicas. Supondo que a produção e estimação de magnitudes sejam emparelhadas, esperar-se-ia um expoente igual ou próximo a 1,0, considerando-se a razão entre os expoentes médios $(0,97 / 0,95)$, ou igual a 1,02, tomando-se a razão entre os expoentes medianos $(1,09 / 0,96)$, obtém-se 1,13 . O expoente desta função $(1,02)$ não foi diferente do expoente esperado $(1,0)$ resultante da transitividade das escalas (ver Tabela 9).

Tabela 9 - Resultados da análise estatística do Teste t de Student, entre os expoentes obtidos dos métodos de estimação de magnitudes e produção de magnitudes, dos sujeitos do sexo feminino

\begin{tabular}{lcccccccc}
\hline & Mean & Std.Dv. & $\mathrm{n}$ & Diff. & $\begin{array}{c}\text { Std.Dv. } \\
\text { Diff. }\end{array}$ & $\mathrm{t}$ & $\mathrm{df}$ & $\mathrm{p}$ \\
\hline EM vs. PM & 1,02 & 0,3734 & & & & & & \\
VALOR HIPOTÉTICO & 1 & 0 & 10 & 0,0228 & 0,3734 & 0,1935 & 9 & 0,850809 \\
\hline
\end{tabular}




\subsubsection{Experimento 2 B: Validação psicofísica da escala de razão de preferência pela prática de atividades físicas e esportivas}

\subsubsection{Método}

\subsection{Participantes}

Participaram do presente estudo 20 sujeitos, universitários, 10 homens e 10 mulheres, dos diferentes cursos de graduação do Instituto Educacional de Assis IEDA (AssisSP) e das Faculdades Integradas de Bauru - FIB (Bauru-SP), com idades variando entre 20 e 29 anos. Esses mesmos sujeitos participaram das Tarefas de Calibração 1 e 2. Todos desconheciam a priori os propósitos do experimento e nenhum tinha sido submetido aos experimentos anteriormente.

\subsection{Material}

Foram utilizadas quatro folhas de papel, contendo cada uma instruções específicas do método de comprimento de linhas e do método de estimação de magnitudes, com as respectivas folhas de resposta para cada julgamento. Os estímulos julgados (as atividades físicas e esportivas) foram apresentados aos participantes na forma de 20 cartões, em cada cartão estava escrito uma atividade física ou esportiva, em ordem totalmente aleatória. No método de comprimento de linhas foi utilizada uma trena de 3m/10 de comprimento/largura (3M/do Brasil). 


\subsection{Procedimentos}

Adotou-se o método de estimação de magnitudes numéricas e o de emparelhamento intermodal de comprimento de linhas. Com o método de estimação de magnitudes a tarefa dos sujeitos consistia em assinalar um número a cada atividade física ou esportiva que fosse proporcional à quantidade de preferência pela sua prática, que o sujeito julgasse que ela possuísse. Por exemplo, se o sujeito considerasse que uma dada atividade física e esportiva possuísse duas vezes mais preferência pela sua prática em relação a uma outra, o sujeito deveria assinalar-lhe um número duas vezes maior. Se o sujeito considerasse que uma dada atividade física ou esportiva possuísse metade da preferência pela sua prática em comparação a uma outra, o sujeito deveria assinalar um número que correspondesse a metade. O estímulo padrão e o módulo foram estabelecidos previamente, sendo o atributo de CORRIDA o estímulo padrão, equivalente ao número 100. As diferentes atividades físicas e esportivas foram apresentadas em duas séries de 20, as quais foram dispostas, uma a uma escritas em cartões separados, obedecendo a uma ordem aleatória para cada sujeito. Cada sujeito estabeleceu 40 estimativas, duas para cada atividade física ou esportiva (conforme Apêndice A, p. 161).

Com o método de emparelhamento intermodal envolvendo o contínuo de resposta de comprimentos de linhas, a tarefa dos sujeitos consistia em emparelhar um comprimento de linha a cada atividade física ou esportiva que fosse proporcional à quantidade de preferência que cada atividade possuísse na concepção do sujeito. Por exemplo, se o sujeito considerasse que uma dada atividade física ou esportiva possuísse duas vezes mais preferência pela sua prática em relação a uma outra atividade, o sujeito deveria emparelhar um comprimento de linha que fosse duas vezes maior. Se o sujeito considerasse que uma atividade física ou esportiva possuísse a metade da preferência pela sua prática em comparação a outra, o sujeito deveria emparelhar um comprimento de linhas correspondente a metade. O estímulo padrão e o módulo foram apresentados aos sujeitos, sendo o padrão CORRIDA equivalente a um 
comprimento de linhas de $30 \mathrm{~cm}$. As atividades físicas e esportivas foram apresentadas em duas séries de 20, as quais foram dispostas, uma a uma escritas em cartões separados, em ordem totalmente aleatória para cada sujeito. Cada sujeito estabeleceu 40 julgamentos, dois para cada atividade física ou esportiva (segundo Apêndice E, p. 165).

\subsubsection{Resultados}

As médias geométricas das estimativas numéricas, e as geométricas dos emparelhamentos de comprimentos de linhas, bem como a ordenação das posições de cada uma das diferentes atividades físicas e esportivas, foram inicialmente determinadas neste experimento. Estes resultados encontram-se na Tabela 10.

Tabela 10 - Média geométrica das estimativas de magnitudes (EM), média geométrica dos emparelhamentos de comprimentos de linhas (EMCL) e ordenação das posições da preferência pela prática de atividades físicas ou esportivas de todos os sujeitos

\begin{tabular}{lrrrr}
\hline ATIVIDADE & EM & OP & EMCL & OP \\
\hline Corrida (CO) & 100,00 & 6 & 30,00 & 10 \\
Bicicleta Ergométrica (BE) & 70,99 & 11 & 19,84 & 16 \\
Remo Estacionário (RE) & $\mathbf{1 9 , 7 6}$ & $\mathbf{2 0}$ & $\mathbf{1 0 , 8 3}$ & $\mathbf{2 0}$ \\
Hidroginástica (HI) & 127,11 & 3 & 44,29 & 4 \\
Dança -Valsa (DA) & 49,45 & 16 & 20,30 & 15 \\
Ciclismo (CI) & 76,17 & 10 & 31,83 & 9 \\
Basquetebol (BA) & 90,19 & 8 & 33,26 & 8 \\
Handebol (HA) & 67,29 & 13 & 29,99 & 11 \\
Judô (JU) & 36,96 & 19 & 13,24 & 19 \\
Pular Corda (PC) & 58,62 & 14 & 24,27 & 13 \\
Voleibol (VO) & $\mathbf{1 8 9 , 1 8}$ & $\mathbf{1}$ & $\mathbf{6 2 , 9 8}$ & $\mathbf{1}$ \\
Tênis Simples (TE) & 54,33 & 15 & 23,52 & 14 \\
Caminhada (CA) & 134,61 & 2 & 48,03 & 3 \\
Natação - nado de costas (NC) & 83,17 & 9 & 27,85 & 12 \\
Natação - nado de peito (NP) & 105,71 & 5 & 34,70 & 7 \\
Natação - nado estilo livre (NL) & 124,70 & 4 & 51,26 & 2 \\
Tocar um Instrumento (TI) & 96,16 & 7 & 37,48 & 6 \\
Dardos (DD) & 48,89 & 17 & 17,74 & 18 \\
Futebol (FU) & 69,23 & 12 & 38,42 & 5 \\
Inatividade (IN) & 44,08 & 18 & 19,44 & 17 \\
\hline
\end{tabular}


Pode-se constatar que as ordenações das posições de preferência pela prática de atividades físicas ou esportivas utilizadas neste experimento foram similares entre si, independentemente do contínuo de resposta empregado. De fato, o coeficiente de correlação de ordem de Spearman (rho) foi igual a 0,91 ( $\mathrm{p}<0,001)$ entre as estimativas numéricas e os emparelhamentos de comprimentos de linhas. Este padrão resultante indica que as ordenações dos graus de preferência pela prática de atividades físicas ou esportivas são independentes do tipo de modalidade ou contínuo de resposta empregado. Por exemplo, a atividade esportiva de VOLEIBOL ocupa a primeira posição nos dois tipos de contínuos de repostas e a atividade física de REMO ESTACIONÁRIO ocupa a última posição na preferência pela prática. Deste modo, como mencionado no experimento anterior, com estas duas modalidades de respostas, confirma-se que a preferência pela prática de atividades físicas ou esportivas é tantas vezes maior ou menor que outra. No caso de estimativas numéricas a preferência pela prática do VOLEIBOL $(E M=189,18)$ é cerca de duas vezes maior do que a preferência pela prática da CORRIDA $(E M=100)$. Já, a prática de DARDOS $(E M=48,89)$ possui, aproximadamente, a metade da preferência pela prática em relação à CORRIDA $(E M=100)$. Com emparelhamentos de comprimentos de linhas a CORRIDA (EMCL= 30) possui, aproximadamente, duas vezes mais a preferência em relação ao esporte JUDÔ $(E M=13,24)$ e o esporte VOLEIBOL $(\mathrm{EM}=62,98)$ que, por sua vez, possue três vezes mais preferência em comparação à atividade física de DANÇAR uma valsa $(\mathrm{EM}=20,3)$. Com o resultado desse escalonamento de razão quaisquer outras razões entre os valores escalares podem ser obtidas entre a preferência pela prática de diferentes atividades físicas ou esportivas.

Na Figura 22, as médias geométricas das estimativas numéricas são projetadas em coordenadas logarítmicas em função das correspondentes médias geométricas dos emparelhamentos de comprimentos de linhas para cada atividade física ou esportiva. Uma linha reta com uma inclinação (expoente da função potência) de 0,71 foi obtida. Todavia, 
como o observador tende a restringir a amplitude de seus ajustamentos em função da variável que ele controla, na Figura 23, essas médias foram projetadas em coordenadas invertidas, isto é, houve emparelhamento de comprimento de linhas em função das correspondentes estimativas numéricas para cada atividade física ou esportiva. Uma linha reta com uma inclinação (expoente da função potência) de 0,81 foi obtida.

Tabela 11 - Expoente (n), constante escalar (k) e coeficiente de determinação $\left(r^{2}\right)$ das funções de potência individuais ajustadas para as duas diferentes combinações entre as modalidades de respostas: numérica (EM) e comprimento de linhas (CL)

\begin{tabular}{ccccccc}
\hline & \multicolumn{3}{c}{ EM $\mathbf{x}$ CL } & \multicolumn{3}{c}{ CL $\mathbf{~ E M}$} \\
SUJEITO & $\mathrm{n}$ & $\mathrm{k}$ & $\mathrm{r} 2$ & $\mathrm{n}$ & $\mathrm{k}$ & $\mathrm{r} 2$ \\
\hline 1-Masculino & 0,42 & 0,78 & 0,59 & 1,37 & 0,29 & 0,59 \\
2-Masculino & 0,67 & 0,16 & 0,53 & 0,80 & 0,63 & 0,53 \\
3-Masculino & 0,58 & 0,54 & 0,35 & 0,61 & 0,51 & 0,35 \\
4-Masculino & 0,96 & 0,41 & 0,71 & 0,73 & 0,91 & 0,71 \\
5-Masculino & 0,66 & 0,06 & 0,69 & 1,04 & 0,61 & 0,69 \\
6-Masculino & 0,67 & 0,07 & 0,60 & 0,89 & 0,56 & 0,60 \\
7-Masculino & 0,89 & 0,40 & 0,48 & 0,54 & 1,12 & 0,48 \\
8-Masculino & 0,65 & 0,28 & 0,62 & 0,95 & 0,58 & 0,62 \\
9-Masculino & 0,52 & 0,48 & 0,63 & 1,21 & 0,11 & 0,63 \\
10-Masculino & 0,41 & 0,57 & 0,25 & 0,61 & 1,04 & 0,25 \\
11-Feminino & 0,61 & 0,41 & 0,57 & 0,93 & 0,54 & 0,57 \\
12-Feminino & 0,76 & 0,04 & 0,65 & 0,85 & 0,57 & 0,65 \\
13-Feminino & 0,59 & 0,18 & 0,67 & 1,13 & 0,36 & 0,67 \\
14-Feminino & 0,97 & 0,49 & 0,34 & 0,35 & 1,66 & 0,34 \\
15-Feminino & 1,81 & 2,24 & 0,59 & 0,33 & 1,64 & 0,59 \\
16-Feminino & 0,14 & 1,37 & 0,07 & 0,49 & 1,09 & 0,07 \\
17-Feminino & 0,92 & 0,12 & 0,93 & 1 & 0,71 & 0,93 \\
18-Feminino & 0,41 & 0,77 & 0,37 & 0,88 & 0,48 & 0,37 \\
19-Feminino & 0,71 & 0,04 & 0,54 & 0,76 & 0,8 & 0,54 \\
20-Feminino & 0,86 & 0,27 & 0,78 & 0,90 & 0,61 & 0,78 \\
\hline Média & 0,71 & 0,48 & 0,55 & 0,81 & 0,70 & 0,54 \\
\hline Mediana & 0,66 & 0,40 & 0,59 & 0,86 & 0,59 & 0,59 \\
\hline DP & 0,33 & 0,52 & 0,20 & 0,27 & 0,43 & 0,19 \\
\hline
\end{tabular}




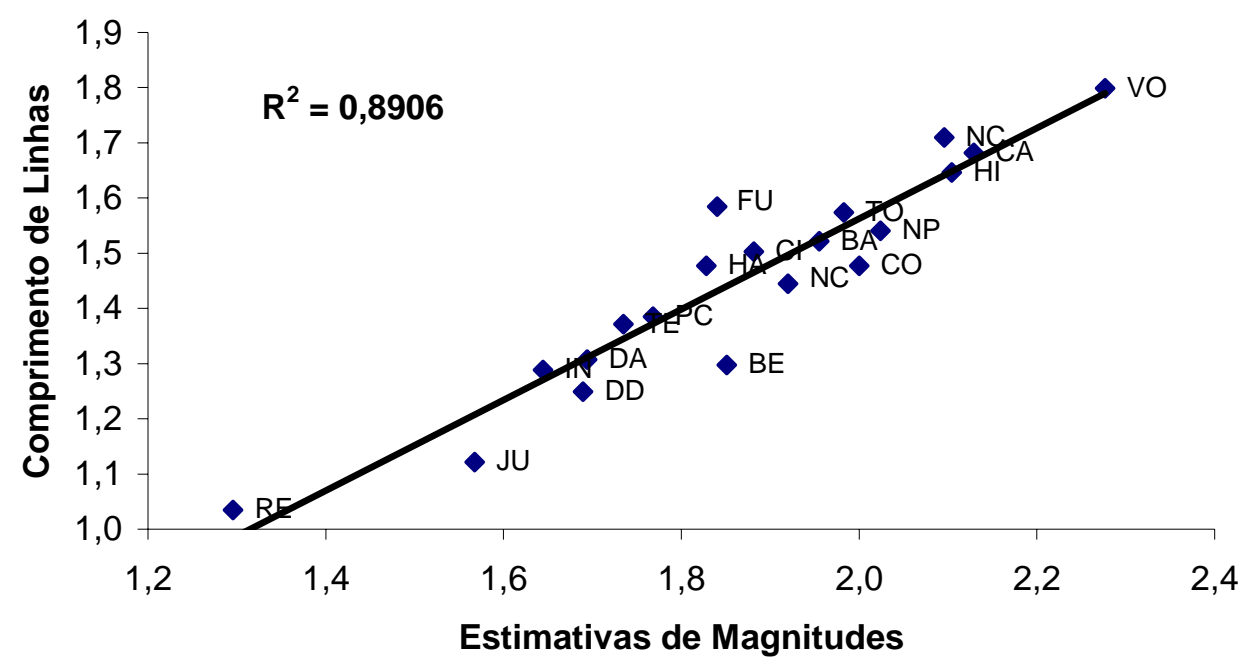

Figura 22 - Relação entre os logaritmos das médias geométricas das estimativas de magnitudes e os logaritmos das médias geométricas dos emparelhamentos de comprimentos de linhas, da preferência pela prática de atividades físicas e esportivas. Dados do Experimento 2 B

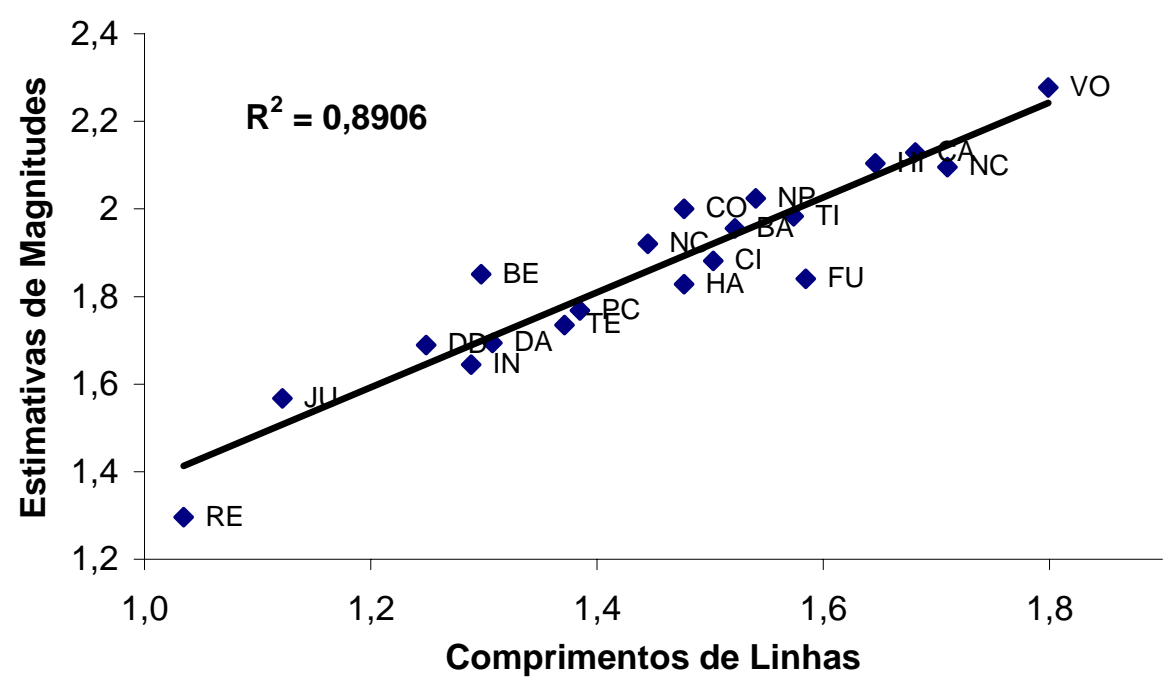

Figura 23 - Relação entre os logaritmos das médias geométricas dos emparelhamentos de comprimentos de linhas e os logaritmos das médias geométricas das estimativas de magnitudes da preferência pela prática de atividades físicas e esportivas. Dados do Experimento $2 \mathrm{~B}$ 
Este "efeito de regressão" tem sido verificado em diferentes experimentos e foi analisado por Stevens e Greenbaum (1966) e Stevens (1975). Indow (1961) sugere que obtendo-se a média geométrica das duas inclinações pode-se constituir numa maneira apropriada de mediar o efeito de regressão. No presente caso, a média geométrica de 0,71 e 0,81 é 0,76. Nenhuma das inclinações, das Figuras 22 e 23 foram significativamente semelhantes ao valor que é geralmente predito de 1,0 (respectivamente, t (19) $=-3,87, \mathrm{p}=0,001$ e t (19) $=-2,96, p=0,007)$. Porém, estes valores não foram significativamente diferentes dos expoentes de 0,91 e 0,89, resultantes dos expoentes individuais obtidos no Experimento 2 A, Teste de Calibração 1 e 2 respectivamente (ver Tabela 12).

Tabela 12 - Resultados da análise estatística do Teste t de Student, entre os expoentes obtidos dos métodos de estimação de magnitudes e comprimento de linhas, a partir dos julgamentos de preferência pela prática de atividades físicas e esportivas. Comparados com os valores dos expoentes médios de 0,91 e 0,89 obtidos a partir do Teste de Calibração no Experimento 2 A

\begin{tabular}{lcccccccc}
\hline & Mean & Std.Dv. & $\mathrm{N}$ & Diff. & $\begin{array}{c}\text { Std.Dv. } \\
\text { Diff. }\end{array}$ & $\mathrm{t}$ & $\mathrm{df}$ & $\mathrm{P}$ \\
\hline EM vs. CL & $\mathbf{0 , 7 2}$ & $\mathbf{0 , 3 3}$ & & & & & & \\
VALOR DE & & & & & & & & \\
CALIBRAÇÃO - EM & $\mathbf{0 , 9 1}$ & $\mathbf{0 , 2 9 4 7}$ & 20 & $-0,0315$ & 0,8718 & $-1,4942$ & 19 & $\mathbf{0 , 0 6 3 2}$ \\
\hline CL vs. EM & $\mathbf{0 , 8 1}$ & $\mathbf{0 , 2 7}$ & & & & & & \\
VALOR DE & & & & & & & & \\
CALIBRAÇÃO - PM & $\mathbf{0 , 8 9}$ & $\mathbf{0 , 1 2}$ & 20 & $-0,0715$ & 0,2738 & 0,1676 & 19 & $\mathbf{0 , 2 5 7}$ \\
\hline
\end{tabular}

A partir deste momento serão apresentadas as Figuras 24 e 25 contendo o desviopadrão da média aritmética em função das estimativas de magnitudes numéricas e dos comprimentos de linhas das diferentes atividades físicas e esportivas. Tal como ocorreu no Experimento 1, o desvio-padrão da média aritmética está diretamente relacionado ao aumento das estimativas ou emparelhamentos; indicando, portanto, que a variabilidade das estimativas 
numéricas e dos emparelhamentos de comprimentos de linhas aumentam em função das estimativas das duas modalidades.

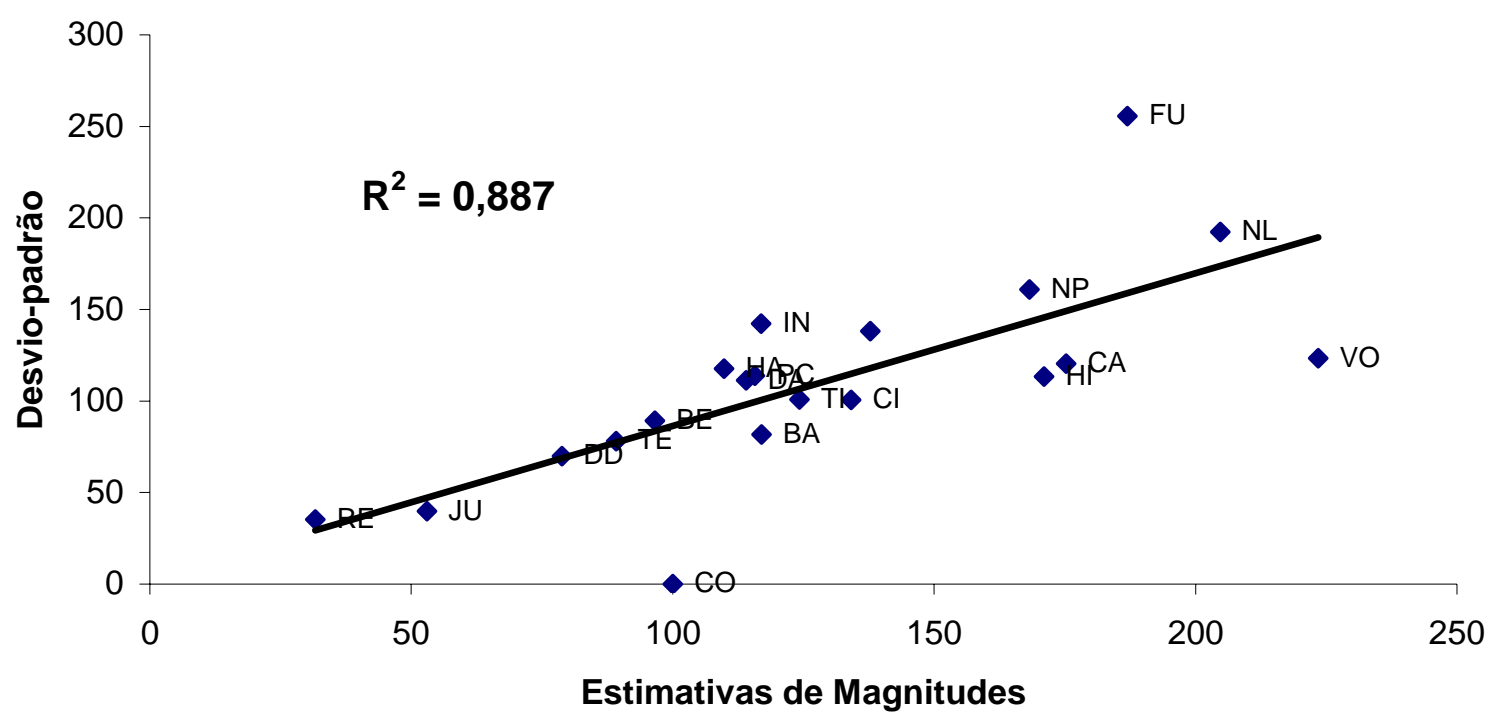

Figura 24 - Desvio-padrão da média aritmética em função da média aritmética das estimativas de magnitudes da preferência pela prática de atividades físicas e esportivas. Dados do Experimento $2 \mathrm{~B}$

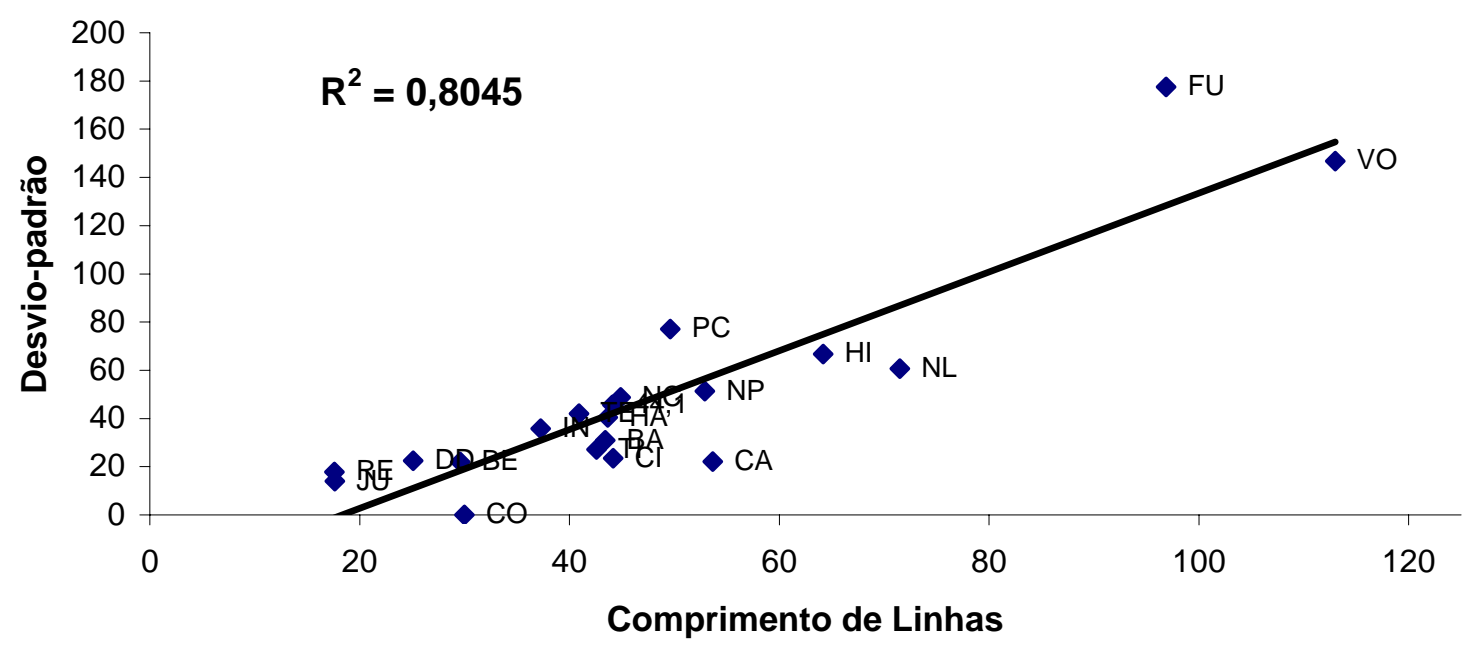

Figura 25 - Desvio-padrão da média aritmética em função da média aritmética dos emparelhamentos de comprimentos de linhas da preferência pela prática de atividades físicas e esportivas. Dados do Experimento $2 \mathrm{~B}$ 
As médias geométricas das estimativas numéricas e dos emparelhamentos de comprimentos de linhas, bem como as ordenações das posições de cada uma das diferentes atividades físicas e esportivas serão também demonstradas a seguir, entretanto, esta apresentação será dividida quanto ao aproveitamento entre homens e mulheres. Estes resultados encontram-se nas Tabelas 13 e 14.

Tabela 13 - Média geométrica das estimativas de magnitudes (EM), média geométrica dos emparelhamentos de comprimentos de linhas (EMCL) e ordenação das posições da preferência pela prática de atividades físicas ou esportivas dos sujeitos do sexo masculino

\begin{tabular}{lrrrr}
\hline ATIVIDADE & \multicolumn{1}{c}{ EM } & OP & EMCL & OP \\
\hline Corrida (CO) & 100,00 & 7 & 30,00 & 9 \\
Bicicleta Ergométrica (BE) & 53,46 & 13 & 16,75 & 14 \\
Remo Estacionário (RE) & 21,78 & 19 & 13,65 & 17 \\
Hidroginástica (HI) & 91,32 & 10 & 26,56 & 11 \\
Dança - Valsa (DA) & 26,54 & 18 & 9,34 & 19 \\
Ciclismo (CI) & 129,70 & 5 & 44,94 & 4 \\
Basquetebol (BA) & 99,24 & 8 & 32,43 & 8 \\
Handebol (HA) & 71,98 & 11 & 28,80 & 10 \\
Judô (JU) & 42,61 & 15 & 15,82 & 15 \\
Pular corda (PC) & 28,32 & 17 & 13,20 & 18 \\
Voleibol (VO) & 154,54 & 2 & 47,05 & 2 \\
Tênis Simples (TE) & 45,96 & 14 & 13,72 & 16 \\
Caminhada (CA) & 106,61 & 6 & 42,14 & 6 \\
Natação - nado de costas (NC) & 71,66 & 12 & 23,94 & 12 \\
Natação - nado de peito (NP) & 99,17 & 9 & 32,50 & 7 \\
Natação - nado estilo livre (NL) & 141,32 & 4 & 46,87 & 3 \\
Tocar um Instrumento (TI) & 147,60 & 3 & 44,09 & 5 \\
Dardos (DD) & 37,47 & 16 & 16,76 & 13 \\
Futebol (FU) & $\mathbf{1 9 5 , 1 4}$ & $\mathbf{1}$ & $\mathbf{8 8 , 0 9}$ & $\mathbf{1}$ \\
Inatividade (IN) & $\mathbf{1 2 , 5 5}$ & $\mathbf{2 0}$ & $\mathbf{7 , 3 3}$ & $\mathbf{2 0}$ \\
\hline
\end{tabular}


Tabela 14 - Média geométrica das estimativas de magnitudes (EM), média geométrica dos emparelhamentos de comprimentos de linhas (EMCL) e a ordenação das posições da preferência pela prática de atividades físicas ou esportivas dos sujeitos do sexo feminino

\begin{tabular}{lrrrr}
\hline ATIVIDADE & EM & OP & EMCL & OP \\
\hline Corrida (CO) & 100,00 & 8 & 30,00 & 14 \\
Bicicleta Ergométrica (BE) & 94,29 & 10 & 23,49 & 15 \\
Remo Estacionário (RE) & $\mathbf{1 7 , 9 3}$ & $\mathbf{2 0}$ & $\mathbf{8 , 5 9}$ & $\mathbf{2 0}$ \\
Hidroginástica (HI) & 176,93 & 2 & 73,84 & 2 \\
Dança - Valsa (DA) & 92,14 & 11 & 44,13 & 7 \\
Ciclismo (CI) & 44,73 & 17 & 22,55 & 16 \\
Basquetebol (BA) & 81,96 & 12 & 34,11 & 10 \\
Handebol (HA) & 62,92 & 15 & 31,22 & 13 \\
Judô (JU) & 32,05 & 18 & 11,08 & 19 \\
Pular Corda (PC) & 121,36 & 5 & 44,63 & 6 \\
Voleibol (VO) & $\mathbf{2 3 1 , 5 7}$ & $\mathbf{1}$ & $\mathbf{8 4 , 3 1}$ & $\mathbf{1}$ \\
Tênis Simples (TE) & 64,23 & 13 & 40,33 & 8 \\
Caminhada (CA) & 169,97 & 3 & 54,74 & 4 \\
Natação - nado de costas (NC) & 96,52 & 9 & 32,41 & 11 \\
Natação - nado de peito (NP) & 112,68 & 6 & 37,06 & 9 \\
Natação - nado estilo livre (NL) & 110,04 & 7 & 56,06 & 3 \\
Tocar um Instrumento (TI) & 62,64 & 16 & 31,87 & 12 \\
Dardos (DD) & 63,77 & 14 & 18,78 & 17 \\
Futebol (FU) & 24,56 & 19 & 16,76 & 18 \\
Inatividade (IN) & 154,74 & 4 & 51,57 & 5 \\
\hline
\end{tabular}

Pode-se constatar que as ordenações das posições de preferência pela prática de atividade física ou esportiva, apontaram uma alta similaridade entre os dois métodos (estimação de magnitudes e comprimento de linhas) feitos tanto pelos homens como pelas mulheres, por outro lado, houve uma fraca correlação entre homens e mulheres, nas ordenações das posições da preferência pela prática de atividades físicas ou esportivas, indicando claramente que a preferência não é semelhante na comparação dos julgamentos 
entre homens e mulheres. De fato, o coeficiente de correlação de ordem de Spearman (rho) constatou que na comparação entre os dois métodos, tanto os homens $(0,97-p<0,001)$ como as mulheres $(0,87-\mathrm{p}<0,001)$ apresentaram altas correlações. Porém, quando comparadas às ordenações dos julgamentos de homens e mulheres nos métodos de estimação de magnitudes as correlações foram pequenas ou quase nulas (ver Tabela 15) entre as estimativas numéricas e os emparelhamentos de comprimentos de linhas.

Tabela 15 - Resultado do teste de correlação de Spearman (rho), indicando a baixa correlação entre os julgamentos de homens e mulheres na preferência pela prática de atividades físicas ou esportivas. Dados do Experimento $2 \mathrm{~B}$

\begin{tabular}{clc}
\hline Comparações & N & Sperman (rho) \\
\hline Homem_EM x Mulher_EM & 20 & 0,06 \\
Homem_EM x Mulher_CL & 20 & 0,13 \\
Homem_CL x Mulher_EM & 20 & 0,01 \\
Homem_CL x Mulher CL & 20 & 0,07 \\
\hline
\end{tabular}

Este padrão resultante indica que as ordenações dos graus de preferência, pela prática de atividades físicas ou esportivas, são independentes do tipo de modalidade ou contínuo de resposta empregado. No caso dos sujeitos masculinos, por exemplo, a atividade esportiva de FUTEBOL ocupa a primeira posição nos dois tipos de contínuos de repostas e a INATIVIDADE (permanecendo inerte, vendo um filme, assistindo à TV, lendo um livro) ocupa a última posição na preferência pela prática. Também, no caso das mulheres, independente do método utilizado, o esporte coletivo de VOLEIBOL foi apontado como o de maior preferência pela sua prática e a atividade física de REMO ESTACIONÁRIO a de menor preferência. Deste modo, tal como mencionado no Experimento anterior, com estas duas modalidades de respostas, se confirma que a preferência pela prática de atividades físicas e esportivas é tantas vezes maior ou menor que outra. No caso dos homens com estimativas 
numéricas a preferência pela prática do FUTEBOL $(E M=195,14)$ é aproximadamente duas vezes maior do que a preferência pela prática da CORRIDA $(E M=100)$. Já, a prática de pedalar uma BICICLETA ERGOMÉTRICA (EM = 53,46), possui, aproximadamente, a metade da preferência em relação à prática da CORRIDA $(\mathrm{EM}=100)$. Com emparelhamentos de comprimentos de linhas, o FUTEBOL $(\mathrm{CL}=88,09)$ possui, cerca de três vezes mais a preferência do que a CORRIDA $(C L=30)$ e o esporte JUDÔ $(C L=15,82)$ possui a metade da preferência em comparação à CORRIDA. No caso do julgamento das mulheres, a modalidade de VOLEIBOL $(E M=231,57)$ possui cerca de duas vezes e meia maior preferência do que a CORRIDA $(\mathrm{EM}=100)$, que por sua vez é quatro vezes apontada como tendo mais preferência do que o FUTEBOL $(\mathrm{EM}=24,56)$. Com o emparelhamento de comprimento de linhas, no caso das mulheres, a modalidade de HIDROGINÁSTICA (CL = 73,84) foi apontada como tendo duas vezes e meia a preferência em comparação à CORRIDA $(C L=30)$, que por sua vez foi apontada como tendo duas vezes mais a preferência das mulheres do que a atividade de arremesso de DARDOS na parede (CL $=18,78)$. Com o resultado desse escalonamento de razão quaisquer outras razões entre os valores escalares podem ser obtidas entre a preferência pela prática de diferentes atividades físicas ou esportivas.

Nas Figuras 26 e 27 as médias geométricas das estimativas numéricas são projetadas em coordenadas logarítmicas em função das correspondentes médias geométricas dos emparelhamentos de comprimentos de linhas para cada atividade física ou esportiva tanto dos homens como das mulheres. 


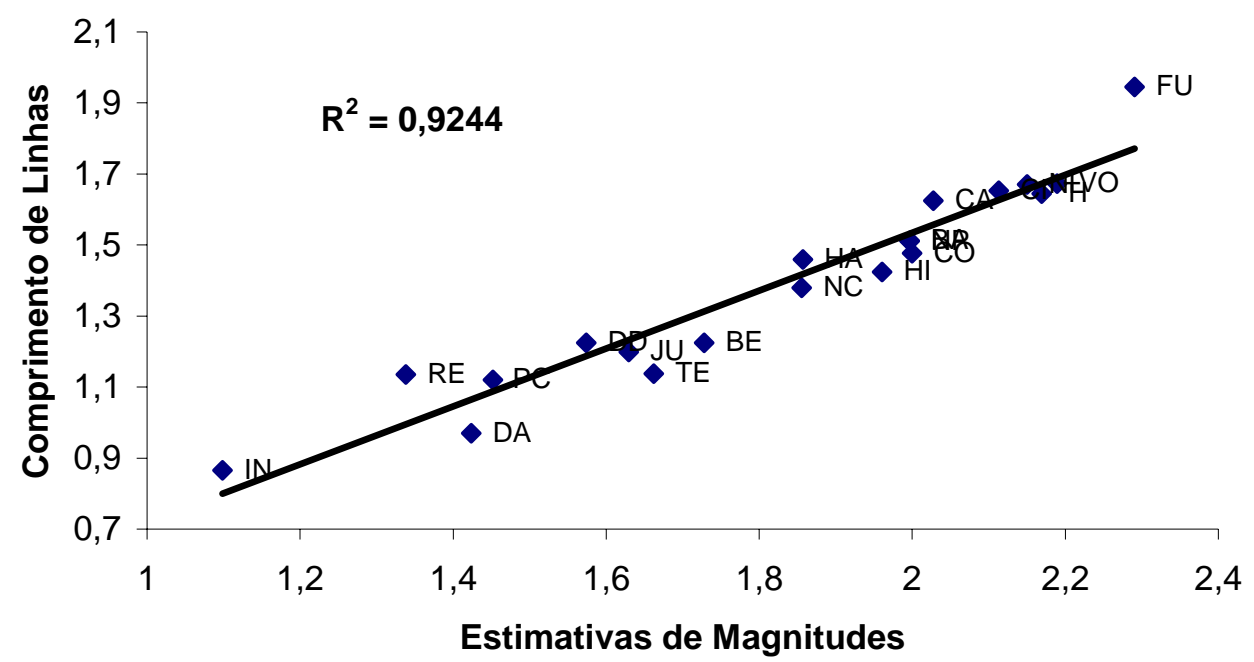

Figura 26 - Relação entre os logaritmos das médias geométricas das estimativas de magnitudes e os logaritmos das médias geométricas dos emparelhamentos de comprimentos de linhas, da preferência pela prática de atividades físicas e esportivas, dos sujeitos do sexo masculino. Dados do Experimento 2 B

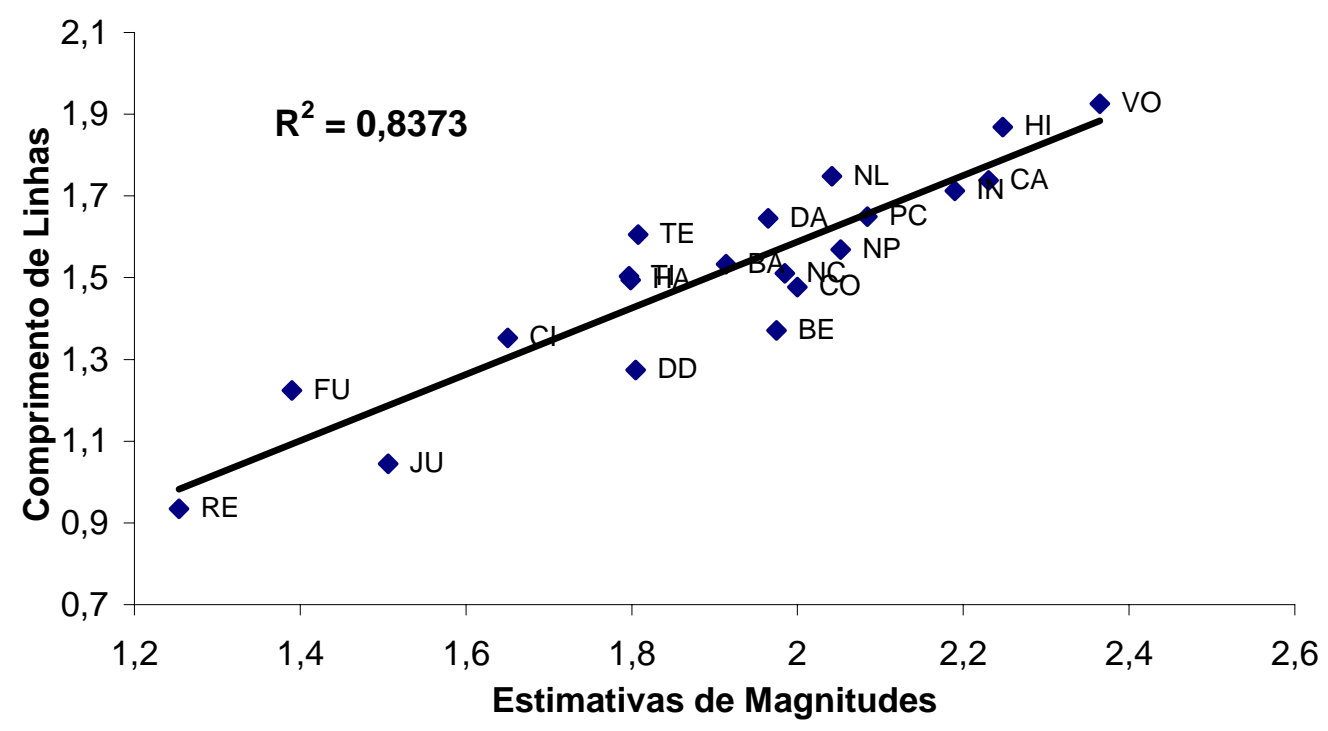

Figura 27 - Relação entre os logaritmos das médias geométricas das estimativas de magnitudes e os logaritmos das médias geométricas dos emparelhamentos de comprimentos de linhas, da preferência pela prática de atividades físicas e esportivas, dos sujeitos do sexo feminino. Dados do Experimento $2 \mathrm{~B}$ 
Uma linha reta com uma inclinação (expoente da função potência) de 0,64 foi obtida pelos homens e 0,78 para as mulheres. Todavia, como o observador tende a restringir a amplitude de seus ajustamentos em função da variável que ele controla, foi também projetado nas Figuras 28 e 29, abaixo, tanto para homens como para mulheres, essas médias em coordenadas invertidas, isto é, o emparelhamento de comprimento de linhas em função das correspondentes estimativas numéricas para cada atividade física ou esportiva. Uma linha reta com uma inclinação (expoente da função potência) de 0,87 e 0,76 foi obtida tanto para homens como para mulheres, respectivamente (ver Figuras 28 e 29).

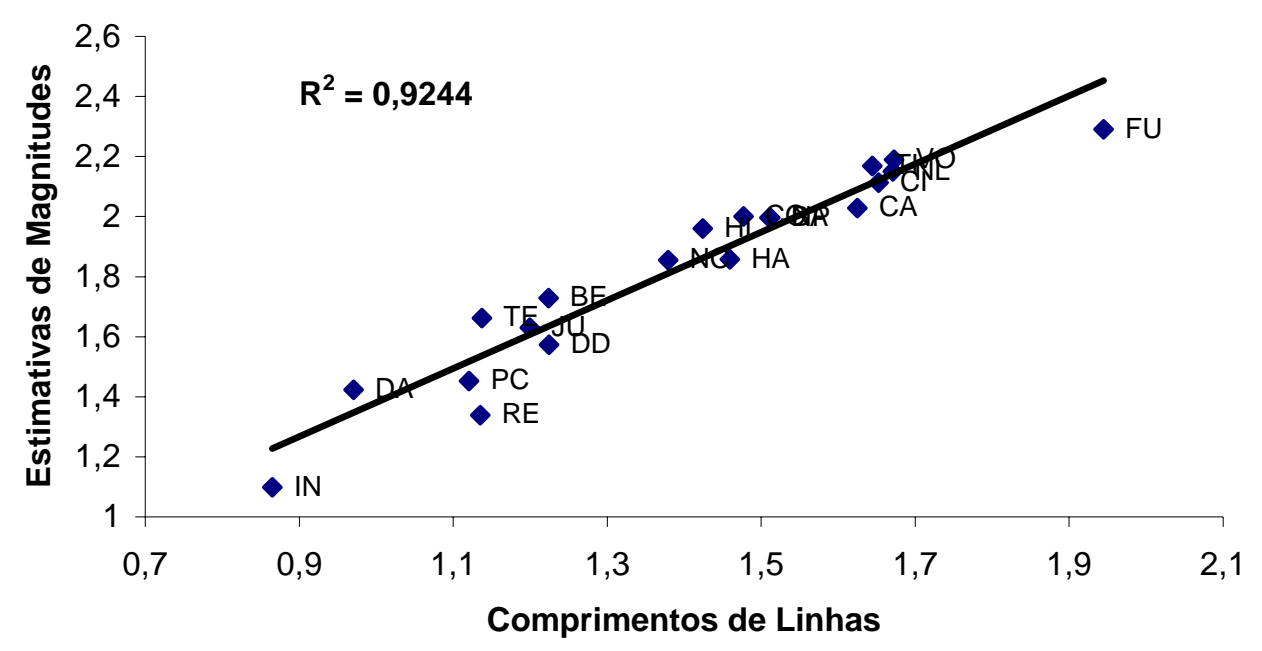

Figura 28 - Relação entre os logaritmos das médias geométricas dos emparelhamentos de comprimentos de linhas e os logaritmos das médias geométricas das estimativas de magnitudes da preferência pela prática de atividades físicas e esportivas, dos sujeitos do sexo masculino. Dados do Experimento 2 B 


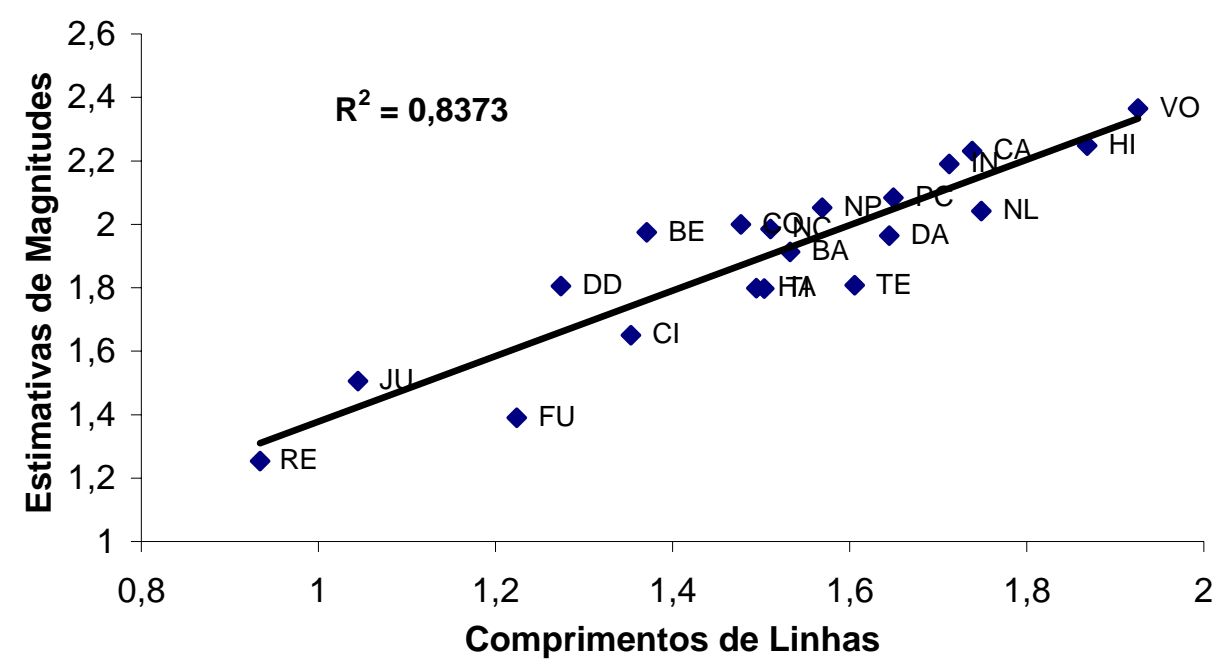

Figura 29 - Relação entre os logaritmos das médias geométricas dos emparelhamentos de comprimentos de linhas e os logaritmos das médias geométricas das estimativas de magnitudes da preferência pela prática de atividades físicas e esportivas, dos sujeitos do sexo feminino. Dados do Experimento 2 B

Tabela 16 - Expoente (n), constante escalar (k) e coeficiente de determinação $\left(r^{2}\right)$ das funções de potência individuais ajustadas para as duas diferentes combinações entre as modalidades de respostas: numérica (EM) e comprimento de linhas (CL), sujeitos do sexo masculino e feminino em resultados distintos

\begin{tabular}{ccccccc}
\hline & \multicolumn{3}{c}{ EM x CL } & \multicolumn{3}{c}{ CL x EM } \\
SUJEITO & $\mathrm{n}$ & $\mathrm{k}$ & $\mathrm{r}^{2}$ & $\mathrm{~N}$ & $\mathrm{k}$ & $\mathrm{r}^{2}$ \\
\hline 1-Masculino & 0,42 & 0,78 & 0,59 & 1,37 & 0,29 & 0,59 \\
2-Masculino & 0,67 & 0,16 & 0,53 & 0,80 & 0,63 & 0,53 \\
3-Masculino & 0,58 & 0,54 & 0,35 & 0,61 & 0,51 & 0,35 \\
4-Masculino & 0,96 & 0,41 & 0,71 & 0,73 & 0,91 & 0,71 \\
5-Masculino & 0,66 & 0,06 & 0,69 & 1,04 & 0,61 & 0,69 \\
6-Masculino & 0,67 & 0,07 & 0,60 & 0,89 & 0,56 & 0,60 \\
7-Masculino & 0,89 & 0,4 & 0,48 & 0,54 & 1,12 & 0,48 \\
8-Masculino & 0,65 & 0,28 & 0,62 & 0,95 & 0,58 & 0,62 \\
9-Masculino & 0,52 & 0,48 & 0,63 & 1,21 & 0,11 & 0,63 \\
10-Masculino & 0,41 & 0,57 & 0,25 & 0,61 & 1,04 & 0,25 \\
\hline Média & 0,64 & 0,38 & 0,55 & 0,87 & 0,63 & 0,54 \\
\hline Mediana & 0,65 & 0,40 & 0,59 & 0,84 & 0,59 & 0,59 \\
\hline DP & 0,18 & 0,23 & 0,15 & 0,27 & 0,31 & 0,14 \\
\hline
\end{tabular}


(conclusão)

\begin{tabular}{ccccccc}
\hline & \multicolumn{3}{c}{ EM x CL } & \multicolumn{3}{c}{ CL x EM } \\
SUJEITO & $\mathrm{n}$ & $\mathrm{k}$ & $\mathrm{r}^{2}$ & $\mathrm{n}$ & $\mathrm{K}$ & $\mathrm{r}^{2}$ \\
\hline 11-Feminino & 0,61 & 0,41 & 0,57 & 0,93 & 0,54 & 0,57 \\
12-Feminino & 0,76 & 0,04 & 0,65 & 0,85 & 0,57 & 0,65 \\
13-Feminino & 0,59 & 0,18 & 0,67 & 1,13 & 0,36 & 0,67 \\
14-Feminino & 0,97 & 0,49 & 0,34 & 0,35 & 1,66 & 0,34 \\
15-Feminino & 1,81 & 2,24 & 0,59 & 0,33 & 1,64 & 0,59 \\
16-Feminino & 0,14 & 1,37 & 0,07 & 0,49 & 1,09 & 0,07 \\
17-Feminino & 0,92 & 0,12 & 0,93 & 1 & 0 & 0,93 \\
18-Feminino & 0,41 & 0,77 & 0,37 & 0,88 & 0,48 & 0,37 \\
19-Feminino & 0,71 & 0,04 & 0,54 & 0,76 & 0,8 & 0,54 \\
20-Feminino & 0,86 & 0,27 & 0,78 & 0,9 & 0,61 & 0,78 \\
\hline Média & 0,78 & 0,59 & 0,55 & 0,76 & 0,77 & 0,55 \\
\hline Mediana & 0,73 & 0,34 & 0,58 & 0,86 & 0,59 & 0,58 \\
\hline DP & 0,44 & 0,71 & 0,24 & 0,27 & 0,53 & 0,24 \\
\hline
\end{tabular}

O “efeito de regressão” já verificado nos dados demonstrados anteriormente, foi visualizado na observação em separado de homens e mulheres. Como sugerido por Indow (1961), deve-se obter a média geométrica das duas inclinações para constituir uma maneira apropriada de mediar o efeito de regressão. No presente caso, a média geométrica de 0,64 e 0,87 é 0,74 , para os homens e, quanto às mulheres a média de 0,78 e 0,76 é 0,77 . Nenhuma dessas inclinações, conforme as Figuras 26, 27, 28 e 29, foram semelhantes significativamente ao valor predito de 1,0. Porém estes valores foram significativamente semelhantes ao expoente de $0,85(\mathrm{t}(09)=0,27, \mathrm{p}=0,69)$ e $0,83(\mathrm{t}(09)=0,52, \mathrm{p}=0,61)$ no caso dos homens, e 0,97 (t (09) $=-2,14, \mathrm{p}=0,60)$ e $0,95(\mathrm{t}(09)=-2,14, \mathrm{p}=0,60)$ no caso das mulheres, resultantes dos expoentes individuais obtidos no Experimento 2 A (ver Tabelas 6 e 8), em que os sujeitos estimaram magnitudes de diferentes comprimentos de linhas.

A partir deste momento, serão apresentadas as Figuras 30, 31, 32 e 33 contendo o desvio-padrão da média aritmética em função das estimativas de magnitudes numéricas e dos comprimentos de linhas das diferentes atividades físicas e esportivas, de homens e de 
mulheres. Tal como ocorreu no Experimento 1, o desvio-padrão da média aritmética está diretamente relacionado ao aumento das estimativas ou emparelhamentos que indicam, portanto, que a variabilidade das estimativas numéricas e dos emparelhamentos de comprimentos de linhas aumenta em função das estimativas das duas modalidades.

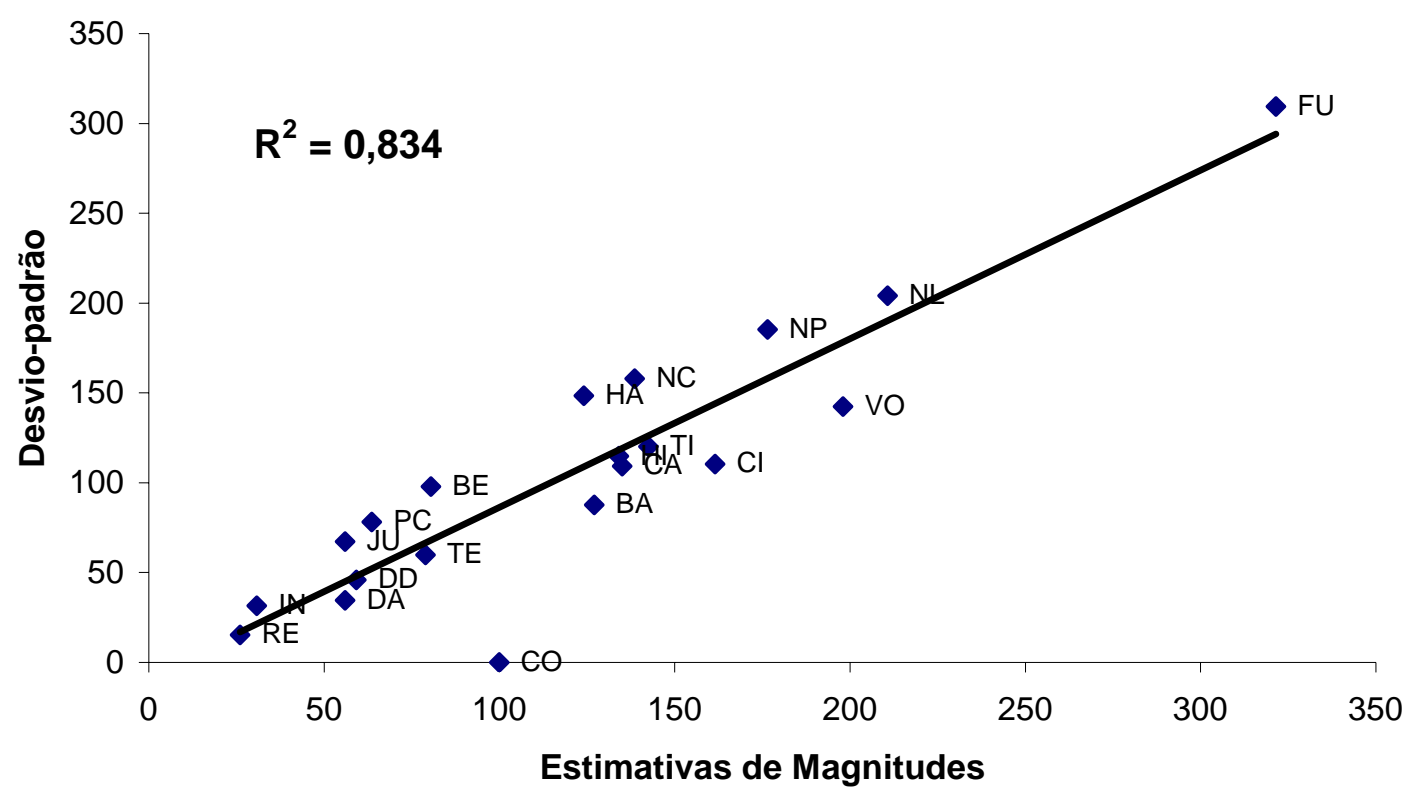

Figura 30 - Desvio-padrão da média aritmética em função da média aritmética das estimativas de magnitudes da preferência pela prática de atividades físicas e esportivas, dos sujeitos do sexo masculino. Dados do Experimento 2 B 


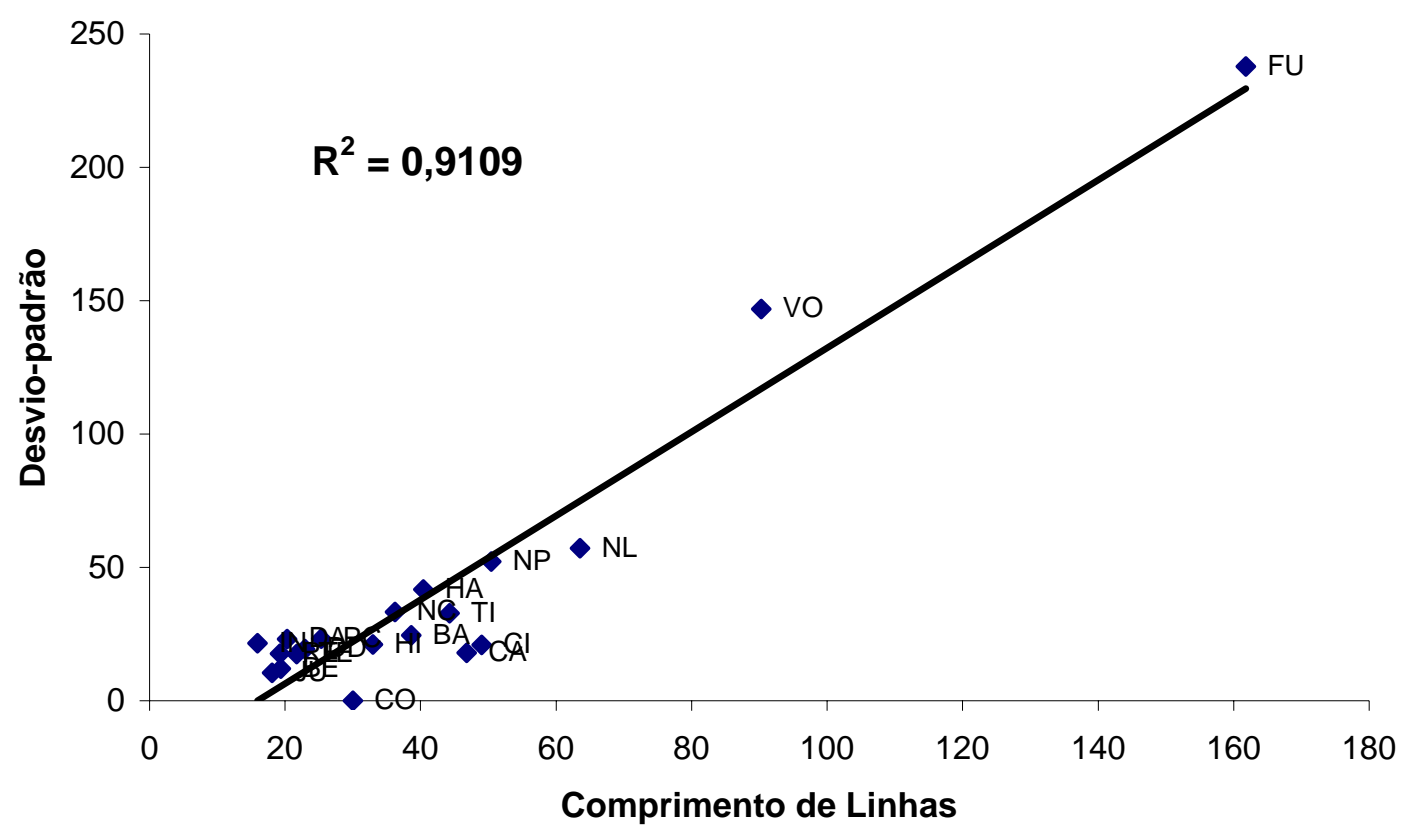

Figura 31 - Desvio-padrão da média aritmética em função da média aritmética dos emparelhamentos de comprimentos de linhas da preferência pela prática de atividades físicas e esportivas, dos sujeitos do sexo masculino. Dados do Experimento 2 B

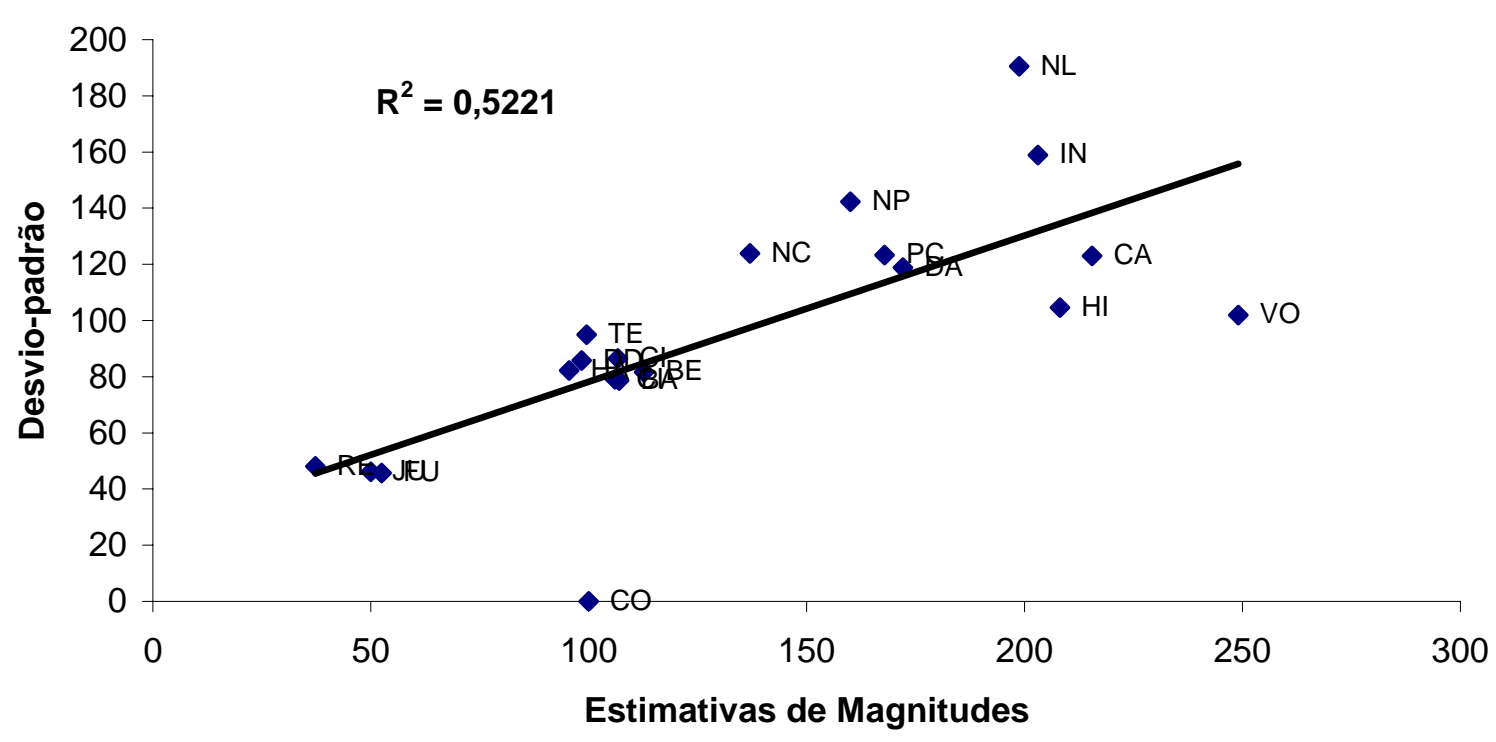

Figura 32 - Desvio-padrão da média aritmética em função da média aritmética das estimativas de magnitudes da preferência pela prática de atividades físicas e esportivas, dos sujeitos do sexo feminino. Dados do Experimento 2 B 


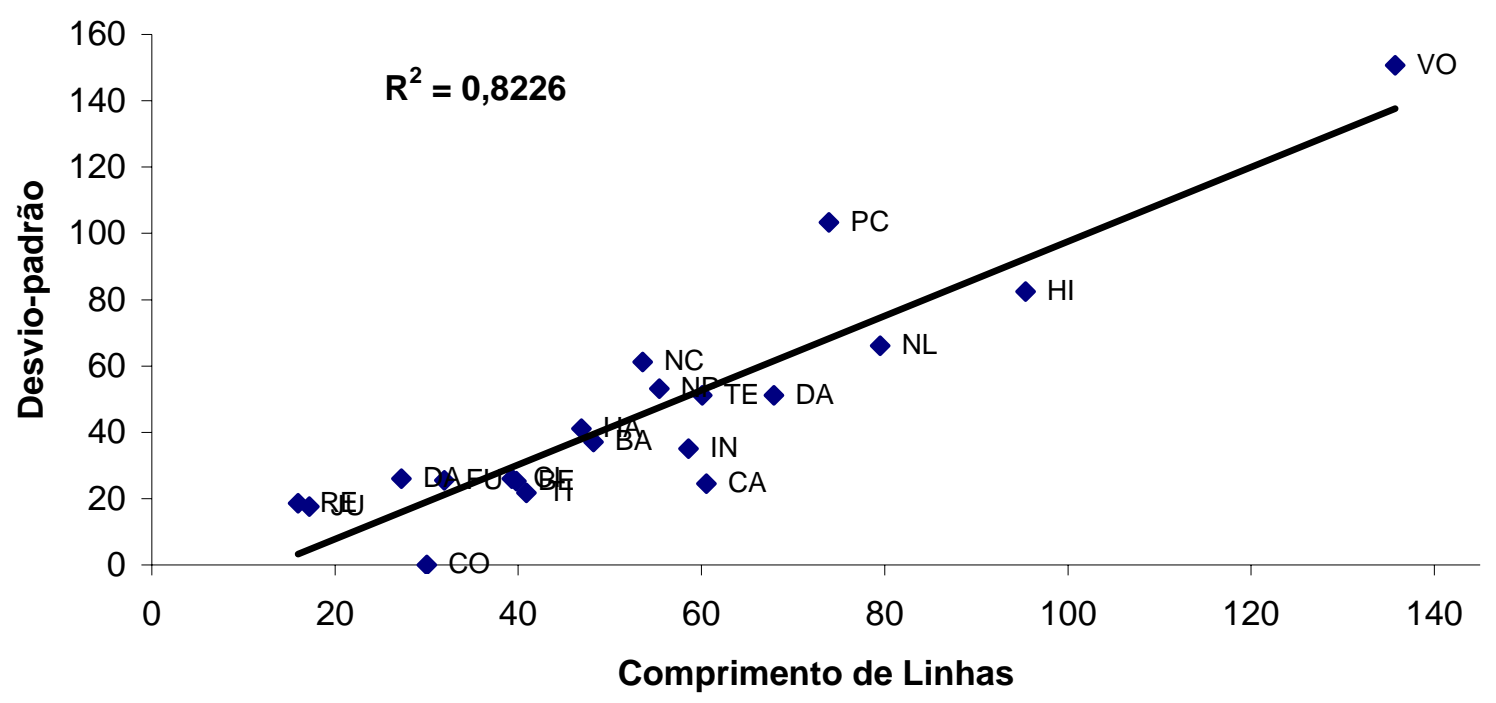

Figura 33 - Desvio-padrão da média aritmética em função da média aritmética dos emparelhamentos de comprimentos de linhas da preferência pela prática de atividades físicas e esportivas, dos sujeitos do sexo feminino. Dados do Experimento 2 B 


\section{EXPERIMENTO 3}

\subsection{Comparação entre os métodos psicofísicos escalares de estimação de magnitudes e estimação de comparação aos pares}

Os resultados do Experimento 1 mostraram, a partir da relação funcional entre as estimativas em categorias e as estimativas de magnitudes, que o contínuo social de preferência pela prática de atividades físicas e esportivas parece ter características protéticas ou aditivas. No entanto, a concavidade ascendente desta função não foi muito perceptível. Deste modo, este Experimento 3 teve como objetivo: a) verificar a generalidade destes resultados, comparando os valores escalares obtidos pelo método de estimação de magnitudes com os obtidos pelo método de estimação de comparação aos pares; b) verificar se as ordenações dos graus de preferência pela prática de atividades físicas ou esportivas derivados de ambos os métodos escalares são similares entre si; c) verificar a generalidade dos indícios dos princípios da Lei de Ekman; e d) demonstrar as diferenças entre gêneros dos graus de preferência pela prática de atividades físicas e esportivas.

\subsubsection{Método}

\subsubsection{Participantes}

Participaram do presente estudo 40 estudantes universitários, 20 do sexo masculino (média de 23 anos e 5 meses) e 20 do sexo feminino (24 anos e 2 meses) dos diferentes cursos de graduação e pós-graduação do Instituto Educacional de Assis - IEDA (Assis-SP) e das Faculdades Integradas de Bauru - FIB (Bauru-SP). Todos desconheciam $a$ 
priori os propósitos do experimento e nenhum tinha sido submetido aos experimentos anteriores.

\subsubsection{Material}

Foram elaborados dois blocos de papel contendo, na primeira página, instruções específicas para cada tipo de método psicofísico, e nas páginas seguintes uma lista das mesmas atividades físicas e esportivas do Experimento 1.

\subsubsection{Procedimentos}

Os métodos escalares utilizados foram o de estimação de magnitudes e o de estimação de comparação aos pares. O procedimento utilizado no primeiro método foi idêntico àquele descrito no Experimento 1 (conforme Apêndice A, p. 161).

No segundo método, a tarefa dos sujeitos foi comparar atividades físicas ou esportivas que foram sempre apresentadas aos pares e, em seguida marcar com um círculo aquela que possuía a maior preferência para o julgador. Em outras palavras, o participante deveria indicar entre as duas atividades físicas e esportivas aquela que possuía a maior preferência, mesmo que ele julgasse que duas atividades físicas e esportivas tivessem o mesmo grau de preferência, deveria decidir qual das duas seria preferencial para ele. Previamente, não foram indicadas aos participantes as atividades físicas e esportivas de preferência máxima ou mínima. As 20 diferentes atividades físicas e esportivas foram apresentadas em cinco páginas separadas, contendo duas tabelas que indicavam duas 
diferentes atividades físicas e esportivas, para serem comparadas aos pares, perfazendo um total de 86 pares nas quatro primeiras folhas e uma tabela única na quinta folha contendo 46 pares, somando um total de 380 pares para serem julgados. Deste modo, cada participante estabeleceu 380 comparações. A ordem de distribuição destas 20 atividades físicas e esportivas, na forma de comparação aos pares, foi totalmente aleatória e variou de participante para participante (Apêndice F, p.166).

Semelhante ao Experimento 1, as instruções fornecidas para os participantes, independente do método escalar utilizado, requeriam que os julgamentos fossem realizados em termos da preferência pela prática de atividades físicas e esportivas. Os mesmos 40 participantes executaram os dois métodos psicofísicos, sendo que metade dos participantes julgou primeiro pelo método de estimação de magnitudes e depois pelo método de estimação de comparação aos pares, e a outra metade julgou na ordem inversa. O Experimento foi realizado em uma sala, na qual permaneceram apenas o participante e o experimentador e fizeram os julgamentos individualmente.

\subsubsection{Resultados}

Na primeira coluna, da Tabela 17, localizam-se as médias geométricas das estimativas de magnitudes da preferência pela prática de atividades físicas e esportivas julgadas pelos 40 participantes. Na segunda coluna, estão dispostas as ordenações dos graus de preferência das atividades físicas e esportivas. Na terceira coluna, estão resumidas as proporções médias de indicações das atividades físicas e esportivas de maior preferência derivadas de uma matriz de 20 x 20 contendo os 380 julgamentos (pares de atividades físicas ou esportivas não idênticas) estabelecidos para cada um dos 40 participantes. Na quarta 
coluna, estão indicadas as ordenações dos graus de preferência destas atividades físicas e esportivas. Na quinta coluna, encontram-se apresentados os escores z médios derivados dos escores z respectivos de cada proporção da matriz de indicações das atividades físicas e esportivas de maior preferência (ver Apêndices G, J e M; páginas 167, 170 e 173). Estes escores representam as distâncias psicológicas entre uma atividade física ou esportiva e cada uma das outras (THURSTONE, 1927; BAIRD; NOMA, 1978; PASQUALI, 1999). A sexta coluna contém os valores escalares ajustados, após estabelecer à atividade física ou à esportiva de menor preferência o valor escalar médio é zero. Isto foi feito porque o método de comparação aos pares gera uma escala de intervalo na qual a adição de uma constante qualquer (no caso, + 0,68, valor referente ao escore z médio da atividade física e esportiva de menor prestígio) deixa a escala intacta. Na sétima coluna, encontram-se as ordenações dos graus de preferência destas atividades físicas e esportivas, baseadas nos valores escalares ajustados.

Tabela 17 - Média geométrica das estimativas de magnitudes de todos os sujeitos (EM-MGTODOS), proporções médias (PM), escores z médios (Z) e valores escalares ajustados (VA) derivados da matriz de julgamentos pelo método de comparação aos pares, com suas respectivas ordenações de posições OP, OP/PM e OP de preferência julgadas a cada atividade física e esportiva

\begin{tabular}{lcrrrrrr}
\hline & EM-MG-TODOS & OP & PM & OP/PM & Z & VA & OP \\
\hline Corrida (CO) & 100,00 & 11 & 0,59 & 8 & 0,26 & 0,94 & 8 \\
Bicicleta Ergométrica (BE) & 110,33 & 8 & 0,58 & 9 & 0,24 & 0,92 & 9 \\
Remo (RE) & 35,82 & 16 & 0,28 & 18 & $-0,68$ & $\mathbf{0}$ & $\mathbf{2 0}$ \\
Hidroginástica (HI) & $\mathbf{2 1 6 , 5 9}$ & $\mathbf{1}$ & $\mathbf{0 , 7 8}$ & $\mathbf{1}$ & 0,91 & $\mathbf{1 , 6 0}$ & $\mathbf{1}$ \\
Dança (DA) & 31,92 & 17 & 0,28 & 19 & $-0,56$ & 0,11 & 18 \\
Ciclismo (CI) & 138,70 & 6 & 0,64 & 6 & 0,44 & 1,14 & 5 \\
Basquetebol (BA) & 164,85 & 4 & 0,65 & 5 & 0,44 & 1,13 & 6 \\
Handebol (HA) & 106,47 & 10 & 0,52 & 12 & 0,06 & 0,75 & 12 \\
& & & & & & & (continua)
\end{tabular}


(conclusão)

\begin{tabular}{lcrrrrrr}
\hline & EM-MG-TODOS & OP & PM & OP/PM & Z & VA & OP \\
\hline Judô (JU) & 43,77 & 15 & 0,43 & 14 & $-0,16$ & 0,52 & 14 \\
Pular Corda (PC) & 54,52 & 14 & 0,42 & 15 & $-0,21$ & 0,46 & 15 \\
Voleibol (VO) & 190,95 & 2 & 0,69 & 3 & 0,54 & 1,22 & 3 \\
Tênis (TE) & 67,73 & 13 & 0,44 & 13 & $-0,14$ & 0,53 & 13 \\
Caminhada (CA) & 153,85 & 5 & 0,66 & 4 & 0,46 & 1,14 & 4 \\
Natação-Costas (NC) & 107,68 & 9 & 0,57 & 11 & 0,18 & 0,86 & 11 \\
Natação-Peito (NP) & 110,73 & 7 & 0,58 & 10 & 0,20 & 0,89 & 10 \\
Natação-Livre (NL) & 183,45 & 3 & 0,71 & 2 & 0,64 & 1,32 & 2 \\
Tocar Instrumento (TI) & 31,83 & 18 & 0,35 & 16 & $-0,41$ & 0,27 & 16 \\
Dardos (DD) & 14,59 & 19 & 0,32 & 17 & $-0,53$ & 0,14 & 17 \\
Futebol (FU) & 87,54 & 12 & 0,61 & 7 & 0,28 & 0,97 & 7 \\
Inatividade (IN) & $\mathbf{1 1 , 7 7}$ & $\mathbf{2 0}$ & $\mathbf{0 , 2 2}$ & $\mathbf{2 0}$ & $-0,62$ & 0,05 & 19 \\
\hline
\end{tabular}

Semelhante aos resultados obtidos no Experimento 1, esses apresentados na Tabela 17 também mostram uma alta concordância entre as ordenações derivadas de ambos os métodos e entre as duas alternativas de descrever os dados dos julgamentos de comparação aos pares. De fato, o coeficiente de concordância de Kendall (W), corrigido para empates, obtido a partir das ordenações das atividades físicas e esportivas resultantes das estimativas de magnitudes, proporções médias e valores escalares ajustados, foi igual a 0,953 ( $p<0,001$ ). Por exemplo, no método de estimação de magnitudes a INATIVIDADE foi considerada a de menor preferência, enquanto que a atividade física de HIDROGINÁSTICA, a de maior preferência. Levando-se em conta as proporções médias resultantes da matriz de julgamentos do método de comparação aos pares, as ordenações destas duas atividades físicas foram idênticas. Considerando-se os valores escalares ajustados derivados dos escores z médios, a atividade física de menor preferência foi a de REMO Estacionário, seguida pela INATIVIDADE, e a de maior preferência foi a de HIDROGINÁSTICA. Deste modo, os dois métodos e também as duas alternativas de ordenações de posições resultantes do método de comparação aos pares foram altamente concordantes entre si. No entanto, uma diferença fundamental persiste entre os resultados obtidos em ambos os métodos, isto é, no método de 
estimação de magnitudes podemos estabelecer as ordenações, as diferenças e principalmente as razões entre os graus de preferência das diferentes atividades físicas e esportivas. No método de comparação aos pares, semelhante ao método de estimação em categorias, podemos apenas estabelecer as ordenações e as diferenças entre os graus de preferência. Com este método nada podemos conhecer a respeito das razões entre os graus de preferência. Por exemplo, com os resultados dos dados apresentados na Tabela 17, referente às estimativas de magnitudes, podemos afirmar que a atividade de NATAÇÃO (livre) $(\mathrm{EM}=183,45)$ é aproximadamente dezesseis vezes maior que a INATIVIDADE $(E M=11,77)$; e que a preferência pelo BASQUETEBOL $(E M=190,95)$ é duas vezes maior que a preferência pela CORRIDA $(E M=100)$. Quaisquer outras razões e operações estatísticas são permissíveis com dados desta natureza.

Para verificar se o contínuo social de preferência pela prática de atividades físicas e esportivas apresenta características protéticas ou metatéticas, as proporções médias e os escores z médios ajustados foram projetados em função das médias geométricas das estimativas de magnitudes em coordenadas lineares e mono-logarítmicas. A Figura 34 mostra a relação entre as proporções médias e as médias geométricas das estimativas de magnitudes. 


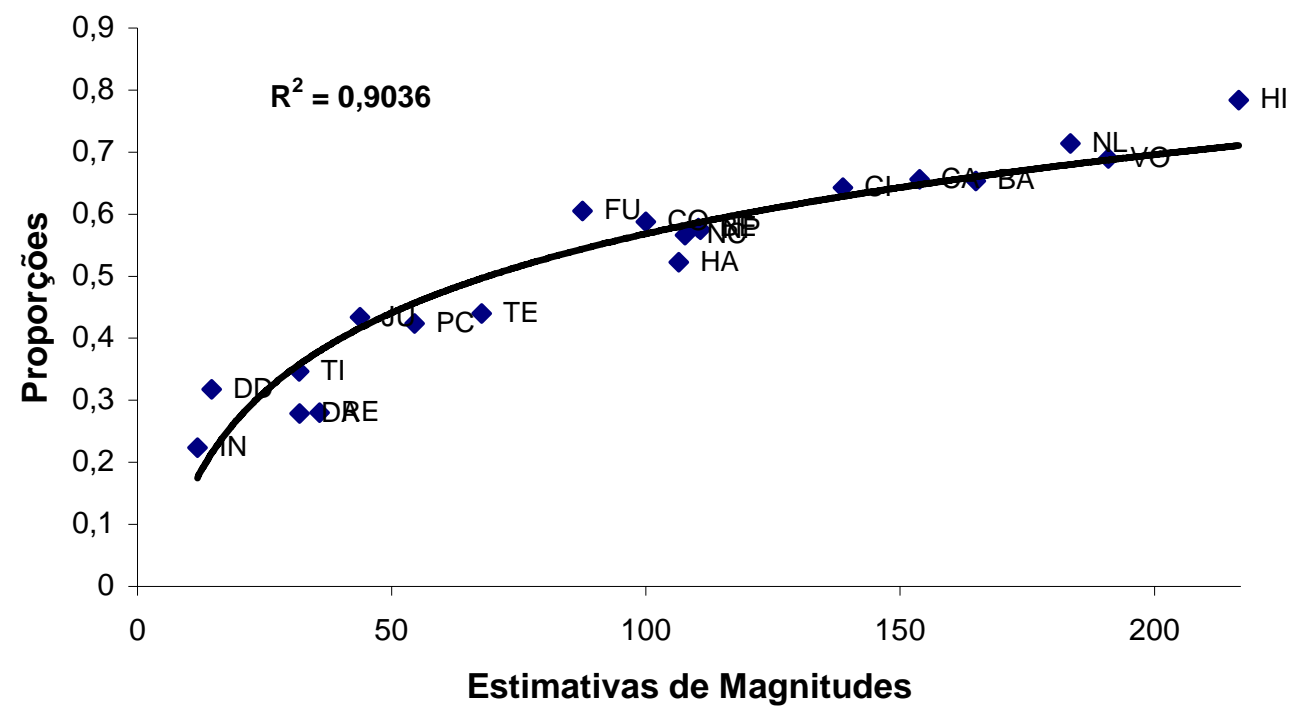

Figura 34 - Relação entre as proporções médias e as médias geométricas das estimativas de magnitudes da preferência pela prática de atividades físicas e esportivas em coordenadas lineares. Dados do Experimento 3

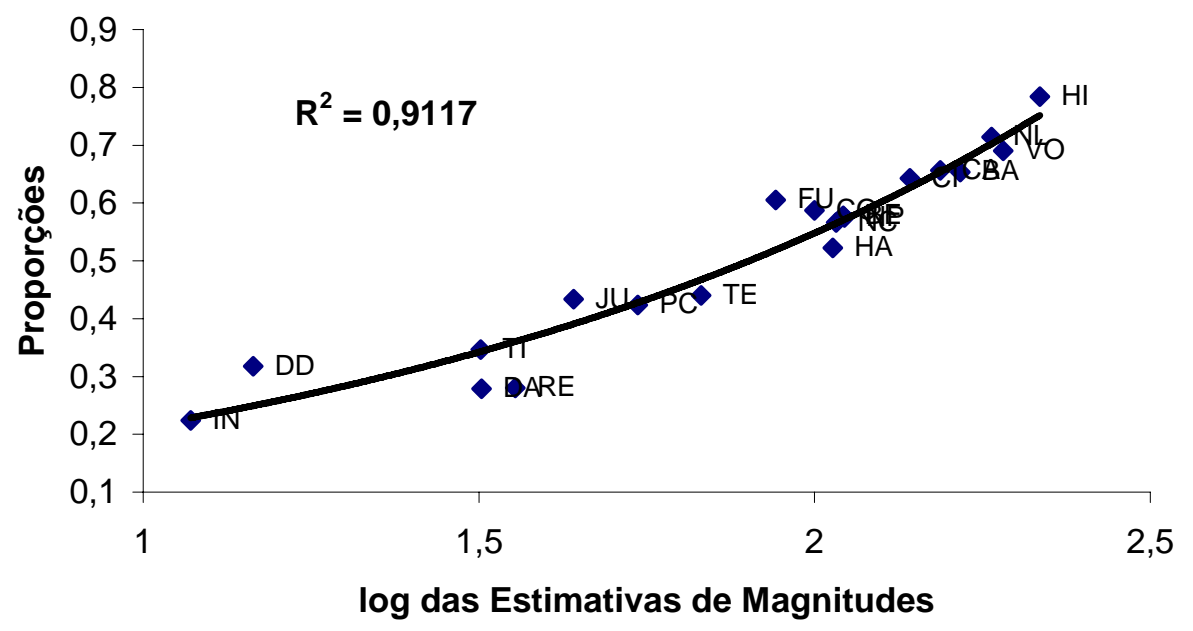

Figura 35 - Relação entre as proporções médias e os logaritmos das médias geométricas das estimativas de magnitudes da preferência pela prática de atividades físicas e esportivas. Dados do Experimento 3 


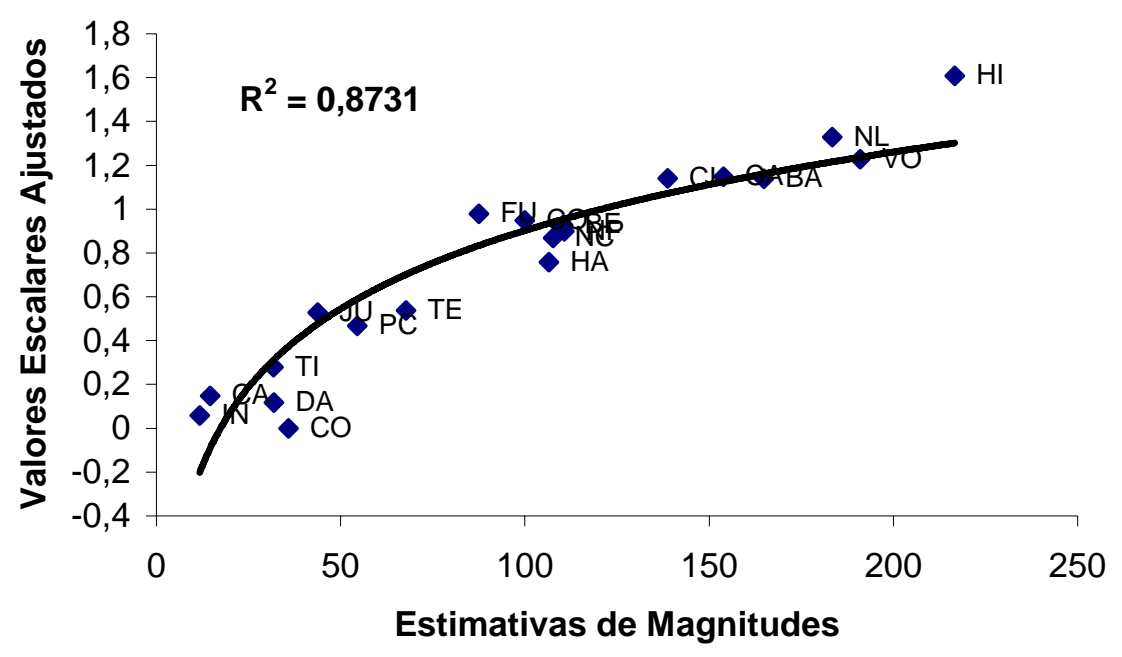

Figura 36 - Relação entre os valores escalares ajustados e as médias geométricas das estimativas de magnitudes da preferência pela prática de atividades físicas e esportivas em coordenadas lineares. Dados do Experimento 3

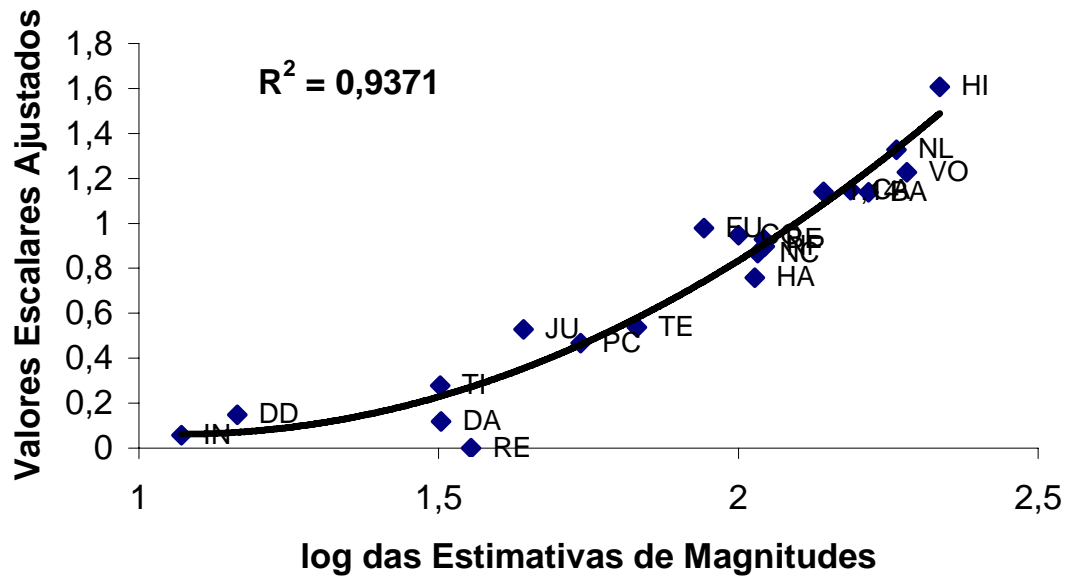

Figura 37 - Relação entre os valores escalares ajustados e os logaritmos das médias das estimativas de magnitudes da preferência pela prática de atividades físicas e esportivas. Dados do Experimento 3

O que se pode constatar é que a função mostra uma concavidade acentuadamente ascendente ou uma função quase-logarítmica. Quando estas mesmas proporções são projetadas em função dos logaritmos das estimativas de magnitudes (ver Figura 35) a relação mostra uma concavidade descendente. Do mesmo modo, quando os valores escalares 
ajustados, em notas z, são projetados em função das estimativas de magnitudes em coordenadas lineares, a relação mostra novamente uma concavidade acentuadamente ascendente ou uma função quase-logarítmica (ver Figura 36). Também, quando os valores escalares ajustados são projetados em função dos logaritmos das estimativas de magnitudes, a relação mostra uma concavidade descendente (ver Figura 37). Resumindo, os dados apresentados nestas figuras sustentam fortemente que a preferência pela prática de atividades físicas e esportivas é um contínuo protético ou aditivo.

Similarmente aos resultados obtidos no Experimento 1, a relação, representada na Figura 38, revela que o desvio-padrão da média aritmética aumenta em função das estimativas de magnitudes. Portanto, de modo semelhante ao Experimento 1, este padrão de resultado pode confirmar os indícios da Lei de Ekman, ou seja, a variabilidade das estimativas é uma função linear da magnitude das estimativas. O mesmo padrão de resultado, não é encontrado, quando é demonstrado o desvio-padrão da média aritmética das proporções médias, ou seja, quanto maior a proporção média tanto menor o desvio padrão da média aritmética (ver Figura, 39).

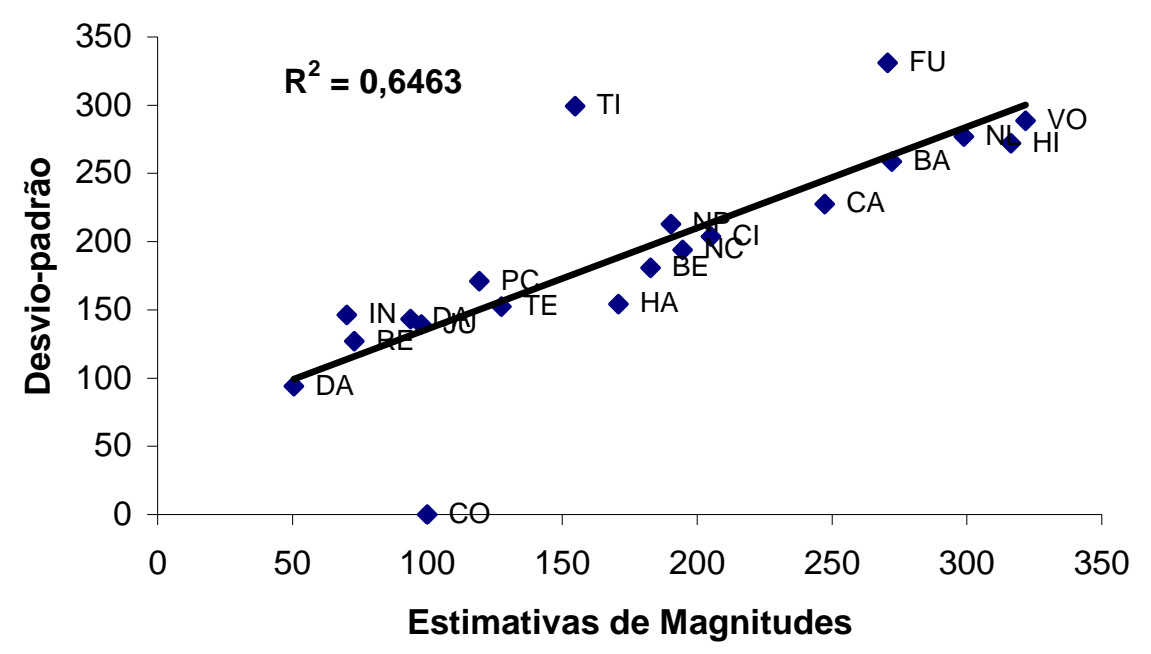

Figura 38 - Desvio-padrão da média aritmética em função das médias aritméticas das estimativas de magnitudes da preferência pela prática de atividades físicas e esportivas. Dados do Experimento 3 


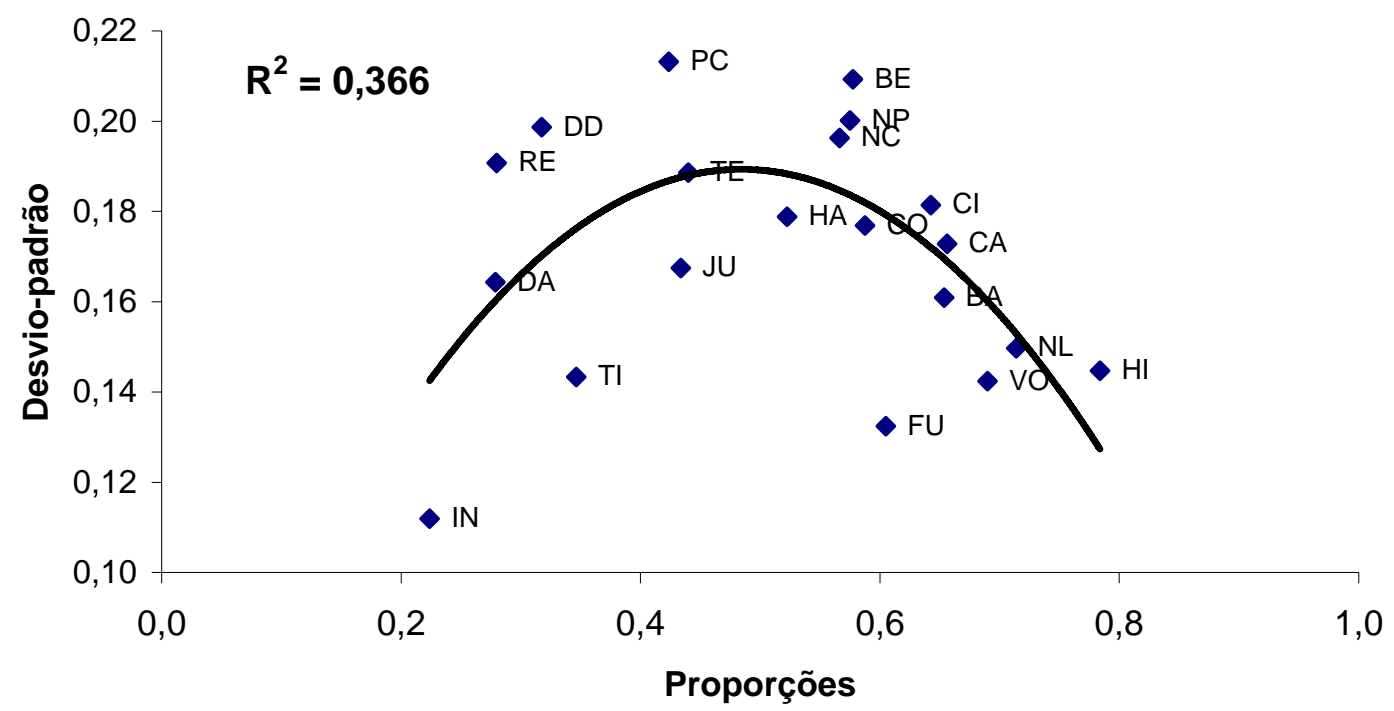

Figura 39 - Desvio-padrão da média aritmética em função das médias aritméticas das proporções médias da preferência pela prática de atividades físicas e esportivas. Dados do Experimento 3

As Tabelas 18 e 19, indicam os resultados do Experimento 3, dos julgamentos de estimação de magnitudes e estimação de comparação aos pares, de homens e mulheres respectivamente. 
Tabela 18 - Média geométrica das estimativas de magnitudes dos sujeitos do sexo masculino (EM-MG-MASC), proporções médias (PM), escores z médios (Z) e valores escalares ajustados (VA) derivados da matriz de julgamentos pelo método de comparação aos pares, com suas respectivas ordenações de posições OP, OP/PM e OP de preferência julgadas a cada atividade física e esportiva

\begin{tabular}{lrrrrrrr}
\hline & EM-MG-MASC. & OP & PM & OP/PM & Z & VA & OP \\
\hline Corrida (CO) & 100,00 & 8 & 0,63 & 7 & 0,40 & 1,45 & 7 \\
Bicicleta Ergométrica (BE) & 67,45 & 12 & 0,53 & 12 & 0,10 & 1,15 & 12 \\
Remo Estacionário (RE) & 26,31 & 17 & 0,31 & 17 & $-0,61$ & 0,46 & 17 \\
Hidroginástica (HI) & 161,42 & 4 & 0,76 & 3 & 0,84 & 1,90 & 3 \\
Dança (DA) & 16,42 & 18 & 0,22 & 19 & $-0,87$ & 0,19 & 19 \\
Ciclismo (CI) & 147,55 & 5 & 0,69 & 5 & 0,64 & 1,69 & 5 \\
Basquetebol (BA) & 162,21 & 3 & 0,71 & 4 & 0,65 & 1,71 & 4 \\
Handebol (HA) & 74,64 & 11 & 0,54 & 11 & 0,13 & 1,18 & 11 \\
Judô (JU) & 35,12 & 15 & 0,49 & 13 & $-0,01$ & 1,05 & 13 \\
Pular Corda (PC) & 35,29 & 14 & 0,39 & 15 & $-0,33$ & 0,74 & 16 \\
Voleibol (VO) & 120,95 & 6 & 0,64 & 6 & 0,41 & 1,46 & 6 \\
Tênis (TE) & 63,67 & 13 & 0,48 & 14 & $-0,05$ & 1,02 & 14 \\
Caminhada (CA) & 105,07 & 7 & 0,58 & 10 & 0,24 & 1,30 & 10 \\
Natação - Costas (NC) & 87,93 & 10 & 0,59 & 9 & 0,26 & 1,32 & 9 \\
Natação - Peito (NP) & 96,51 & 9 & 0,61 & 8 & 0,31 & 1,36 & 8 \\
Natação - (NL) & 193,42 & 2 & $\mathbf{0 , 8 0}$ & $\mathbf{1}$ & $\mathbf{0 , 9 8}$ & $\mathbf{2 , 0 3}$ & $\mathbf{1}$ \\
Tocar Instrumento (TI) & 29,09 & 16 & 0,39 & 16 & $-0,31$ & 0,76 & 15 \\
Dardos (DD) & 10,38 & 19 & 0,27 & 18 & $-0,74$ & 0,32 & 18 \\
Futebol (FU) & $\mathbf{3 2 5 , 7 0}$ & $\mathbf{1}$ & 0,78 & 2 & 0,87 & 1,92 & 2 \\
Inatividade (IN) & $\mathbf{7 , 1 1}$ & $\mathbf{2 0}$ & $\mathbf{0 , 1 5}$ & $\mathbf{2 0}$ & $\mathbf{- 1 , 0 7}$ & $\mathbf{0}$ & $\mathbf{2 0}$ \\
\hline
\end{tabular}


Tabela 19 - Média geométrica das estimativas de magnitudes dos sujeitos do sexo feminino (EM-MG-FEMIN), proporções médias (PM), escores $\mathrm{z}$ médios (Z) e valores escalares ajustados (VA) derivados da matriz de julgamentos pelo método de comparação aos pares, com suas respectivas ordenações de posições OP, OP/PM e OP de preferência julgadas a cada atividade física e esportiva

\begin{tabular}{|c|c|c|c|c|c|c|c|}
\hline & EM-MG-FEMIN. & $\mathbf{O P}$ & PM & OP/PM & $\mathbf{Z}$ & VA & $\mathbf{O P}$ \\
\hline Corrida (CO) & 100,00 & 11 & 0,548 & 8 & 0,14 & 0,93 & 8 \\
\hline Bicicleta Ergométrica (BE) & 180,46 & 4 & 0,630 & 5 & 0,40 & 1,19 & 5 \\
\hline Remo Estacionário (RE) & 48,78 & 16 & 0,253 & 20 & $-0,80$ & $\mathbf{0}$ & 20 \\
\hline Hidroginástica (HI) & 290,62 & 2 & 0,805 & 1 & 0,99 & 1,78 & 1 \\
\hline Dança (DA) & 62,05 & 14 & 0,340 & 17 & $-0,52$ & 0,28 & 17 \\
\hline Ciclismo (CI) & 130,38 & 9 & 0,598 & 7 & 0,30 & 1,10 & 6 \\
\hline Basquetebol (BA) & 167,54 & 6 & 0,603 & 6 & 0,29 & 1,90 & 7 \\
\hline Handebol (HA) & 151,87 & 7 & 0,505 & 11 & 0,01 & 0,81 & 11 \\
\hline Judô (JU) & 54,57 & 15 & 0,378 & 15 & $-0,32$ & 0,49 & 15 \\
\hline Pular Corda (PC) & 84,23 & 12 & 0,463 & 12 & $-0,13$ & 0,67 & 12 \\
\hline Voleibol (VO) & 301,47 & 1 & 0,740 & 2 & 0,72 & 1,52 & 3 \\
\hline Tênis (TE) & 72,04 & 13 & 0,405 & 14 & $-0,24$ & 0,56 & 14 \\
\hline Caminhada (CA) & 225,28 & 3 & 0,738 & 3 & 0,72 & 1,52 & 2 \\
\hline Natação - Costas (NC) & 131,86 & 8 & 0,543 & 9 & 0,10 & 0,89 & 10 \\
\hline Natação - Peito (NP) & 127,05 & 10 & 0,543 & 10 & 0,11 & 0,91 & 9 \\
\hline Natação - Livre (NL) & 174,00 & 5 & 0,633 & 4 & 0,39 & 1,19 & 4 \\
\hline Tocar Instrumento (TI) & 34,82 & 17 & 0,305 & 18 & $-0,57$ & 0,24 & 18 \\
\hline Dardos (DD) & 20,50 & 19 & 0,363 & 16 & $-0,40$ & 0,40 & 16 \\
\hline Futebol (FU) & 23,53 & 18 & 0,428 & 13 & $-0,22$ & 0,59 & 13 \\
\hline Inatividade (IN) & 19,48 & 20 & 0,303 & 19 & $-0,56$ & 0,24 & 19 \\
\hline
\end{tabular}

Os resultados apresentados nas Tabelas 18 e 19 (masculino e feminino, respectivamente) também mostram uma alta concordância entre as ordenações derivadas de ambos os métodos e entre as duas alternativas de descrever os dados dos julgamentos de comparação aos pares. O coeficiente de concordância de Kendall (W), corrigido para empates, obtido a partir das ordenações das atividades físicas e esportivas resultantes das estimativas de magnitudes, proporções médias e valores escalares ajustados, dos sujeitos masculinos e femininos, descrito, a seguir nas Tabelas 20 e 21, respectivamente. 
Tabela 20 - Resultado da análise estatística do coeficiente de concordância de Kendall (W), das ordens de posição, das estimativas de magnitudes (EM), proporções médias (PM) e dos valores ajustados (VA), dos sujeitos do sexo masculino (M)

\begin{tabular}{cccccc}
\hline & & N & $(\mathrm{W})$ & $\mathrm{Z}$ & $\mathrm{p}<$ level \\
\hline EM_M \& & PM_M & 20 & 0,91578 & 5,645306 & 0,001 \\
EM_M \& & VA_M & 20 & 0,90526 & 5,580417 & 0,001 \\
VA_M \& & PM_M & 20 & 0,98947 & 6,099525 & 0,001 \\
\hline
\end{tabular}

Tabela 21 - Resultado da análise estatística do coeficiente de concordância de Kendall (W), das ordens de posição, das estimativas de magnitudes (EM), proporções médias (PM) e dos valores ajustados (VA), dos sujeitos do sexo feminino (F)

\begin{tabular}{cccccc}
\hline & & $\mathrm{N}$ & $(\mathrm{W})$ & $\mathrm{Z}$ & $\mathrm{p}<$ level \\
\hline EM_F \& & PM_F & 20 & 0,78947 & 4,866643 & 0,001 \\
EM_F \& & VA_F & 20 & 0,75789 & 4,671977 & 0,001 \\
PM_F \& & VA_F & 20 & 0,96842 & 5,969748 & 0,001 \\
\hline
\end{tabular}

Observa-se que, no caso dos homens, pelo método de estimação de magnitudes o esporte FUTEBOL, seguido pela NATAÇÃO (nado livre), foram as práticas consideradas de maior preferência, enquanto que a INATIVIDADE, a de menor preferência. Considerando-se as proporções médias resultantes da matriz de julgamentos do método de comparação aos pares, a NATAÇÃO (nado livre), seguida pelo FUTEBOL, alcançaram maior preferência pelos homens, enquanto que a INATIVIDADE recebeu menor preferência.

Para as participantes femininas, o VOLEIBOL, seguido pela HIDROGINÁSTICA foram as atividades apontadas como de maior preferência, respectivamente. Por outro lado, a INATIVIDADE recebeu menor preferência nos resultados do método de estimação de magnitudes. Nos resultados obtidos do método de comparação aos pares a HIDROGINÁSTICA, seguida pelo VOLEIBOL, respectivamente, foram as atividades físicas 
e esportivas indicadas como de maior preferência, enquanto que as atividades de REMO Estacionário e a INATIVIDADE tiveram menor preferência.

Outro resultado interessante, foi a comparação entre os julgamentos de homens e mulheres. O coeficiente de concordância de Kendall (W), corrigido para empates, obtido a partir das ordenações das atividades físicas e esportivas resultantes das estimativas de magnitudes, proporções médias e valores escalares ajustados, descrito abaixo na Tabela 22.

Tabela 22 - Resultado da análise estatística do coeficiente de concordância de Kendall (W), das ordens de posição, das estimativas de magnitudes (EM), proporções médias (PM) e dos valores ajustados (VA), dos sujeitos do sexo masculino (M) e do sexo feminino $(\mathrm{F})$

\begin{tabular}{llllcl}
\hline & & N & $(\mathrm{W})$ & Z & p-level \\
\hline EM_M \& & EM_F & 20 & 0,515789 & 3,179540 & 0,00147 \\
EM_M \& & PM_F & 20 & 0,642105 & 3,958203 & 0,00007 \\
EM_M \& & VA_F & 20 & 0,663158 & 4,087980 & 0,00004 \\
PM_M \& & EM_F & 20 & 0,473684 & 2,919986 & 0,00350 \\
PM_M \& & PM_F & 20 & 0,621053 & 3,828425 & 0,00012 \\
PM_M \& & VA_F & 20 & 0,621053 & 3,828425 & 0,00012 \\
VA_M \& & EM_F & 20 & 0,463158 & 2,855097 & 0,00430 \\
VA_M \& & PM_F & 20 & 0,610526 & 3,763537 & 0,00016 \\
VA_M \& & VA_F & 20 & 0,610526 & 3,763537 & 0,00016 \\
\hline
\end{tabular}

Da análise estatística do coeficiente de concordância de Kendall (W), obtida a partir das estimativas de magnitudes EM_M e EM-F (masculino e feminino) constatou-se uma baixa concordância, na ordem de preferência, dos sujeitos do sexo masculino, comparados com os do sexo feminino, sendo a média de 0,580 p $<0,05$, abaixo de 0,70, valores de referência para demonstração de concordância. 
No entanto, uma diferença fundamental persiste entre os resultados obtidos em ambos os métodos, isto é, no método de estimação de magnitudes podemos estabelecer as ordenações, as diferenças e principalmente as razões entre os graus de preferência das diferentes atividades físicas e esportivas. Enquanto que o método de comparação aos pares, semelhantes ao método de estimação em categorias, permitiu apenas estabelecer as ordenações e as diferenças entre os graus de preferência. Com este método nada podemos conhecer a respeito das razões entre os graus de preferência.

Para verificar se o contínuo social de preferência pela prática de atividades físicas e esportivas apresenta características protéticas ou metatéticas, as proporções médias e os escores $\mathrm{z}$ médios ajustados foram projetados em função das médias geométricas das estimativas de magnitudes em coordenadas lineares e mono-logarítmicas, em separado, tanto de homens como de mulheres. As Figuras 40 e 41 mostram a relação entre as proporções médias e as médias geométricas das estimativas de magnitudes de homens e mulheres, respectivamente, e as Figuras 42 e 43, indicam a relação entre as proporções médias e os logs das médias geométricas das estimativas de magnitudes de homens e mulheres, respectivamente. Ainda, nas Figuras, 44, 45, 46 e 47 são demonstradas as mesmas disposições, dos resultados, para os valores escalares ajustados, tanto para homens quanto para mulheres. 


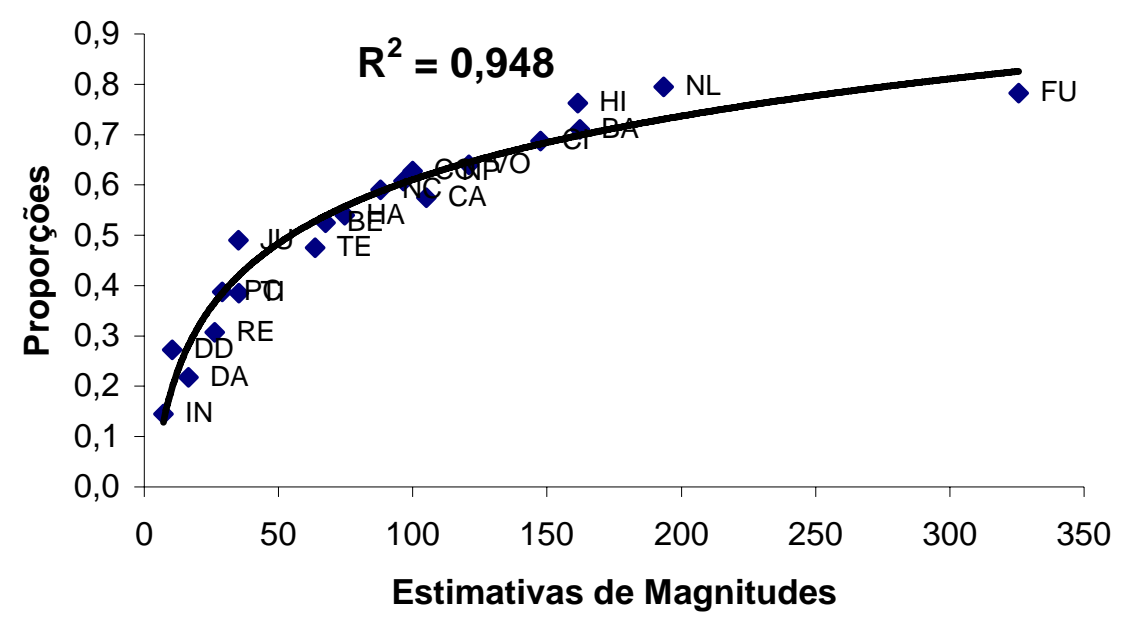

Figura 40 - Relação entre as proporções médias e as médias geométricas das estimativas de magnitudes da preferência pela prática de atividades físicas e esportivas em coordenadas lineares. Dados do Experimento 3, participantes do sexo masculino

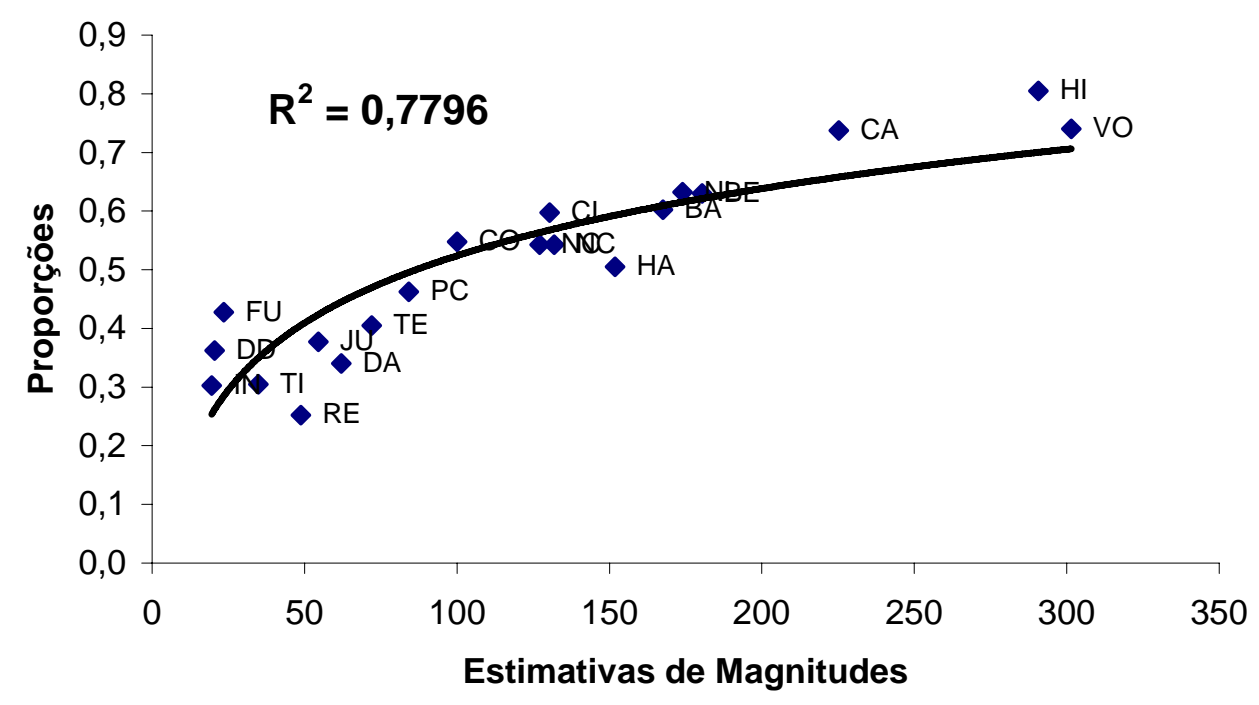

Figura 41 - Relação entre as proporções médias e as médias geométricas das estimativas de magnitudes da preferência pela prática de atividades físicas e esportivas em coordenadas lineares. Dados do Experimento 3, participantes do sexo feminino 


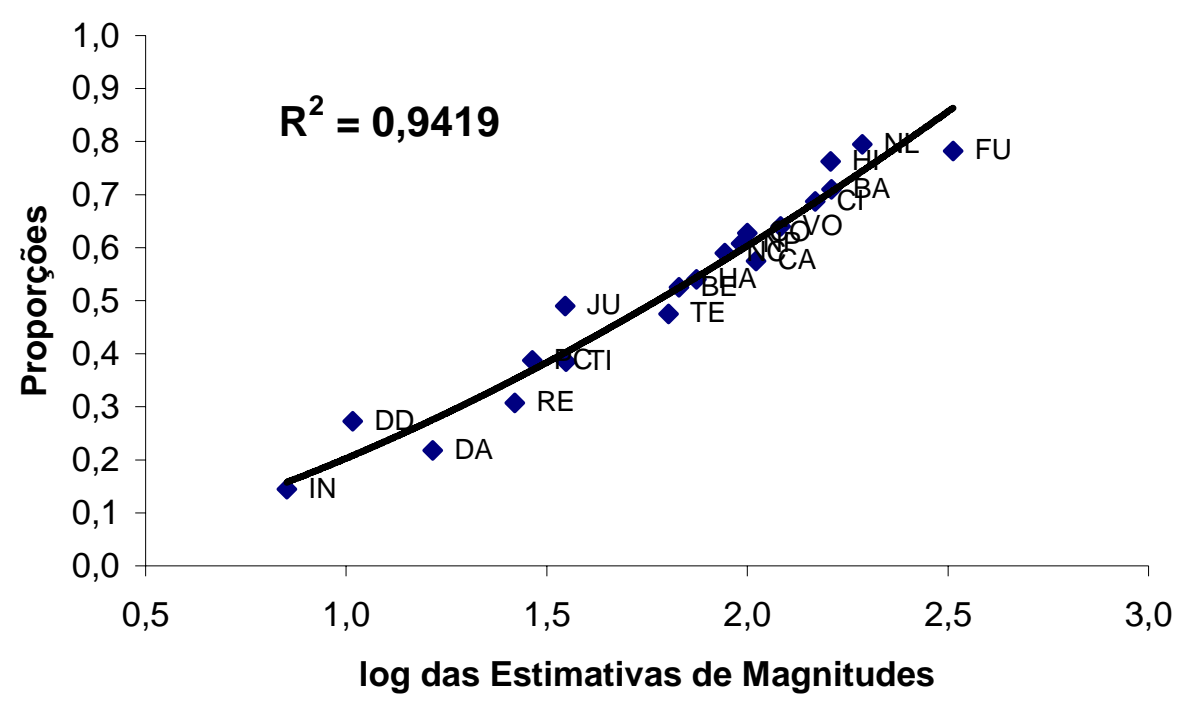

Figura 42 - Relação entre as proporções médias e os logaritmos das médias geométricas das estimativas de magnitudes da preferência pela prática de atividades físicas e esportivas. Dados do Experimento 3, participantes do sexo masculino

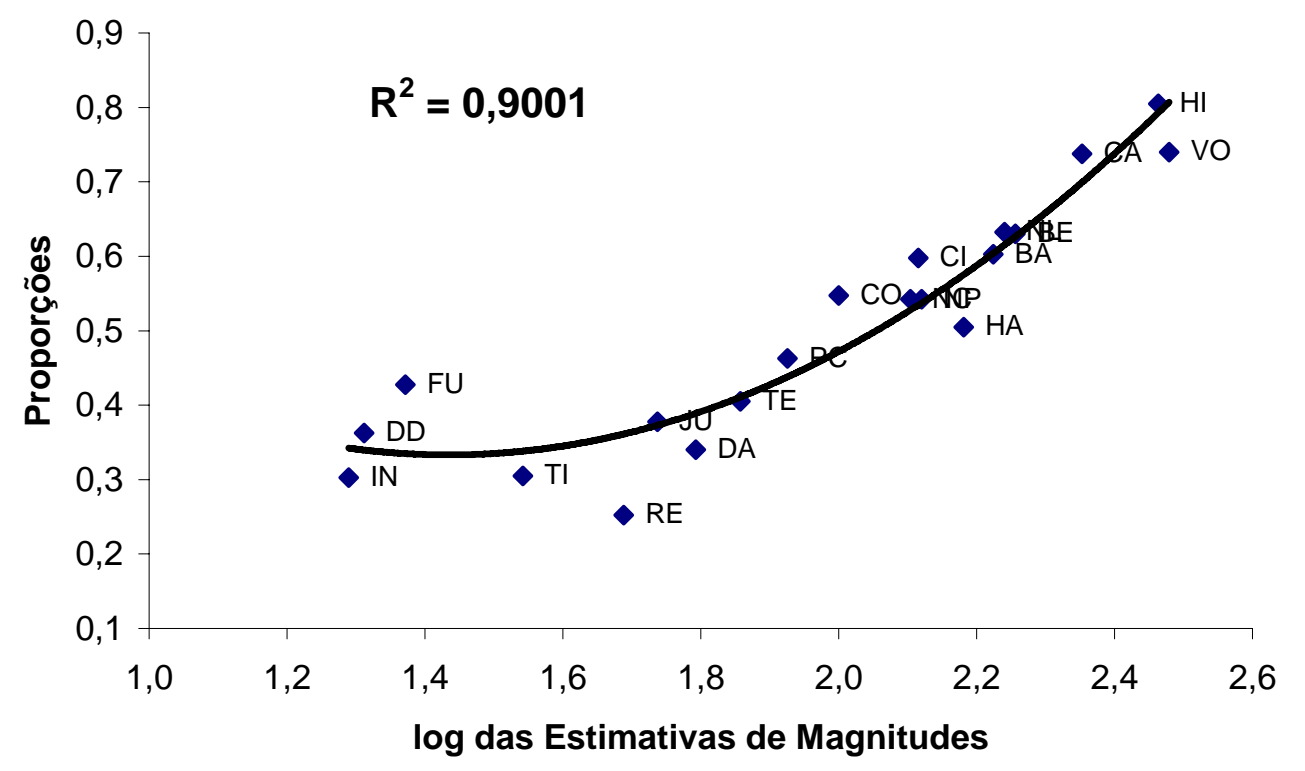

Figura 43 - Relação entre as proporções médias e os logaritmos das médias geométricas das estimativas de magnitudes da preferência pela prática de atividades físicas e esportivas. Dados do Experimento 3, participantes do sexo feminino. 


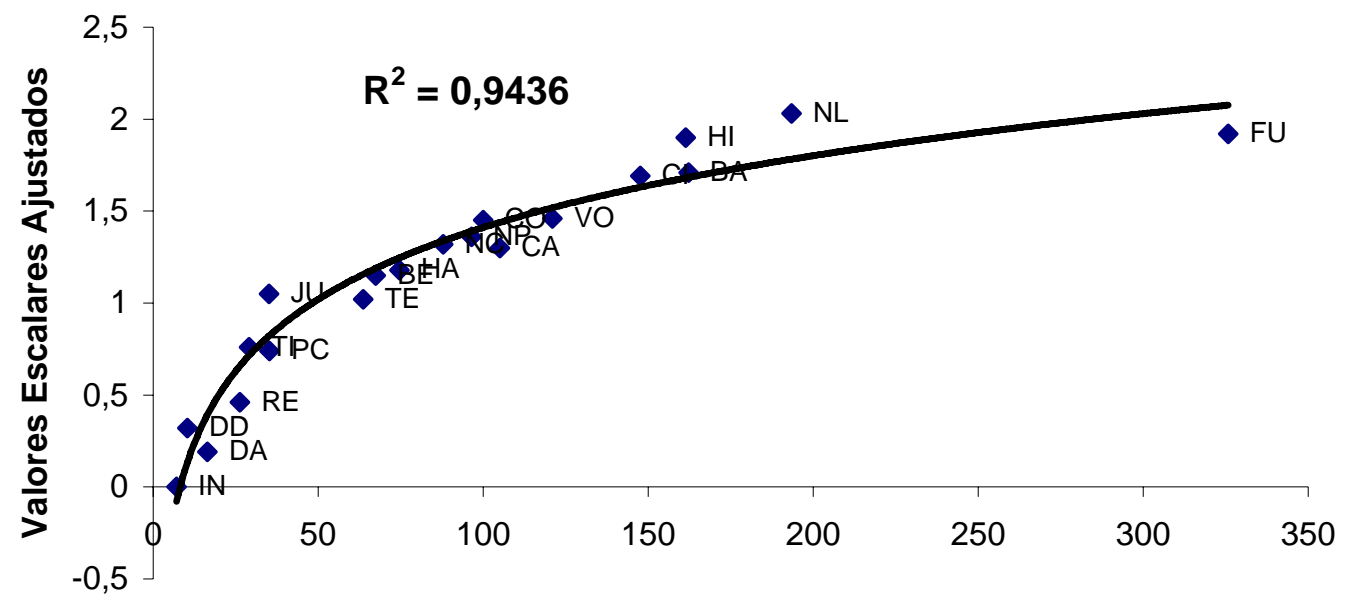

Estimativas de Magnitudes

Figura 44 - Relação entre os valores escalares ajustados e as médias geométricas das estimativas de magnitudes da preferência pela prática de atividades físicas e esportivas em coordenadas lineares. Dados do Experimento 3, participantes do sexo masculino

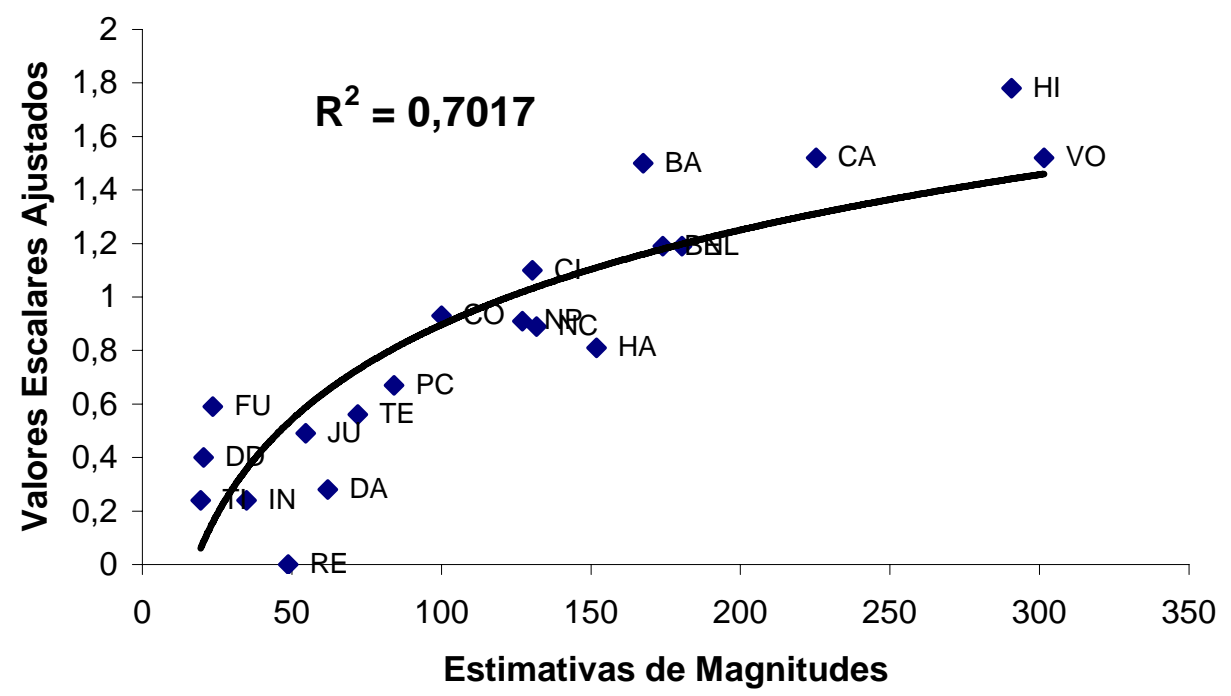

Figura 45 - Relação entre os valores escalares ajustados e as médias geométricas das estimativas de magnitudes da preferência pela prática de atividades físicas e esportivas em coordenadas lineares. Dados do Experimento 3, participantes do sexo feminino 


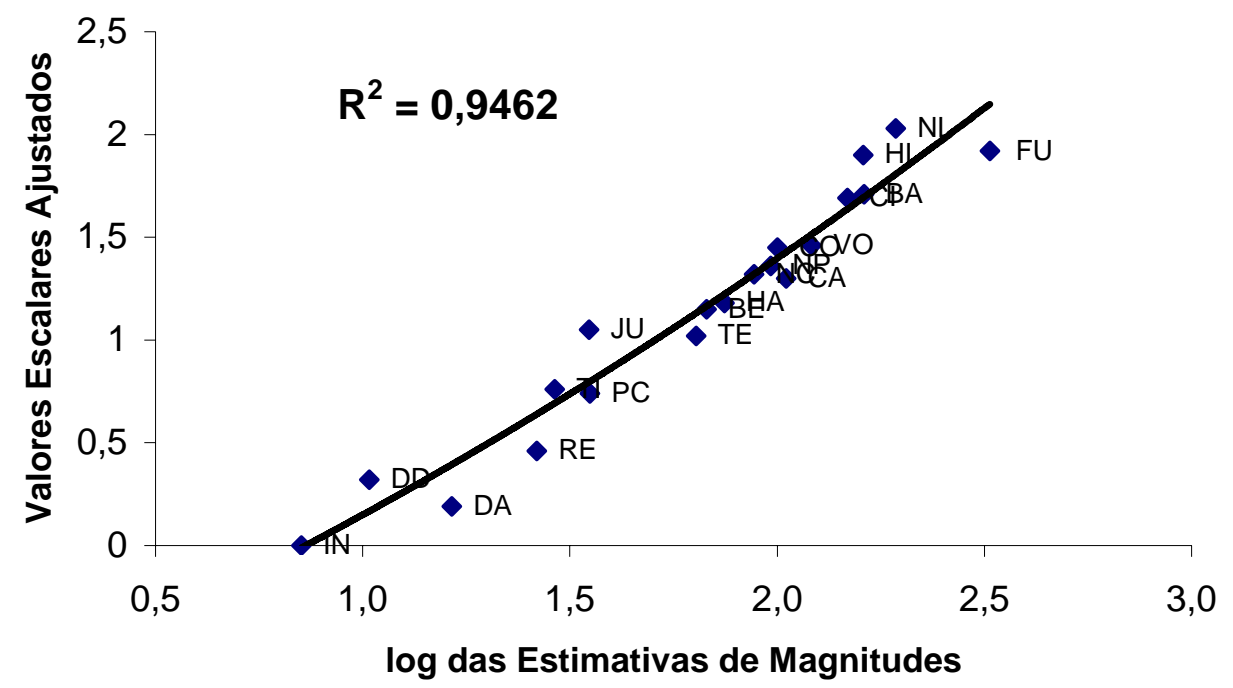

Figura 46 - Relação entre os valores escalares ajustados e os logaritmos das médias das estimativas de magnitudes da preferência pela prática de atividades físicas e esportivas. Dados do Experimento 3, participantes do sexo masculino

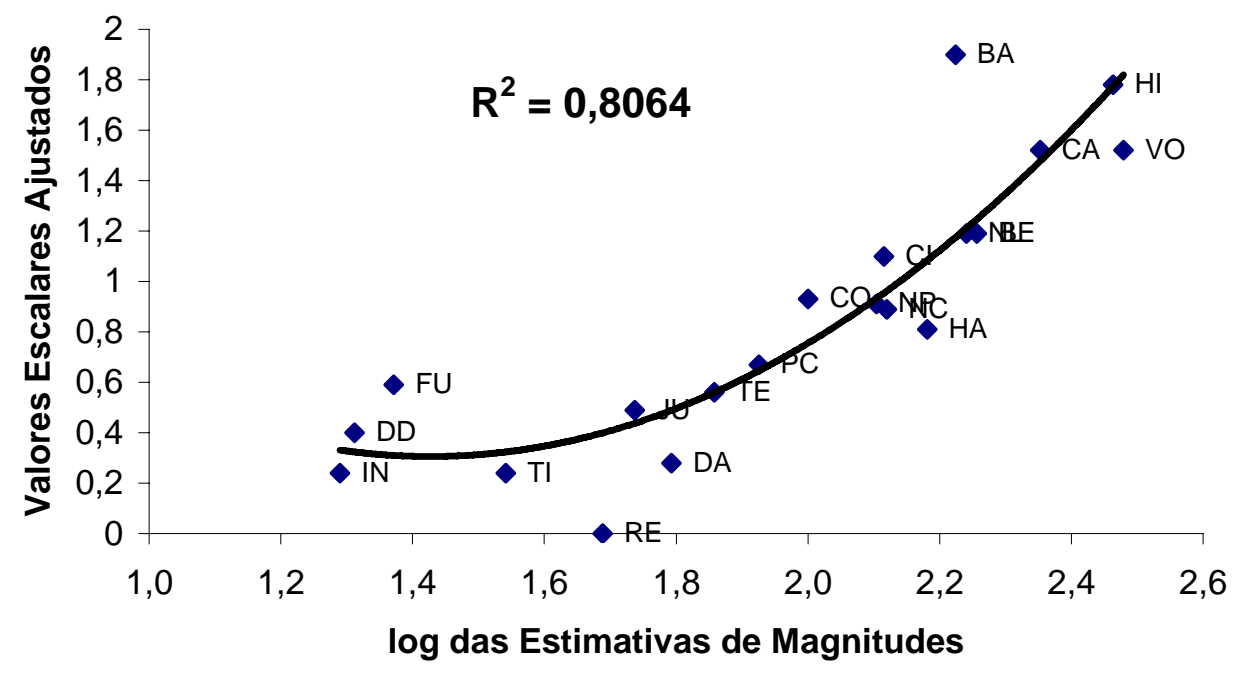

Figura 47 - Relação entre os valores escalares ajustados e os logaritmos das médias das estimativas de magnitudes da preferência pela prática de atividades físicas e esportivas. Dados do Experimento 3, participantes do sexo feminino 
Também, encontram-se descritas a seguir, nas Figuras 48, 49, 50 e 51 as generalizações dos princípios da Lei de Ekman, tanto dos participantes do sexo masculino, como do sexo feminino, as quais, mostram que o desvio-padrão da média aritmética aumenta linearmente, em função das estimativas de magnitudes. Deste modo, a variabilidade das estimativas é uma função linear da magnitude das estimativas, porém isto não ocorre do mesmo modo com as proporções médias, no teste de comparação aos pares.

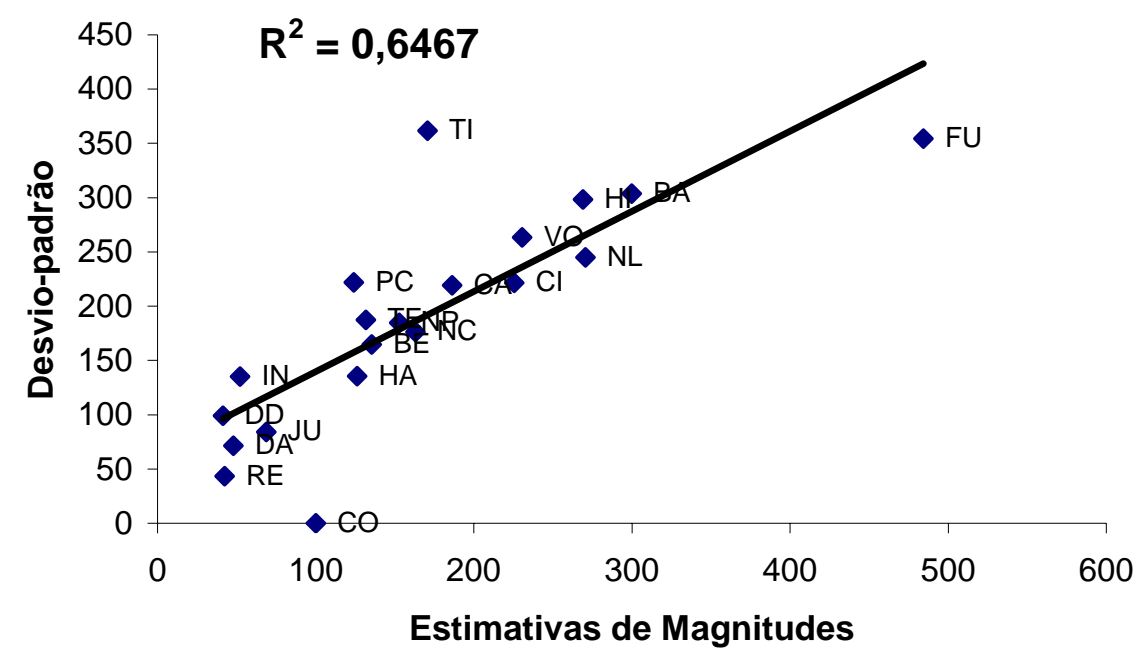

Figura 48 - Desvio-padrão da média aritmética em função das médias aritméticas das estimativas de magnitudes da preferência pela prática de atividades físicas e esportivas. Dados do Experimento 3, participantes do sexo masculino 


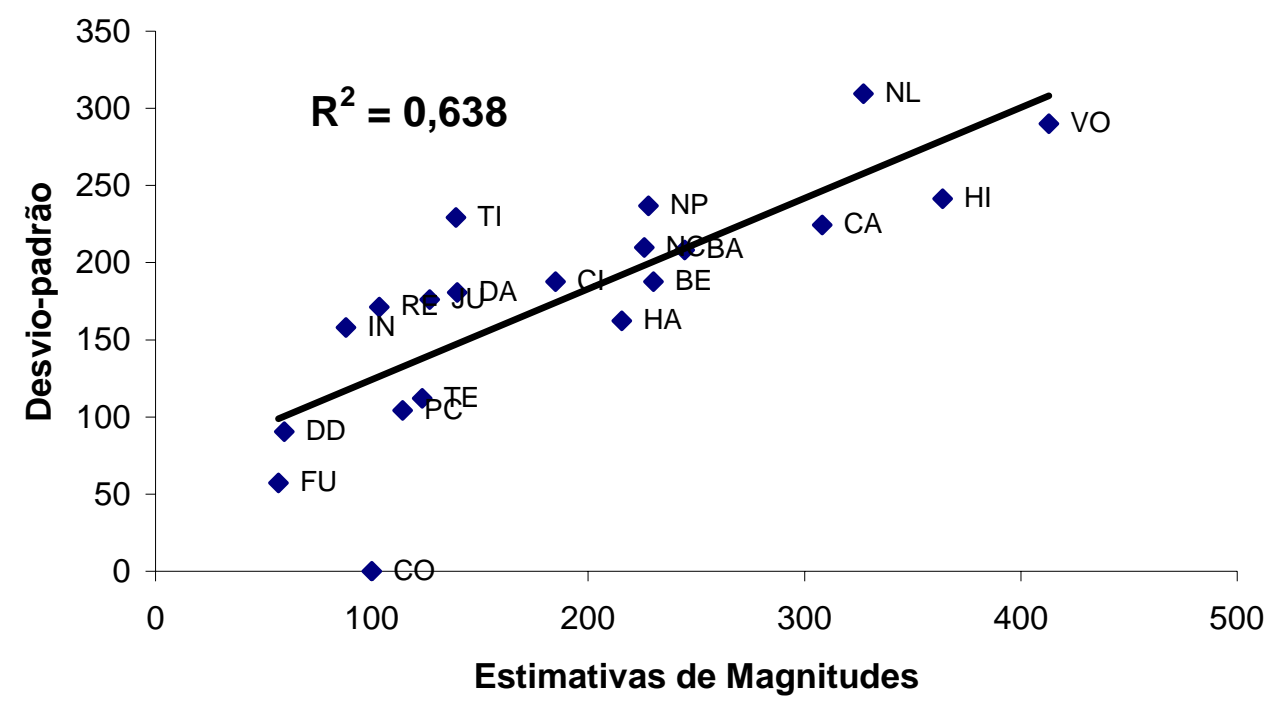

Figura 49 - Desvio-padrão da média aritmética em função das médias aritméticas das estimativas de magnitudes da preferência pela prática de atividades físicas e esportivas. Dados do Experimento 3, participantes do sexo feminino

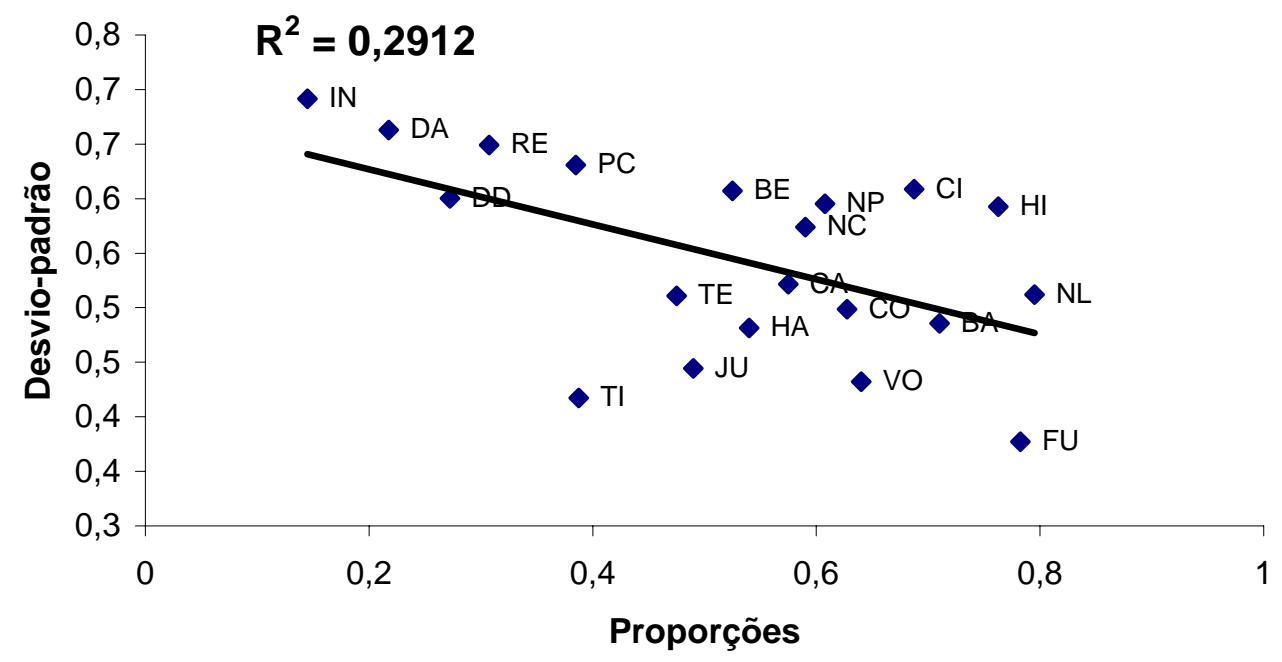

Figura 50 - Desvio-padrão da média aritmética em função das médias aritméticas das proporções médias da preferência pela prática de atividades físicas e esportivas. Dados do Experimento 3, dos participantes do sexo masculino. 


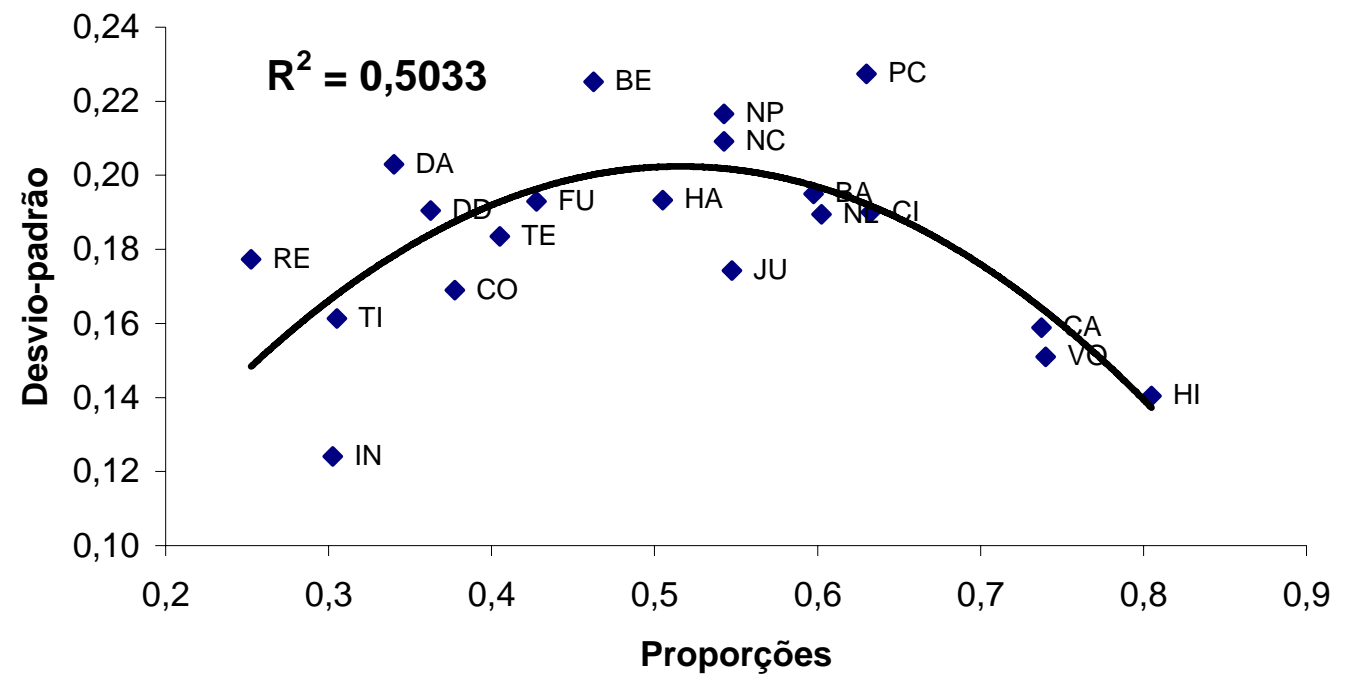

Figura 51 - Desvio-padrão da média aritmética em função das médias aritméticas das proporções médias da preferência pela prática de atividades físicas e esportivas. Dados do Experimento 3, participantes do sexo feminino 


\section{COMPARAÇÃO ENTRE OS MÉTODOS DE ESTIMAÇÃO DE MAGNITUDES DOS TRÊS EXPERIMENTOS}

\subsection{Comparação entre os métodos psicofísicos escalares de estimação de magnitudes dos três experimentos, de todos os sujeitos}

Na Tabela 23, abaixo, estão apresentadas as médias geométricas das estimativas de magnitudes e a ordem dessas estimativas, da preferência pela prática de atividades físicas e esportivas, julgadas nos três experimentos.

Tabela 23 - Média geométrica das estimativas de magnitudes, de todos os sujeitos, ordenados nas posições de maior preferência para a de menor preferência, dos três experimentos.

\begin{tabular}{lcclcclcc}
\hline Exp. 1 & \multicolumn{3}{c}{ Exp. 2 } & \multicolumn{5}{l}{ Exp.3 } \\
\hline ATIVIDADES & EM & OP & ATIVIDADES & EM & OP & ATIVIDADES & EM & OP \\
\hline Caminhada & 233,67 & 1 & Voleibol & 189,18 & 1 & Hidroginást. & 216,59 & 1 \\
Voleibol & 184,11 & 2 & Caminhada & 134,61 & 2 & Voleibol & 190,95 & 2 \\
Futebol & 157,58 & 3 & Hidroginást. & 127,11 & 3 & Nat.(livre) & 183,45 & 3 \\
Ciclismo & 138,81 & 4 & Nat.(livre) & 124,70 & 4 & Basquetebol & 164,85 & 4 \\
Inatividade & 130,56 & 5 & Nat.(peito) & 105,71 & 5 & Caminhada & 153,85 & 5 \\
Nat.(livre) & 123,52 & 6 & Corrida & 100,00 & 6 & Ciclismo & 138,70 & 6 \\
Hidroginást. & 114,16 & 7 & Tocar Inst. & 96,16 & 7 & Nat.(peito) & 110,73 & 7 \\
Corrida & 100,00 & 8 & Basquetebol & 90,19 & 8 & Bic Erg. & 110,33 & 8 \\
Bic. Erg. & 95,75 & 9 & Nat. (costas) & 83,17 & 9 & Nat. (costas) & 107,68 & 9 \\
Nat.(peito) & 86,95 & 10 & Ciclismo & 76,17 & 10 & Handebol & 106,47 & 10 \\
Nat. (costas) & 79,82 & 11 & Bic. Erg. & 70,99 & 11 & Corrida & 100,00 & 11 \\
Tocar Inst. & 76,20 & 12 & Futebol & 69,23 & 12 & Futebol & 87,54 & 12 \\
Pular Corda & 70,07 & 13 & Handebol & 67,29 & 13 & Tênis & 67,73 & 13 \\
Basquetebol & 66,92 & 14 & Pular Corda & 58,62 & 14 & Pular Corda & 54,52 & 14 \\
Handebol & 61,93 & 15 & Tênis & 54,33 & 15 & Judô & 43,77 & 15 \\
Dança & 49,87 & 16 & Dança & 49,45 & 16 & Remo & 35,82 & 16 \\
Tênis & 40,47 & 17 & Dardos & 48,89 & 17 & Dança & 31,92 & 17 \\
Judô & 36,31 & 18 & Inatividade & 44,08 & 18 & Tocar Inst. & 31,83 & 18 \\
Dardos & 27,78 & 19 & Judô & 36,96 & 19 & Dardos & 14,59 & 19 \\
Remo & 24,22 & 20 & Remo & 19,76 & 20 & Inatividade & 11,77 & 20 \\
\hline
\end{tabular}


Os resultados da correlação de Spearman, entre os três métodos de estimação de magnitudes, dos três experimentos mostrados na Tabela 23, revelaram uma correlação de 0,684 ( $\mathrm{p}<0,001)$ entre os testes de estimação de magnitudes na comparação entre o Experimento 1 com o Experimento 2, correlação de 0,551 ( $<$ 0,01) entre o Experimento 1 e o Experimento 3 e a maior correlação observada foi de 0,804 (p < 0,001) entre o Experimento 2 e o Experimento 3. Estes resultados indicaram que, nos três experimentos, as atividades físicas e esportivas foram ordenadas de forma semelhante por todos os participantes do presente estudo. Destacando-se as atividades de VOLEIBOL e a CAMINHADA como as de maior preferência, enquanto que REMO ESTACIONÁRIO e DARDOS NA PAREDE foram as de menor preferência e as demais alternaram-se com preferências intermediárias.

\subsection{Comparação entre os métodos psicofísicos escalares de estimação de magnitudes dos três experimentos, tanto dos sujeitos do sexo masculino como do sexo feminino}

Na Tabela 24, estão apresentadas as médias geométricas das estimativas de magnitudes e a ordem dessas estimativas da preferência pela prática de atividades físicas e esportivas julgadas nos três experimentos, dos sujeitos do sexo masculino. 
Tabela 24 - Média geométrica das estimativas de magnitudes, dos sujeitos do sexo masculino, ordenados nas posições de maior preferência para a de menor preferência, dos três experimentos.

\begin{tabular}{lcclcclcc}
\hline Exp. 1 & \multicolumn{9}{l}{ Exp.2 } & \multicolumn{5}{l}{ Exp.3 } \\
\hline ATIVIDADES & EM & OP & ATIVIDADES & EM & OP & ATIVIDADES & EM & OP \\
\hline Futebol & 298,95 & 1 & Futebol & 195,14 & 1 & Futebol & 325,70 & 1 \\
Caminhada & 215,16 & 2 & Voleibol & 154,54 & 2 & Nat. (livre) & 193,42 & 2 \\
Inatividade & 173,58 & 3 & Tocar Inst.. & 147,60 & 3 & Basquetebol & 162,21 & 3 \\
Nat. (livre) & 162,96 & 4 & Nat. (livre) & 141,32 & 4 & Hidroginást. & 161,42 & 4 \\
Voleibol & 160,01 & 5 & Ciclismo & 129,70 & 5 & Ciclismo & 147,55 & 5 \\
Ciclismo & 158,16 & 6 & Caminhada & 106,61 & 6 & Voleibol & 120,95 & 6 \\
Corrida & 100,00 & 7 & Corrida & 100,00 & 7 & Caminhada & 105,07 & 7 \\
Hidroginást. & 90,03 & 8 & Basquetebol & 99,24 & 8 & Corrida & 100,00 & 8 \\
Nat. (peito) & 88,73 & 9 & Nat. (peito) & 99,17 & 9 & Nat. (peito) & 96,51 & 9 \\
Nat. (costas) & 82,03 & 10 & Hidroginást. & 91,32 & 10 & Nat. (costas) & 87,93 & 10 \\
Basquetebol & 69,68 & 11 & Handebol & 71,98 & 11 & Handebol & 74,64 & 11 \\
Bic Erg. & 65,89 & 12 & Nat. (costas) & 71,66 & 12 & Bic Erg. & 67,45 & 12 \\
Judô & 65,66 & 13 & Bic Erg. & 53,46 & 13 & Tênis & 63,67 & 13 \\
Tocar Inst. & 64,47 & 14 & Tênis & 45,96 & 14 & Pular Corda & 35,29 & 14 \\
Handebol & 50,52 & 15 & Judô & 42,61 & 15 & Judô & 35,12 & 15 \\
Pular Corda & 44,44 & 16 & Dardos & 37,47 & 16 & Tocar Inst. & 29,09 & 16 \\
Dança & 37,11 & 17 & Pular Corda & 28,32 & 17 & Remo & 26,31 & 17 \\
Dardos & 30,52 & 18 & Dança & 26,54 & 18 & Dança & 16,42 & 18 \\
Tênis & 29,88 & 19 & Remo & 21,78 & 19 & Dardos & 10,38 & 19 \\
Remo & 22,62 & 20 & Inatividade & 12,55 & 20 & Inatividade & 7,11 & 20 \\
\hline
\end{tabular}

Os resultados da correlação de Spearman, entre os três métodos de estimação de magnitudes, dos três experimentos, dos julgamentos feitos pelos sujeitos do sexo masculino mostrados na Tabela 24, indicaram uma correlação de 0,619 (p < 0,01) entre os testes de estimação de magnitudes na comparação entre o Experimento 1 com o Experimento 2; correlação de 0,642 ( $\mathrm{p}<0,01$ ) entre o Experimento 1 e o Experimento 3; e a maior correlação observada foi de 0,789 ( $\mathrm{p}<0,001)$ entre o Experimento 2 e o Experimento 3. Estes resultados indicaram que, nos três experimentos, as atividades físicas e esportivas foram ordenadas de forma semelhante pelos sujeitos do sexo masculino. Destacando-se as 
atividades de FUTEBOL e NATAÇÃO (LIVRE) como as de maior preferência, enquanto que REMO ESTACIONÁRIO, DARDOS NA PAREDE, DANÇA e INATIVIDADE receberam menor preferência e as demais alternaram-se com preferências intermediárias.

Na Tabela 25, abaixo, encontram-se as médias geométricas das estimativas de magnitudes e a ordem dessas estimativas da preferência pela prática de atividades físicas e esportivas julgadas nos três experimentos, dos sujeitos do sexo feminino.

Tabela 25 - Média geométrica das estimativas de magnitudes, dos sujeitos do sexo feminino, ordenadas nas posições de maior preferência para a de menor preferência, dos três experimentos

\begin{tabular}{lccccclcc}
\hline Exp. 1 & \multicolumn{3}{l}{ Exp.2 } & \multicolumn{7}{l}{ Exp.3 } \\
\hline ATIVIDADES & EM & OP & ATIVIDADES & EM & OP & ATIVIDADES & EM & OP \\
\hline Caminhada & 253,78 & 1 & Voleibol & 231,57 & 1 & Voleibol & 301,47 & 1 \\
Voleibol & 211,83 & 2 & Hidroginast. & 176,93 & 2 & Hidroginast. & 290,62 & 2 \\
Hidroginast. & 144,75 & 3 & Caminhada & 169,97 & 3 & Caminhada & 225,28 & 3 \\
Bic. Erg. & 139,15 & 4 & Inatividade & 154,74 & 4 & Bic. Erg. & 180,46 & 4 \\
Ciclismo & 121,84 & 5 & Pular Corda & 121,36 & 5 & Nat. (livre) & 174,00 & 5 \\
Pular Corda & 110,47 & 6 & Nat. (peito) & 112,68 & 6 & Basquetebol & 167,54 & 6 \\
Corrida & 100,00 & 7 & Nat. (livre) & 110,04 & 7 & Handebol & 151,87 & 7 \\
Inatividade & 98,20 & 8 & Corrida & 100,00 & 8 & Nat. (costas) & 131,86 & 8 \\
Nat. (livre) & 93,63 & 9 & Nat. (costas) & 96,52 & 9 & Ciclismo & 130,38 & 9 \\
Tocar Inst. & 90,08 & 10 & Bic. Erg. & 94,29 & 10 & Nat. (peito) & 127,05 & 10 \\
Nat. (peito) & 85,22 & 11 & Dança & 92,14 & 11 & Corrida & 100,00 & 11 \\
Futebol & 83,06 & 12 & Basquetebol & 81,96 & 12 & Pular Corda & 84,23 & 12 \\
Nat. (costas) & 77,68 & 13 & Tênis & 64,23 & 13 & Tênis & 72,04 & 13 \\
Handebol & 75,91 & 14 & Dardos & 63,77 & 14 & Dança & 62,05 & 14 \\
Dança & 67,02 & 15 & Handebol & 62,92 & 15 & Judô & 54,57 & 15 \\
Basquetebol & 64,27 & 16 & Tocar Inst. & 62,64 & 16 & Remo & 48,78 & 16 \\
Tênis & 54,81 & 17 & Ciclismo & 44,73 & 17 & Tocar Inst. & 34,82 & 17 \\
Dardos & 25,29 & 18 & Judô & 32,05 & 18 & Futebol & 23,53 & 18 \\
Remo & 25,94 & 19 & Futebol & 24,56 & 19 & Dardos & 20,50 & 19 \\
Judô & 20,08 & 20 & Remo & 17,93 & 20 & Inatividade & 19,48 & 20 \\
\hline
\end{tabular}


Os resultados da correlação de Spearman, entre os três métodos de estimação de magnitudes, dos três experimentos, dos julgamentos feitos pelos sujeitos do sexo feminino mostrados na Tabela 25, indicaram uma correlação de 0,696 (p < 0,001) entre os testes de estimação de magnitudes na comparação entre o Experimento 1 com o Experimento 2; correlação de 0,589 (p < 0,01) entre o Experimento 1 e o Experimento 3 e uma correlação menor foi observada de 0,551 ( $\mathrm{p}<0,001)$ entre o Experimento 2 e o Experimento 3. Estes resultados indicaram que, nos três experimentos, as atividades físicas e esportivas, foram ordenadas de forma semelhante pelos sujeitos do sexo feminino. Destacando-se as atividades de VOLEIBOL, HIDROGINÁSTICA e CAMINHADA como as de maior preferência, enquanto que FUTEBOL, REMO ESTACIONÁRIO e JUDÔ foram as de menor preferência e as demais alternaram-se com preferências intermediárias. 


\section{DISCUSSÃO}

A preferência pela prática de atividades físicas e esportivas foi investigada através da aplicação de diferentes métodos psicofísicos e os pontos evidenciados no presente estudo seguem sendo relacionados com os resultados já existentes na literatura revisada.

a) A preferência pela prática de atividades físicas e esportivas

Os resultados encontrados pelo escalonamento da preferência das atividades físicas e esportivas podem estar relacionados ao que é colocado por Ekcert (1993), Bee (1997) e Gallahue e Ozmun (2001) de que é durante a iniciação esportiva ou a fase de conscientização para a prática de atividades físicas, por volta dos 10 aos 15 anos de idade, que é necessário instrumentalizar, o seres humanos, para saberem executar movimentos organizados e sentir prazer nisso. Práticas esportivas aprendidas no ambiente escolar ao longo da formação educativa, contribuem para a sua preferência como fica indicado nos apontamentos favoráveis em relação às atividades físicas esportivas coletivas (Voleibol, Basquetebol, Handebol e Futebol) que são atividades esportivas geralmente adquiridas neste processo educacional. E subentendemos, que foram de alguma forma captadas pelos participantes desta pesquisa, uma vez que se tratou de pessoas com um nível de instrução alto (graduandos) e certamente vivenciarão ao longo do seu desenvolvimento educacional estas práticas.

A preferência por atividades ou esportes coletivos sendo, ora apontadas como intermediária ora como as de maior preferência, pelos participantes desta pesquisa, demonstra o papel da sociabilização, ao qual esta inerente nestas práticas, confirmando com 
as indicações de Lovisolo (1997) que o gosto é algo profundamente individual, ao mesmo tempo o gosto é amplamente compartilhado, ocorrendo, deste modo, que o gosto ou a preferência, não tem apenas a função de construção da identidade pessoal, mas também constroem-se as identidades coletivas.

No caso das atividades esportivas individuais como a Natação, fica demonstrado que a própria prática do movimento em si, faz com que a preferência seja escalonada de forma semelhante pelos participantes como mostrado no presente estudo, independente da atividade ser praticada de forma individual. Os sujeitos indicaram como sendo a Natação, em estilo livre, a prática de maior preferência, seguida pelo estilo de peito e pelo estilo costas, de fato Netto (1995) e Massaud e Correa (2001) indicam que a facilidade dos movimentos, a eficiência do estilo de nado e o gasto energético são indicadores que determinam a maior aceitação da prática do estilo livre em comparação a outros tipos de estilo (costas, peito e borboleta, apesar deste ultimo não ter sido investigado no presente estudo).

Outro fator, apontado por Papalia e Olds (2000), que pode explicar, a alta preferência em relação à prática de atividades físicas e esportivas é o chamado “modismo”. No caso dos dias atuais, a caminhada, tem sido recomendada, para todas as idades, como sendo um excelente fator de prevenção de doenças cárdio-pulmonares, e como demonstrado pelos resultados, do presente estudo, também foi apontada com altos índices de preferência, estando de acordo com as afirmações de Turíbio (1997) e Fox e Matheus (1983). Hoje as atividades feitas para culto ao corpo, típicas atividades desenvolvidas dentro academias e que, acabam sendo algo, de meio de relacionamento social, acabam por determinar o conceito de preferência também. Por exemplo, no presente estudo, a Hidroginástica, seguida pela prática da Bicicleta Ergométrica, foram apontadas como práticas com altos e 
moderados índices, respectivamente, de preferência em relação a outras atividades. Este mesmo item, ou seja, o fator da sociabilização e o modismo também contribuíram nos apontamentos com baixos índices de preferência para as práticas de Arremessar dardos na parede e Remo estacionário. O que estas atividades têm em comum, a ponto de serem apontadas, como tendo menor índice de preferência, do que outras atividades, é a quantidade do número de participantes, o fato de serem atividades individuais (com movimentos muito específicos) e ainda o fator competitivo, que não é algo que caracteriza estas modalidades.

A demanda fisiológica, também é outro fator demonstrado, no presente estudo, como sendo um indicativo de se determinar à preferência. Atividades físicas com demandas fisiológicas moderadas, como no caso da Corrida, o Pular Corda, Tocar um Instrumento, Ciclismo e Dançar uma Valsa, receberam indicações de preferência intermediárias. Neste sentido, quando do escalonamento da preferência pela prática de atividades físicas e esportivas a recomendação de Stevens (1975) e Sousa (2000) com relação à utilização de um módulo padrão para auxiliar os julgamentos, pode ser mais indicada, adotar atributos que se encontram no meio do contínuo a ser escolhido. Como no caso de atributos sociais este, “meio” não fica bem claro devido às propriedades dos atributos sociais, no caso de atividades físicas, a corrida parece ser uma atividade que pode ser recomendada como padrão, uma vez que, as suas próprias características da demanda fisiológica moderada, podem garantir um bom parâmetro de comparação com outras atividades físicas, com demandas fisiológicas muito intensas e muito baixas.

Estes resultados discutidos até então, demonstram as médias das preferências, dos julgamentos de todos os participantes, esta forma de análise se justifica uma vez que os trabalhos de diversos profissionais que estão envolvidos com o movimento humano, 
organizado, são feitos de forma homogênea e sem a distinção entre homens e mulheres. Deste modo, a preferência que geralmente é tida como parâmetro de trabalho é a opinião conjunta de homens e mulheres e a partir disso, traça-se metas a serem atingida, constroemse mecanismos e programas de trabalho, para melhor atender clientes e alunos objetivando maximizar a performance aliada ao prazer da prática, como apontam Souza Junior e Darido (2002).

b) A preferência pela prática de atividades físicas e esportivas entre homens e mulheres

Quando se observa o julgamento dos participantes do sexo masculino, as atividades físicas, com menor preferências foram Remo Estacionário, Dança, Dardos e a Inatividade, já para as do sexo feminino foram o Futebol, o Judô, o Remo estacionário e Dardos, indicando uma semelhança entre homens e mulheres. Esta semelhança foi com relação, as atividades de Remo estacionário e Dardos, e uma grande diferença, foi notada, entre as Atividades de Futebol, Judô, Inatividade e Dança. Para as atividades apontadas como as de maior preferência, temos para os participantes masculinos o Futebol, a Caminhada e a Natação (estilo livre), como as que mais se destacam, e para as participantes femininas a Caminhada, o Voleibol e a Hidroginástica, revelando preferências distintas. Estas semelhanças demonstradas por homens e mulheres, quanto a menor preferência destas atividades físicas e esportivas, recaem sobre a própria característica das atividades (Remo estacionário e Dardos) são atividades com pouco envolvimento competitivo, o qual, geralmente, é um fator determinante, na demonstração da diferenciação entre os gêneros e na escolha da preferência, como demonstrado por Romero (1994). Porém, no caso do Judô e do Futebol, indica que as atividades, possuem tal caráter competitivo, porém neste caso, 
outros fatores, como a o papel da cultura, do esporte e a motivação (incentivo), para a prática, podem ter sido os reais motivos, pelos quais, os participantes, do sexo feminino, terem apontado, como sendo, de menor preferência, enquanto que o maior contato corporal, a exigência de força e a maior utilização de grandes grupos musculares, podem ter influenciado a grande preferência pela prática, pelos participantes do sexo masculino. O mesmo ocorreu com a Dança, sendo apontada com baixo índice para o homens e índices moderados pelas mulheres, porém agora o fator "modismo" e o papel cultural parecem estar mais presentes, de acordo com Altmann (1998). Os indicativos apontados, como possíveis explicações, para as pequenas diferenças encontradas para a menor preferência, serve também para demonstrar a grande diferença encontrada no quesito de maior preferência. Estas diferenças, entre gêneros, tanto com questões culturais, fisiológicas e da própria característica da tarefa (atividade física ou esportiva) estão de acordo com os apontamentos também descritos por Soares et eli (1992), Viana (1994), Romero (1994), Altmann (1998) e Souza Junior e Darido (2002).

Uma alternativa para tentar equilibrar este quadro poderia ser, na fase anterior a iniciação a prática dos esportes, dos 06 aos 10 anos de idade, oferecer para meninos e meninas os mesmo estímulos motores amplamente explorados pelos meninos, minimizando-se assim os efeitos proporcionados, pelo maior envolvimento dos meninos, com diversas atividades, que ocorre não só na escola, mas em casa, na rua, no parque, no clube, como sugere também Souza Junior e Darido (2002), Eckert (1993) e Bee (1997).

Além disso, como recomendado por Gallahue e Ozmun (2001), durante a iniciação esportiva de 10 aos 15 anos de idade, seria importante instrumentalizar meninos e meninas, para uma participação efetiva e prazerosa na cultura esportiva, para que ambos, indistintamente, possam desfrutar dos benefícios proporcionados por estas atividades, bem 
como, a reflexão quanto às razões, da construção histórica de papéis e atribuições diferenciadas.

c) Os diferentes métodos psicofísicos utilizados

Desde a primeira condição experimental, na qual, se propôs avaliar a preferência pela prática de atividades físicas e esportivas, utilizando dois métodos psicofísicos diferentes, estimação de magnitudes e estimação em categorias, passando pela segunda condição experimental, na qual, foram aplicados os métodos de estimação de magnitudes e estimação de comprimento de linhas e finalizando, com a terceira condição experimental, que comparou dois métodos psicofísicos a estimação de magnitudes e a comparação aos pares, todos demonstraram que, independentemente, do método psicofísico escalar utilizado houve uma alta correlação dos julgamentos.

O grande diferencial do presente estudo, é que mesmo que existem algumas diferenças fundamentais nos escalonamentos obtidos, segundo Stevens (1975), pelo método de estimação em categorias e pelo método de comparação aos pares, podemos obter tanto a ordenação quanto a diferença entre os graus de preferência, porém não podemos afirmar o quanto o grau de preferência pela prática de atividade física e esportiva é maior ou menor em comparação ao grau de uma outra. Porém, com o método de estimação de magnitudes, podemos obter a ordenação, a diferença, e também as razões, entre os graus de preferência das diferentes atividades físicas e esportivas. Os resultados encontrados, nos permite afirmar que, o grau de preferência da atividade física CAMINHADA $(E M=233,67)$ é 
aproximadamente, uma vez e meia maior, do que o grau de preferência da CORRIDA (EM = 100), ou aproximadamente, nove vezes maior do que a atividade de REMO ESTACIONÁRIO (EM = 24,22).

Porém, em outros estudos como o de Wills e Moore (1994) é indicado para que estes resultados sejam encarados com uma certa dose de cautela. Foi demonstrado, por estes autores, que nem sempre o método de estimação de magnitudes é superior ao método de estimação em categorias para escalonar estados subjetivos nas pesquisas. Estes pesquisadores argumentam que, em muitas pesquisas, o foco de interesse esta nas diferenças dos estados subjetivos, entre grupos de pessoas, ou entre indivíduos e, portanto torna-se importante fazer inferências sobre as diferenças nos estados subjetivos, baseados nas diferenças das ordenações, destes estados escalonados. Apesar disso, é importante que os pesquisadores estejam cientes das variabilidades inter e intra sujeitos, vindas do emprego de qualquer um desses métodos baseados em julgamentos de razão (estimação de magnitudes) ou em julgamentos de diferenças (estimação em categorias e comparação aos pares).

d) Contínuo protético versus contínuo metatético

Para Stevens (1975) podemos julgar tanto a qualidade quanto a quantidade de um dado estímulo. Quando julgamos a qualidade devemos pensar num contínuo metatético e quando julgamos a quantidade, num contínuo protético. A distinção entre estes 
dois tipos de contínuos é muito importante dentro da teoria psicofísica moderna, uma vez que, diferentes leis parecem governar estes dois diferentes tipos de reações sensoriais.

No presente estudo, os resultados obtidos tanto no Experimento 1 quanto no Experimento 3 apontam que o contínuo de preferência pela prática de atividades físicas e esportivas possui características quantitativas, ou seja, um contínuo protético. A característica quantitativa do contínuo protético, também foi demonstrada nos estudos de Schiavetti, Metz e Sitler (1981) e Schiavetti et al. (1983) nos quais foram comparados testes de estimação de magnitudes com o teste de estimação em categorias para mensurar a inteligibilidade da fala e o entendimento da pronuncia de sujeitos com gagueira severa, respectivamente.

Portanto, quando foram projetados graficamente os dados do teste de estimação de magnitudes e os do teste de estimação em categorias, no Experimento 1, a linha do gráfico obtida desta relação foi uma linha curvilínea, indicando um típico contínuo protético. Em concordância com os autores citados acima, os resultados apontam que o método de estimação de magnitudes é preferível em relação ao método de estimação em categorias para a mensuração da preferência pela prática de atividades físicas e esportivas, no sentido, em que neste método é possível, além de saber se as atividades físicas e esportivas são percebidas de forma diferente, é possível identificar também o quanto esta atividade física é mais ou menos preferível em relação à outra.

O mesmo padrão de resultado, indicando ser um contínuo protético, quantitativo, foi obtido no Experimento 3, quando foram projetadas as proporções médias e os escores z médios ajustados, em função das médias geométricas das estimativas de magnitudes. O padrão da curva obtida mostrou uma concavidade ascendente e quando foram projetadas em função dos logaritmos das estimativas de magnitudes a concavidade 
mostrou-se descendente, estes resultados, também se confirmam em outros estudos como Ekman e Kunnapas (1963), que propuseram mensurar um atributo social, este atributo foi a mensuração da importância política dos monarcas suecos, indicando um contínuo com características quantitativas e não qualitativas e nos estudos de Sousa (2000), Sousa e Da Silva (2001), Sousa Kamizaki e Da Silva (2001) que mensuraram o contínuo social do prestígio de profissões e a mensuração de atributos clínicos, utilizando os métodos de estimação de magnitudes, estimação em categorias e ainda o teste de comparação aos pares.

Estes achados podem ser de grande ajuda para profissionais que programam, planejam e indicam atividades físicas e esportivas. Lovisolo (1997) coloca que é bem complicado identificar a preferência das pessoas na escolha da prática de atividades físicas e esportivas, devido a grande complexidade de aspectos que estão inerentes e exteriormente influenciando o ser humano, a todo o momento. Assim, saber quantidades e não apenas qualidades, dos julgamentos de preferência, podem apontar minúcias que, às vezes, são imperceptíveis perante a um simples julgamento, “de gosto ou não gosto”, “pratico por me sentir bem”, “nunca pratiquei e não vou gostar”, frases estas que formam parâmetros para o profissional trabalhar. Como é ressaltados por Tubino (1988) o gosto e o prazer, quando empregados à prática de atividades físicas e esportivas, podem ser fatores essenciais na maximização das capacidades físicas, psíquicas e sociais promovidas por estas práticas, portanto, estes fatores podem ser identificados mais precisamente utilizando testes psicofísicos buscando a análise quantitativa da preferência.

Enfim, o contínuo da preferência pela prática de atividades físicas e esportivas tendo características protéticas, ou seja, quantitativas, nos permite saber o quanto, um cliente ou aluno, prefere mais ou menos, uma atividade física ou esportiva em relação a uma outra. Ainda, é recomendado que o teste de estimação de magnitudes, possa 
ser uma melhor ferramenta, para a mensuração da preferência pela prática de atividades físicas e esportivas.

Ainda, segundo Sousa e Da Silva (2001) evidenciam que é necessário atingir pelo menos um, dentro de dois critérios, para afirmar se um contínuo social, tem características protéticas ou não. O primeiro critério seria verificar a função quaselogarítmica entre as estimativas de magnitudes e as estimativas em categorias. O segundo critério seria verificar se os dados seguem os indícios da Lei de Ekman, ou seja, que a variabilidade é uma função linear do aumento das estimativas. Por isso, que a seguir, segue a discussão sobre a comprovação ou não, dos princípios da Lei de Ekman, no contínuo social, da preferência pela prática de atividades físicas e esportivas.

\section{d) Os princípios da Lei de Ekman}

No presente estudo, os dados revelaram uma relação linear entre a variabilidade medida pelo desvio padrão e a média aritmética das estimativas de magnitudes para cada estímulo. Este padrão de resultado indica que quanto maior a estimativa de magnitude maior foi o desvio padrão da média aritmética produzida. Estes resultados foram observados nos três experimentos e tomados juntos podem ser considerados como um possível indício do que é conhecido como a Lei de Ekman.

No caso do Experimento 1, quando comparadas as médias aritméticas das estimativas de magnitudes com os respectivos desvios padrões aritméticos foi obtida uma relação linear com um alto índice do coeficiente de determinação $r^{2}=0,7686$. Este padrão 
de resultado, semelhante, foi observado tanto no Experimento 2 quanto no Experimento 3. No caso do Experimento 2 a comparação dos resultados do teste de estimação de magnitudes como no teste de comprimento de linhas apontou, respectivamente, os seguintes resultados dos coeficientes de determinação EM x DP $r^{2}=0,887$ e CL x DP $r^{2}=$ 0,8573. No caso do Experimento 3, quando comparadas as médias aritméticas das estimativas de magnitudes com os respectivos desvios padrões aritméticos foi obtida uma relação linear, com um coeficiente de determinação de $r^{2}=0,6463$. Obtendo-se a média dos valores do coeficiente de determinação, dos três experimentos, visualiza-se um alto coeficiente de determinação $r^{2}=0,7898$,

Todos estes resultados podem ser usados como comprovantes complementares do princípio de Ekman e estão de acordo com Teghtossonian (1971), Petrov (2003) e Allen (2000) que apontam que, quando esta equação $\Delta \Psi=$ b $\Psi$, de Ekman é aplicada ao contínuo psicológico, é exatamente análoga a Lei de Weber (que o tamanho subjetivo das diferenças apenas perceptíveis - d.a.p., aumenta em proporção com a magnitude da sensação), $\Delta \phi=$ $\mathrm{c} \phi$, no contínuo físico.

Por outro lado, quando os desvios padrões aritméticos, foram projetados em função das médias aritméticas dos testes de estimativas em categorias (Experimento 1) não foi observado indícios deste princípio da Lei de Ekman. O coeficiente de determinação obtido, entre o desvio padrão aritmético e a médias aritmética, das estimativas em categorias apontou um baixo coeficiente $r^{2}=0,4943$, para uma curva com concavidade ascendente. Resultados semelhantes foram encontrados em outros estudos como os de Sousa e Da Silva (2001), Allen (2000) e Donald e colaboradores (2001). 
Ao contrário, do que acontece com o teste de estimação de magnitudes, que é uma tarefa que mensura razões, que ocorre um aumento linear, dos desvios padrão das médias aritméticas, em função das estimativas de magnitudes, como colocam Teghtsoonian (1973) e Pashler (2002), este aumento não acontece com as estimativas em categorias, por se tratar de um método intervalar. Deste modo, quanto maior a estimativa em categoria tanto menor o desvio padrão da média aritmética ou tanto menor a variabilidade. Portanto, mesmo quando se atribuem instruções para que os sujeitos julguem diferenças e não razões,

entre os graus de preferência, a variabilidade indicada pelo desvio padrão diminui com o aumento das estimativas em categorias.

Resumindo, este padrão de resultado, demonstrado no presente estudo, mostra indícios do princípio conhecido como Lei de Ekman, discutidos também por Stevens (1966a) e (1975). Este princípio aponta que a variabilidade das estimativas é uma função linear da magnitude das estimativas. Em contra partida, a mesma relação não ocorreu com as estimativas em categorias, na qual, quanto maior a estimativa em categoria, na qual, quanto maior a estimativa em categoria, tanto menor o desvio padrão da média aritmética.

\section{e) A Validação da Escala de Razão}

No presente estudo, foi pedido para que os participantes emparelhassem duas modalidades sensoriais, ou seja, estimativa numérica e comprimento de linhas com o atributo social que estava sendo testado, a preferência pela prática de atividades físicas e esportivas. De fato, como também sugere Stevens (1975) e Lodge (1982), tal como ocorre 
com estímulos métricos, quando duas ou mais modalidades de respostas de magnitudes são emparelhadas, a um mesmo conjunto de estímulos sociais, o princípio subjacente, a esse relacionamento, é o de que, intensidades iguais, a uma mesma intensidade, são iguais umas às outras. Acrescentando, de acordo com Cross (1974), uma escala subjetiva pode ser validada, pelo método de emparelhamento intermodal, quando a inclinação obtida dos emparelhamentos, com um conjunto comum de estímulos sociais, se aproxima da inclinação obtida, a partir da razão, entre as duas inclinações características, das duas medidas de respostas psicofísicas.

A razão predita (teste de critério para validar a escala de magnitude) é uma função entre os dois contínuos (ou modalidades) de respostas e não entre dois estímulos, uma vez que os sujeitos estão usando as duas respostas para expressar suas impressões das intensidades dos estímulos. Em conformidade com Sousa, Kamizaki e Da Silva (1999) no escalonamento social, podemos ter duas alternativas para obtermos este processo de validação da escala de razão, a partir do método de emparelhamento intermodal. A primeira alternativa é comparar o expoente empírico (inclinação derivada), quando as modalidades de respostas são emparelhadas com estímulos sociais, com o expoente teórico (inclinação teórica) característica dos relacionamentos dessas modalidades quando emparelhadas com estímulos físicos. A segunda alternativa é a comparação desse expoente empírico, derivado das estimativas dos estímulos sociais, com o expoente empírico obtido num experimento de calibração, no qual os mesmos participantes tenham emparelhado, as mesmas duas modalidades de respostas, com estímulos sensoriais. Esse experimento de calibração envolve, uma tarefa de escalonamento psicofísico, que serve como treino dos observadores, no uso das duas modalidades de respostas, para que façam julgamentos proporcionais. Essas mesmas, duas modalidades, deverão ser empregadas num segundo experimento, de 
escalonamento de magnitudes, o qual os observadores julgarão a intensidade de um dado estímulo social.

O pressuposto teórico-experimental é que, os mesmos entraves que afetam as respostas aos estímulos sensoriais, atuariam, de modo, semelhante, nas respostas aos estímulos sociais. Qualquer que seja a alternativa de comparação, o importante é que cada um dos expoentes empíricos e a razão entre eles precisam ser funções de potência. Deste modo, quando esse critério é satisfeito a escala derivada é uma escala de razão, dita psocifisicamente validada como ressalta também Baird e Noma (1978) e Stevens (1975).

A comprovação desta equivalência entre o expoente empírico e o predito, numa tarefa de calibração, envolvendo diretamente sensações entre duas modalidades, constitui-se uma forte evidência, da validade do método de estimação de magnitudes e, por conseqüência, da lei de potência ou lei de Stevens. Tanto o método de comprimento de linhas como o de estimação de magnitudes, têm sido, freqüentemente, utilizados, como julgamentos das tarefas de emparelhamento intermodal (STEVENS, 1969; 1975; ver também STEVENS; GUIRAO, 1963; TEGHTSOONIAN, 1965; COLLINS; GESCHEIDER, 1989; MORGON; GUIRARDELLO, 2004).

De fato, estes autores, Stevens (1969; 1975), Stevens e Guirao (1963), Teghtsoonian (1965), Collins e Gescheider (1989), Morgon e Guirardello (2004), Sousa (2000) e Sousa e Da Silva (2001) tem consistentemente, verificado que estimativas numéricas de magnitudes de comprimentos de linhas produzem uma função de potência com expoente muito próximo a 1,0. Colocado de outra forma, comprimentos de linhas são linearmente proporcionais aos comprimentos físicos. Empregando ao paradigma do emparelhamento intermodal, podemos emparelhar comprimentos de linhas a quaisquer outras modalidades sensoriais ou perceptivas. De fato, como demonstraram Stevens e 
Guirao (1963) e Collins e Gescheider (1989), a predição é quase perfeita tanto para brilho quanto para sonoridade.

Vejamos um outro exemplo, publicado no estudo de Stevens e Marks (1980), que envolve contínuos métricos e que é bastante ilustrativo deste procedimento de emparelhamento intermodal. Esse estudo é de grande interesse teórico, porque, envolve brilho e som, que têm expoentes similares iguais a 0,33, quando os níveis dos estímulos são expressos em energia sonora e luminância. Conseqüentemente, o expoente predito das funções de emparelhamento, em qualquer direção, é aproximadamente 1,0. O valor exato do expoente predito é bastante difícil de ser estimado, dado às diferenças individuais, de procedimentos de um experimento para outro, além de variáveis específicas de cada modalidade como, por exemplo, estado de adaptação e duração para brilho. Com base nos resultados publicados (HELLMAN; ZWISLOCHI, 1963; STEVENS, 1955; 1971; STEVENS; MARKS, 1980) a função de emparelhamento teria um expoente na vizinhança de 1,0 a 1,2. De fato, Stevens e Marks (1980), mesmo variando a amplitude dos estímulos empregados, obtiveram expoentes que foram bem próximos daqueles preditos pela propriedade de transitividade das escalas. Os expoentes foram 1,08, 1,15 e 0,93 para diferentes variações de amplitude. Para inúmeros outros exemplos, da robustez do método de emparelhamento intermodal, usados como contínuos sensoriais ou aditivos, podem ser encontrados em Stevens (1975) e Daning (1983).

Neste sentido, os resultados encontrados neste estudo, comprovam estes achados, uma vez que, nas tarefas de Calibração 1 e 2 é bastante ilustrativa a robustez do paradigma do emparelhamento intermodal. Os expoentes médios obtidos para estimativas de magnitudes e produção de magnitudes foram 0,91 (mediana = 0,98) e 0,89 (mediana = 0,94), respectivamente. Supondo que a produção e estimação de magnitudes sejam emparelhadas 
esperar-se-ia um expoente igual ou próximo a 1,0 considerando-se a razão entre os expoentes médios $(0,91 / 0,89)$, ou igual a 1,02 tomando-se a razão entre os expoentes medianos $(0,98 / 0,94)$, obtém 1,05 . O expoente desta função $(1,02)$ não foi estatisticamente diferente do expoente esperado $(1,0)$, estando em conformidade com os resultados encontrados nos trabalhos, acima citados.

Quando as médias geométricas das estimativas numéricas foram projetadas em coordenadas logarítmicas em função das correspondentes médias geométricas dos emparelhamentos de comprimentos de linhas para cada atividade física ou esportiva. Uma linha reta com uma inclinação (expoente da função potência) de $0,71\left(r^{2}=0,55\right)$ foi obtida. Todavia, como o observador tende a restringir a amplitude de seus ajustamentos em função da variável que ele controla, essas médias foram projetadas em coordenadas invertidas, isto é, o emparelhamento de comprimento de linhas em função das correspondentes estimativas numéricas para cada atividade física ou esportiva. Uma linha reta, com uma inclinação (expoente da função potência) de $0,81\left(r^{2}=0,54\right)$ foi obtida. Este efeito, do observador restringir a amplitude de seus ajustamentos em função da variável que ele controla, tem sido verificado em diferentes experimentos e foi analisado por Stevens e Greenbaum (1966) e Stevens (1975). Indow (1961) sugere que obtendo a média geométrica das duas inclinações pode-se constituir numa maneira apropriada de mediar este efeito, como demonstrado também neste estudo.

A partir da média geométrica obtida desses dois expoentes 0,71 e 0,81, obteve-se o resultado de 0,76. Nenhuma das inclinações, foram significativamente semelhantes ao valor que é geralmente predito de 1,0, como geralmente tem sido demonstrado por Stevens (1969; 1975), Stevens e Guirao (1963), Teghtsoonian (1965), Collins e Gescheider (1989), Morgon e Guirardello (2004), Estes achados podem provavelmente demonstrar que houve 
uma pequena amplitude dos comprimentos físicos de linhas utilizados neste experimento. De fato, Ekman e Kunnapas (1963), Da Silva e Macedo (1983) e Sousa (1993) têm mostrado que o expoente da função potência diminui com o aumento da amplitude dos estímulos. Com comprimentos físicos variando de 1 a $200 \mathrm{~cm}$, ou seja, com uma amplitude quase quatro vezes maior que aquela que foi utilizada no presente experimento, Stevens e Guirao (1963) encontraram um expoente muito próximo à unidade. Deste modo, poderíamos ter obtido um expoente muito próximo à unidade, se tivéssemos empregado pelo menos o dobro da amplitude de 5 a 82 cm utilizada no Experimento 2 A.

Porém, estes valores não foram significativamente diferentes dos expoentes de 0,91 e 0,89, resultantes dos expoentes individuais obtidos no Experimento 2 A, Teste de Calibração 1 e 2 respectivamente, atendendo, desta forma, a segunda alternativa apontada por Sousa, Kamizaki e Da Silva (2001) (que reza, derivado das estimativas dos estímulos sociais, com o expoente empírico obtido num experimento de calibração, no qual, os mesmos participantes tenham emparelhado, as mesmas duas modalidades de respostas, com estímulos métricos) para validação da escala de razão. Os mesmos efeitos, com relação a validação da escala de razão, foram obtidos quando da análise em separado de homens e mulheres, indicando que os expoentes empíricos e a razão entre eles, obtidos no teste de calibração, são funções de potência. Assim, atendendo um critério essencial para a escala de razão, dita psicoficamente validada. 


\section{CONCLUSÕES}

A partir dos resultados obtidos das três condições experimentais é possível concluir que:

- Independente do método escalar utilizado, a atividade física de REMO ESTACIONÁRIO foi julgada como a de menor preferência, enquanto que a CAMINHADA a de maior preferência. Pelo método de estimação de magnitudes, podemos obter a ordenação, a diferença, e também as razões, entre os graus de preferência das diferentes atividades físicas e esportivas.

- O coeficiente de correlação entre as ordenações das estimativas resultantes dos métodos de estimação de magnitudes e de estimação em categorias demonstra que os dois métodos produzem preferências altamente concordantes.

- O contínuo social de preferência pela prática de atividades físicas e esportivas apresenta características protéticas.

- Evidentemente, é notada uma relação linear, indicando que quanto maior a estimativa de magnitude maior será o desvio-padrão da média produzida. Deste modo, este padrão de resultados mostram indícios do princípio geral conhecido como Lei de Ekman, encontrado geralmente em contínuos sensoriais.

- No julgamento dos participantes do sexo masculino a atividade física de menor preferência foi apontada como sendo a de REMO ESTACIONÁRIO, acompanhada pelas atividades de TÊNIS e DARDOS, já para as participantes do sexo feminino foi indicado o JUDÔ como a atividade de menor preferência, seguida, por REMO ESTACIONÁRIO e DARDOS, indicando uma semelhança relativa à preferência, entre homens e mulheres. 
- Para as atividades apontadas como as de maior preferência, temos para os participantes masculinos o FUTEBOL, a CAMINHADA e a INATIVIDADE e para as participantes femininas a CAMINHADA, o VOLEIBOL e a HIDROGINÁSTICA, indicando preferências não muito semelhantes em relação aos homens.

- A utilização dos diferentes métodos (EM e EC) foi fidedigna tanto pelos participantes do sexo masculino como do sexo feminino, porém houve uma pequena diferença entre os julgamentos feitos entre homens e mulheres indicando que a prática de atividades físicas e esportivas, por estas pessoas, é percebida de modo semelhante mas não igual no tocante à escolha da preferência.

- A relação entre as estimativas de magnitudes e as estimativas em categorias é uma função potência com um expoente significativamente diferente de 1,0.

- A escala de preferência pela prática de atividades físicas e esportivas é válida, estável e consistente, uma vez que os expoentes obtidos por meio dos emparelhamentos de números e comprimentos de linhas não foram significativamente diferentes dos expoentes preditos pela propriedade de transitividade das escalas.

Em resumo, os resultados apontam para uma escala de preferência pela prática de atividades físicas e esportivas, que é válida, estável e consistente. 


\section{REFERÊNCIAS}

ALLEN, J. The intensity JND comes from Poisson neural noise: implications for image coding. Vision, n. 21, 59-69, 2000.

ALLIPRANDINI, P. M. Z.; DA SILVA, J. A. Psychophysical power functions for apparent area in perceptive, memory, and inference conditions for observers of different age groups. Perceptual and Motor Skills, v. 91, p. 783-788, 2000.

ALTMANN, H. Rompendo fronteiras de gênero: marias (e) homens na educação física. Dissertação (Mestrado em Educação) - Faculdade de Educação, Universidade Federal de Minas Gerais, Belo Horizonte, 1998.

BAIRD, J. C. Psychophysical analysis of visual space. London: Pergamon Press, 1970.

BAIRD, J. C.; NOMA, E. Fundamentals of scaling and psychophysical. New York: Wiley, 1978.

BEE, H. O ciclo vital, ed. Artes Médicas:Porto Alegre, 1997

BORG, G. Escalas de Borg para a dor e o esforço percebido. São Paulo: Manole, 2000.

COLLINS, A. A.; GESCHEIDER, G. A. The measurement of loudness in individual children and adults by absolute magnitude estimation and cross-modality matching. Journal of the Acoustical Society of American, v. 85, p. 2012-2021, 1989.

CROSS, D. V. Some technical notes on psychophysical scaling. In: HOSKOWITZ, H.; B. SCHARF, B.; STEVENS, J. C. Sensation and Measurement: Papers in honor of S. S. Stevens. Dordrecht, the Netherlands, Reidel, 1974. p.23-26.

DANING, R. Intraindividual consistencies in cross-modal matching across continun. Perception \& Pschophysics, v. 33, p. 516-522, 1983.

DA SILVA, J. A. Processos psicofisiológicos subjacentes à função de potência: uma crítica à psicofísica de Stevens. Arq. Brás. Psic., Rio de Janeiro, v. 38, n. 4, p. 3-21, 1985.

DA SILVA, J. A.; MACEDO, L. A função-potência na percepção - significado e procedimentos de cálculo do expoente. Arq. Brás. Psic., Rio de Janeiro, v. 34, n. 4, p. 27-45, 1982. 
Efeitos de algumas variáveis experimentais sobre a invariância das escalas perceptivas. Arq. Brás. Psic. Rio de Janeiro, v. 29, n. 2, p.48-70, 1983.

DONALD, A. M.; ROBERTO, M.; WARD, J.; BAIRD, J. C. Continuous measurement of breathlessness during exercise: validity, reliability, and responsiveness. J. Appl. Physiol., v. 90, p. 2188-2196, 2001.

EBE, K.; GRIFFIN, M. J. Qualitative models of seat discomfort including static and dinamic factors. Ergonomics, v.43, n. 6, p. 771-790, 2000.

ECKERT, H. M. Desenvolvimento motor. 3 ed., Manole:São Paulo, 1993.

ELLIS, L.; FICEK, C. Color preferences according to gender and sexual orientation. Personality and Individual Diferences, v. 31, n. 8, p. 1375-1379, 2001.

EKMAN, G.; KUNNAPAS, T. A further of direct and indirect scaling methods. Scandinavian Journal of Psychology, 4, 77-80, 1963.

FLIGIO, R. M. The seriousness of offenses: An evaluation by offenders and non-offenders. Journal of Criminal Law and Criminology, v. 66, p. 189-200, 1976.

FOX, E. L.; MATHEWS, D. K. Bases fisiológicas da educação física e dos desportos. Rio de Janeiro: Interamericana, 1983.

GALLAHUE, D. L.; OZMUN, J. C. Compreendendo o desenvolvimento motor: bebês, crianças, adolescentes e adultos. São Paulo: Phorte, 2001.

GUEDES, D. P.; GUEDES, J. E. R. P. Crescimento composição corporal e desempenho motor: de crianças e adolescentes, São Paulo:CLR Balieiro, 1997.

GUIRAO, M. Métodos psicofísicos. In: GUIRAO, M. Los sentidos bases de la perception. Madrid: Alhambra Universidad, 1980. p. 59-78.

GESCHEIDER, G. A. Psychophysical scaling. Ann. Rev. Psychol., v. 39, p.169-200, 1988.

GUYTON, A. C. Fisiologia humana. Rio de Janeiro: Guanabara/Koogan, 1988. v.6.

HAN, S. H.; JUNG, E. S.; JUNG, M. K.; PARK, S. Psychophysical methods and passenger preferences of interior designs. Applied Ergonomics, v. 29, n.06, p. 499-506, 1998. 
HELLMAN, R. P.; ZWISLOCHI, J. J. Monoaural loudness function at 1000 cps and interaural summation. Journal of the Acoustical Society of America, v. 35, 856-865, 1963.

INDOW, T. An example of motivation research applied to product design. Chosa, To Gijutsu, v. 102, p. 45-60, 1961.

JACOB, S. W; FRANCONE, C. A.; LOSSOW, W. J. Anatomia e fisiologia humana: sistema nervoso, Rio de Janeiro: Guanabara, 1990. v. 5, p. 2005-2299.

KREIMAN, J.; GERRATT, B. R. Validity of rating scale measures of voice quality. J. Acoust. Soc. Am. v. 104, n. 3, p. 1598-1608, 1998.

KROGER, C.; ROTH, K. Escola da bola: um abc para iniciantes nos jogos esportivos, Phorte:São Paulo, 2002.

KRUEGER, L. E. Reconciling Fechner and Stevens: toward a unified psychophysical law. Behavioral and Brain Science, v. 12, p. 251-320, 1989.

KWAN, Y. K.; CHEUNG, W.; KWAN, P. A crime index with thurstone`s scaling of crime severity. Journal of Criminal Justice, v. 28, p. 237 - 244, 2000.

LODGE, M. Magnitude scaling: quantitative measurement of opinions. Beverly Hills, USA: Sage Publications, 1982.

LOVISOLO, H. Estética, esporte e educação física, Sprint:Rio de Janeiro, 1997.

LYNCH, J. P.; DANNER, M. J. E. Offense seriousness scaling: an alternative to scenario methods. Journal of Quantitative Criminology, v. 9, n. 3, p. 25- 37, 1999.

MAGILL, R. A. Aprendizagem motora: conceitos e aplicações. São Paulo: Edgard Blucher, 2000. v. 5.

MASSAUD, M. G.; CORREA, C. R. F. Natação para adultos, Sprint, Rio de Janeiro, 2001.

MEDINA, J. P. O brasileiro e seu corpo: educação e política do corpo, Papirus:Campinas/SP., 1987. 
MORGON, F. H.; GUIRARDELLO, E. B. Validação da escala de razão das necessidades de familiares em unidade de terapia intensiva. Revista Latina Americana de Enfermagem. v. 12, 198-203, 2004.

NETTO, J. B. Natação: a didática moderna da aprendizagem, Grupo Palestra Sports, Rio de Janeiro, 1995.

PAPALIA, D. E.; OLDS, S. W. Desenvolvimento humano. Artmed: Porto Alegres, 2000.

PASHLER, H. Stevens' handbook of experimental psychology. John Wiley \& Sons, v. 4, n. 3, 2002.

PASQUALI, L. Escalas psicométricas. In: PASQUALI, L. Instrumentos psicológicos: manual prático de elaboração. Brasília; LabPAM;IBAPP, 1999; p. 105-127.

PETROV, A. A. Additive or multiplicative perceptual noise? Two equivalent forms of the ANCHOR model. In R. Alterman \& D. Kirsh (Eds.), Proceedings of the 25th Annual Conference of the Cognitive Science Society. Hillsdale, 2003.

PIQUERO, A. R. Assessing the relationships between gender, chronicity, seriosness, and offense skeness in criminal offending. Journal of Criminal Justice, v. 28, p. 103 - 115, 2000.

POWERS, S K.; HOWLEY, E. T. Fisiologia do exercício: teoria e aplicação ao condicionamento e ao desempenho. São Paulo: Manole, 2000.

PURDY, S. C.; PAVLOVIC, C. V. Reliability, sensitivity and validity of magnitude estimation, category scaling and paired-comparison judgments of speech intelligibility by older listeners. Audiology, v.31, p. 254-271, 1992.

QUINE, W. V. Persuit of truth. Cambridge: Havard University Press, 1990.

ROMERO, E. A. Educação física a serviço da ideologia sexista. Revista Brasileira de Ciências do Esporte. V 15, n. 3, 1994.

SELLIN, J. T.; WOLGANG, M. E. The measurement of delinquency. New York: John Wiley, 1964.

SCHIAVETTI, N.; METZ, D. E.; SITLER, R. W. Construct validity of direct magnitude estimation and interval scaling of speech intelligibility: evidence from a study of the hearing impaired. J. of Speech and Hearing Research, v. 24, p. 441-445, 1981. 
SCHIAVETTI, N.; SACCO, P. R.; METZ, D. E.; SITLER, R. W. Direct magnitude estimation and interval scaling of stuttering severity, J. of Speech and Hearing Research, v. 26, p. 568-573, 1983.

SCHMIDT, R. F.; ALTNER, H.; DUDEL, J.; GRUSSER, O. J.; KLINKE, R.; ZIMMERMAN, M. Fisiologia sensorial. São Paulo: EPU: Springer: EDUSP, 1980.

SCHIMIDT, R. A.; WRISBERG, A. Aprendizagem e performance motora: uma abordagem da aprendizagem baseada no problema. Porto Alegre: Artmed, 2001.

SCOTT, J. Gênero: uma categoria útil na análise histórica. Educação e Realidade, Porto Alegre, v. 20, n. 2, 1995.

SILVA, J. B. Educação física, esporte e lazer: aprender a aprender fazendo, Lido:Londrina/PR, 1995.

SOARES, C. L.; TAFFAREL, C. N. Z.; VARJAL, E.; FILHO, L. C.; ESCOBAR, M. O.; BRACHT, V. Metodologia do ensino de educação física, Coletivo de Autores/Cortez:São Paulo, 1992.

SOUSA, F. A E. F. Mensuração de atributos sociais e clínicos: um enfoque experimental. Ribeirão Preto: FUNPEC-RP, 2000.

SOUSA, F. A. E. F.; KAMIZAKI, R.; DA SILVA, J. A. Social and clinical psychophysics: theory and applications. Psychologica, v. 28, p. 243-268, 2001.

SOUSA, F. A. E. F. Prestígio profissional do enfermeiro: um enfoque da psicofísica social. 1993. 197 f. Tese (Doutorado em Enfermagem) - FFCLRP - Universidade de São Paulo (USP), Ribeirão Preto, 1993.

SOUSA, F. A. E. F.; DA SILVA, J. A. Prestígio profissional do enfermeiro: estimação de magnitudes e de categorias expandidas. Rev. Latino-am. Enfermagem, v. 9, n. 6; p. 19-24, 2001.

SOUTHWOOD, M. H.; FLEGE, J. E. Scaling foreign accent: direct magnitude estimation versus interval scaling. Clinical Linguistics \& Phonetics, n. 5, p. 338-49, 1999.

SOUZA JR, O. M. S.; DARIDO, S. C. A prática do futebol feminino no ensino fundamental. Motriz, Rio Claro, v. 8, n. 1, p.1-9, 2002. 
STEVENS, S. S. The measurement of loudness. Journal of the Acoustical Society of America, v. 27, p. 815-820, 1955.

. On the psychophysical law. The psichological review, v. 64, n. 3, p. 153-81, 1957.

. Cross-madality validation of subjective scales for loudness, vibration, and electric shock. Journal of Experimental Psychology, v. 57, p. 201-209, 1958.

. The psychophysics of sensory function. American Scientist, v. 48, p. 226-253, 1960.

. To honor Fechner and repeal his law. Science, v. 133, p. 80-86,1961.

. A metric for the social consensus. Science, v. 151, p. 530-541, 1966a.

1966b.

. On the operation known as judgement. American Scientist, v. 54, p. 385-401, . On predicting exponents for cross-modality matches. Perception \& Psychophysics, v. 6, p. 251-256, 1969.

Neural events and the pychophysical law. Science, v. 170, p. 1043-1050, 1970.

. Issues in psychophysical measurement. Psychological Review, v. 78, p. 426-450, 1971.

Perceptual magnitude and its measurements. In: CARTERETTE, E.C.; FREDMAN, N. P. Handbook of Perception: psychophysical Judgment and measurement. New York: Academic Press, 1974. v. 2, p. 361-389.

Psychophysic. New York: Wiley, 1975.

STEVENS, S. S.; GREENBAUM, H. B. Regressiomn effect in psychophysical judgment. Perception \& Psychophysics, v.1, p. 439-446, 1966.

STEVENS, S. S.; GUIRAO, M. Subjective scaling of length and area and the matching of length to loudness and brightness. Journal of Experimental Psychology, v. 66, p. 177-186, 1963. 
STEVENS, S. S.; MARKS, L. E. Cross-modality matching functions generated by magnitude estimation. Perception \& Psychophysics, v. 27, p. 379-389, 1980.

STYLIANOU, S. Measuring crime seriousness perceptions: what have we learned and what else do we want to know. Journal of Criminal Justice, v.31, p. 37-56, 2003.

TEGHTSOOnian, R. The judgment of size. American Journal of Psychology, v. 78, p. 392-402, 1965.

On the exponents in stevens' law and the constant in ekman's law, Psychological Review, v. 78, n.1, p. 71-80, 1971.

Range effects in psychophysical scaling and a revision of stevens' law, American Journal of Psychology, v. 86, n. 1, p. 3-27, 1973.

THURSTONE, L. L. A law of comparative judgment. Psichological Review, v. 34, p. 273286, 1927.

TUBINO, M. J. G. Repensando o esporte brasileiro, Ibrasa:São Paulo, 1988.

TURIBIO, B. N. Exercício saúde e desempenho. São Paulo: Atheneu, 1997.

VIANA, E. O poder do esporte. Sprint:Rio de Janeiro, 1994.

WEINBERG, R. S.; GOULD, D. Psicologia do esporte e do exercício. 2.ed. Porto Alegre: Artmed, 2001.

WHITEHILL, T. L.; LEE, A. S. Y.; CHUN, J. C. Direct magnitude estimation and interval scaling of hypernasality. Journal of Speech, Language, and Hearing Research, v. 45, p. 80-88, 2002.

WILLS, C. E.; MOORE, C. F. A controversy in scaling of subjective states: magnitude estimation versus category rating methods. Research in Nursing \& Health, v. 17, 231-237, 1994. 


\title{
APÊNDICE A
}

\section{INFORMAÇÕES PARA O MÉTODO}

\begin{abstract}
Nome:
Data:

Idade:

Sexo: $\mathrm{M}$ $\mathrm{F}$

Método: Estimação de Magnitude para Preferência por Pratica de Atividades Físicas e Esportivas
\end{abstract}

Você está sendo convidado a participar de um método que ocupará 15 minutos ou menos de seu tempo. Será mantido sigilo sobre sua identidade quanto à participação no método. A tarefa que você irá realizar não é difícil de ser realizada, porém, se em algum momento você desejar interromper o experimento, avise-nos e ele será interrompido e encerrado.

O método tem o propósito de investigar como as pessoas diferenciam o grau de preferência na escolha de suas atividades físicas e esportivas. Serão apresentadas a você 20 atividades físicas e esportivas (tanto coletivas como individuais), em ordem aleatória, dispostas em uma lista. Em uma das atividades físicas, a CORRIDA, você irá assinalar como padrão de sua preferência por esta prática o número 100. Em seguida, assinale a cada uma das outras atividades um número que reflita sua impressão subjetiva sobre a preferência pela prática da atividade correspondente. Se uma dada atividade parecer-lhe duas vezes mais preferível a você do que a atividade que está assinalada com 100, (A CORRIDA) assinale a ela o valor 200. Se outra atividade parecer-lhe metade preferível a você, comparado ao que você assinalou 100, assinale 50 e assim por diante. Não tente ser consistente, mas assinale números que reflitam sua verdadeira impressão subjetiva de preferência pela prática das atividades. Você pode usar quaisquer números, sejam eles inteiros, fracionários ou decimais, exceto zero e número negativos.

Alguma questão ? Muito obrigado pela contribuição no estudo. 


\section{APÊNDICE B \\ INFORMAÇÕES PARA O MÉTODO}

Nome:

Data:

Idade:

Sexo: $\mathrm{M}$ $\mathrm{F}$

Método: Estimação em Categorias para Preferência por Pratica de Atividades Físicas e Esportivas

Você está sendo convidado a participar de um método que ocupará 15 minutos ou menos de seu tempo. Será mantido sigilo sobre sua identidade quanto à participação no método. A tarefa que você irá realizar não é difícil de ser realizada, porém, se em algum momento você desejar interromper o experimento, avise-nos e ele será interrompido e encerrado.

Este método tem o propósito de investigar como as pessoas diferenciam o grau de preferência na escolha de suas atividades físicas e esportivas. Sua tarefa será assinalar um escore, que variará de 1 a 7, conforme a sua preferência pela prática de cada atividade física e esportiva (tanto coletivas como individuais). Por exemplo, se você achar que uma atividade física ou esportiva tem a sua maior preferência em relação às atividades físicas ou esportivas que lhe forem apresentadas você deverá assinalar a ela o escore máximo 7. Se achar que uma outra atividade física ou esportiva possui apenas uma pequena ou um mínimo de sua preferência você deverá assinalar o número 1. Você deve utilizar os outros escores intermediários, ou seja, os escores 2, 3, 4, 5 e 6, para indicar graus intermediários de sua preferência das atividades físicas e esportivas. Por favor, tente utilizar todos os escores e evidentemente se achar que algumas atividades físicas ou esportivas têm o mesmo grau de preferência ou similaridade para você assinale a elas os mesmos escores. Lembre-se que o escore 7 indica o máximo de preferência e o escore 1 o mínimo de preferência pela prática de atividade física ou esportiva. Você deverá assinalar estes escores as diferentes atividades físicas ou esportivas na ordem em que elas forem requisitadas no bloco de respostas. Você não poderá assinalar números decimais ou fracionários apenas números inteiros de 1 a 7.

Alguma questão ? Muito obrigado pela contribuição no estudo. 


\section{APÊNDICE C \\ INFORMAÇÕES PARA O MÉTODO}

Nome:

Data:

Idade:

Sexo: $\mathrm{M}$ $\mathrm{F}$

Método: Estimação de Comprimento de Linhas

Você está sendo convidado a participar de um método que ocupará 15 minutos ou menos de seu tempo. Será mantido sigilo sobre sua identidade quanto à participação no método. A tarefa que você irá realizar não é difícil de ser realizada, porém, se em algum momento você desejar interromper o experimento, avise-nos e ele será interrompido e encerrado.

Este método tem o propósito de investigar como as pessoas estimam comprimento de linhas. Sua tarefa será estimar o comprimento de diferentes linhas mostradas numa trena. Você deverá estimar os diferentes comprimentos assinalando a cada comprimento um número que seja proporcional a sua dimensão aparente. Será apresentado a você um comprimento de linhas que você deverá indicar como seu padrão o número 100. Em seguida, você deverá estimar os outros comprimentos indicados na trena dando a cada um deles um número que reflita seu comprimento aparente. Por exemplo, se você achar que um dado comprimento é duas vezes maior do que aquele primeiramente apresentado, você deverá assinalar a ele um número duas vezes maior, por exemplo 200. Se achar que um outro comprimento parece ter a metade do comprimento, você deverá assinalar a ele um número que seja a metade (50) daquele assinalado ao inicialmente apresentado. Assim, você deverá assinalar números que sejam proporcionais aos comprimentos indicados, levando sempre em consideração o valor que você assinalou ao primeiro estímulo (100).

Não tente ser consistente fazendo cálculos, mas assinale um número que represente o comprimento aparente de cada um dos comprimentos indicados na trena. Lembre-se, você poderá usar qualquer número que lhe pareça apropriado: números inteiros, fracionários ou decimais, exceto o zero e números negativos. Não tente relembrar os números que você assinalou aos comprimentos anteriores apenas lembre-se do padrão (100). Você deve assinalar números aos comprimentos na ordem em que eles forem requisitados.

Alguma questão? Muito obrigado pela contribuição no estudo. 


\section{APÊNDICE D}

\section{INFORMAÇÕES PARA O MÉTODO}

Nome:

Data:

Idade:

Sexo: $\mathrm{M}$ $\mathrm{F}$

Método: Produção de Comprimento de Linhas

Você está sendo convidado a participar de um método que ocupará 15 minutos ou menos de seu tempo. Será mantido sigilo sobre sua identidade quanto à participação no método. A tarefa que você irá realizar não é difícil de ser realizada, porém, se em algum momento você desejar interromper o experimento, avise-nos e ele será interrompido e encerrado.

Este método tem o propósito de investigar como as pessoas produzem comprimentos de linhas proporcionalmente. Sua tarefa será produzir diferentes comprimentos de linhas utilizando uma trena. Você deverá produzir diferentes comprimentos de linhas mediante a apresentação de números que seja proporcional a sua dimensão aparente. Será apresentado a você um número padrão 100 no qual você deverá produzir um comprimento de linhas na trena que lhe pareça proporcional a este número. Em seguida, você deverá produzir os outros comprimentos de linhas a partir dos outros números que lhe forem apresentados. Por exemplo, se você achar que um dado número é duas vezes maior do que aquele primeiramente apresentado (100), você deverá produzir um comprimento de linha que seja duas vezes maior do que aquele que foi produzido para indicar o valor 100 . Se achar que um outro número parece ter a metade do número apresentado como padrão 100, você deverá produzir um comprimento de linhas que seja a metade daquele produzido quando da apresentação do padrão 100. Assim, você deverá produzir comprimentos de linhas que sejam proporcionais aos números indicados, levando sempre em consideração a produção de comprimento de linhas feita no primeiro estímulo padrão (100).

Não tente ser consistente fazendo cálculos, mas produza comprimentos de linhas que represente o número que lhe for apresentado. Lembre-se, você poderá usar qualquer comprimento que lhe pareça apropriado. Não tente relembrar os comprimentos que você produziu aos comprimentos anteriores apenas lembre-se do padrão (100) e o comprimento que você produzir para indicá-lo. Você deve produzir comprimentos na ordem em que eles forem requisitados a partir da apresentação dos números.

Alguma questão? Muito obrigado pela contribuição no estudo. 


\section{APÊNDICE E \\ INFORMAÇÕES PARA O MÉTODO}

Nome:

Data:

Idade:

Sexo: $\mathrm{M}$ $\mathrm{F}$

Método: Comprimento de Linhas e Preferência pela Prática de Atividades Físicas e Esportivas

Você está sendo convidado a participar de um método que ocupará 15 minutos ou menos de seu tempo. Será mantido sigilo sobre sua identidade quanto à participação no método. A tarefa que você irá realizar não é difícil de ser realizada, porém, se em algum momento você desejar interromper o experimento, avise-nos e ele será interrompido e encerrado.

Este método tem por objetivo investigar como as pessoas avaliam a quantidade de preferência atribuída a diferentes atividades físicas e esportivas. Serão apresentadas a você 20 atividades físicas e esportivas (tanto coletivas como individuais), em ordem aleatória, dispostas em uma lista. Em uma das atividades físicas, a CORRIDA, você irá ser instruído pelo experimentador assinalar como padrão de sua preferência por esta prática o comprimento $30 \mathrm{~cm}$. Em seguida, atribua a cada uma das outras atividades um número que reflita sua impressão sobre a preferência pela prática da atividade correspondente. Se uma dada atividade parecer-lhe duas vezes mais preferível a você do que a atividade que está assinalada com 30 $\mathrm{cm}$, (A CORRIDA) assinale a ela o valor $60 \mathrm{~cm}$. Se outra atividade parecer-lhe metade preferível a você, comparado ao que você assinalou $30 \mathrm{~cm}$, assinale $15 \mathrm{~cm}$ e assim por diante. Não tente ser consistente, mas assinale aquele comprimento que reflitam sua verdadeira impressão da preferência pela prática das atividades. Você pode usar qualquer comprimento desde que a razão produzida reflita a sua preferência em relação à atividade padrão (a CORRIDA).

Não tente ser consistente fazendo cálculos, mas produza comprimentos de linhas que represente a sua preferência. Lembre-se, você poderá usar qualquer comprimento que lhe pareça apropriado comparando com o padrão $30 \mathrm{~cm}$ (a CORRIDA). Não tente relembrar os comprimentos que você produziu aos comprimentos anteriores apenas lembre-se do padrão $(30 \mathrm{~cm})$ e o comprimento que você produzir para indicá-lo. Você deve produzir comprimentos na ordem em que eles forem requisitados a partir da apresentação das atividades físicas e esportivas.

Alguma questão? Muito obrigado pela contribuição no estudo. 


\section{APÊNDICE F}

\section{INFORMAÇÕES PARA O MÉTODO}

Nome:

Idade:

Sexo: $\mathrm{M}$ $\mathrm{F}$

Data: 1

Método: Comparação aos Pares

Você está sendo convidado a participar de um método que ocupará 15 minutos ou menos de seu tempo. Será mantido sigilo sobre sua identidade quanto à participação no método. A tarefa que você irá realizar não é difícil de ser realizada, porém, se em algum momento você desejar interromper o experimento, avise-nos e ele será interrompido e encerrado.

Este método tem o propósito de investigar como as pessoas comparam o grau de preferência (escolha) de diferentes atividades físicas ou de atividades esportivas. A tarefa consistirá em comparar atividades físicas ou esportivas apresentadas aos pares e em seguida marcar com um círculo aquele que possui o maior grau de sua preferência (escolha). Em outras palavras, você deve julgar em termos de sua preferência atribuída a uma atividade física ou esportiva comparada a outra. Assim, você sempre deverá indicar qual entre as duas atividades físicas ou esportivas aquela que possui o seu maior grau de preferência. Você deve fazer isso, mesmo que você considerar que duas atividades físicas ou esportivas possam ter o mesmo grau de preferência. Você deve portanto, decidir qual das duas tem mais preferência na sua opinião.

Alguma questão? Muito obrigado pela contribuição no estudo. 


\section{APÊNDICE G}

Matriz de indicações das atividades físicas e esportivas de maior preferência derivadas das 380 comparações aos pares estabelecidas por cada um dos 40 participantes.

\begin{tabular}{|c|c|c|c|c|c|c|c|c|c|c|c|c|c|c|c|c|c|c|c|c|c|}
\hline Atividades & Corrida & Bicic. E & Remo & Hidro & Dança & Ciclismo & Basq & Hand & Judo F & Pular c. & Volei & Tênis & Caminh & N. Costas & N. Peito & N. Livre & T instru & Dardos & Fut & Ina & ATIVIDADES \\
\hline Corrida & 0 & 24 & 35 & 11 & 28 & 15 & 13 & 21 & 28 & 28 & 17 & 29 & 19 & 23 & 23 & 18 & 30 & 33 & 20 & 35 & Corrida \\
\hline Bicic. Ergom & 18 & 0 & 36 & 7 & 36 & 14 & 14 & 23 & 26 & 31 & 13 & 24 & 15 & 22 & 24 & 19 & 31 & 34 & 22 & 33 & Bicic. Ergom \\
\hline Remo & 8 & 4 & 0 & 1 & 24 & 2 & 4 & 9 & 12 & 15 & 5 & 13 & 7 & 9 & 11 & 2 & 21 & 20 & 11 & 26 & Remo \\
\hline Hidroginástica & 30 & 34 & 38 & 0 & 39 & 27 & 26 & 31 & 33 & 39 & 25 & 32 & 30 & 33 & 33 & 22 & 36 & 37 & 24 & 38 & Hidroginástica \\
\hline Dança & 16 & 3 & 18 & 1 & 0 & 6 & 10 & 11 & 13 & 9 & 7 & 11 & 2 & 10 & 10 & 5 & 17 & 13 & 13 & 28 & Dança \\
\hline Ciclismo & 24 & 28 & 39 & 15 & 34 & 0 & 18 & 24 & 28 & 32 & 16 & 30 & 20 & 22 & 24 & 17 & 30 & 37 & 21 & 35 & Ciclismo \\
\hline Basquetebol & 29 & 26 & 37 & 13 & 33 & 24 & 0 & 31 & 29 & 27 & 21 & 32 & 18 & 27 & 24 & 18 & 30 & 36 & 23 & 27 & Basquetebol \\
\hline Handebol & 20 & 17 & 30 & 11 & 29 & 16 & 8 & 0 & 23 & 24 & 11 & 23 & 17 & 18 & 21 & 14 & 30 & 32 & 22 & 32 & Handebol \\
\hline Judo & 17 & 13 & 25 & 9 & 28 & 13 & 10 & 17 & 0 & 16 & 8 & 21 & 13 & 14 & 17 & 11 & 25 & 26 & 13 & 31 & Judo \\
\hline Pular corda & 16 & 10 & 25 & 2 & 31 & 9 & 11 & 17 & 20 & 0 & 9 & 20 & 11 & 18 & 14 & 5 & 25 & 31 & 14 & 31 & Pular corda \\
\hline Voleibol & 28 & 28 & 37 & 18 & 31 & 27 & 22 & 30 & 33 & 32 & 0 & 31 & 23 & 28 & 23 & 17 & 34 & 32 & 24 & 34 & Voleibol \\
\hline Tenis & 15 & 17 & 30 & 8 & 27 & 11 & 9 & 17 & 21 & 21 & 9 & 0 & 11 & 13 & 16 & 12 & 21 & 28 & 12 & 34 & Tenis \\
\hline Caminhada & 30 & 25 & 35 & 14 & 36 & 21 & 18 & 25 & 28 & 33 & 18 & 32 & 0 & 22 & 25 & 19 & 36 & 35 & 22 & 31 & Caminhada \\
\hline Natação Costas & 19 & 23 & 33 & 14 & 31 & 20 & 20 & 23 & 29 & 29 & 14 & 28 & 17 & 0 & 18 & 3 & 29 & 34 & 18 & 31 & Natação Costas \\
\hline Natação Peito & 20 & 22 & 33 & 11 & 34 & 20 & 18 & 24 & 25 & 28 & 16 & 26 & 18 & 25 & 0 & 3 & 30 & 32 & 20 & 35 & Natação Peito \\
\hline Natação Livre & 28 & 28 & 27 & 19 & 33 & 22 & 23 & 28 & 30 & 36 & 21 & 31 & 24 & 34 & 38 & 0 & 33 & 38 & 24 & 34 & Natação Livre \\
\hline Tocar inst. & 12 & 12 & 20 & 3 & 20 & 11 & 11 & 13 & 16 & 14 & 11 & 18 & 8 & 14 & 9 & 7 & 0 & 16 & 13 & 29 & Tocar instrumento \\
\hline Dardos & 12 & 7 & 25 & 3 & 24 & 7 & 5 & 8 & 17 & 12 & 7 & 15 & 7 & 8 & 10 & 2 & 24 & 0 & 12 & 29 & Dardos \\
\hline Futebol & 23 & 22 & 32 & 15 & 28 & 22 & 19 & 25 & 27 & 24 & 18 & 33 & 18 & 23 & 22 & 21 & 28 & 31 & 0 & 33 & Futebol \\
\hline Inatividade & 8 & 4 & 15 & 1 & 13 & 9 & 8 & 13 & 9 & 11 & 6 & 10 & 2 & 7 & 6 & 5 & 11 & 10 & 11 & 0 & Inatividade \\
\hline
\end{tabular}




\section{APÊNDICE H}

Matriz de indicações das atividades físicas e esportivas de maior preferência derivadas das 380 comparações aos pares estabelecidas por cada um dos 20 participantes do sexo masculino.

\begin{tabular}{|c|c|c|c|c|c|c|c|c|c|c|c|c|c|c|c|c|c|c|c|c|c|}
\hline Atividades & Corrida & sicic. E & Remo & Hidro & Dança & Ciclismo & Basq & Hand & Judo & Pular c. & Volei & Tenis & Caminh & N. Costas & N. Peito & N. Livre 7 & $T$ instru| & Dardos & Fut & Ina & ATIVIDADES \\
\hline Corrida & 0 & 15 & 18 & 6 & 15 & 7 & 6 & 12 & 15 & 16 & 11 & 14 & 13 & 12 & 12 & 8 & 17 & 18 & 7 & 19 & Corrida \\
\hline Bicic. Ergom & 7 & 0 & 16 & 5 & 18 & 4 & 5 & 12 & 12 & 16 & 7 & 10 & 9 & 8 & 10 & 7 & 14 & 17 & 5 & 18 & Bicic. Ergom \\
\hline Remo & 4 & 4 & 0 & 0 & 18 & 1 & 3 & 5 & 6 & 8 & 3 & 7 & 6 & 4 & 5 & 0 & 10 & 11 & 3 & 15 & Remo \\
\hline Hidroginástica & 14 & 17 & 19 & 0 & 19 & 12 & 13 & 16 & 16 & 19 & 13 & 15 & 18 & 17 & 16 & 8 & 18 & 18 & 8 & 19 & Hidroginástica \\
\hline Dança & 5 & 2 & 7 & 1 & 0 & 1 & 3 & 5 & 5 & 3 & 4 & 2 & 2 & 4 & 6 & 1 & 6 & 4 & 3 & 13 & Dança \\
\hline Ciclismo & 12 & 18 & 20 & 8 & 18 & 0 & 8 & 14 & 13 & 18 & 12 & 15 & 14 & 12 & 13 & 8 & 15 & 20 & 7 & 20 & Ciclismo \\
\hline Basquetebol & 16 & 17 & 20 & 8 & 18 & 13 & 0 & 15 & 14 & 16 & 15 & 16 & 12 & 14 & 14 & 10 & 16 & 20 & 7 & 13 & Basquetebol \\
\hline Handebol & 9 & 12 & 15 & 7 & 16 & 6 & 4 & 0 & 12 & 15 & 7 & 11 & 11 & 9 & 10 & 5 & 15 & 17 & 7 & 18 & Handebol \\
\hline Judo & 10 & 9 & 15 & 6 & 16 & 7 & 7 & 10 & 0 & 11 & 5 & 10 & 10 & 7 & 8 & 5 & 14 & 14 & 4 & 18 & Judo \\
\hline Pular corda & 6 & 8 & 11 & 1 & 17 & 3 & 3 & 7 & 8 & 0 & 5 & 8 & 6 & 10 & 6 & 1 & 10 & 15 & 3 & 16 & Pular corda \\
\hline Voleibol & 13 & 15 & 18 & 9 & 15 & 11 & 7 & 13 & 16 & 16 & 0 & 13 & 13 & 13 & 11 & 6 & 16 & 18 & 6 & 17 & Voleibol \\
\hline Tenis & 6 & 11 & 17 & 5 & 16 & 5 & 5 & 10 & 10 & 14 & 5 & 0 & 9 & 9 & 7 & 5 & 10 & 15 & 2 & 19 & Tenis \\
\hline Caminhada & 12 & 12 & 17 & 6 & 18 & 7 & 6 & 11 & 10 & 17 & 8 & 14 & 0 & 10 & 11 & 5 & 17 & 18 & 6 & 15 & Caminhada \\
\hline Natação Costas & 10 & 14 & 18 & 9 & 17 & 11 & 8 & 12 & 14 & 13 & 10 & 15 & 10 & 0 & 8 & 2 & 15 & 18 & 5 & 17 & Natacão Costas \\
\hline Natação Peito & 11 & 14 & 17 & 8 & 18 & 11 & 8 & 14 & 14 & 13 & 10 & 12 & 12 & 12 & 0 & 1 & 16 & 18 & 6 & 18 & Natacão Peito \\
\hline Natação Livre & 17 & 19 & 13 & 12 & 18 & 13 & 12 & 16 & 18 & 19 & 14 & 17 & 18 & 19 & 20 & 0 & 17 & 20 & 9 & 17 & Natacão Livre \\
\hline Tocar inst. & 6 & 9 & 11 & 2 & 12 & 5 & 6 & 7 & 7 & 11 & 8 & 9 & 6 & 7 & 5 & 4 & 0 & 10 & 5 & 15 & Tocar instrumento \\
\hline Dardos & 3 & 4 & 12 & 1 & 12 & 0 & 1 & 3 & 7 & 6 & 3 & 6 & 4 & 4 & 3 & 0 & 11 & 0 & 3 & 16 & Dardos \\
\hline Futebol & 14 & 17 & 18 & 11 & 16 & 13 & 14 & 17 & 18 & 16 & 17 & 19 & 15 & 15 & 14 & 16 & 15 & 19 & 0 & 19 & Futebol \\
\hline Inatividade & 2 & 1 & 5 & 0 & 6 & 2 & 2 & 4 & 2 & 5 & 1 & 2 & 0 & 2 & 2 & 1 & 5 & 4 & 2 & 0 & Inatividade \\
\hline
\end{tabular}




\section{APÊNDICE I}

Matriz de indicações das atividades físicas e esportivas de maior preferência derivadas das 380 comparações aos pares estabelecidas por cada um dos 20 participantes do sexo feminino.

\begin{tabular}{|c|c|c|c|c|c|c|c|c|c|c|c|c|c|c|c|c|c|c|c|c|c|}
\hline Atividades & Corrida & Bicic. E & Remo & Hidro & Dança & Ciclismo & Basq & Hand & Judo F & Pular c. & Volei & Tenis & Caminh & N. Costas & N. Peito & N. Livre & T instru| & Dardos & Fut & Ina & ATIVIDADES \\
\hline Corrida & 0 & 9 & 17 & 5 & 13 & 8 & 7 & 9 & 13 & 12 & 6 & 15 & 6 & 11 & 11 & 10 & 13 & 15 & 13 & 16 & Corrida \\
\hline Bicic. Ergom & 11 & 0 & 20 & 2 & 18 & 10 & 9 & 11 & 14 & 15 & 6 & 14 & 6 & 14 & 14 & 12 & 17 & 17 & 17 & 15 & Bicic. Ergom \\
\hline Remo & 4 & 0 & 0 & 1 & 6 & 1 & 1 & 4 & 6 & 7 & 2 & 6 & 1 & 5 & 6 & 2 & 11 & 9 & 8 & 11 & Remo \\
\hline Hidroginástica & 16 & 17 & 19 & 0 & 20 & 15 & 13 & 15 & 17 & 20 & 12 & 17 & 12 & 16 & 17 & 14 & 18 & 19 & 16 & 19 & Hidroginástica \\
\hline Dança & 11 & 1 & 11 & 0 & 0 & 5 & 7 & 6 & 8 & 6 & 3 & 9 & 0 & 6 & 4 & 4 & 11 & 9 & 10 & 15 & Dança \\
\hline Ciclismo & 12 & 10 & 19 & 7 & 16 & 0 & 10 & 10 & 15 & 14 & 4 & 15 & 6 & 10 & 11 & 9 & 15 & 17 & 14 & 15 & Ciclismo \\
\hline Basquetebol & 13 & 9 & 17 & 5 & 15 & 11 & 0 & 16 & 15 & 11 & 6 & 16 & 6 & 13 & 10 & 8 & 14 & 16 & 16 & 14 & Basquetebol \\
\hline Handebol & 11 & 5 & 15 & 4 & 13 & 10 & 4 & 0 & 11 & 9 & 4 & 12 & 6 & 9 & 11 & 9 & 15 & 15 & 15 & 14 & Handebol \\
\hline Judo & 7 & 4 & 10 & 3 & 12 & 6 & 3 & 7 & 0 & 5 & 3 & 11 & 3 & 7 & 9 & 6 & 11 & 12 & 9 & \begin{tabular}{|l|}
13 \\
\end{tabular} & Judo \\
\hline Pular corda & 10 & 2 & 14 & 1 & 14 & 6 & 8 & 10 & 12 & 0 & 4 & 12 & 5 & 8 & 8 & 4 & 15 & 16 & 11 & 15 & Pular corda \\
\hline Voleibol & 15 & 13 & 19 & 9 & 16 & 16 & 15 & 17 & 17 & 16 & 0 & 18 & 10 & 15 & 12 & 11 & 18 & 14 & 18 & 17 & Voleibol \\
\hline Tenis & 9 & 6 & 13 & 3 & 11 & 6 & 4 & 7 & 11 & 7 & 4 & 0 & 2 & 4 & 9 & 7 & 11 & 13 & 10 & 15 & Tenis \\
\hline Caminhada & 18 & 13 & 18 & 8 & 18 & 14 & 12 & 14 & 18 & 16 & 10 & 18 & 0 & 12 & 14 & 14 & 19 & 17 & 16 & 16 & Caminhada \\
\hline Natação Costas & 9 & 9 & 15 & 5 & 14 & 9 & 12 & 11 & 15 & 16 & 4 & 13 & 7 & 0 & 10 & 1 & 14 & 16 & 13 & 14 & Natação Costas \\
\hline Natação Peito & 9 & 8 & 16 & 3 & 16 & 9 & 10 & 10 & 11 & 15 & 6 & 14 & 6 & 13 & 0 & 2 & 14 & 14 & 14 & 17 & Natação Peito \\
\hline Natação Livre & 11 & 9 & 14 & 7 & 15 & 9 & 11 & 12 & 12 & 17 & 7 & 14 & 6 & 15 & 18 & 0 & 16 & 18 & 15 & 17 & Natação Livre \\
\hline Tocar inst. & 6 & 3 & 9 & 1 & 8 & 6 & 5 & 6 & 9 & 3 & 3 & 9 & 2 & 7 & 4 & 3 & 0 & 6 & 8 & 14 & Tocar instrumento \\
\hline Dardos & 9 & 3 & 13 & 2 & 12 & 7 & 4 & 5 & 10 & 6 & 4 & 9 & 3 & 4 & 7 & 2 & 13 & 0 & 9 & 13 & Dardos \\
\hline Futebol & 9 & 5 & 14 & 4 & 12 & 9 & 5 & 8 & 9 & 8 & 1 & 14 & 3 & 8 & 8 & 5 & 13 & 12 & 0 & \begin{tabular}{|l|}
14 \\
\end{tabular} & Futebol \\
\hline Inatividade & 6 & 3 & 10 & 1 & 7 & 7 & 6 & 9 & 7 & 6 & 5 & 8 & 2 & 5 & 4 & 4 & 6 & 6 & 9 & 0 & Inatividade \\
\hline
\end{tabular}




\section{APÊNDICE J}

Proporções médias das atividades físicas e esportivas de maior preferência derivadas da matriz (Apêndice G) contendo as 380 comparações aos pares estabelecidas por cada um dos 40 participantes

\begin{tabular}{|c|c|c|c|c|c|c|c|c|c|c|c|c|c|c|c|c|c|c|c|c|c|}
\hline Atividades & Corrida & Bicic. E & Remo & Hidro & Dança & Ciclismo & asq & Hand & Judo & Pular c. & Volei & ênis & Caminh & Costas & N. Peito & N. Livre & instrt & Dardos & Fut & Ina & ATIVIDADES \\
\hline Corrida & 0,50 & 0,45 & 0,20 & 0,75 & 0,40 & 0,60 & 0,73 & 0,50 & 0,43 & 0,40 & 0,70 & 0,38 & 0,75 & 0,48 & 0,50 & 0,70 & 0,30 & 0,30 & 0,58 & 0,20 & Corrida \\
\hline Bicic. Ergom & 0,60 & 0,50 & 0,10 & 0,85 & 0,08 & 0,70 & 0,65 & 0,43 & 0,33 & 0,25 & 0,70 & 0,43 & 0,63 & 0,58 & 0,55 & 0,70 & 0,30 & 0,18 & 0,55 & 0,10 & Bicic. Ergom \\
\hline Remo & 0,88 & 0,90 & 0,50 & 0,95 & 0,45 & 0,98 & 0,93 & 0,75 & 0,63 & 0,63 & 0,93 & 0,75 & 0,88 & 0,83 & 0,83 & 0,68 & 0,50 & 0,63 & 0,80 & 0,38 & Remo \\
\hline Dança & 0,70 & 0,90 & 0,60 & 0,98 & 0,50 & 0,85 & 0,83 & 0,73 & 0,70 & 0,78 & 0,78 & 0,68 & 0,90 & 0,78 & 0,85 & 0,83 & 0,50 & 0,60 & 0,70 & 0,33 & Dan \\
\hline Ciclismo & 0,38 & 0,35 & 0,05 & 0,68 & 0,15 & 0,50 & 0,60 & 0,40 & 0,33 & 0,23 & 0,68 & 0,28 & 0,53 & 0,50 & 0,50 & 0,55 & 0,28 & 0,18 & 0,55 & 0,23 & Ciclismo \\
\hline Basquetebol & 0,33 & 0,35 & 0,10 & 0,65 & 0,25 & 0,45 & 0,50 & 0,20 & 0,25 & 0,28 & 0,55 & 0,23 & 0,45 & 0,50 & 0,45 & 0,58 & 0,28 & 0,13 & 0,48 & 0,20 & etebol \\
\hline Judo & 0,70 & 0,65 & 0,30 & 0,83 & 0,33 & 0,70 & 0,73 & \begin{tabular}{|l|}
0,58 \\
\end{tabular} & 0,50 & 0,50 & 0,83 & 0,53 & 0,70 & 0,73 & 0,63 & 0,75 & 0,40 & 0,43 & 0,68 & 0,23 & Judo \\
\hline Pula & 0,70 & 0,78 & 0,38 & 0,98 & 0,23 & 0,80 & 0,68 & 0,60 & 0,40 & 0,50 & 0,80 & 0,53 & 0,83 & 0,73 & 0,70 & 0,90 & 0,35 & 0,30 & 0,60 & 0,28 & Pu \\
\hline Voleil & 0,43 & 0,33 & 0,13 & 0,63 & 0,18 & 0,40 & 0,53 & 0,28 & 0,20 & 0,23 & 0,50 & 0,23 & 0,45 & 0,35 & 0,40 & 0,53 & 0,28 & 0,18 & 0,45 & 0,15 & ol \\
\hline Tenis & 0,73 & 0,60 & 0,33 & 0,80 & 0,28 & 0,75 & 0,80 & 0,58 & 0,53 & 0,50 & 0,78 & 0,50 & 0,80 & 0,70 & 0,65 & 0,78 & 0,45 & 0,38 & 0,83 & 0,25 & Tenis \\
\hline Caminhada & 0,48 & 0,38 & 0,18 & 0,75 & 0,05 & 0,50 & 0,45 & 0,43 & 0,33 & 0,28 & 0,58 & 0,28 & 0,50 & 0,43 & 0,45 & 0,60 & 0,20 & 0,18 & 0,45 & 0,05 & Camin \\
\hline Nata & 0,58 & 0,55 & 0,23 & 0,83 & 0,25 & 0,55 & 0,68 & 0,45 & 0,35 & 0,45 & 0,70 & 0,33 & 0,55 & 0,50 & 0,63 & 0,85 & 0,35 & 0,20 & 0,58 & 0,18 & \\
\hline Natação Peito & 0,58 & 0,60 & 0,28 & 0,83 & 0,25 & 0,60 & 0,60 & 0,53 & 0,43 & 0,35 & 0,58 & 0,40 & 0,63 & 0,45 & 0,50 & 0,95 & 0,23 & 0,25 & 0,55 & 0,15 & Peito \\
\hline Natação Livre & 0,45 & 0,48 & 0,05 & 0,55 & 0,13 & 0,43 & 0,43 & 0,35 & 0,28 & 0,13 & 0,43 & 0,30 & 0,48 & 0,08 & 0,08 & 0,50 & 0,18 & 0,05 & 0,53 & 0,13 & Natação Livre \\
\hline Dard & 0,83 & 0,85 & 0,50 & 0,93 & 0,33 & 0,93 & 0,90 & 0,80 & 0,65 & 0,78 & 0,80 & 0,70 & 0,88 & 0,85 & 0,80 & 0,95 & 0,40 & 0,50 & 0,78 & 0,25 & \\
\hline Futebol & 0,50 & 0,55 & 0,28 & 0,60 & 0,33 & 0,53 & 0,58 & 0,55 & 0,33 & 0,35 & 0,60 & 0,30 & 0,55 & 0,45 & 0,50 & 0,60 & 0,33 & 0,30 & 0,50 & 0,28 & \\
\hline Inatividade & 0,88 & 0,83 & 0,65 & 0,95 & 0,70 & 0,88 & 0,68 & 0,80 & 0,78 & 0,78 & 0,85 & 0,85 & 0,78 & 0,78 & 0,88 & 0,85 & 0,73 & 0,73 & 0,83 & 0,50 & Inatividade \\
\hline TOTAL & 11,75 & 11,55 & 5,60 & 15,68 & 5,58 & 12,85 & 13,08 & 10,45 & 8,68 & 8,48 & 13,80 & 8,80 & 13,13 & 11,33 & 11,50 & 14,28 & 6,93 & 6,35 & 12,10 & 4,48 & \\
\hline MÉDIA & 0, & 0,58 & 0,28 & 0,78 & 0,28 & 0,64 & 0,65 & 0,52 & 0,43 & 0,42 & 0,69 & 0,44 & 0,66 & 0,57 & 0,58 & 0,71 & 0,35 & 0,32 & 0,61 & 0,22 & \\
\hline ORDENAC & 8 & 9 & 18 & 1 & 19 & 6 & 5 & 12 & 14 & 15 & 3 & 13 & 4 & 11 & 10 & 2 & 16 & 17 & 7 & 20 & ORDEN \\
\hline
\end{tabular}




\section{APÊNDICE K}

Proporções médias das atividades físicas e esportivas de maior preferência derivadas da matriz (Apêndice H) contendo as 380 comparações aos pares estabelecidas por cada um dos 20 participantes do sexo masculino.

\begin{tabular}{|c|c|c|c|c|c|c|c|c|c|c|c|c|c|c|c|c|c|c|c|c|c|}
\hline Atividades & Corrida & Bicic. E & Remo & Hidro & Dança & Ciclismo & Basq & Hand & Judo & Pular c. & Volei & Tênis & Caminh & N. Costas & N. Peito & N. Livre & $T$ instru & Dardos & Fut & Ina & ATIVIDADES \\
\hline Corrida & 0,5 & 0,35 & 0,2 & 0,7 & 0,25 & 0,6 & 0,8 & 0,45 & 0,5 & 0,3 & 0,65 & 0,3 & 0,6 & 0,5 & 0,55 & 0,85 & 0,3 & 0,15 & 0,7 & 0,1 & Corrida \\
\hline Bicic. Ergom & 0,75 & 0,5 & 0,2 & 0,85 & 0,1 & 0,9 & 0,85 & 0,6 & 0,45 & 0,4 & 0,75 & 0,55 & 0,6 & 0,7 & 0,7 & 0,95 & 0,45 & 0,2 & 0,85 & 0,05 & Bicic. Ergom \\
\hline Remo & 0,9 & 0,8 & 0,5 & 0,95 & 0,35 & 1 & 1 & 0,75 & 0,75 & 0,55 & 0,9 & 0,85 & 0,85 & 0,9 & 0,85 & 0,65 & 0,55 & 0,6 & 0,9 & 0,25 & Remo \\
\hline Dança & 0,75 & 0,9 & 0,9 & 0,95 & 0,5 & 0,9 & 0,9 & 0,8 & 0,8 & 0,85 & 0,75 & 0,8 & 0,9 & 0,85 & 0,9 & 0,9 & 0,6 & 0,6 & 0,8 & 0,3 & Dança \\
\hline Ciclismo & 0,35 & 0,2 & 0,05 & 0,6 & 0,05 & 0,5 & 0,65 & 0,3 & 0,35 & 0,15 & 0,55 & 0,25 & 0,35 & 0,55 & 0,55 & 0,65 & 0,25 & 0 & 0,65 & 0,1 & Ciclismo \\
\hline Basquetebol & 0,3 & 0,25 & 0,15 & 0,65 & 0,15 & 0,4 & 0,5 & 0,2 & 0,35 & 0,15 & 0,35 & 0,25 & 0,3 & 0,4 & 0,4 & 0,6 & 0,3 & 0,05 & 0,7 & \begin{tabular}{|l|}
0,1 \\
\end{tabular} & Basquetebol \\
\hline Judo & 0,75 & 0,6 & 0,3 & 0,8 & 0,25 & 0,65 & 0,7 & 0,6 & 0,5 & 0,4 & 0,8 & 0,5 & 0,5 & 0,7 & 0,7 & 0,9 & 0,35 & 0,35 & 0,9 & 0,1 & Judo \\
\hline Pular cord & 0,8 & 0,8 & 0,4 & 0,95 & 0,15 & 0,9 & 0,8 & 0,75 & 0,55 & 0,5 & 0,8 & 0,7 & 0,85 & 0,65 & 0,65 & 0,95 & 0,55 & 0,3 & 0,8 & 0,25 & $\mathrm{Pu}$ \\
\hline Voleibol & 0,55 & 0,35 & 0,15 & 0,65 & 0,2 & 0,6 & 0,75 & 0,35 & 0,25 & 0,25 & 0,5 & 0,25 & 0,4 & 0,5 & 0,5 & 0,7 & 0,4 & 0,15 & 0,85 & 0,05 & Voleibol \\
\hline Tenis & 0,7 & 0,5 & 0,35 & 0,75 & 0,1 & 0,75 & 0,8 & 0,55 & 0,5 & 0,4 & 0,65 & 0,5 & 0,7 & 0,75 & 0,6 & 0,85 & 0,45 & 0,3 & 0,95 & 0,1 & Tenis \\
\hline Caminhada & 0,65 & 0,45 & 0,3 & 0,9 & 0,1 & 0,7 & 0,6 & 0,55 & 0,5 & 0,3 & 0,65 & 0,45 & 0,5 & 0,5 & 0,6 & 0,9 & 0,3 & 0,2 & 0,75 & 0 & Caminhada \\
\hline Natação Costas & 0,6 & 0,4 & 0,2 & 0,85 & 0,2 & 0,6 & 0,7 & 0,45 & 0,35 & 0,5 & 0,65 & 0,45 & 0,5 & 0,5 & 0,6 & 0,95 & 0,35 & 0,2 & 0,75 & 0,1 & tas \\
\hline Natação Peito & 0,6 & 0,5 & 0,25 & 0,8 & 0,3 & 0,65 & 0,7 & 0,5 & 0,4 & 0,3 & 0,55 & 0,35 & 0,55 & 0,4 & 0,5 & 1 & 0,25 & 0,15 & 0,7 & 0,1 & Natação Peito \\
\hline Natação Livre & 0,4 & 0,35 & 0 & 0,4 & 0,05 & 0,4 & 0,5 & 0,25 & 0,25 & 0,05 & 0,3 & 0,25 & 0,25 & 0,1 & 0,05 & 0,5 & 0,2 & 0 & 0,8 & 0,05 & Natação Livre \\
\hline Dard & 0,9 & 0,85 & 0,55 & 0,9 & 0,2 & 1 & 1 & 0,85 & 0,7 & 0,75 & 0,9 & 0,75 & 0,9 & 0,9 & 0,9 & 1 & 0,5 & 0,5 & 0,95 & 0,2 & Dardos \\
\hline Futebol & 0,35 & 0,25 & 0,15 & 0,4 & 0,15 & 0,35 & 0,35 & 0,35 & 0,2 & 0,15 & 0,3 & 0,1 & 0,3 & 0,25 & 0,3 & 0,45 & 0,25 & 0,15 & 0,5 & 0,1 & bol \\
\hline Inatividade & 0,95 & 0,9 & 0,75 & 0,95 & 0,65 & 1 & 0,65 & 0,9 & \begin{tabular}{|l|}
0,9 \\
\end{tabular} & 0,8 & 0,85 & 0,95 & 0,75 & 0,85 & 0,9 & 0,85 & 0,75 & 0,8 & 0,95 & 0,5 & Inatividade \\
\hline TOTAL & 12,55 & 10,5 & 6,15 & 15,25 & 4,35 & 13,75 & 14,2 & 10,8 & 9,8 & 7,7 & 12,8 & 9,5 & 11,5 & 11,8 & 12,15 & 15,9 & 7,75 & 5,45 & 15,65 & 2,9 & TOTAL \\
\hline MÉDIA & 0,6275 & 0,525 & 0,3075 & 0,7625 & 0,2175 & 0,6875 & 0,71 & 0,54 & 0,49 & 0,385 & 0,64 & 0,475 & 0,575 & 0,59 & 0,6075 & 0,795 & 0,3875 & 0,2725 & 0,7825 & 0,145 & 5 MÉDIA \\
\hline ORDENAC & 7 & 12 & 17 & 3 & 19 & 5 & 4 & 11 & 13 & 16 & 6 & 14 & 10 & 9 & 8 & 1 & 15 & 18 & 2 & 20 & ORDEN \\
\hline
\end{tabular}




\section{APÊNDICE L}

Proporções médias das atividades físicas e esportivas de maior preferência derivadas da matriz (Apêndice I) contendo as 380 comparações aos pares estabelecidas por cada um dos 20 participantes do sexo feminino.

\begin{tabular}{|c|c|c|c|c|c|c|c|c|c|c|c|c|c|c|c|c|c|c|c|c|c|}
\hline Atividades & Corrida & Bicic. E & Remo & Hidro & Dança & Ciclismo & Basq & Hand & Judo & Pular c. & Volei & Tênis & Caminh & N. Costas & N. Peito & N. Livre & $T$ instru & Dardos & Fut & Ina & ATIVIDADES \\
\hline Corrida & 0,5 & 0,55 & 0,2 & 0,8 & 0,55 & 0,6 & 0,65 & 0,55 & 0,35 & 0,5 & 0,75 & 0,45 & 0,9 & 0,45 & 0,45 & 0,55 & 0,3 & 0,45 & 0,45 & 0,3 & Corrida \\
\hline Bicic. Ergom & 0,45 & 0,5 & 0 & 0,85 & 0,05 & 0,5 & 0,45 & 0,25 & 0,2 & 0,1 & 0,65 & 0,3 & 0,65 & 0,45 & 0,4 & 0,45 & 0,15 & 0,15 & 0,25 & 0,15 & Bicic. Ergom \\
\hline Remo & 0,85 & 1 & 0,5 & 0,95 & 0,55 & 0,95 & 0,85 & 0,75 & 0,5 & 0,7 & 0,95 & 0,65 & 0,9 & 0,75 & 0,8 & 0,7 & 0,45 & 0,65 & 0,7 & 0,5 & Remo \\
\hline Hidroginástica & 0,25 & 0,1 & 0,05 & 0,5 & 0 & 0,35 & 0,25 & 0,2 & 0,15 & 0,05 & 0,45 & 0,15 & 0,4 & 0,25 & 0,15 & 0,35 & 0,05 & 0,1 & 0,2 & 0,05 & Hidroginástica \\
\hline Dança & 0,65 & 0,9 & 0,3 & 1 & 0,5 & 0,8 & 0,75 & 0,65 & 0,6 & 0,7 & 0,8 & 0,55 & 0,9 & 0,7 & 0,8 & 0,75 & 0,4 & 0,6 & 0,6 & 0,35 & Dança \\
\hline Ciclismo & 0,4 & 0,5 & 0,05 & 0,75 & 0,25 & 0,5 & 0,55 & 0,5 & 0,3 & 0,3 & 0,8 & 0,3 & 0,7 & 0,45 & 0,45 & 0,45 & 0,3 & 0,35 & 0,45 & 0,35 & Ciclismo \\
\hline Basquetebol & 0,35 & 0,45 & 0,05 & 0,65 & 0,35 & 0,5 & 0,5 & 0,2 & 0,15 & 0,4 & 0,75 & 0,2 & 0,6 & 0,6 & 0,5 & 0,55 & 0,25 & 0,2 & 0,25 & 0,3 & Basquetebol \\
\hline Handebol & 0,45 & 0,55 & 0,2 & 0,75 & 0,3 & 0,5 & 0,8 & 0,5 & 0,35 & 0,5 & 0,85 & 0,35 & 0,7 & 0,55 & 0,5 & 0,6 & 0,3 & 0,25 & 0,4 & 0,45 & Handebol \\
\hline Judo & 0,65 & 0,7 & 0,3 & 0,85 & 0,4 & 0,75 & 0,75 & 0,55 & 0,5 & 0,6 & 0,85 & 0,55 & 0,9 & 0,75 & 0,55 & 0,6 & 0,45 & 0,5 & 0,45 & 0,35 & Judo \\
\hline Pular corda & 0,6 & 0,75 & 0,35 & 1 & 0,3 & 0,7 & 0,55 & 0,45 & 0,25 & 0,5 & 0,8 & 0,35 & 0,8 & 0,8 & 0,75 & 0,85 & 0,15 & 0,3 & 0,4 & 0,3 & Pular corda \\
\hline Voleibol & 0,3 & 0,3 & 0,1 & 0,6 & 0,15 & 0,2 & 0,3 & 0,2 & 0,15 & 0,2 & 0,5 & 0,2 & 0,5 & 0,2 & 0,3 & 0,35 & 0,15 & 0,2 & 0,05 & 0,25 & Voleibol \\
\hline Tenis & 0,75 & 0,7 & 0,3 & 0,85 & 0,45 & 0,75 & 0,8 & 0,6 & 0,55 & 0,6 & 0,9 & 0,5 & 0,9 & 0,65 & 0,7 & 0,7 & 0,45 & 0,45 & 0,7 & 0,4 & Tenis \\
\hline Caminhada & 0,3 & 0,3 & 0,05 & 0,6 & 0 & 0,3 & 0,3 & 0,3 & 0,15 & 0,25 & 0,5 & 0,1 & 0,5 & 0,35 & 0,3 & 0,3 & 0,1 & 0,15 & 0,15 & 0,1 & Caminhada \\
\hline Natação Costas & 0,55 & 0,7 & 0,25 & 0,8 & 0,3 & 0,5 & 0,65 & 0,45 & 0,35 & 0,4 & 0,75 & 0,2 & 0,6 & 0,5 & 0,65 & 0,75 & 0,35 & 0,2 & 0,4 & 0,25 & Natação Costas \\
\hline Natação Peito & 0,55 & 0,7 & 0,3 & 0,85 & 0,2 & 0,55 & 0,5 & 0,55 & 0,45 & 0,4 & 0,6 & 0,45 & 0,7 & 0,5 & 0,5 & 0,9 & 0,2 & 0,35 & 0,4 & 0,2 & Natação Peito \\
\hline Natação Livre & 0,5 & 0,6 & 0,1 & 0,7 & 0,2 & 0,45 & 0,4 & 0,45 & 0,3 & 0,2 & 0,55 & 0,35 & 0,7 & 0,05 & 0,1 & 0,5 & 0,15 & 0,1 & 0,25 & 0,2 & Natação Livre \\
\hline Tocar inst. & 0,65 & 0,85 & 0,55 & 0,9 & 0,55 & 0,75 & 0,7 & 0,75 & 0,55 & 0,75 & 0,9 & 0,55 & 0,95 & 0,7 & 0,7 & 0,8 & 0,5 & 0,65 & 0,65 & 0,3 & Tocar instrumento \\
\hline Dardos & 0,75 & 0,85 & 0,45 & 0,95 & 0,45 & 0,85 & 0,8 & 0,75 & 0,6 & 0,8 & 0,7 & 0,65 & 0,85 & 0,8 & 0,7 & 0,9 & 0,3 & 0,5 & 0,6 & 0,3 & Dardos \\
\hline Futebol & 0,65 & 0,85 & 0,4 & 0,8 & 0,5 & 0,7 & 0,8 & 0,75 & 0,45 & 0,55 & 0,9 & 0,5 & 0,8 & 0,65 & 0,7 & 0,75 & 0,4 & 0,45 & 0,5 & 0,45 & Futebol \\
\hline \begin{tabular}{|l} 
Inatividade \\
\end{tabular} & 0,8 & 0,75 & 0,55 & 0,95 & 0,75 & 0,75 & 0,7 & 0,7 & 0,65 & 0,75 & 0,85 & 0,75 & 0,8 & 0,7 & 0,85 & 0,85 & 0,7 & 0,65 & 0,7 & 0,5 & Inatividade \\
\hline TOTAL & 10,95 & 12,6 & 5,05 & 16,1 & 6,8 & 11,95 & 12,05 & 10,1 & 7,55 & 9,25 & 14,8 & 8,1 & 14,75 & 10,85 & 10,85 & 12,65 & 6,1 & 7,25 & 8,55 & 6,05 & TOTAL \\
\hline MÉDIA & 0,5475 & 0,63 & 0,2525 & 0,805 & 0,34 & 0,5975 & 0,6025 & 0,505 & 0,37 & 0,4625 & 0,74 & 0,405 & 0,7375 & 0,5425 & 0,5425 & 0,6325 & 0,305 & 0,3625 & 0,4275 & 0,302 & MÉDIA \\
\hline ORDENAÇÃo & 8 & 5 & 20 & 1 & 17 & 7 & 6 & 11 & 15 & 12 & 2 & 14 & 3 & 10 & 9 & 4 & 18 & 16 & 13 & 19 & ORDENAÇÃO \\
\hline
\end{tabular}




\section{APÊNDICE M}

Escores Z médios derivados da matriz (Apêndice J) contendo as proporções médias das atividades físicas e esportivas contendo as 380 comparações aos pares estabelecidas por cada um dos 40 participantes.

\begin{tabular}{|c|c|c|c|c|c|c|c|c|c|c|c|c|c|c|c|c|c|c|c|c|c|}
\hline Atividades & Corrida & Bicic. E & Remo & Hidro & Dança & Ciclismo & Basq & Hand & Judo & Pular c. & Volei & Tenis & Caminh & N. Costas & N. Peito & N. Livre & T instru & Dardos & Fut & Ina & ATIVIDADES \\
\hline Corrida & 0 & $-0,12$ & $-0,84$ & 0,67 & \begin{tabular}{|l|}
$-0,25$ \\
\end{tabular} & 0,25 & 0,61 & 0 & $-0,17$ & $-0,25$ & 0,52 & $-0,3$ & 0,67 & $-0,05$ & 0 & 0,52 & $-0,52$ & $-0,52$ & 0,2 & $-0,84$ & Corrida \\
\hline Bicic. Ergom & 0,25 & 0 & $-1,28$ & 1,03 & $-1,4$ & 0,52 & 0,38 & $-0,17$ & $-0,43$ & $-0,67$ & 0,52 & $-0,17$ & 0,33 & 0,2 & 0,12 & 0,52 & $-0,52$ & $-0,91$ & 0,12 & $-1,28$ & Bicic. Ergom \\
\hline Remo & 1,17 & 1,28 & 0 & 1,64 & $-0,12$ & 1,98 & 1,47 & 0,67 & 0,33 & 0,33 & 1,47 & 0,67 & 1,17 & 0,95 & 0,95 & 0,46 & 0 & 0,33 & 0,84 & $-0,3$ & Remo \\
\hline idroginástica & $-0,58$ & $-0,91$ & $-1,88$ & 0 & $-1,88$ & $-0,3$ & $-0,52$ & $-0,58$ & $-0,73$ & $-1,64$ & $-0,12$ & $-0,84$ & $-0,38$ & $-0,38$ & $-0,58$ & $-0,05$ & $-1,4$ & $-1,4$ & $-0,3$ & 1,88 & oqinástica \\
\hline Dança & 0,52 & 1,28 & 0,25 & 1,98 & 0 & 1,03 & 0,95 & 0,61 & 0,52 & 0,77 & 0,77 & 0,46 & 1,28 & 0,77 & 1,03 & 0,95 & 0 & 0,25 & 0,52 & $-0,43$ & Dança \\
\hline Ciclismo & $-0,3$ & $-0,38$ & $-1,64$ & 0,46 & $-1,03$ & 0 & 0,25 & $-0,25$ & $-0,43$ & $-0,73$ & 0,46 & $-0,58$ & 0,07 & 0 & 0 & 0,12 & $-0,58$ & $-0,91$ & 0,12 & $-0,73$ & Ciclismo \\
\hline Basquetebol & $-0,43$ & $-0,38$ & $-1,28$ & 0,38 & $-0,67$ & $-0,12$ & 0 & $\begin{array}{l}-0,84 \\
\end{array}$ & $-0,67$ & $-0,58$ & 0,12 & $-0,73$ & $-0,12$ & 0 & $-0,12$ & 0,2 & \begin{tabular}{|c|}
$-0,58$ \\
\end{tabular} & $-1,12$ & $-0,05$ & $-0,84$ & Basquetebol \\
\hline Handebol & 0,07 & 0,2 & $-0,73$ & 0,77 & $-0,58$ & 0,25 & 0,77 & 0 & $-0,17$ & $-0,17$ & 0,67 & $-0,17$ & 0,33 & 0,2 & 0,25 & 0,52 & \begin{tabular}{|c|c|}
$-0,43$ \\
\end{tabular} & $-0,84$ & 0,33 & $-0,43$ & Handebol \\
\hline Judo & 0,52 & 0,38 & $-0,52$ & 0,95 & $-0,43$ & 0,52 & 0,61 & 0,2 & 0 & 0 & 0,95 & 0,07 & 0,52 & 0,61 & 0,33 & 0,67 & $-0,25$ & $-0,17$ & 0,46 & $\begin{array}{c}-0,73 \\
\end{array}$ & Judo \\
\hline Pular cord & 0,52 & 0,77 & $-0,3$ & 1,98 & $-0,73$ & 0,84 & 0,46 & 0,25 & $-0,25$ & 0 & 0,84 & 0,07 & 0,95 & 0,61 & 0,52 & 1,28 & \begin{tabular}{|l|l|}
$-0,38$ \\
\end{tabular} & $-0,52$ & 0,25 & $-0,58$ & Pular corda \\
\hline Voleibol & $-0,17$ & $-0,43$ & $-1,12$ & 0,33 & 0,91 & $-0,25$ & 0,07 & $-0,58$ & $-0,84$ & $-0,73$ & 0 & $-0,73$ & $-0,12$ & $-0,38$ & $-0,25$ & 0,07 & $-0,58$ & $-0,91$ & $-0,25$ & $-1,03$ & Voleibol \\
\hline Tenis & 0,61 & 0,25 & $-0,43$ & 0,84 & $-0,58$ & 0,67 & 0,84 & 0,2 & 0,07 & 0 & 0,77 & 0 & 0,84 & 0,52 & 0,38 & 0,77 & $-0,12$ & $-0,3$ & 0,95 & $-0,67$ & Tenis \\
\hline Caminhada & $-0,05$ & $-0,3$ & $-0,91$ & 0,67 & $-1,64$ & 0 & $-0,12$ & $-0,17$ & $-0,43$ & $-0,58$ & 0,2 & $-0,58$ & 0 & $-0,17$ & $-0,12$ & 0,25 & $-0,84$ & $-0,91$ & $-0,12$ & $-1,64$ & Caminhada \\
\hline Natação Costas & 0,2 & 0,12 & $\begin{array}{c}-0,73 \\
\end{array}$ & 0,95 & $-0,67$ & 0,12 & 0,46 & \begin{tabular}{c|c|}
$-0,12$ \\
\end{tabular} & $-0,38$ & $-0,12$ & 0,52 & $-0,43$ & 0,12 & 0 & 0,33 & 1,03 & \begin{tabular}{|c|}
$-0,38$ \\
\end{tabular} & $-0,84$ & 0,2 & $-0,91$ & Natação Costas \\
\hline Natação Peito & 0,2 & 0,25 & \begin{tabular}{c|}
$-0,58$ \\
\end{tabular} & 0,95 & $-0,67$ & 0,25 & 0,25 & 0,07 & $-0,17$ & $-0,38$ & 0,2 & $-0,25$ & 0,33 & $-0,12$ & 0 & 1,64 & $-0,73$ & $-0,67$ & 0,12 & $-1,03$ & Natação Peito \\
\hline Natação Livre & $-0,12$ & $-0,05$ & $-1,64$ & 0,12 & $-1,12$ & $-0,17$ & $-0,17$ & $-0,38$ & $-0,58$ & $-1,12$ & $-0,17$ & $-0,52$ & $-0,05$ & $-1,4$ & $-1,4$ & 0 & $-0,91$ & $-1,64$ & 0,07 & $-1,12$ & Natação Livre \\
\hline Tocar inst. & 0,67 & 0,77 & 0,07 & 1,28 & $-0,17$ & 0,67 & 0,67 & 0,67 & 0,33 & 0,33 & 1,03 & 0,07 & 1,28 & 0,61 & 0,67 & 0,95 & 0 & 0,25 & 0,52 & $-0,58$ & Tocar instrumento \\
\hline Dardos & 0,95 & 1,03 & 0 & 1,47 & \begin{tabular}{|l|}
$-0,43$ \\
\end{tabular} & 1,47 & 1,28 & 0,84 & 0,38 & 0,77 & 0,84 & 0,52 & 1,17 & 1,03 & 0,84 & 1,64 & $-0,25$ & 0 & 0,77 & $-0,67$ & Dardos \\
\hline Futebol & 0 & 0,12 & $-0,58$ & 0,25 & \begin{tabular}{|l|}
$-0,43$ \\
\end{tabular} & 0,07 & 0,2 & 0,12 & $-0,43$ & $-0,38$ & 0,25 & $\begin{array}{c}-0,52 \\
\end{array}$ & 0,12 & $-0,12$ & 0 & 0,25 & $-0,43$ & $-0,52$ & 0 & $\begin{array}{c}-0,58 \\
\end{array}$ & Futebol \\
\hline Inatividade & 1,17 & 0,95 & 0,38 & 1,64 & 0,52 & 1,17 & 0,46 & 0,84 & 0,77 & 0,77 & 1,03 & 1,03 & 0,77 & 0,77 & 1,17 & 1,03 & 0,61 & 0,61 & 0,95 & 0 & Inatividade \\
\hline TOT & 5,2 & 4,83 & $-13,76$ & 18,36 & $-11,37$ & 8,97 & 8,92 & 1,38 & $\begin{array}{l}-3,28 \\
\end{array}$ & $-4,38$ & 10,87 & $-2,93$ & 9,28 & 3,65 & 4,12 & 12,82 & $-8,29$ & $-10,74$ & 5,7 & $-12,51$ & TTOTAL \\
\hline MED & 0,26 & 0,24 & $-0,69$ & 0,92 & \begin{tabular}{|l|}
$-0,57$ \\
\end{tabular} & 0,45 & 0,45 & 0,07 & $-0,16$ & $-0,22$ & 0,54 & $-0,15$ & 0,46 & 0,18 & 0,21 & 0,64 & $-0,41$ & $-0,54$ & 0,29 & $-0,63$ & \\
\hline $\begin{array}{l}\text { ESCALA } \\
\text { AJUSTADA }\end{array}$ & 0,948 & 0,928 & 0 & 1,608 & 0,118 & 1,14 & 1,138 & 0,758 & 0,528 & 0,468 & 1,228 & 0,538 & 1,148 & 0,868 & 0,898 & 1,328 & 0,278 & 0,148 & 0,978 & 0,058 & \begin{tabular}{|l} 
ESCALA \\
AJUSTADA
\end{tabular} \\
\hline ORDENAÇÃo & 8 & 9 & 20 & 1 & 18 & 5 & 6 & 12 & 14 & 15 & 3 & 13 & 4 & 11 & 10 & 2 & 16 & 17 & 7 & 19 & ORDENAÇÃO \\
\hline
\end{tabular}




\section{APÊNDICE N}

Escores Z médios derivados da matriz (Apêndice K) contendo as proporções médias das atividades físicas e esportivas contendo as 380 comparações aos pares estabelecidas por cada um dos 20 participantes do sexo masculino.

\begin{tabular}{|c|c|c|c|c|c|c|c|c|c|c|c|c|c|c|c|c|c|c|c|c|c|}
\hline Atividades & Corrida & Bicic. E & Remo & Hidro & Dança & Ciclismo & Basq & Hand & Judo & Pular c. & Volei & Tênis & Caminh & N. Costas & N. Peito & N. Livre & $T$ instru & Dardos & Fut & Ina & ATIVIDADES \\
\hline Corrida & 0 & $-0,39$ & $-0,84$ & 0,53 & \begin{tabular}{|l|l|}
$-0,67$ \\
\end{tabular} & 0,26 & 0,85 & $-0,12$ & 0 & $-0,52$ & 0,39 & \begin{tabular}{|l|l|}
$-0,52$ \\
\end{tabular} & 0,26 & 0 & 0,13 & 1,04 & $-0,52$ & $-1,03$ & 0,53 & $-1,23$ & Corrida \\
\hline Bicic. Ergom & 0,68 & 0 & $-0,84$ & 1,04 & $-1,28$ & 1,29 & 1,04 & 0,26 & $-0,12$ & 0,25 & 0,68 & 0,13 & 0,26 & 0,53 & 0,53 & 1,65 & $-0,12$ & $-0,84$ & 1,04 & $-1,64$ & Bicic. Ergom \\
\hline Remo & 1,29 & 0,85 & 0 & 1,65 & $-0,39$ & 2 & 2 & 0,68 & 0,68 & 0,13 & 1,29 & 1,04 & 1,04 & 1,29 & 1,04 & 0,39 & 0,13 & 0,26 & 1,29 & $-0,67$ & Remo \\
\hline idroginástica & $-0,52$ & $-0,67$ & -2 & 0 & $-1,64$ & $-0,25$ & $-0,25$ & $-0,39$ & $-0,52$ & $-1,64$ & $-0,12$ & $-0,67$ & $-0,52$ & $-0,12$ & $-0,25$ & 0,26 & $-1,28$ & $-1,64$ & 0,13 & -2 & Jroginástica \\
\hline Dança & 0,68 & 1,29 & 1,29 & 1,65 & 0 & 1,29 & 1,29 & 0,85 & 0,85 & 1,04 & 0,68 & 0,85 & 1,29 & 1,04 & 1,29 & 1,29 & 0,26 & 0,26 & 0,85 & $-0,52$ & Dança \\
\hline Ciclismo & $-0,39$ & $-0,84$ & $-1,64$ & 0,26 & $-1,64$ & 0 & 0,39 & $-0,52$ & $-0,39$ & $-1,03$ & 0,13 & $-0,67$ & $-0,39$ & 0,13 & 0,13 & 0,39 & $-0,67$ & -2 & 0,39 & $-1,28$ & Ciclismo \\
\hline Basquetebol & $-0,52$ & $-0,67$ & $-1,03$ & 0,39 & $-1,03$ & $-0,25$ & 0 & $-0,84$ & $-0,39$ & $-1,03$ & $-0,39$ & $-0,67$ & $-0,52$ & $-0,25$ & $-0,25$ & 0,26 & $-0,52$ & $-1,64$ & 0,53 & $-1,28$ & Basquetebol \\
\hline Handebol & 0,26 & 0,26 & $-0,67$ & 0,85 & $-0,67$ & 0,53 & 0,68 & 0 & 0 & $-0,39$ & 0,39 & 0 & 0,13 & 0,26 & 0,53 & 0,85 & $-0,39$ & $-1,03$ & 1,04 & $-0,84$ & Handebol \\
\hline Judo & 0,68 & 0,26 & $-0,52$ & 0,85 & $-0,67$ & 0,39 & 0,53 & 0,26 & 0 & $-0,25$ & 0,85 & 0 & 0 & 0,53 & 0,53 & 1,29 & $-0,39$ & $-0,39$ & 1,29 & $-1,28$ & Judo \\
\hline Pular corda & 0,85 & 0,85 & $-0,25$ & 1,65 & $-1,03$ & 1,29 & 0,85 & 0,68 & 0,13 & 0 & 0,85 & 0,53 & 1,04 & 0,39 & 0,39 & 1,65 & 0,13 & $-0,52$ & 0,85 & $-0,67$ & Pular corda \\
\hline Voleibol & 0,13 & $-0,39$ & $-1,03$ & 0,39 & $-0,84$ & 0,26 & 0,68 & $-0,39$ & $-0,67$ & $-0,67$ & 0 & $-0,67$ & $-0,25$ & 0 & 0 & 0,53 & $-0,25$ & $-1,03$ & 1,04 & $-1,64$ & Voleibol \\
\hline Tenis & 0,53 & 0 & $-0,39$ & 0,68 & $-1,28$ & 0,68 & 0,85 & 0,13 & 0 & $-0,25$ & 0,39 & 0 & 0,53 & 0,68 & 0,26 & 1,04 & $-0,12$ & $-0,52$ & 1,65 & $-1,28$ & Tenis \\
\hline Caminhada & 0,39 & $-0,12$ & $-0,52$ & 1,29 & $-1,28$ & 0,53 & 0,26 & 0,13 & 0 & $-0,52$ & 0,39 & $-0,12$ & 0 & 0 & 0,26 & 1,29 & $-0,52$ & $-0,84$ & 0,68 & 0 & Caminhada \\
\hline Natação Costas & 0,26 & $-0,25$ & $-0,84$ & 1,04 & $-0,84$ & 0,26 & 0,53 & $-0,12$ & $-0,39$ & 0 & 0,39 & $-0,12$ & 0 & 0 & 0,26 & 1,65 & $-0,39$ & $-0,84$ & 0,68 & $-1,28$ & Natação Costas \\
\hline Natação Peito & 0,26 & 0 & $-0,65$ & 0,85 & $-0,52$ & 0,39 & 0,53 & 0 & $-0,25$ & $-0,52$ & 0,13 & $-0,39$ & 0,13 & $-0,25$ & 0 & 2 & $-0,65$ & $-1,03$ & 0,53 & $-1,28$ & Natação Peito \\
\hline Natação Livre & $-0,25$ & $-0,39$ & -2 & $-0,25$ & $-1,64$ & $-0,25$ & 0 & $-0,67$ & $-0,67$ & $-1,64$ & $-0,52$ & $-0,67$ & $-0,67$ & $-1,28$ & $-1,64$ & 0 & $-0,84$ & -2 & 0,85 & $-1,64$ & Natação Livre \\
\hline Tocar inst. & 1,04 & 0,53 & 0 & 1,29 & $-0,52$ & 0,68 & 0,85 & 0,68 & 0,53 & 0 & 0,85 & 0 & 1,04 & 0,68 & 0,85 & 1,04 & 0 & 0,13 & 0,68 & $-0,67$ & Tocar instrumento \\
\hline Dardos & 1,29 & 1,04 & 0,13 & 1,29 & $-0,84$ & 2 & 2 & 1,04 & 0,53 & 0,68 & 1,29 & 0,68 & 1,29 & 1,29 & 1,29 & 2 & 0 & 0 & 1,65 & 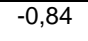 & Dardos \\
\hline Futebol & $-0,39$ & $-0,67$ & \begin{tabular}{|c|}
$-1,03$ \\
\end{tabular} & $-0,25$ & \begin{tabular}{|l|}
$-1,03$ \\
\end{tabular} & $-0,39$ & $\begin{array}{c}-0,39 \\
\end{array}$ & $-0,39$ & $-0,84$ & $-1,03$ & $\begin{array}{c}-0,52 \\
\end{array}$ & $-1,28$ & \begin{tabular}{|c|}
$-0,52$ \\
\end{tabular} & $-0,67$ & $-0,52$ & $-0,12$ & $-0,67$ & $\begin{array}{l}-1,03 \\
\end{array}$ & 0 & $-1,28$ & Futebol \\
\hline Inatividade & 1,65 & 1,29 & 0,68 & 1,65 & 0,39 & 2 & 0,39 & 1,29 & 1,29 & 0,85 & 1,04 & 1,65 & 0,68 & 1,04 & 1,29 & 1,04 & 0,68 & 0,85 & 1,65 & 0 & Inatividade \\
\hline TOT & 7,92 & 1,98 & $-12,15$ & 16,85 & $-17,42$ & 12,71 & 13,08 & 2,56 & $-0,23$ & $-6,54$ & 8,19 & $-0,9$ & 4,82 & 5,29 & 6,12 & 19,54 & $\begin{array}{l}-6,13 \\
\end{array}$ & \begin{tabular}{|l|}
$-14,88$ \\
\end{tabular} & 17,35 & $-21,32$ & TOTAL \\
\hline MÉD & 0,396 & 0,099 & $-0,6075$ & 0,8425 & $\mid-0,871$ & 0,6355 & 0,654 & 0,128 & $-0,0115$ & $\mid-0,327$ & 0,4095 & $-0,045$ & 0,241 & 0,2645 & 0,306 & 0,977 & \begin{tabular}{|c|}
$-0,3065$ \\
\end{tabular} & \begin{tabular}{|l|}
$-0,744$ \\
\end{tabular} & 0,8675 & $-1,066$ & MÉDIA \\
\hline $\begin{array}{l}\text { ESCALA } \\
\text { AJUSTADA }\end{array}$ & 1,45 & 1,15 & 0,46 & 1,9 & 0,19 & 1,69 & 1,71 & 1,18 & 1,05 & 0,74 & 1,46 & 1,02 & 1,3 & 1,32 & 1,36 & 2,03 & 0,76 & 0,32 & 1,92 & 0 & \begin{tabular}{|l} 
ESCALA \\
AJUSTADA
\end{tabular} \\
\hline ORDENAÇÃO & 7 & 12 & 17 & 3 & 19 & 5 & 4 & 11 & 13 & 16 & 6 & 14 & 10 & 9 & 8 & 1 & 15 & 18 & 2 & 20 & ORDENAÇÃO \\
\hline
\end{tabular}




\section{APÊNDICE O}

Escores Z médios derivados da matriz (Apêndice L) contendo as proporções médias das atividades físicas e esportivas contendo as 380 comparações aos pares estabelecidas por cada um dos 20 participantes do sexo feminino.

\begin{tabular}{|c|c|c|c|c|c|c|c|c|c|c|c|c|c|c|c|c|c|c|c|c|c|}
\hline Atividades & Corrida & Bicic. E & Remo & Hidro & Dança & Ciclismo & Basq & Hand & Judo & Pular c. & Volei & Tenis & Caminh & N. Costas & N. Peito & N. Livre & $T$ instru & Dardos & Fut & Ina & ATIVIDADES \\
\hline Corrida & 0 & 0,13 & $-0,81$ & 0,85 & 0,13 & 0,26 & 0,39 & 0,13 & $-0,39$ & 0 & 0,68 & $-0,12$ & 1,29 & $-0,12$ & $-0,12$ & 0,13 & \begin{tabular}{|c|}
$-0,52$ \\
\end{tabular} & $-0,12$ & $-0,12$ & $-0,52$ & Corrida \\
\hline Bicic. Ergom & $-0,12$ & 0 & -2 & 1,04 & $-1,65$ & 0 & $-0,12$ & $-0,67$ & $-0,84$ & $-1,28$ & 0,39 & $-0,52$ & 0,39 & $-0,12$ & $-0,25$ & $-0,12$ & $-1,03$ & $-1,03$ & $-0,67$ & $-1,03$ & Bicic. Ergom \\
\hline Remo & 1,04 & 2 & 0 & 1,65 & 0,13 & 1,65 & 1,04 & 0,68 & 0 & 0,53 & 1,65 & 0,39 & 1,29 & 0,68 & 0,85 & 0,53 & $-0,12$ & 0,39 & 0,53 & 0 & Remo \\
\hline idroginástica & $-0,67$ & $-1,28$ & $-1,65$ & 0 & -2 & $-0,39$ & $-0,67$ & $-0,84$ & $-1,03$ & $-1,65$ & $-0,12$ & $-1,03$ & $-0,25$ & $-0,67$ & $-1,03$ & $-0,39$ & $-1,65$ & $-1,28$ & $-0,84$ & $-1,65$ & oginástica \\
\hline Dança & 0,39 & 1,29 & $-0,52$ & 2 & 0 & 0,85 & 0,68 & 0,39 & 0,26 & 0,53 & 0,85 & 0,13 & 1,29 & 0,53 & 0,85 & 0,68 & $-0,25$ & 0,26 & 0,26 & $-0,39$ & Dança \\
\hline Ciclismo & $-0,25$ & 0 & $-1,65$ & 0,68 & $-0,67$ & 0 & 0,13 & 0 & $-0,52$ & $-0,52$ & 0,85 & $-0,52$ & 0,53 & $-0,12$ & $-0,12$ & $-0,12$ & $-0,52$ & $-0,39$ & $-0,12$ & $-0,39$ & Ciclismo \\
\hline Basquetebol & $-0,39$ & $-0,12$ & $-1,65$ & 0,39 & $-0,39$ & 0 & 0 & $-0,84$ & $-1,03$ & $-0,25$ & 0,68 & $-0,84$ & 0,26 & 0,26 & 0 & 0,13 & \begin{tabular}{|c|}
$-0,67$ \\
\end{tabular} & $-0,84$ & $-0,67$ & $-0,52$ & Basquetebol \\
\hline Handebol & $-0,12$ & 0,13 & $-0,84$ & 0,68 & $-0,52$ & 0 & 0,85 & 0 & $-0,39$ & 0 & 1,04 & $-0,39$ & 0,53 & 0,13 & 0 & 0,26 & $-0,52$ & $-0,67$ & $-0,25$ & $-0,12$ & Handebol \\
\hline Judo & 0,39 & 0,53 & $-0,52$ & 1,04 & $-0,25$ & 0,68 & 0,68 & 0,13 & 0 & 0,26 & 1,04 & 0,13 & 1,29 & 0,68 & 0,13 & 0,26 & \begin{tabular}{|c|}
$-0,12$ \\
\end{tabular} & 0 & $-0,12$ & $-0,39$ & Judo \\
\hline Pular corda & 0,26 & 0,68 & $-0,39$ & 2 & $-0,52$ & 0,53 & 0,13 & $-0,12$ & $-0,67$ & 0 & 0,85 & $-0,39$ & 0,85 & 0,85 & 0,68 & 1,04 & $-1,03$ & $-0,52$ & $-0,25$ & $-0,52$ & Pular corda \\
\hline Voleibol & $-0,52$ & $-0,52$ & $-1,28$ & 0,26 & $-1,03$ & $-0,84$ & $-0,52$ & $-0,84$ & $-1,03$ & $-0,84$ & 0 & $-0,84$ & 0 & $-0,84$ & $-0,52$ & $-0,39$ & $-1,03$ & $-0,84$ & $-1,65$ & $-0,67$ & Voleibol \\
\hline Tenis & 0,68 & 0,53 & $-0,52$ & 1,04 & $-0,12$ & 0,68 & 0,85 & 0,26 & 0,13 & 0,26 & 1,29 & 0 & 1,29 & 0,39 & 0,53 & 0,53 & $-0,12$ & $-0,12$ & 0,53 & $-0,25$ & Tenis \\
\hline Caminhada & $-0,52$ & $-0,52$ & $-1,65$ & 0,26 & -2 & $-0,52$ & $-0,52$ & $-0,52$ & $-1,03$ & $-0,67$ & 0 & $-1,28$ & 0 & $-0,39$ & $-0,52$ & $-0,52$ & $-1,28$ & $-1,03$ & $-1,03$ & $-1,28$ & Caminhada \\
\hline Natação Costas & 0,13 & 0,53 & $-0,67$ & 0,85 & $-0,52$ & 0 & 0,39 & $-0,12$ & $-0,39$ & $-0,25$ & 0,68 & $-0,84$ & 0,26 & 0 & 0,39 & 0,68 & $-0,39$ & $-0,84$ & $-0,25$ & $-0,67$ & Natação Costas \\
\hline Natação Peito & 0,13 & 0,53 & $\begin{array}{c}-0,52 \\
\end{array}$ & 1,04 & $-0,84$ & 0,13 & 0 & 0,13 & $-0,12$ & $-0,25$ & 0,26 & $-0,12$ & 0,53 & 0 & 0 & 1,29 & $-0,84$ & $-0,39$ & $-0,25$ & \begin{tabular}{|l|}
$-0,84$ \\
\end{tabular} & Natação Peito \\
\hline Natação Livre & 0 & 0,26 & $-1,28$ & 0,53 & $-0,84$ & $-0,12$ & $-0,25$ & $-0,12$ & $-0,52$ & $-0,84$ & 0,13 & $-0,39$ & 0,53 & $-1,65$ & $-1,28$ & 0 & $-1,03$ & $-1,28$ & $-0,67$ & $-0,84$ & Natação Livre \\
\hline ist. & 0,39 & 1,04 & 0,13 & 1,29 & 0,13 & 0,68 & 0,53 & 0,68 & 0,68 & 0,68 & 1,29 & 0,68 & 1,65 & 0,53 & 0,53 & 0,85 & 0 & 0,39 & 0,39 & $-0,52$ & instrum \\
\hline Dardos & 0,68 & 1,04 & $-0,12$ & 1,65 & $-0,12$ & 1,04 & 0,85 & 0,68 & 0,26 & 0,85 & 0,53 & 0,39 & 1,04 & 0,85 & 0,53 & 1,29 & $-0,52$ & 0 & 0,26 & $-0,52$ & Dar \\
\hline Futebol & 0,39 & 1,04 & $-0,25$ & 0,85 & 0 & 0,55 & 0,85 & 0,68 & $\begin{array}{c}-0,12 \\
\end{array}$ & 0,13 & 1,29 & 0 & 0,85 & 0,39 & 0,55 & 0,68 & $-0,25$ & $-0,12$ & 0 & $-0,12$ & Futebol \\
\hline Inatividade & 0,85 & 0,68 & 0,13 & 1,65 & 0,68 & 0,68 & 0,53 & 0,53 & 0,39 & 0,68 & 1,04 & 0,68 & 0,85 & 0,53 & 1,04 & 1,04 & 0,53 & 0,39 & 0,53 & 0 & Inatividade \\
\hline TOT & 2,74 & 7,97 & $-16,06$ & 19,75 & $-10,4$ & 5,86 & 5,82 & 0,22 & $\begin{array}{l}-6,36 \\
\end{array}$ & $-2,63$ & 14,42 & $-4,88$ & 14,47 & 1,91 & 2,24 & 7,85 & $\mid-11,36$ & $-8,04$ & \begin{tabular}{|c|}
$-4,39$ \\
\end{tabular} & $-11,24$ & TOTAL \\
\hline MEDI & 0,137 & 0,3985 & $-0,803$ & 0,9875 & \begin{tabular}{|l|}
$-0,52$ \\
\end{tabular} & 0,293 & 0,291 & 0,011 & $-0,318$ & $-0,1315$ & 0,721 & $-0,244$ & 0,7235 & 0,0955 & 0,112 & 0,3925 & \begin{tabular}{|l|}
$-0,568$ \\
\end{tabular} & \begin{tabular}{|l|}
$-0,402$ \\
\end{tabular} & $-0,2195$ & $-0,562$ & MÉDIA \\
\hline $\begin{array}{l}\text { ESCALA } \\
\text { AJUSTADA }\end{array}$ & 0,93 & 1,19 & 0 & 1,78 & 0,28 & 1,1 & 1,1 & 0,81 & 0,49 & 0,67 & 1,52 & 0,56 & 1,52 & 0,89 & 0,91 & 1,19 & 0,24 & 0,4 & 0,59 & 0,24 & \begin{tabular}{|l} 
ESCALA \\
AJUSTADA
\end{tabular} \\
\hline ORDENACÃO & 8 & 4 & 20 & 1 & 17 & 6 & 7 & 11 & 15 & 12 & 3 & 14 & 2 & 10 & 9 & 5 & 19 & 16 & 13 & 18 & \\
\hline
\end{tabular}

